U.S. Department of Energy

Idaho Operations Office

\title{
Project Execution Plan for the Remote- Handled Low-Level Waste Disposal Project
}

July 2014 

DOE/ID-11466

Revision 0

\section{Project Execution Plan for the Remote-Handled Low- Level Waste Disposal Project}

July 2014

Prepared for the

U.S. Department of Energy

DOE Idaho Operations Office 



\section{Project Execution Plan for the Remote-Handled Low- Level Waste Disposal Project}

DOE/ID-11466

Revision 0

July 2014

Concurrence by:

David S. Duncan, Project Manager

Remote-Handled Low-Level Waste Disposal

Project
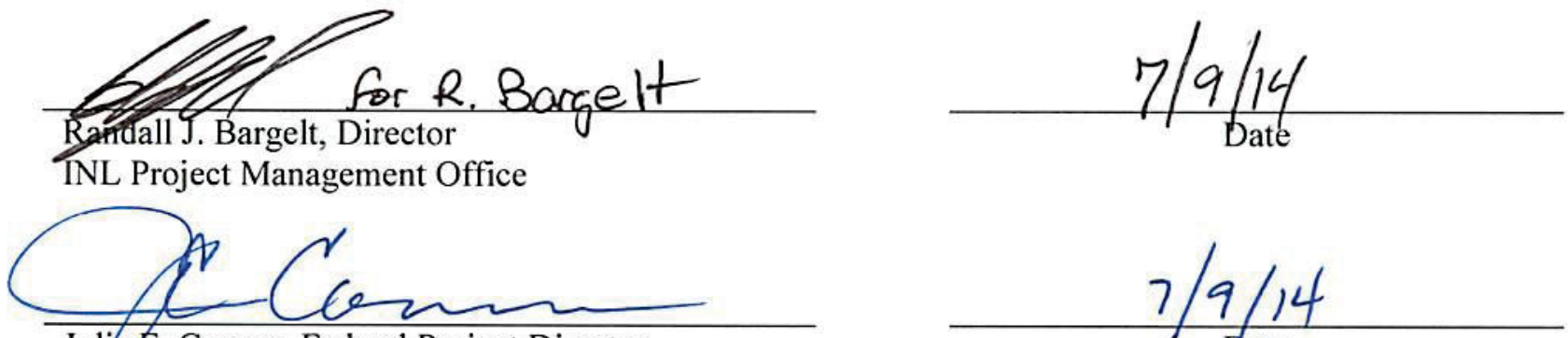

Julie E. Conner, Federal Project Director Idaho Operations Office
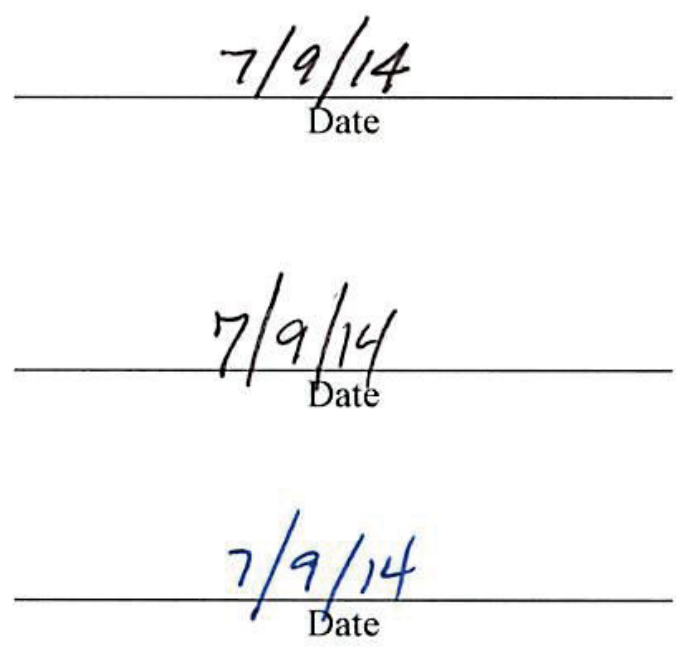

Approved by:
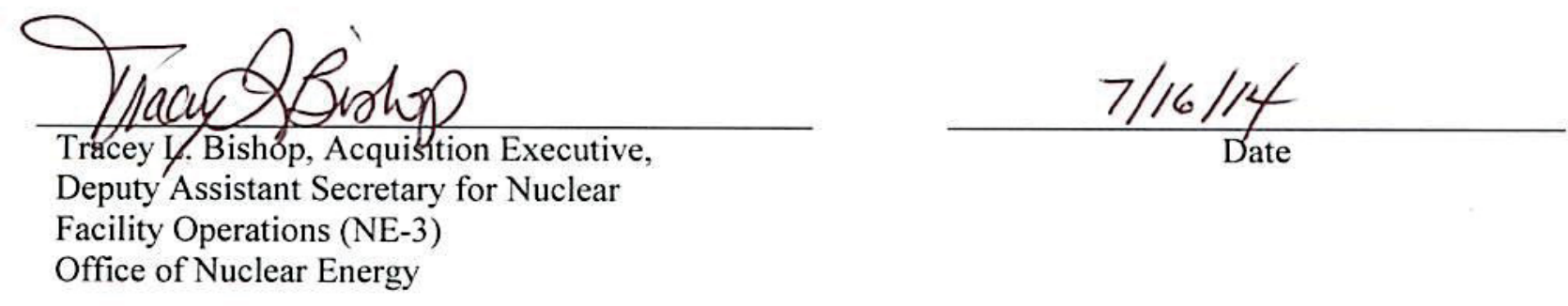



\section{EXECUTIVE SUMMARY}

As part of ongoing cleanup activities at the Idaho National Laboratory (INL), closure of the Radioactive Waste Management Complex (RWMC) is proceeding under the Comprehensive Environmental Response, Compensation, and Liability Act (42 USC 9601 et seq. 1980). INL-generated radioactive waste has been disposed of at RWMC since 1952. The Subsurface Disposal Area (SDA) at RWMC accepted the bulk of INL's contact and remote-handled low-level waste (LLW) for disposal. Disposal of contact-handled LLW and remote-handled LLW ion-exchange resins from the Advanced Test Reactor in the open pit of the SDA ceased September 30, 2008. Disposal of remote-handled LLW in concrete disposal vaults at RWMC will continue until the facility is full or until it must be closed in preparation for final remediation of the SDA.

The continuing nuclear mission of INL, associated ongoing and planned operations, and naval spent nuclear fuel activities at the Naval Reactors Facility (NRF) require continued capability to appropriately dispose of contact and remote-handled LLW.

On July 13, 2011, the Office of Nuclear Energy approved Critical Decision-1, selecting development of a new facility for disposal of remote-handled LLW generated at the Idaho site as the preferred alternative to meet the mission need. In accordance with the National Environmental Policy Act (42 USC $\$ 4321$ et seq.), a thorough analysis of a range of reasonable alternatives was subsequently performed. After evaluating the results of the analysis, the Department of Energy Idaho Operations Office Manager issued a Finding of No Significant Impact on December 21, 2011. The selected action involves construction and operation of a new onsite disposal facility for disposal of remote-handled LLW generated at INL, as well as allowing continued disposition of Advanced Test Reactor resins, hardware, and filters at the Nevada National Security Site. The Department of Energy selected this combination to retain flexibility in responding to future circumstances and needs while meeting the INL site's disposal needs for up to 50 years. The Department of Energy believes its decision provides dependable and predictable disposal in support of the Department of Energy's mission and minimizes exposure to the public from routine shipments and accidents.

The remote-handled LLW disposal facility must be operational prior to the disposal vaults at the SDA being filled or the RWMC undergoing final closure to support uninterrupted INL operations and ensure no disruption of Office of Nuclear Energy and Naval Reactors mission-critical operations. The concept for the disposal facility is similar to that of the current concrete remote-handled LLW disposal vaults in use at the SDA to accommodate, to the maximum extent possible, uninterrupted operations at the generating facilities and to capitalize on operations experience and cost efficiencies of current remote-handled LLW disposal practices. The disposal facility is planned to be designed and operated as a Hazard Category 2 nuclear facility per DOE-STD-1027, "Hazard Categorization and Accident Analysis Techniques for Compliance with DOE Order 5480.23, Nuclear Safety Analysis Reports."

The Remote-Handled LLW Disposal Project will use a design-build project delivery method. The design-build method was chosen because the project has well defined requirements based on current remote-handled LLW disposal 
operations at INL, the disposal facility is not complex, and there is limited risk with the design and construction phases of the project. Bids were solicited from three qualified vendors in fiscal year (FY) 2012 in anticipation of capital funding in FY 2013. The request for proposals was conditioned on meeting well defined technical and functional requirements and facility performance specifications that are specifically identified to allow meeting environmental and nuclear safety requirements. The subcontract was competitively bid to qualified subcontractors with nuclear facility experience. Responses to the request for proposal were evaluated using a "best-value" selection process conditioned on meeting the requirements of the technical and functional requirements and facility performance specifications. A design-build subcontract was conditionally awarded in March 2014. The subcontractor is not authorized to proceed with design activities until Critical Decision (CD)-2/3 approval.

This project execution plan defines DOE project objectives, roles and responsibilities of project participants, project organization, and controls to effectively manage the acquisition of a new remote-handled LLW disposal facility. The plan addresses the policies, requirements, and critical decision responsibilities identified in DOE Order 413.3B, "Program and Project Management for the Acquisition of Capital Assets." This plan is an evolution of the Preliminary Project Execution Plan (DOE/ID-11370) and will continue as a living document that will be periodically updated as the project continues to progress through the critical decision process. 


\section{CONTENTS}

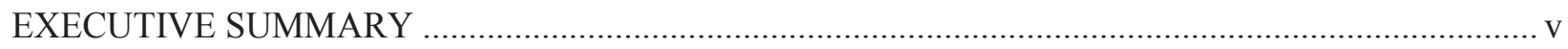

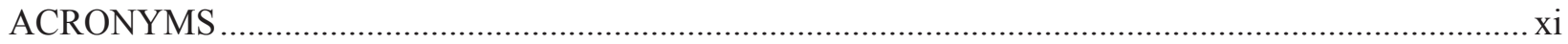

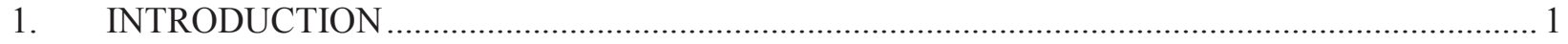

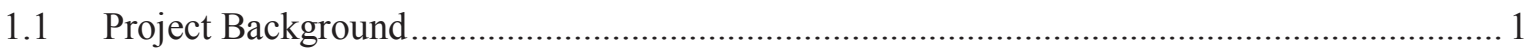

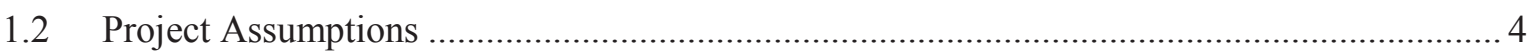

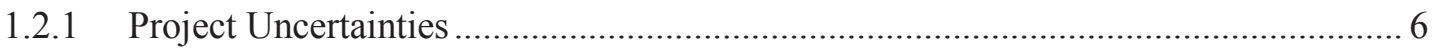

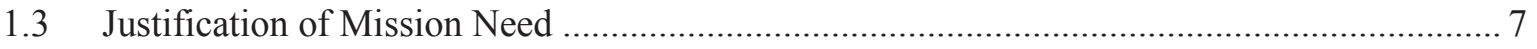

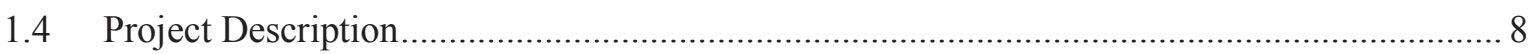

2. MANAGEMENT STRUCTURE AND INTEGRATED PROJECT TEAMS ............................... 10

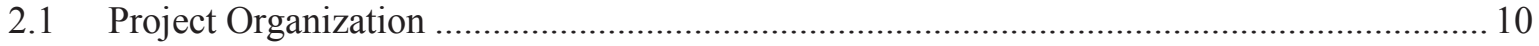

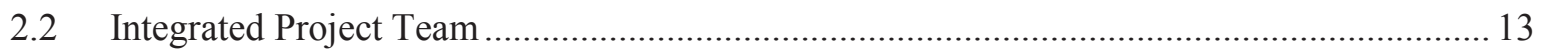

2.3 Idaho National Laboratory Project Organization ............................................................. 15

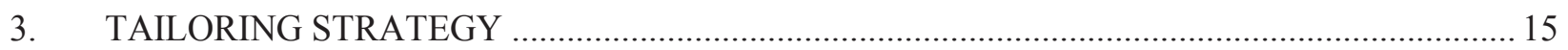

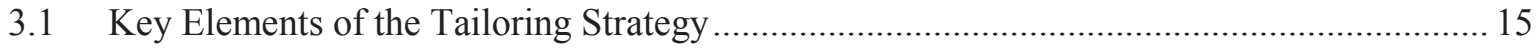

3.2 Critical Decision-3 Construction Hold Points and Releases ................................................ 18

3.2.1 Construction Hold Points ........................................................................................ 18

3.2.2 Hold Point Release Process........................................................................................ 18

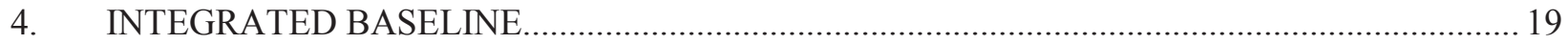

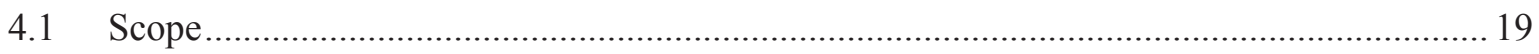

4.1.1 Substantive Changes to Scope since Critical Decision-0 _.......................................... 20

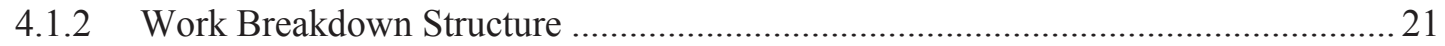

4.1.3 Key Performance Parameters ......................................................................... 21

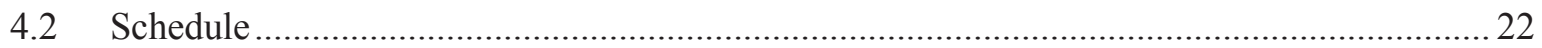

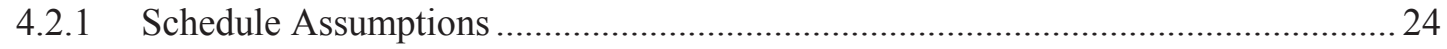

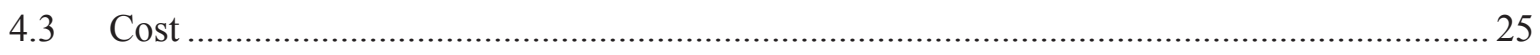

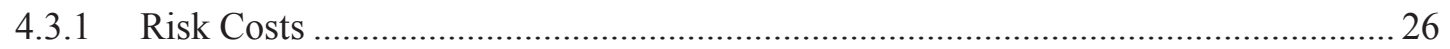

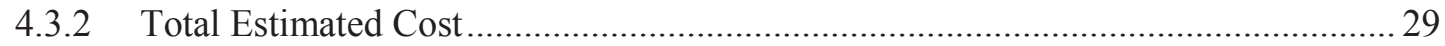

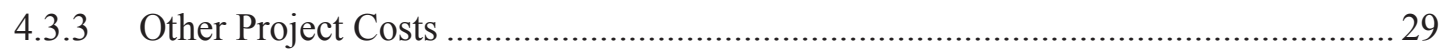

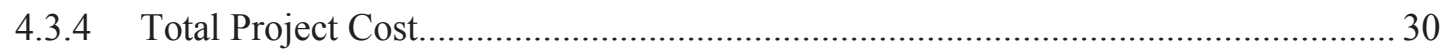

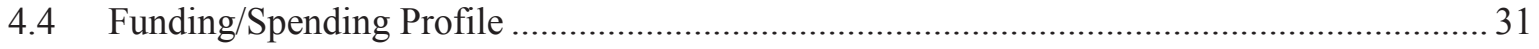

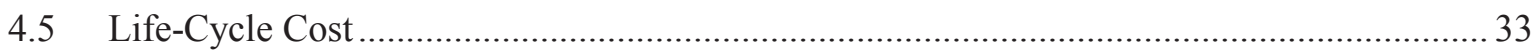

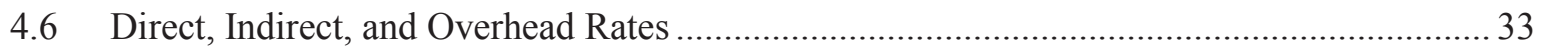

4.6.1 Independent Project Reviews and Annual Reviews................................................. 34

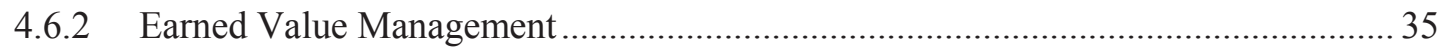

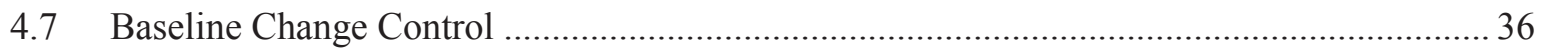




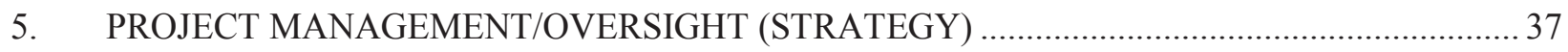

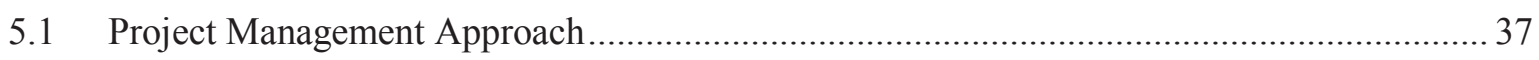

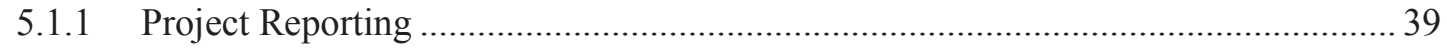

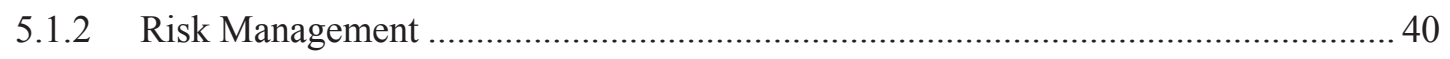

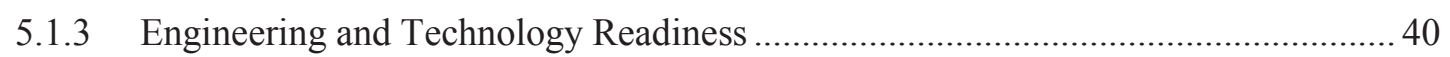

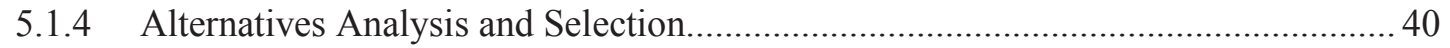

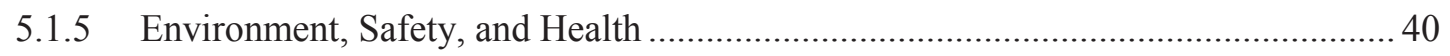

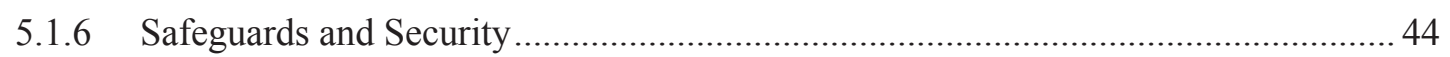

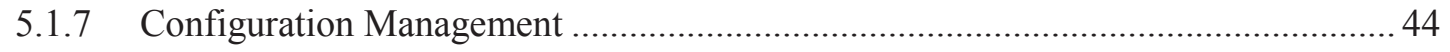

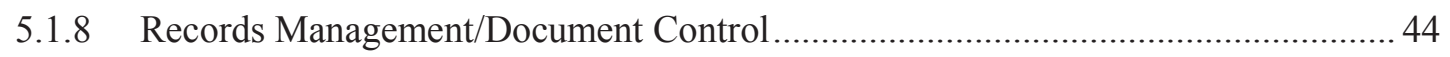

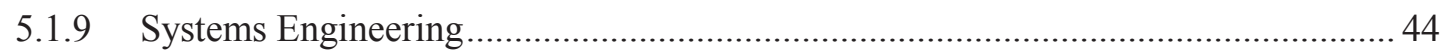

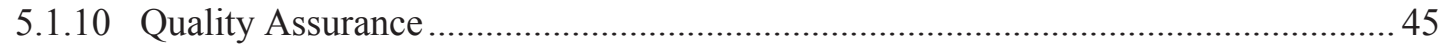

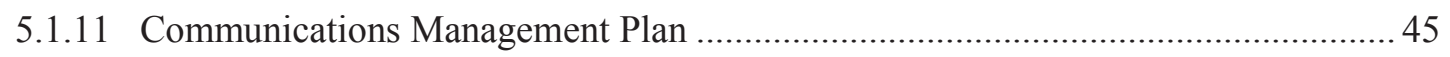

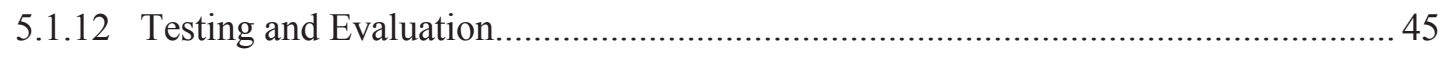

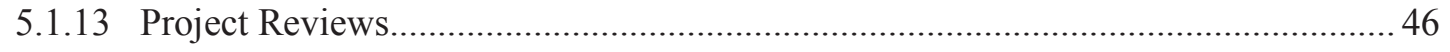

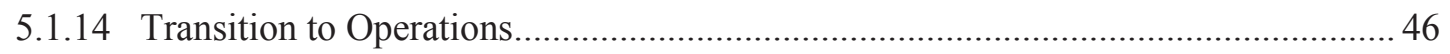

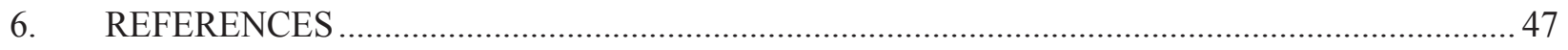

Appendix A Integrated Project Team Charter …............................................................................. 51

Appendix B Hold Point Review Checklist …............................................................................. 53

Appendix C Summary Work Breakdown Structure Dictionary........................................................... 55

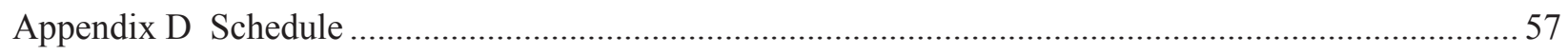

Appendix E Cost Estimate Summary for Total Estimated Cost and Other Project Cost (9A87) ............. 59

Appendix F Cost Estimate Summary for Operations and Closure (9A28-H4) .................................... 61

\section{FIGURES}

1. Idaho National Laboratory remote-handled low-level waste disposal requirements.................. 3

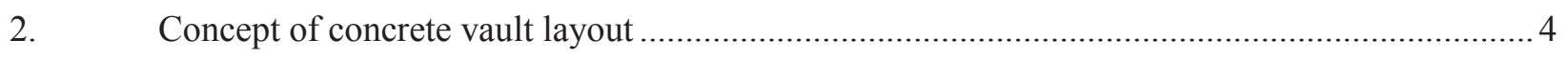

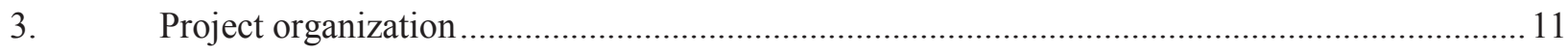

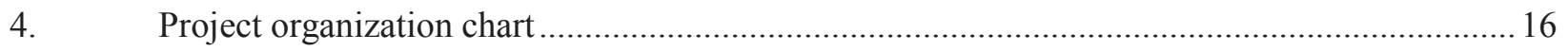

5. $\quad$ Funding (total project cost) versus spending (performance measurement baseline) .................. 32

6. Naval Reactors/Office of Nuclear Energy proposed cost sharing

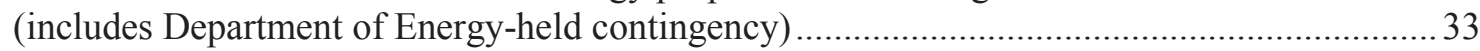


7. Idaho interaction of required National Environmental Policy Act documentation and DOE Order 435.1 documentation in the critical decision process

\section{TABLES}

1. Waste canister projections and types planned for receipt during 20 years of operations .............9

2. Remote-handled low-level waste Integrated Project Team functional responsibilities and assignments

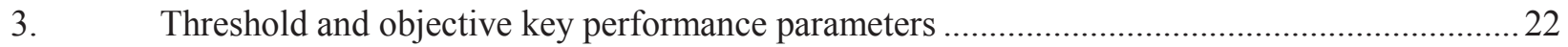

4. Summary schedule for the Remote-Handled Low-Level Waste Disposal Project ....................23

5. Internal risks and associated costs - the basis for risk contribution to management

reserve.....

6. External risks and associated costs - the basis of a recommendation for Department of

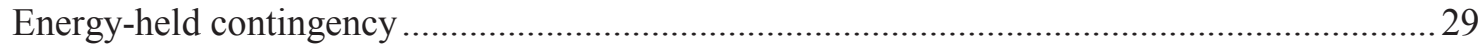

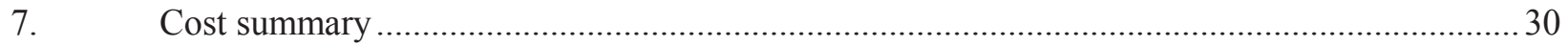

8. Remote-Handled Low-Level Waste Disposal Project reviews..................................................35

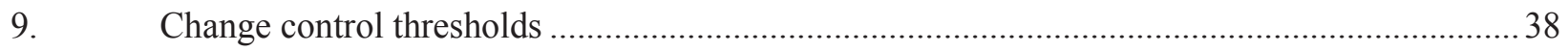




\section{ACRONYMS}

\begin{tabular}{|c|c|}
\hline ATR & Advanced Test Reactor \\
\hline BEA & Battelle Energy Alliance, LLC \\
\hline $\mathrm{CBB}$ & contract budget base \\
\hline $\mathrm{CD}$ & critical decision \\
\hline CERCLA & Comprehensive Environmental Response, Compensation, and Liability Act \\
\hline CVAS & cask-to-vault adapting structure \\
\hline DAS & Disposal Authorization Statement \\
\hline DOE & U.S. Department of Energy \\
\hline DOE-ID & U.S. Department of Energy, Idaho Operations Office \\
\hline FPD & Federal Project Director \\
\hline FTC & facility transfer container \\
\hline FY & fiscal year \\
\hline INL & Idaho National Laboratory \\
\hline IPT & Integrated Project Team \\
\hline KPP & key performance parameters \\
\hline LFRG & LLW Federal Review Group \\
\hline LLW & low-level waste \\
\hline MFC & Materials and Fuels Complex \\
\hline $\mathrm{NE}$ & DOE Office of Nuclear Energy \\
\hline NEPA & National Environmental Policy Act \\
\hline NR & Naval Reactors \\
\hline NRF & Naval Reactors Facility \\
\hline $\mathrm{OPC}$ & other project cost \\
\hline ORR & operational readiness review \\
\hline $\mathrm{PB}$ & performance baseline \\
\hline
\end{tabular}




$\begin{array}{ll}\text { PDSA } & \mathrm{p} \\ \text { reliminary } & \text { documented safety analysis } \\ \text { PMB } & \text { performance measurement baseline } \\ \text { PMSO } & \text { DOE-NE Project Management Support Office } \\ \text { RFP } & \text { request for proposal } \\ \text { RWMC } & \text { Radioactive Waste Management Complex } \\ \text { SDA } & \text { Subsurface Disposal Area } \\ \text { TEC } & \text { total estimated cost } \\ \text { TPC } & \text { total project cost } \\ \text { WBS } & \text { work breakdown structure }\end{array}$




\section{REVISION LOG}

\begin{tabular}{|c|c|c|l|}
\hline Rev. & Date & Affected Pages & \multicolumn{1}{c|}{ Revision Description } \\
\hline 0 & $07 / 18 / 14$ & All & New issue. \\
\hline & & & \\
\hline & & & \\
\hline & & & \\
\hline & & & \\
\hline & & & \\
\hline & & & \\
\hline & & & \\
\hline & & & \\
\hline
\end{tabular}




\section{Project Execution Plan for the Remote-Handled Low- Level Waste Disposal Project}

\section{INTRODUCTION}

This project execution plan defines U.S. Department of Energy (DOE) project objectives, roles and responsibilities of project participants, project organization, and controls to effectively manage acquisition of capital funds for construction of a remote-handled low-level waste (LLW) disposal facility at the Idaho National Laboratory (INL). The plan addresses the policies, requirements, and critical decision $(\mathrm{CD})$ responsibilities identified in DOE Order 413.3B, "Program and Project Management for the Acquisition of Capital Assets." This plan evolved from the preliminary project execution plan and will continue to be a "living document" that will be periodically updated as the project progresses through construction and turnover for operation.

\subsection{Project Background}

As part of ongoing cleanup activities at INL, closure of the Radioactive Waste Management Complex (RWMC) is proceeding under the Comprehensive Environmental Response, Compensation, and Liability Act (CERCLA) (42 USC 9601 et seq. 1980). INL-generated radioactive waste has been disposed of at RWMC since 1952. The Subsurface Disposal Area (SDA) at RWMC accepted the bulk of INL's contact and remote-handled LLW for disposal. Disposal of INL contact-handled LLW and remote-handled LLW ion-exchange resins from the Advanced Test Reactor (ATR) in the open pit of the SDA ceased on September 30, 2008. Disposal of remote-handled LLW in concrete disposal vaults at RWMC will continue until the facility is full or until it must be closed in preparation for final remediation of the SDA.

The continuing nuclear mission of INL, associated ongoing and planned operations, and naval spent nuclear fuel activities at the Naval Reactors Facility (NRF) require continued capability to appropriately dispose of contact and remote-handled LLW. DOE's Idaho programs have been coordinating efforts on waste management activities at INL. Plans and projects are in place to address DOE's legacy waste management issues and are being implemented by the DOE Office of Environmental Management and the Office of Nuclear Energy (NE).

A programmatic analysis of disposal alternatives for contact-handled and remote-handled LLW generated at INL was conducted by the INL contractor in FY 2006; subsequent evaluations were completed in FY 2007. The result of these analyses was a recommendation to DOE that all contact-handled LLW generated after September 30, 2008 be disposed of offsite and that DOE proceed with a capital project to establish replacement remote-handled LLW disposal capability. An analysis of the alternatives for providing replacement remote-handled LLW disposal capability was performed to support CD-1. CD-1 was approved on July 13, 2011, by the DOE Assistant Secretary for Nuclear Energy. At that time, the Acquisition Executive authority for subsequent CDs was delegated to the Deputy Assistant Secretary for Nuclear Facility Operations (NE-3) for the Office of Nuclear Energy.

In accordance with the National Environmental Policy Act (NEPA) (42 USC§ 4321 et seq.), a thorough analysis of a range of reasonable alternatives was subsequently performed. After evaluating the results of the analysis, the DOE Idaho Operations Office (DOE-ID) manager issued a Finding of No Significant Impact on December 21, 2011. The selected action involves construction and operation of a new onsite disposal facility for disposal of remote-handled LLW generated at INL, as well as allowing continued disposition of ATR resins, hardware, and filters at the Nevada National Security Site. DOE selected this combination to retain flexibility in responding to future circumstances and needs while meeting the INL site's disposal needs for up to 50 years. DOE believes its decision provides dependable and predictable disposal in support of DOE's mission and minimizes exposure to the public from routine shipments and accidents. 
As required by DOE Order 435.1, a radiological performance assessment has been conducted for the facility. The objective of this order is to ensure that all DOE radioactive waste is managed in a manner that is protective of worker and public health, safety, and the environment. The order requires that all radioactive waste be managed in accordance with the requirements of DOE Manual 435.1-1. The facility performance assessment has been reviewed by the Low-Level Waste Federal Review Group (LFRG) and a preliminary Disposal Authorization Statement (DAS) was issued in April 2012, allowing design of the facility. The LFRG will review the final design prior to start of construction and verify that the conditions of the Preliminary DAS have been met.

In addition, a preliminary safety design report has been developed to support the Remote-Handled LLW Disposal Project. This document is the third in a prescribed evolution of safety-related documentation prescribed by DOE-STD-1189. The preliminary safety design report is required to show that the preliminary facility design meets the nuclear safety requirements.

The analyses supporting the Finding of No Significant Impact, preliminary disposal authorization statement, and preliminary safety design report were based on anticipated waste inventories, waste type, and a reference design for the facility. The anticipated waste inventory is limited to remote-handled LLW (i.e., greater than $200 \mathrm{mR} /$ hour on contact) generated at INL. Remote-handled LLW generated at INL includes ion-exchange resins, activated metals, and a limited volume of additional debris that qualifies as remote-handled LLW.

Projected packaged waste volumes are indicated in Table 1 by waste type and generator facility. ATR ion-exchange resins from pool and reactor operations are generated approximately four to six times annually from reactor loop and reactor ion-exchange systems. The generation rate depends on reactor operations and also varies during the years when core internal change-outs are performed. The ATR generates activated metals resulting from core internal change-outs every 8 to 10 years. These components require decay time before they can be handled for disposal and are currently in storage at the ATR Complex. During routine operations, NRF currently primarily produces activated metals and resins. The activated metals stream also includes a limited volume of additional debris that qualifies as remotehandled LLW. Activated metals and debris are also expected to be generated from new missions and from processing remote-handled waste stored in the Radioactive Scrap and Waste Facility at the Materials and Fuels Complex (MFC). There may be additional miscellaneous remote-handled LLW generated at INL through other operational activities that also will be accepted by the disposal facility. The primary waste generators and waste types are shown in Figure 1.

The reference design for the vault system is similar to the remote-handled LLW concrete disposal vaults currently in use in the SDA. This concept will accommodate uninterrupted operations at the generating facilities and will capitalize on operations experience and cost efficiencies of current remote-handled LLW disposal practices. In the reference concept, vaults were conceived as precast concrete cylinders (i.e., pipe sections) stacked on end and placed in a honeycomb-type array (see Figure 2). This concept allows stacking of canisters in various configurations within each vault. This configuration provides the ability to dispose of remote-handled LLW within the smallest footprint possible.

It is assumed that similar cask canister placement methods currently used at RWMC will be used at the new remote-handled LLW disposal facility. Waste is packaged into steel waste canisters by the generating facility. The steel waste canister is placed into a shipping cask and is transported to the facility. The specific operational systems and placement procedures that will be used for each cask will be determined once the generating facilities identify their specific canister configurations. However, for all casks, it is assumed that the following general operational sequence will be used for placement of the waste canisters into the associated disposal vaults: 
- Once waste is transported to the site, a crane will be used to remove the top plug on the vault and prepare the vault opening for waste canister placement with a shielded cask-to-vault adapting structure (CVAS).

- Using the crane, the canister will be removed from the cask and positioned over the disposal vault, or the cask will be placed on the CVAS.

- The waste canister will be lowered into the disposal vault.

- The waste canister handling and shielding equipment will be removed and the vault plug replaced.

\begin{tabular}{ccc} 
Generating & Maste & Mission \\
Facility & Stream & Disposal \\
\hline
\end{tabular}

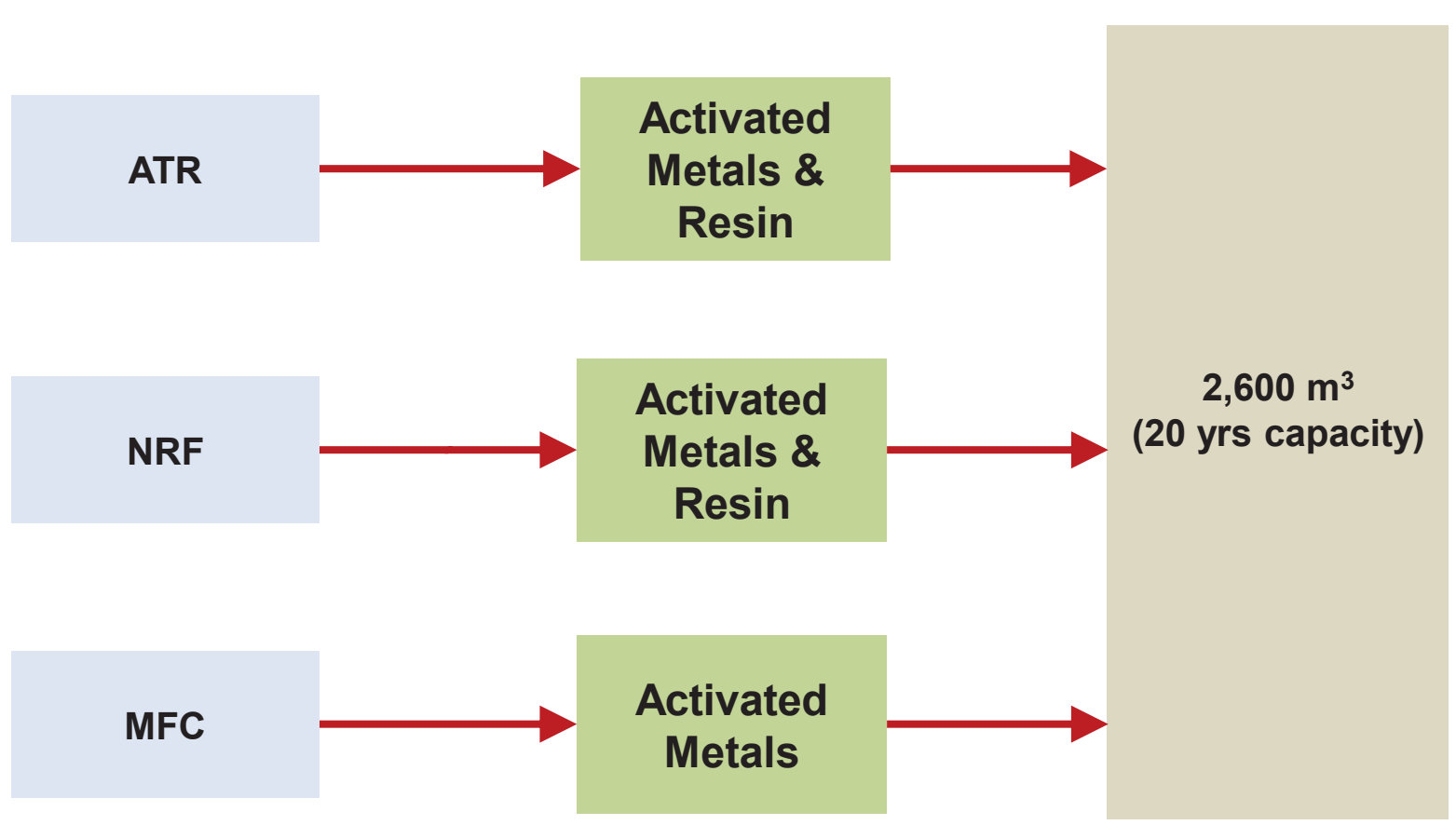

Figure 1. Idaho National Laboratory remote-handled low-level waste disposal requirements.

To support disposal operations, the INL Remote-Handled LLW Disposal Project will develop a new remote-handled LLW disposal facility similar to the reference concept. The remote-handled LLW disposal facility will be operational prior to exhausting the vault capacity at the SDA and final closure of the RWMC in order to support uninterrupted NE and Naval Reactors (NR) mission-related operations. Site infrastructure will include necessary features to support the disposal vault system, such as subsurface water drainage, security and safeguards (e.g., fences and controlled entry equipment), utilities (e.g., electricity, firewater, communications, sewer, and potable water), an administration building, a maintenance building, supporting equipment (e.g., crane, forklift, radiological monitoring devices, and maintenance equipment), and monitoring wells.

In order for this to occur, INL must:

- Complete all necessary documentation, including the DOE Order 435.1, "Radioactive Waste Management," radiological performance assessment and composite analysis 
- Complete facility design

- Complete construction activities

- Complete operational readiness activities to ensure no disruption of mission-critical operations.

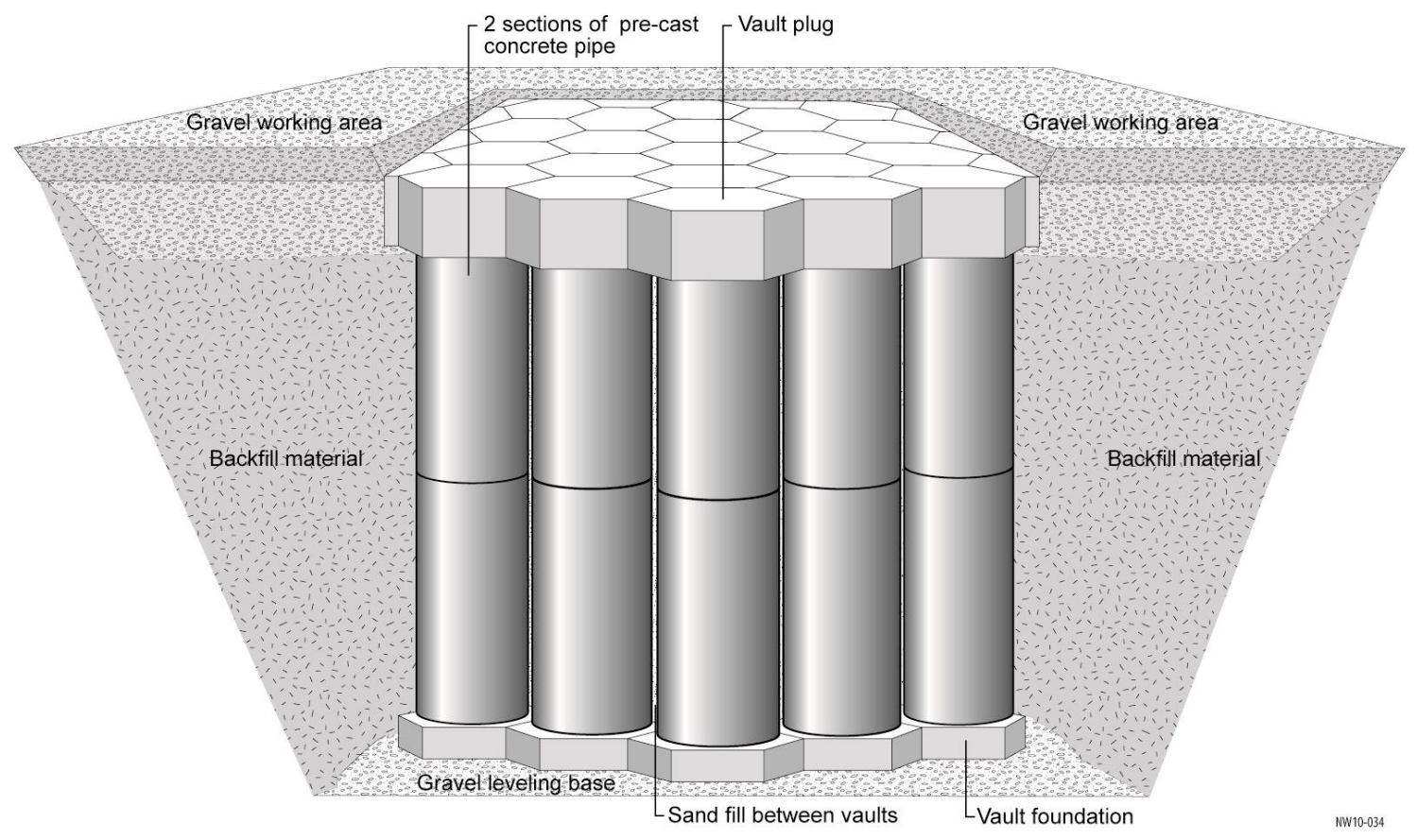

Figure 2. Concept of concrete disposal vault layout.

\subsection{Project Assumptions}

The following key assumptions are associated with development of an onsite remote-handled LLW disposal facility, as reflected in the conceptual design:

1. The facility will be government-owned and contractor-operated. DOE will provide oversight of siting, design, construction, and operation of the facility.

2. Project schedule and cost estimates are based on identifying funding levels that will support uninterrupted project staffing and procurement through design, construction, and startup.

3. Vault layout will be designed to support 20 years of disposal capability with expansion capacity to support up to 50 years of waste disposal.

4. Disposal vaults will be designed to meet nuclear safety and environmental requirements as specified in TFR-483 and SPC-1437.

5. The number of vaults constructed in the facility must be sufficient to emplace the estimated waste canister numbers and types identified in Table 1 of this document.

6. Waste accepted for disposal at the facility will primarily consist of activated metals from NRF, the ATR Complex, and MFC, with resins from NRF and the ATR Complex. The NRF and MFC waste streams also will include a limited volume of additional debris that qualifies as remote-handled LLW. The waste volumes used for conceptual design purposes are shown in Figure 1. The facility will be designed to accept waste with a typical contact exposure rate up to $60,000 \mathrm{R} /$ hour. 
7. When 55-ton waste canister emplacement operations are planned to begin, NRF will use its existing 55-ton cask and associated transfer system or similarly designed equipment. A portion of planned NRF Disposal vaults will be sized for 55-ton cask waste canisters. A number of vaults for NRF will also be sized to handle NRF's new large concept waste canister.

8. The existing NRF 55-ton cask and Manitowoc 3900W crane will not be available to support facility fit-up, emplacement testing, or facility start-up until RWMC SDA emplacement operations are complete, expected to occur in FY 2020. Hence, 55-ton waste canister and emplacement testing will not be completed as part of the operational readiness review (ORR).

9. NRF is expected to transition to the new large concept waste canister currently under development. The NRF large concept cask will not be available to support fit-up, emplacement testing, or facility start-up. Therefore, the NRF large concept cask and associated waste canister are excluded from the ORR scope.

10. A larger crane will be needed to handle NRF's new large concept waste canister and transport cask, but is considered to be outside the scope of this project. This crane will be procured by NRF and is required for disposal operations for the large concept waste canisters. The first established need for the new crane is anticipated to be several years after commencing initial facility operation. Its use is outside the scope of this project.

11. A smaller crane, provided as part of the design-build subcontract, will be used to support fit-up, emplacement testing, and facility start-up of the MFC HFEF-5 and ATR Resins waste canisters during the ORR.

12. Any activity involved in the design, fabrication, or modification of the NRF transportation casks (55ton scrap or the new large concept) is considered to be outside the scope of this project.

13. Any activity involved in the design or fabrication of the facility transfer container (FTC) or the ATR activated metals cask is considered to be outside the scope of this project.

14. The ORR will be scoped to complete emplacement operations testing for the $\mathrm{NuPac}^{\circledR} 14-210 \mathrm{~L}$ cask (ATR Resins) and the MFC HFEF-5 cask.

15. Activated metals generated at ATR will be transported in a suitable waste cask, referred to as the ATR HFEF-5 cask. This cask will be procured, designed, and fabricated in the future outside of the project and will not be available to support facility fit-up, emplacement testing, and facility start-up and therefore will not be part of the ORR.

16. Activated metals that could be generated from potential new missions and from processing of remotehandled scrap and waste currently stored at MFC will be transported in an HFEF-5 waste canister using the HFEF-5 Cask. For the purposes of conducting the ORR, a dummy waste canister will be provided by MFC.

17. The following government furnished equipment is assumed to be provided by NE for use during the ORR and future facility operations: 1) one dummy ATR resins waste canister (may be carbon steel for the ORR) and 2) one MFC HFEF-5 waste canister. This equipment will be used to support the ORR. This equipment must be provided to support ORR preparation activities, planned to commence immediately following the completion of construction.

18. Following the project ORR, and after closure of the project, NR will provide the following equipment to support readiness activities prior to commencing NR waste disposal operations: 1) one 55-ton scrap cask with appropriate CVAS and cask handling equipment; 2) one dummy 55-ton waste canister; 3) the Manitowoc 3900W Boom Crane; 4) one large concept cask with appropriate CVAS and cask handling equipment; 5) one dummy large concept waste canister; and 6) one large crane, sized to handle and complete emplacement operations for the large concept cask. 
19. Disposal vaults for waste generated from processing of remote-handled scrap and waste currently stored at MFC will be sized to accept HFEF-5 waste canisters. Any specific rigging needed to use the MFC HFEF-5 cask at the disposal facility will be designed and procured as part of this project.

20. The NuPac ${ }^{\circledR} 14-210 \mathrm{~L}$ cask will be used for shipments of the ion-exchange resins waste generated from the ATR Complex. The disposal vaults for this waste will be sized to accept the ATR resins waste canisters currently used at the ATR Complex. Any canister-specific ancillary equipment needed for canister emplacement will be designed and procured as part of the project under the design-build subcontract. Typical hoisting and rigging equipment is excluded.

21. An overpack canister will be used for MFC legacy waste currently stored in 24" below-grade liners at the Radioactive Scrap and Waste Facility. This overpack canister will be transported using a modified FTC. Design and procurement of the overpack canister and modified FTC is outside the scope of this project.

22. The Manitowoc crane currently in use at RWMC will be transferred for use to this facility prior to commencement of 55-ton waste canister receipt and disposal.

23. The facility maintenance building will be designed to accommodate staging of planned, loaded transportation systems due to schedule or weather impacts. The large concept cask and trailer are not considered because dimensions are currently unknown.

24. Updates to INL waste management processes and procedures, will be provided outside of the scope of this project.

25. A new documented safety analysis will be required for the disposal facility.

26. Changes to infrastructure at waste-generating facilities are not included as part of the scope of this project.

27. The Remote-Handled LLW Disposal Project is based on its development and approval as a line item construction project per DOE Order 413.3B.

28. The design-build subcontractor is responsible for preparation of operations and maintenance procedures and assistance with completion of the contractor and DOE operational readiness reviews.

\subsubsection{Project Uncertainties}

In executing this project, uncertainties about given aspects of the project require identification to clarify assumptions and act as the basis for establishing and maintaining a risk management plan. The primary risks are introduced through lack of complex-wide experience and lessons learned in constructing a nuclear facility using the design-build delivery method. Additional risks are introduced through programmatic considerations. As captured in the risk register contained in the risk management plan, primary uncertainties include the following:

- Design-build impacts on the facility performance assessment and analyses supporting the environmental assessment

- Design-build impacts on nuclear safety

- Design-build impacts on safeguards and security

- Design-build impacts on operability requirements caused by design flexibility allowed in the facility performance specification

- Materials availability/cost uncertainty

- Project delays 
- Uncertainty about the accommodation/collaboration achievable between the design-build subcontractor to ensure that all nuclear safety and environmental requirements are incorporated into the design

- Future operator of the facility has not been selected; selection of the operator may change the operational readiness review/turnover approach.

Risks and mitigations relative to the uncertainties identified above have been identified and initiated. They include, but are not limited to, the development of the facility performance specification and the technical and functional requirements. A reconciliation plan was implemented to further identify risks associated with these uncertainties, and ensure that they were addressed in the risk register.

\subsection{Justification of Mission Need}

The continuing nuclear mission of INL, associated ongoing and planned operations, and naval spent nuclear fuel activities at NRF require continued capability to appropriately dispose of remote-handled LLW. Providing continued disposal capability for remote-handled waste supports DOE-NE's mission "to lead the DOE investment in the development and exploration of advanced nuclear science and technology." Without established, viable remote-handled LLW disposal capability, ongoing and future nuclear energy programs at INL would be adversely impacted because remote-handled LLW disposal options would need to be considered on a program-by-program basis, resulting in increased costs and schedule. The lack of remote-handled LLW disposal capability also may impede DOE's ability to initiate new programs at INL.

Remote-handled LLW disposal capability also is critical to meeting the Naval Reactor's mission to "provide the United States Navy with safe, militarily effective nuclear propulsion plants and to ensure the safe and reliable operation of those plants." All spent nuclear fuel from the Navy's nuclear-powered fleet is sent to NRF for examination, processing, dry storage, and eventual shipment to a permanent geologic repository. A reliable disposal path for remote-handled LLW generated during spent nuclear fuel handling and packaging operations is essential to NRF's continued receipt and processing of naval spent nuclear fuel and, therefore, to national security.

The mission need statement for the INL Remote-Handled LLW Disposal Project, created as a result of evaluating INL-generated LLW disposal options, is as follows:

The INL will develop replacement remote-handled low-level waste disposal capability by the end of Fiscal Year 2015 to support cost-effective, efficient operations in support of INL's nuclear energy mission and the Naval Nuclear Propulsion Program. Such disposal capability is required to enhance ongoing Departmental and National mission-based research, defense, and energy programs.

The project mission need statement (CD-0 approval) was approved by NE-1 on July 1, 2009. Since then, closure of RWMC was extended, resulting in an extension of the project need date beyond its original 2015 date. The project need date continues to be constrained by the current SDA vault capacity and closure schedule for RWMC. The SDA vault capacity is currently predicted to be exhausted by FY 2020.

Completion of this project is critical to the long-term conduct of DOE's missions at INL. If the Remote-Handled LLW Disposal Project is not approved, the impacts are as follows:

- Processing of naval spent nuclear fuel at NRF will be negatively impacted once existing interim storage is exhausted, impacting DOE's ability to support the Navy's nuclear-powered fleet and jeopardizing DOE's ability to comply with the terms of the Idaho Settlement Agreement (State of Idaho 1995; State of Idaho 2008). 
- Failure to meet the terms of the Idaho Settlement Agreement could result in fines and penalties of up to $\$ 60,000$ per day and termination of naval spent nuclear fuel receipt at INL (State of Idaho 1995; State of Idaho 2008)

- Continuity of INL mission-critical operations will be at risk

- Operations at ATR will be curtailed once existing interim storage capacity is exhausted

- Future INL nuclear programs that rely on safe, compliant, remote-handled LLW disposal may be impacted

- DOE will continue to spend significant resources in identifying alternate remote-handled LLW disposal pathways, interim storage capabilities, and approaches for short-term management of INL's remote-handled LLW waste streams

- DOE and contractor resources will be partially diverted from mission to waste management issues.

In summary, if the replacement remote-handled LLW disposal capability is not established, the long-term viability of INL as the nation's lead nuclear energy laboratory will be adversely affected.

\subsection{Project Description}

The INL Remote-Handled LLW Disposal Project will develop an onsite disposal facility for INL-generated remote-handled LLW to provide uninterrupted disposal capability in support of NE and NR missions. Remote-handled LLW is generated from nuclear programs conducted at DOE's Idaho Site, including spent nuclear fuel handling and operations at NRF and operations at ATR. Legacy remotehandled LLW stored in the Radioactive Scrap and Waste Facility at MFC also will be disposed of in the facility.

The project scope is defined by two key performance parameters (KPPs), which will be used to confirm successful completion of the project. These parameters are as follows:

1. Design and construct a vault disposal system with the capacity to dispose of a minimum of 673 waste canisters.

This KPP will be verified through inspection and verification of quality documentation supporting concrete test results, dimensional inspections, and numbers of disposal vaults installed. These activities will ensure that the constructed disposal vaults meet established requirements for materials, dimensions, and installation.

2. Design and construct facility infrastructure to support waste disposal operations (necessary infrastructure includes an administration building, maintenance building, water and electrical systems, security systems and road access).

This KPP will be verified through design review report(s), inspection and quality control during construction, and documented facility turnover from the design-build subcontractor.

To support these parameters, the scope of the project consists of (1) site infrastructure including security; (2) a disposal vault system; and (3) procedures and plans necessary for operations. The infrastructure will include necessary features to support the disposal vault system. The emplacement system components include a CVAS and other associated handling equipment. The disposal vault system will meet all of the requirements identified in TFR-483 and SPC-1437, with allowed modifications to the reference design. These requirements were derived from the systems evaluation of engineered features, including an analysis of liner alternatives performed to determine the vault features required to be protective of the environment and to provide worker safety. Because of the requirements provided in TFR-483 and SPC-1437, allowed modifications cannot adversely impact facility performance but may introduce design and cost efficiencies. Procedures and plans include those specifically listed in SPC-1437 and TFR-483 and required for facility operations. 
Table 1 presents the estimated waste disposal capacity required to support 20 years of projected waste generation. It also provides waste canister details, identifying the generator facility and specifics about canister dimensions and numbers, and provides one possible canister vault loading configuration.

From Table 1, six different waste canister designs are considered for emplacement in the facility. The first design is the 55-ton scrap cask waste canister used by NRF for transport of activated metals and resin remote-handled LLW. The disposal capacity needed for this canister type has been determined by the planned shipping schedule from the generator facility. For the 20 year operational period, the facility will be designed to emplace approximately164 55-ton scrap canisters.

During the operational period, NRF also plans to transition to the second canister design, consisting of a new large concept cask and waste canister, replacing the 55-ton scrap cask. This larger waste canister will accommodate activated metals with less sizing and is projected to improve the efficiency of NRF waste processing. This new cask and waste canister will be developed in support of NRF's Spent Fuel Handling Recapitalization Project. Canister size, radiological content, and nuclear safety considerations limit the potential vault loading configurations to one canister per vault. The exact transition time and period needed to phase out of the 55-ton waste canister is unknown; however, large concept disposal vaults will be needed to support transition to the new large concept waste canister. Subsequent to conditional award of the design-build subcontract, NRF identified the need for 60 additional large concept waste canister disposal vaults above initial estimates, in the event that the final cask size is smaller than the maximum size listed in Table 1. This scope has been identified as contingent scope and will be addressed if unused contingency becomes available to fund their fabrication and installation, as detailed in Table 3.

Table 1. Estimated waste canister projections and types planned for receipt during 20 years of operations.

\begin{tabular}{|c|c|c|c|c|c|c|}
\hline \multicolumn{7}{|c|}{ Canisters estimated for Receipt (20 years of operation) } \\
\hline \multirow{2}{*}{ Cask } & \multirow{2}{*}{ Waste Type } & \multirow{2}{*}{$\begin{array}{c}\text { Waste } \\
\text { Generation } \\
\text { Facility }\end{array}$} & \multicolumn{2}{|c|}{ Canister Size } & \multirow{2}{*}{$\begin{array}{c}\text { Estimated } \\
\text { Number of } \\
\text { Canisters }\end{array}$} & \multirow{2}{*}{$\begin{array}{c}\text { Probable } \\
\text { Canister } \\
\text { Stacking } \\
\text { Configuration }\end{array}$} \\
\hline & & & $\begin{array}{c}\text { Diameter } \\
\text { (Inches) }\end{array}$ & $\begin{array}{c}\text { Height } \\
\text { (Inches) }\end{array}$ & & \\
\hline NRF 55-ton Scrap & Resins/Activated Metals & NRF & 48 & 105 & 164 & 2 \\
\hline NRF Large Concept & Resins/Activated Metals & NRF & 60 & 170 & 192 & 1 \\
\hline MFC HFEF-5 & Activated Metals/Debris & MFC & 13 & 75 & 115 & 2 \\
\hline ATR HFEF-5 & Activated Metals & ATR & 13 & 75 & 56 & 2 \\
\hline $\mathrm{NuPac}^{\mathbb{B}} 14-210 \mathrm{~L}$ & Resins & ATR & 75 & 80 & 120 & 2 \\
\hline Modified FTC & Activated Metals/Debris & MFC & 29 & 170 & 272 & 1 \\
\hline
\end{tabular}

The third canister design is based on the assumed configuration of waste containers to be used by MFC for transport of remote-handled LLW activated metals. The bottom/top-loading HFEF-5 cask design was identified to be the most suitable transport cask for disposal of remote-handled activated metals from the MFC hot cells. For the 20-year key scope period, a total of approximately 115 waste containers are assumed to be shipped from MFC.

The fourth canister design, for ATR activated metals, will be similar to the MFC HFEF-5 canister. The ATR remote-handled LLW activated metals will be generated on a periodic basis that is correlated with ATR core internals change out activities. These activities are expected to generate waste requiring approximately 56 ATR HFEF-5 waste canisters. Though the canister design may not be exactly like the MFC HFEF-5 canister, its design is assumed to be similar in sizing due to weight handling restrictions over the ATR canal. Final canister design will be bounded by these restrictions. 
The fifth canister design is currently used by ATR for transport of remote-handled LLW resins. These canisters are used with the NuPac ${ }^{\mathrm{TM}} 14-210 \mathrm{~L}$ transportation cask. For the 20 -year operational period, capacity for approximately 120 canisters is assumed. Currently, these waste resin containers are being shipped to the Nevada National Security Site for disposal. Because continued acceptance of this waste at the Nevada National Security Site cannot be guaranteed, the remote-handled LLW disposal facility is being constructed with capacity to dispose of ATR resins.

The sixth canister design is an overpack container that will hold MFC legacy waste currently stored in 24" diameter, below-grade liners from the Radioactive Scrap and Waste Facility. This overpack canister will be transported using a modified FTC. Approximately 272 of these canisters are estimated to be disposed of at the remote-handled LLW facility during the 20 -year operational period.

In total, disposal capacity for canisters spanning six different designs will be required to fulfill the projected initial 20-year disposal emplacement needs for the facility.

House Report 109-86 mandates One-for-One Replacement legislation and requires that requested project funding be set aside for the elimination of excess buildings and facilities of equivalent size by transfer, sale, or demolition. Off-setting decontamination and demolition for this project will be conducted during CERCLA remediation of the SDA at RWMC. CERCLA remediation will be funded through the Office of Environmental Management; therefore, offsetting decontamination and demolition costs are not reflected in project funding requirements. The currently planned remote-handled LLW disposal facility will have a minimum total footprint of 10 acres. The SDA at RWMC encompasses 97 acres. Additionally, the facility will use a minimum necessary footprint. Two support structures are required for the facility: an administration building and a maintenance building. The anticipated square footage, based on the building conceptual design in the design-build subcontract, is $3,750 \mathrm{ft}^{2}$ and $5,000 \mathrm{ft}^{2}$, respectively. This new square footage also will be offset by elimination of excess square footage from identified footprint reduction activities at INL. INL provides DOE with regular input on asset utilization.

\section{MANAGEMENT STRUCTURE AND INTEGRATED PROJECT TEAMS}

The Remote-Handled LLW Disposal Project is jointly funded and sponsored by DOE-NE and DOE-NR. A memorandum of agreement was signed by DOE-NE and DOE-NR in June 2009 to establish the funding approach and roles/responsibilities for the project. The Assistant Secretary for Nuclear Energy served as the Acquisition Executive for the project through CD-1, with DOE-NR participating on the Energy Systems Acquisition Advisory Board and concurring on CDs related to the project. At CD-1, the Acquisition Executive authority for subsequent CDs was delegated to the Deputy Assistant Secretary for Nuclear Facility Operations (NE-3) for the Office of Nuclear Energy.

The Acquisition Executive appointed a Level 2 Federal Project Director (FPD) at approval of CD-1. The FPD will provide federal oversight and engage the expertise of an Integrated Project Team (IPT) to assist in the oversight process.

The INL management and operating contract requires that Battelle Energy Alliance, LLC (BEA) develop replacement capability for disposal of LLW generated by INL and other tenets upon closure of RWMC. Consistent with INL contract requirements, BEA will perform project management responsibilities in accordance with DOE Order 413.3B.

\subsection{Project Organization}

The project organization meets the requirements of DOE Order 413.3B, DOE Order 414.1D Admin Chg 1, "Quality Assurance," and the DOE Idaho Quality Assurance Manual (IDMS 01.OD.02). The project organization is shown in Figure 3. Functional responsibilities, authorities, and interfaces for key positions shown in the project organization are summarized as follows: 


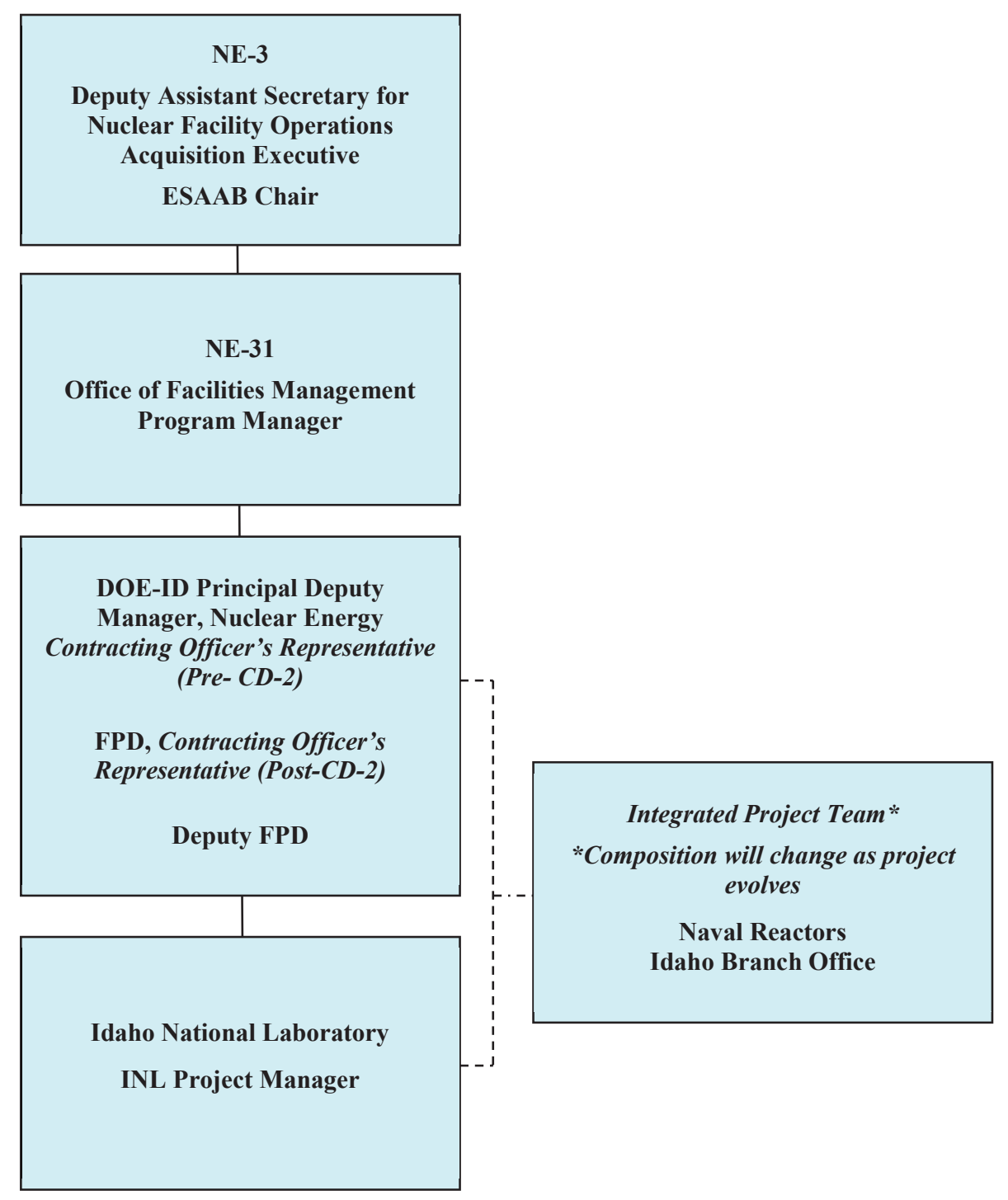

Figure 3. Project organization.

- Acquisition Executive: Based on the total project cost (TPC), the Deputy Assistant Secretary for Nuclear Facility Operations (NE-3) serves as the Acquisition Executive. In this capacity, NE-3 has responsibility for ensuring adequate project planning and execution and for establishing broad policies and requirements for achieving project goals. The Acquisition Executive performs the following responsibilities:

- Chairs the Energy Systems Acquisition Advisory Board

- Approves CDs

- Ensures the FPD is qualified and has the communication and leadership skills necessary to successfully execute the project

- Approves the acquisition plan, project execution plan

- Provides funding for project development and facility construction and operation

- Approves Level 1 baseline change requests

- Conducts quarterly project progress reviews 
- Establishes and provides direction to the Project Management Support Office

- Approves the Design Authority.

- Headquarters Program Manager: NE-31 serves as the Headquarters Program Manager responsible for this project. In this capacity, NE-31 performs the following responsibilities:

- Provides guidance and resources necessary to execute the project

- Serves as a point of contact for communicating with other DOE Headquarters offices, including DOE-NR, as necessary to support project execution

- Reviews and approves project budget requests and ensures their integration within the DOE-NE budget submission

- Reviews and provides recommendations to the Acquisition Executive on proposed Level 1 baseline change requests

- Appoints a representative from NE-31 to participate on the IPT

- Reviews and approves all project documents requiring program approval

- Reviews and concurs on project documents requiring Acquisition Executive approval.

- Project Management Support Office:

- Serves as the Secretariat for the Energy System Acquisition Advisory Board equivalent reviews

- Initiates formal project reviews for NE-sponsored projects at the request of the AE

- Provides independent oversight of projects at the request of the AE

- Sponsors Quarterly Project Progress Reviews.

- Principal Deputy Manager, NE: The Principal Deputy Manager, NE serves as the contracting officers' representative and all related functions, until approval of CD-2. Upon CD-2 approval, this responsibility will be transferred to the FPD. The Principal Deputy Manager, NE will perform the following functions prior to approval of CD-2:

- Serves as the contracting officers' representative

- Interfaces with the NE-31 in executing program office direction at the site

- Approves Level 2 baseline change requests.

- FPD: Upon CD-2 approval, contracting officers' representative responsibilities will transfer to the FPD. In addition to these responsibilities, the FPD performs the following responsibilities:

- Interfaces between federal and contractor staff on all matters relating to the project and its performance

- Principal point of contact between the project, the principal deputy manager, nuclear energy; the Contracting Officer, and the NR Idaho Branch Office

- Approves and maintains the IPT charter, ensures the IPT is properly staffed for the stage of project execution, and oversees the roles and responsibilities of each IPT member

- Coordinates management of project risks and allocation of DOE-held contingency in collaboration with the program office and contracting officer's representative.

- Ensures development and implementation of key project documentation

- Recommends approval of the performance baseline to the Acquisition Executive

- Ensures design, construction, environmental, safety, security, health, and quality efforts performed comply with the contract, public law, regulations, and Executive Orders

- Ensures timely, reliable, and accurate integration of contractor performance data into the project's scheduling, accounting, and performance measurement systems, including PARS II 
- Evaluates and verifies reported progress and makes projections of progress and identifies trends.

- Deputy FPD: This position is a developmental assignment that includes the following responsibilities:

- Assists the FPD as requested

- Fills-in when the FPD is unavailable

- Functions as the Commissioning Authority.

- INL Project Manager: The INL Project Manager is the principal point of contact for development and execution of the project within INL. The INL Project Manager performs the following responsibilities:

- Primary point of contact with the FPD

- Ensures all necessary activities are identified and integrated into the project baseline

- Ensures the project is completed within the approved budget, scope, and schedule

- Ensures effective project management systems, cost controls, and milestone schedules are developed, documented, and implemented to assess project performance

- Ensures project activities are conducted in a safe and environmentally sound manner

- Ensures environment, safety, and health and DOE Order 435.1 responsibilities and requirements are performed and integrated into the project

- Assures compliance with the quality project plan, including, but not limited to, development of quality products and records throughout the life of the project

- Oversees research and development activities, design, fabrication, installation, construction, and commissioning

- Develops the operational readiness strategy for the project and ensures its implementation in support of CD-4 approval and transition to operations

- Represents the project in all interactions with DOE

- Participates in management meetings with DOE and communicates project status and issues

- Requests and coordinates internal and external peer reviews of project

- Chairs the change control board and approves Level 3 change control proposals

- Prepares and provides recommendations to the FPD for Level 1 and 2 change control proposals

- Identifies and manages project risks or elevates them to the FPD as needed

- Chairs the INL IPT.

\subsection{Integrated Project Team}

The objective of the IPT is to bring together diverse subject matter expertise in order to support successful development and execution of the project. The remote-handled LLW disposal IPT was established at CD-0 and will remain in effect through CD-4. The IPT is chaired by the FPD and organized by functional responsibility. Table 2 presents the functional responsibilities and assignments of IPT members at CD-2/3. IPT composition will vary based on the project's requirements as it progresses through implementation. Consistent with DOE Guide 413.3-18, the IPT has been structured to ensure the ratio of federal to contractor personnel is kept to a reasonable balance. However, IPT meetings are open for all project participants to attend. Additional contractor/subcontractor representatives will participate as needed as the project evolves in maturity. Key members of the IPT will handle most IPT issues unless specific additional support is needed by other non-key IPT members. IPT roles and responsibilities are described in the IPT charter presented in Appendix A. 
Table 2. Remote-handled low-level waste Integrated Project Team functional responsibilities and assignments.

\begin{tabular}{|c|c|c|}
\hline Organization & Member & Functional Area of Responsibility \\
\hline $\begin{array}{l}\text { DOE-ID Infrastructure } \\
\text { Projects* }\end{array}$ & Julie Conner & $\begin{array}{l}\text { Federal Project Director and Risk } \\
\text { Management. }\end{array}$ \\
\hline $\begin{array}{l}\text { DOE-ID Infrastructure } \\
\text { Projects* }\end{array}$ & Gerardo Islas Rivera & Deputy Federal Project Director \\
\hline NE-31* & Kim Petry & PSO-Program Sponsor \\
\hline NE-31* & Mary McCune & PSO-Program Sponsor \\
\hline DOE Naval Reactors -IBO* & Christopher Henvit & Naval Reactors (Advisory Capacity) \\
\hline $\begin{array}{l}\text { DOE-ID Contract } \\
\text { Management* }\end{array}$ & Suzette Olson & Contracting Officer \\
\hline DOE-ID Quality \& Safety* & Chris Beaman & Quality Assurance SME \\
\hline DOE-ID Nuclear Safety* & $\begin{array}{l}\text { Primary: } \\
\text { Roger Harshbarger } \\
\text { Secondary: } \\
\text { Charles Maggart }\end{array}$ & Nuclear Safety SME \\
\hline INL Project Manager* & David S. Duncan & BEA Project Manager \\
\hline DOE-ID Public Affairs & Timothy Jackson & Public Affairs and Communications \\
\hline DOE-ID Budget Services & Faye Alexander & Budgets, Planning and Project Controls \\
\hline DOE-ID Facility Representative & $\begin{array}{l}\text { Steve Karns/ John } \\
\text { Martin }\end{array}$ & Facility Operations SME \\
\hline $\begin{array}{l}\text { DOE-ID Infrastructure } \\
\text { Management }\end{array}$ & Mike Hicks & Transportation SME \\
\hline DOE-ID Design Engineering & Greg Bass & Civil Engineer SME \\
\hline DOE-ID Chief Counsel & Erin Walkowiak & Legal and Regulatory \\
\hline DOE-ID Industrial Safety & Kyle A. Morrison & Fire Protection SME \\
\hline DOE-ID Industrial Safety & James B. Lovejoy & $\begin{array}{l}\text { Construction Safety/ Hoisting and Rigging } \\
\text { Safety SME }\end{array}$ \\
\hline INL Manager & Philip J. Breidenbach & BEA MFC Mission Support Director \\
\hline INL Facility Manager & Vince M. Bowen & $\begin{array}{l}\text { BEA Manager, Spent Fuels Treatment/ } \\
\text { Disposal facilities }\end{array}$ \\
\hline INL ATR Canal Operations & Scott Ullsperger & ATR Canal Operations Manager \\
\hline Design Authority & Gary Tarbet & Design Authority \\
\hline
\end{tabular}

* Key Members 


\subsection{Idaho National Laboratory Project Organization}

Project execution is the responsibility of INL under the guidance of the Principal Deputy Manager, Nuclear Energy prior to CD-2 and the FPD post CD-2. The INL project manager will be responsible for administration and management of all project activities. A project engineer will be assigned and responsible for assisting the project manager with the technical aspects of the project, including management of design requirements, specifications, and drawings. The project engineer also will receive independent oversight from the design authority, who is ultimately responsible to ensure that the design and construction complies with all nuclear safety and code-of-record requirements. The project manager will be supported by a minimum of three control account managers, each with responsibilities for managing the work scope within their assigned subprojects, which consist of (1) project management; (2) project documents; (3) infrastructure; and (4) disposal vaults. The project manager and control account managers will ensure that appropriate and qualified personnel from INL support organizations are assigned to support project execution. Support organizations include, but are not limited to, Business Management, nuclear safety engineering, safety, quality assurance, environmental compliance, facility operations, procurement, construction management, and engineering.

As shown in the organization chart of Figure 4, an appointed design authority maintains independent direction over the project engineer to ensure that the design meets all established nuclear safety and technical requirements. The design authority role in this and other projects at the INL is established in PDD-10000.

The project manager will interface with the FPD and IPT to ensure project execution is successful. The INL project organization chart is presented in Figure 4.

Project design and construction activities will be completed by subcontractors. Additional subcontractors will be used as necessary to supplement INL resources during project development and execution. BEA has prime responsibility for technical direction and oversight of all contracts required to execute this project.

Because a large percentage of the projected remote-handled LLW to be disposed of at the facility will be generated by NRF, close coordination with DOE-NR and the NRF contractor will be required as the project progresses. Support from NRF will be required in providing updated waste volumes, waste container interface requirements, waste characterization data, and other operations-related information necessary to ensure the disposal facility meets the waste disposal needs and requirements of NRF.

\section{TAILORING STRATEGY}

\subsection{Key Elements of the Tailoring Strategy}

Based on the design-build project delivery approach, provisions of DOE Order 413.3B will be incorporated to tailor the project execution approach. Key elements of the tailoring strategy include the following:

- CD-0 Mission Need Approved, July 2, 2009

- CD-1 Alternative Selection and Cost Range Approved, July 13, 2011

To support the project schedule, construction funds were requested prior to CD-2 approval. The initial request for capital funds was established at the upper end of the cost range at CD-1. Capital funding for the project was authorized as part of the 2014 Consolidated Appropriations Act. 


\section{Remote-Handled Low-Level Waste Disposal Project \\ July 2014}

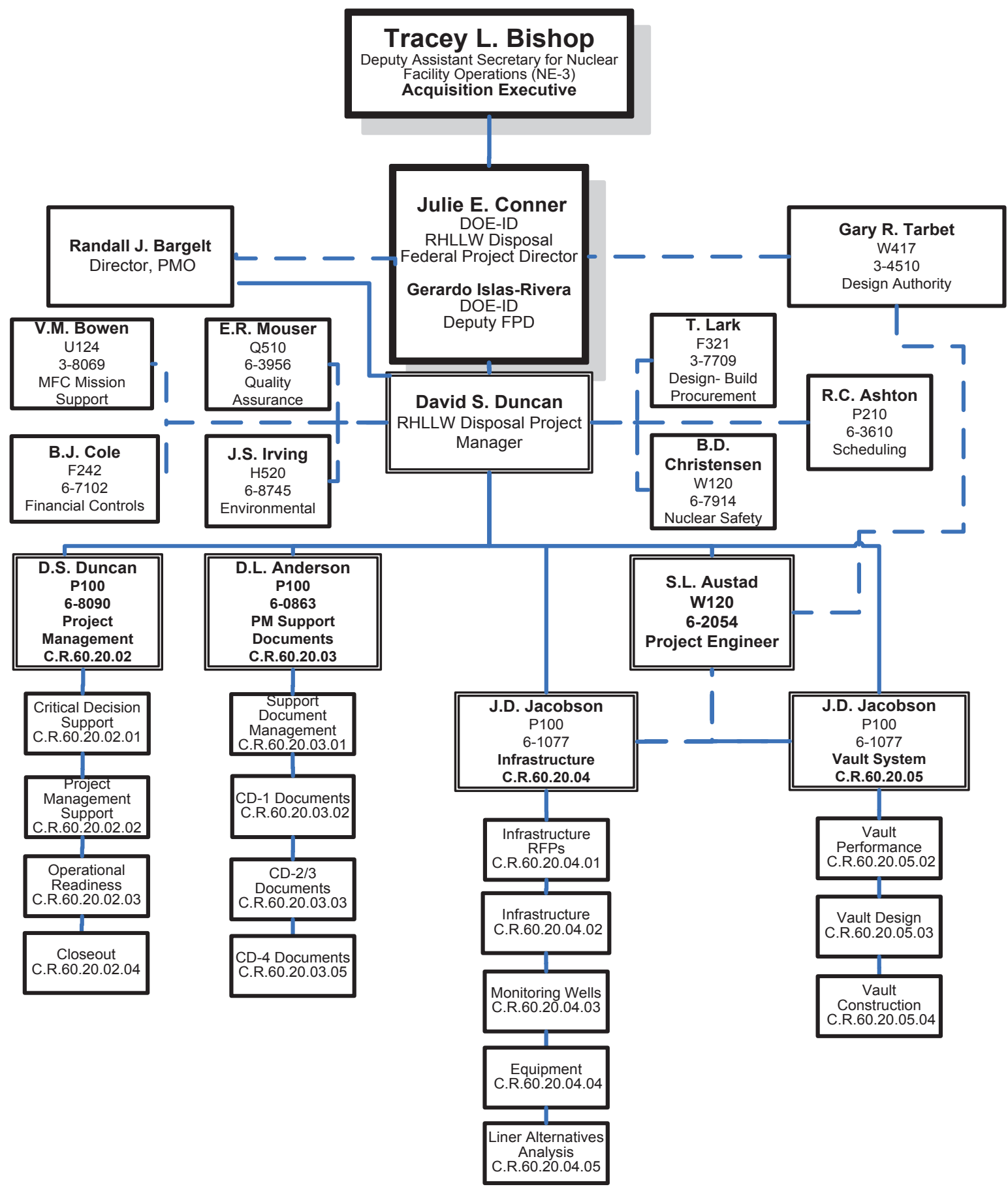

Figure 4. Project organization chart. (updated with new team members, March 2014) 


\section{- CD-2/3 Approve Performance Baseline/Project Execution}

The following approach was used to mitigate risks associated with the design-build project delivery method outlined in the Acquisition Strategy for the Idaho National Laboratory Remote-Handled Low-Level Waste Disposal Project (DOE-IDa). The design-build subcontract was competitively bid by qualified subcontractor teams using a "build to budget" approach. The subcontract was conditionally awarded on a best value basis. INL will perform supporting functions and analyses such as preparation of Nuclear Safety documentation and analyses required for LFRG approval.

The NEPA FONSI was issued and the LFRG review of the facility performance assessment resulted in issuance of a Preliminary Disposal Authorization Statement. In addition to approving the facility performance assessment, the LFRG Review Team performed a detailed review of the performance specification (SPC-1483) to ensure the technical requirements in the request for proposals would meet the primary assumptions of the facility performance assessment. This also ensured that assumptions made to support the NEPA FONSI would be met.

A comprehensive review was performed to compare the design concepts in the conditionally awarded subcontract against the CD-1 facility concept. Substantive differences were documented. These differences were assessed to determine if they introduced additional risk to the project. Risks were documented and included in the management reserve/contingency analysis. A Reconciliation Report is included in the CD-2/3 documentation and documents these differences. The design-build subcontract was conditionally awarded in March 2014, pending CD-2/3 approval. The subcontractor will receive a notice-to-proceed following approval of CD-2/3.

The CD-2/3 approval strategy allows the Acquisition Executive to approve CD-2 and provide conditional approval of CD-3. Approval conditions for CD-3 include DOE review and approval of the final design prior to the Acquisition Executive releasing the construction/fabrication hold point for facility disposal vaults and CVAS.

The project incorporates the use of key performance parameters (KPPs), which represent the minimum scope/requirements necessary for the project to successfully meet the mission need. These KPPs comprise the scope of the official performance baseline. In addition, contingent scope has been identified, which includes additional large concept disposal vaults to achieve a higher desired capacity for shipments projected to arrive from NRF. This approach allows the Program Office to request contingency funds adequate to cover project risks while ensuring that appropriated funds will be effectively utilized if not required to address risks.

To address the desire to use a design-build acquisition strategy in procurement of the remote-handled LLW disposal facility, CD-2 and CD-3 were tailored and combined to obtain approval for both design and construction funding simultaneously. Because the new facility will be very similar to a currently operating facility and the design is not complex, the project risk was considered low enough to allow combination of these critical decisions. Using the design-build delivery method, approval of a "preliminary" design and CD-2 is justified through use of a highly detailed performance specification and a proven operational reference concept. However, meeting the intent of DOE Order 413.3B and the recommendations of DOE Guide 413.3-5A presents a challenge without completion of the final design. To achieve the intent of the order, the project proposed a conditional approval of CD-3 at CD-2. This conditional CD-3 approval includes a future hold point where compliance with specific CD-3 requirements will be demonstrated. The hold point requires Acquisition Executive approval prior to its release for construction/fabrication. This approach allows for use of construction funds to award and execute the design portion of the design-build contract, while simultaneously using a hold point to review and approve the vault system final design prior to construction. The construction hold point and release requirements for full approval of CD-3 are discussed in the next subsection. 
No tailoring needed. All requirements will be met.

\subsection{Critical Decision-3 Construction Hold Point and Release}

One construction hold point has been incorporated in the project baseline schedule for the remotehandled LLW disposal vault subsystem and CVAS. This hold point is planned for the $4^{\text {th }}$ quarter of FY 2015. The criteria that must be met for the hold point to be lifted are consistent with the requirements of CD-3 and are specific to the vault subsystem.

An independent review will be conducted to validate that the construction hold point requirements have been met. The Acquisition Executive will determine if the design and project documentation is complete or if additional information is required. Acquisition Executive approval to release the hold point will constitute authorization to proceed with construction/execution of the vault subsystem work scope. This approach will ensure the intent of DOE Order 413.3B has been met. The hold point will be preceded by a 6 -week activity for DOE review of the hold point documentation and approval by the Acquisition Executive.

\subsubsection{Construction Hold Point}

Remote-handled LLW disposal vault subsystem/CVAS construction hold point - Acquisition Executive release of this hold point will allow construction of the remote-handled LLW disposal facility vault system and all needed CVAS hardware. The vault system includes fabrication and below-grade installation of the disposal vault arrays and supports compliance with DOE Order 435.1. The CVAS hardware includes fabrication of CVAS interfaces for each vault type with the exception of interface hardware needed for the NRF large concept cask. The CVAS components are safety significant and subject to the requirements of DOE Order 420.1C. The review activity for this hold point will commence during the $4^{\text {th }}$ quarter of FY 2015, following DOE review and approval of all supporting nuclear safety documentation.

\subsubsection{Hold Point Release Process}

To commence the hold point release process, BEA will assemble the documentation identified in the following subsection and schedule a focused review meeting with the FPD and appropriate members of the IPT to validate that the hold point requirements have been satisfied. The project will address any comments and formally submit the documentation to the FPD, who will declare (upon IPT concurrence) the documentation ready for review by an independent review team. The submitted documentation will be reviewed against the hold point requirements to ensure the intent of DOE Order 413.3B has been met. The independent review team will provide a recommendation to the Acquisition Executive for consideration. Upon determining that the requirements have been met and the design is complete, the Acquisition Executive may release the hold point and authorize the FPD to proceed with construction/fabrication of the subsystem.

\subsubsection{Hold Point Requirements and Exceptions}

Requirements are identified for the hold point based on the relevant pre-CD-3 requirements of DOE Order 413.3B. All DOE Order 413.3B pre-CD-3 requirements will be met. The project does not take exception to any DOE Order 413.3B requirements; however, the project does take exception to two recommended practices in DOE Guide 413.3-9: (1) value management/engineering and (2) project controls. The value management process is not applicable to the design-build acquisition method. INL's project control system was reviewed recently and determined to adequately meet the requirements of ANSI/EIA-748.

Hold Point: Remote-Handled LLW Disposal Vault Subsystem/CVAS Compliance Evaluation - This review will support release of the construction hold point for the vault subsystem and CVAS hardware. 
Documentation will be provided to allow DOE to independently validate that applicable pre-CD-3 requirements have been met prior to proceeding with vault construction. Revised project documentation that requires Acquisition Executive approval will be included with the hold point release request. The review will address the following documentation in their stated condition:

1. Remote-Handled LLW Disposal Vault Subsystem/CVAS Final Design Report - this document is a report of the final vault subsystem design and the results of the final design review. The vault subsystem final design review must confirm that the design is complete. The final design report must provide documented evidence of the design review, vault system and CVAS constructability, and demonstrate that the final design of both meet the requirements of the PDSA and safety evaluation report. The report must also confirm that that the final design is consistent with the current code of record.

2. Security Vulnerability Assessment Report and Emergency Management Requirements - this document is a revised security vulnerability assessment report which is consistent with the final remote-handled LLW disposal vault subsystem/CVAS and the existing cask designs, and which applies security and emergency management requirements in accordance with DOE O 473.3 and DOE Guide 413.3-3A.

3. Quality Assurance Project Plan - this document is a quality assurance project plan, updated if required, to address construction, field design changes, procurement activities, and the appropriate disposition of quality issues that may occur post CD-3.

4. Construction Safety and Health Plan - this document is a construction safety and health plan inclusive of the vault construction phase and developed in accordance with the requirements of 10 CFR Part 851, Appendix A, Section (d), and that meets the requirements of the performance specification.

5. Preliminary Disposal Authorization Statement (PDAS) Support Document - this document consists of documentation from the LFRG co-chairmen that confirms that the LFRG has reviewed the final design and that it meets the conditions of the PDAS.

6. Safety Design Strategy, Safety Evaluation Report, and PDSA - this documentation consists of 1) a safety design strategy updated to reflect any changes to the security/nuclear safety approach since CD-2; and 2) a Safety Evaluation Report that approves the RHLLW Disposal Project PDSA in accordance with DOE-STD-1189 and DOE Order 420.1C.

7. Start-Up Planning and Operational Readiness - this documentation consists of 1) a start-up and operational readiness plan that accurately reflects the final designs for infrastructure and remotehandled LLW disposal vault/CVAS, , and which addresses the recommendations of DOE Guide 413.3-9 and 2) a draft contractor Plan of Action, developed to support the ORR.

\subsubsection{Lessons Learned}

Within 90 days following release of the Hold Point, a design lessons learned will be submitted to DOE, identifying issues and successes associated with use of the conditional CD-3 and hold point for completion of the vault system design. In addition, within 90 days following approval of CD-4, a project execution, design-build, and start-up lessons learned will be issued to allow exchange of information in the context of project management.

\section{INTEGRATED BASELINE \\ 4.1 Scope}

The scope of the project is to establish an onsite disposal capability for remote-handled LLW. This capability must be established prior to the SDA vault capacity being exhausted and prior to final closure 
of RWMC. Because the TPC to design and build a new remote-handled LLW disposal facility at INL exceeds \$20M, the requirements of DOE Order 413.3B are invoked for this project.

The Remote-Handled LLW Disposal Project will provide capability and capacity to dispose of the remote-handled LLW identified in the subject KPPs of Table 3. The facility must comply with all KPPs of Table 3 .

General requirements, and the basis for each requirement, are identified in the technical and functional requirements document for the project (TFR-483). Specific requirements applicable to the final design and construction of the disposal facility and support infrastructure are defined in the project performance specification (SPC-1437). Both sets of requirements must be addressed by the design-build subcontractor. The requirements are based on a conceptual design for the disposal facility vaults that is similar to that of the current concrete disposal vaults in use at the SDA. This approach will accommodate uninterrupted operations at the generating facilities and capitalize on operational experience and costefficiencies from ongoing operations of other INL disposal activities. The final design developed by the subcontractor may vary from this concept to further improve cost efficiencies, but must still meet operational, nuclear safety, and long-term facility environmental performance requirements. The proposed disposal facility is planned for design and operation as a Hazard Category 2 nuclear facility in accordance with the project Code of Record (INLf).

The work scope addressed by this project execution plan is the aggregate of line item capital project activities establishing replacement remote-handled LLW disposal capability. Specifically, this project will design, construct, and prepare for operation a new onsite remote-handled LLW disposal capability at INL to replace the existing capability. Therefore, the project is defined to encompass design, engineering, and other activities that directly support construction and turnover of a disposal facility to operations for the management of INL and tenant-generated remote-handled LLW. This scope constitutes the contract budget base (CBB) for the project. Other federal costs outside the CBB include United States Geological Survey aquifer monitoring well installation and LFRG review support. These activities are managed by DOE-ID and their costs are included in the project TPC. This project execution plan does not address facility operations following CD-4.

Activities defined and controlled by this project execution plan commenced with approval of CD-0, will culminate at CD-4.

\subsubsection{Substantive Changes to Scope since Critical Decision-0}

The TPC of the project has increased by approximately \$20M since CD-0 approval, when the previous rough-order-of-magnitude cost estimate totaled $\$ 57.7 \mathrm{M}$. Several scope changes resulted in a net increase in project costs. Primary among the changes are the following:

1. Change of facility startup from FY 2016 to FY 2019.

2. Additions and updates in the INL waste generation rate and new consideration for direct emplacement of legacy remote-handled LLW stored at the Radioactive Scrap and Waste Facility.

3. Updates to NRF waste emplacement projections, both through use of the current NRF 55-ton scrap cask and through implementation of their new large concept waste canister cask. This new cask will support planned waste disposal from the Spent Fuel Handling Recapitalization Project at NRF.

4. Reassessment of support required to obtain disposal authorization for a new remote-handled LLW disposal facility. No precedent exists in the complex to assess the DAS cost for a new facility of this type.

5. Identification of the number of waste canisters to be disposed in support of NE and NR mission activities over a 20 year operational period based on current and projected waste generation rates. 
6. Removal of scope for the development of a transportation system to support future disposal of ATR activated metals.

The waste projections increased by nearly $1,000 \mathrm{~m}^{3}$. This increase modified the design and construction costs and increased the nuclear safety and performance analysis support. Combined with several smaller changes (both negative and positive), these activities substantially account for the $\$ 20 \mathrm{M}$ increased target cost. The remainder of the difference in cost is the addition of internal and external risks that have residual cost impact. The number of external risks has increased since CD-1, increasing DOEheld contingency. However, since the initial risk analysis was performed, at least one has been retired. See Section 4.3.1.2 for a discussion of the contributors to this change.

\subsubsection{Work Breakdown Structure}

To effectively implement the scope of work, the project will be organized, managed, and controlled using a work breakdown structure (WBS). This structure is based on project deliverables and products and is the framework for establishment of the performance baseline (PB) and its associated cost estimate and schedule. Following its development, the project WBS becomes the primary tool used to ensure integrated cost and schedule control. The WBS organizes the scope baseline and provides the hierarchical structure for cost and schedule baseline development. It divides the project into six subprojects and 21 control accounts. A summary WBS dictionary, provided in Appendix C, presents project scope information to the control account level. Scope information at the work package level is provided in the work package authorization documents. This summary WBS dictionary describes the scope of work and major deliverables. The milestones, costs, and primary risks are identified in the work authorization documents for each control account and work package.

The WBS structure is used as the framework for the cost estimate provided in Appendix E. The cost estimate and the schedule are developed at an activity level that rolls up to the control account level. The schedule discussed in Section 4.2 and the cost estimate scope referenced in Section 4.3 is organized by the WBS.

\subsubsection{Key Performance Parameters}

KPPs have been established for the project. KPPs are defined as a vital characteristic, function, requirement, or design basis that if changed would have a major impact on the facility or system performance, scope, schedule, cost, or risk, or the ability of an interfacing project to meet its mission requirements. KPPs represent the minimum acceptable scope or performance the project must achieve to be successful. Contingent or optional scope are those items outside the project scope that do not assist in meeting the mission need, but could be funded and included in the project if project contingency is not required during project execution or execution efficiencies are realized.

The focus at INL is to apply performance-based contracting and project management. Using a designbuild contract will maximize performance efficiencies through innovation. In this approach, contingency funds may be available prior to project completion. Should identified external risks remain unrealized, contingency funds may be available to fund contingent scope. NRF has recently identified the need for additional large concept waste canister disposal vaults. This scope has been identified as contingent scope in Table 3. These vaults will be added to the PB as budget allows. 
Table 3. Key performance parameters and contingent scope.

\section{Key Performance Parameters}

1. Design and construct a vault disposal system with the capacity to dispose of a minimum of 673 waste canisters.

This KPP will be verified through inspection and verification of quality documentation supporting concrete test results, dimensional inspections, and numbers of disposal vaults installed. These activities will ensure that the constructed disposal vaults meet established requirements for materials, dimensions, and installation.

2. Design and construct facility infrastructure to support waste disposal operations (necessary infrastructure includes an administration building, maintenance building, water and electrical systems, security systems and road access).

This KPP will be verified through design review report(s), inspection and quality control during construction, and documented facility turnover from the design-build subcontractor.

\section{Contingent Scope (if unused contingency is available)}

Fabricate and install up to 60 NRF large concept waste canister disposal vaults, based on the level of unused contingency available. Each additional vault array row selected (6 disposal vaults per row) will add approximately $\$ 234,000$ to the construction cost of the facility. This per row cost includes estimated costs associated with vault fabrication, facility expansion, excavation, vault installation, and project support. The estimate also assumes that adding 60 disposal vaults would increase the project schedule by three months. The total cost of constructing an additional 60 large concept waste canister vaults is estimated to be $\$ 2.34 \mathrm{M}$. A decision to include this scope must be made prior to completion of original vault scope installation to avoid additional cost.

\subsection{Schedule}

The Remote-Handled LLW Disposal Project CD milestones are scheduled through FY 2019, as shown in Table 4. The CD milestones support a FY 2019 project completion date. The project mission need statement (CD-0) was approved July 1, 2009. The alternative selection and preliminary cost range (CD-1) was approved July 13, 2011. The CD-2/3 approval strategy allows the Acquisition Executive to approve CD-2 and provide conditional approval of CD-3. Approval conditions for CD-3 include DOE review and approval of the final design prior to the Acquisition Executive releasing a pre-defined construction/fabrication hold point for disposal vaults/CVAS. Approval of Start of Operations (CD-4) is established for March 2019.

Waste disposal operations will commence upon successful completion of planned commissioning activities, which includes a management self-assessment, contractor ORR, DOE ORR, and subsequent approval of CD-4. Closure activities (i.e., design, installation of final cover, and building demolition) for the facility will be conducted once waste disposal operations terminate.

The summary schedule presented in Table 4 uses dates from both the performance measurement baseline (PMB) and the PB. It depicts a series of PMB milestones which lead to the completion of construction during the $4^{\text {th }}$ quarter of FY 2016. The last milestone, approval of CD-4, is the PB completion date for the project, occurring during the $2^{\text {nd }}$ quarter of FY 2019. The PB schedule is based on the PMB with appropriate schedule reserve and schedule contingency.

To develop the PMB and PB, the project began with the most-likely activity durations, logic, and planned funding levels. The design-build subcontractor's schedule was reviewed and incorporated, as appropriate, into the project schedule. The project team reviewed the design-build subcontractor's schedule and assessed the validity of activity durations and logic. The durations and logic of 
corresponding activities from the design-build subcontractor's schedule were used to align design and construction activities of the project schedule.

Table 4. Summary schedule for the Remote-Handled Low-Level Waste Disposal Project.

\begin{tabular}{ll}
\hline \multicolumn{1}{c}{ Description } & Dates \\
\hline CD-0, Approve Mission Need & $07 / 2009$ (actual) \\
CD-1, Approve Alternative Selection and Cost Range & $07 / 2011$ (actual) \\
$\begin{array}{l}\text { CD-2/3, Approve Performance Baseline and Start of } \\
\text { Construction/Execution }\end{array}$ & $07 / 2014$ \\
$\quad$ Final design complete (PMB Milestone) & $03 / 2015$ \\
$\quad \begin{array}{l}\text { Commence infrastructure construction (PMB } \\
\text { Milestone) }\end{array}$ & $03 / 2015$ \\
$\quad \begin{array}{l}\text { Approve start of vault construction and CVAS } \\
\text { fabrication (construction hold point) (PMB }\end{array}$ & $09 / 2015$ \\
$\quad \begin{array}{l}\text { Milestone) } \\
\text { Construction complete (PMB Milestone) }\end{array}$ & \\
CD-4, Approve Start of Operations (PMB Project \\
Completion date) \\
$\begin{array}{l}\text { CD-4, Approve Start of Operations (CBB Project } \\
\text { Completion Date) } \\
\begin{array}{l}\text { CD-4, Approve Start of Operations (PB Project } \\
\text { Completion Date) }\end{array}\end{array}$ \\
\hline
\end{tabular}

This deterministic schedule was then analyzed using Project Risk Analysis (PRA ${ }^{\circledR}$ ) schedule risk analysis software in conjunction with Primavera (P6) Project Management scheduling software. Duration uncertainty values were determined and assigned by the project team to schedule activities for the first phase of the schedule risk analysis. The second phase of the schedule risk analysis includes both internal and external risks identified in the risk register. These risks were assigned a probability of occurrence as well as the schedule duration impact to those specifically affected activities. From this analysis the schedule reserve $(\mathrm{CBB})$ was calculated at a 50\% confidence level and schedule contingency $(\mathrm{PB})$ was calculated at an $80 \%$ confidence level. The difference between the PMB completion date $\left(2^{\text {nd }}\right.$ quarter FY $2018)$ and the CBB completion date ( $1^{\text {st }}$ quarter FY 2019) is schedule reserve and the difference between the CBB completion date and PB completion date ( $2^{\text {nd }}$ quarter FY 2019) is the schedule contingency.

The PMB schedule is predicated upon CD-2/3 approval and authorization in July 2014 to commence design activities in August 2014. Following issuance of a notice to proceed to the design-build subcontractor, details of the design-build subcontractor's detailed schedule will be reconciled with the PMB and a baseline change to the PMB processed, as appropriate. Construction will begin for infrastructure in FY 2015. Construction will begin for the disposal vaults following release of the vault construction hold point by the Acquisition Executive. This hold point will allow the Acquisition Executive to verify that, for the vault design, DOE Order 435.1 and nuclear safety requirements have been met prior to initiating construction. Interim PMB milestones reflected in the project schedule are as shown in Table 4. 
The project schedule is included in Appendix D. This PMB schedule does not include the activities prior to CD-2 because they are complete. This schedule and time-phased budget will provide the baseline from which the project earned value will be derived and measured. INL will manage and allocate, via baseline changes, the schedule reserve associated with internal project-specific risks in the CBB. DOE will manage and allocate schedule contingency that falls outside the $\mathrm{CBB}$, but within the performance baseline. DOE changes will be incorporated into the PMB via a baseline change proposal.

\subsubsection{Schedule Assumptions}

The assumptions used to establish the schedule for the project are as follows:

1. The project is a "new start" in FY 2014.

2. Acquisition Executive approval of CD-2/3 will occur by July 18, 2014.

3. The NRF 55-ton scrap cask and necessary crane will not be available to support the ORR. Acceptance of the 55-ton scrap cask disposal vaults will be based on quality inspections and will not require mock-up testing.

4. The modified FTC cask will be delivered as government furnished equipment separate from this project. It will not be part of the ORR scope.

5. A smaller crane, provided as part of the design-build subcontract, will be used to support fit-up, emplacement testing, and facility start-up of the MFC HFEF-5 and ATR Resins waste canisters.

6. The design-build delivery method is used to design and construct the facility.

7. Acquisition Executive approval is required to release the construction hold point identified in the tailoring strategy and Table 4.

8. The LFRG will review and concur on the final design of the disposal vaults in order to confirm that design features support all performance requirements. There also will be extensive data collection and analysis required between approval of the preliminary disposal authorization statement and the final disposal authorization statement to confirm the assumptions made in the performance assessment are valid. The final disposal authorization statement will be issued by NE-3 following review and acceptance of the completed facility and the waste acceptance criteria, which is expected to occur in parallel with the CD-4 approval request review.

9. CD approval requests are assumed to require 2-4 months for processing and approval. The hold point release request is assumed to require 6 weeks for approval.

10. Approval of CD-2/3 requires issuance of the preliminary safety validation report and issuance of a preliminary disposal authorization statement. The PDSA must be reviewed and approved prior to release of the final vault system design for construction.

11. The LFRG must approve the final vault system design prior to its release for construction. Final approval by the LFRG, of the composite analysis and plans will occur following the completion of final design. Concurrence by the LFRG must occur prior to release of the vault construction hold point.

12. The final documented safety analysis must be completed, approved, and implemented prior to initiating the contractor management self-assessment.

13. Project closure activities beyond closure planning will occur following receipt of CD-4.

14. Activities for the ORR may include the demonstration of canister off loads from the MFC HFEF5 and/or NUPAC 14-210L casks, followed by emplacement in their respective disposal vaults, depending on the final plan of action for the ORR. 
15. The startup review activities will include the MFC HFEF-5 cask/canister, and the ATR Resin Cask/canister. The disposal vault system and interfacing equipment are also included.

16. System operability testing will occur before or during operations practice (includes evolutions, operations and emergency preparedness drills) prior to the Management Self-Assessment.

\subsection{Cost}

The project schedule provides a logical sequence of work activities leading to a milestone, event, or decision point to accomplish project objectives. The PB is the anticipated time-phased, sequence of expenditures required to complete the project work scope. The project schedule is integrated with the planning baseline through resource loading to provide the basis for performance analysis. The planning budget and schedule were refined as part of the baseline development activities to support establishment of the performance baseline at CD-2/3. An independent project review, an independent cost review, and a technical independent project review were each performed to support CD-2/3 approval.

Project costs associated with a new remote-handled LLW disposal facility include design and construction of infrastructure and monitoring wells; design and construction of disposal vaults; development of the disposal authorization and safety basis documentation; and project management. Operations and maintenance of the facility and facility closure add to project costs to create life-cycle costs.

Estimates used to establish project costs are classified in accordance with the Association for the Advancement of Cost Engineering International classification matrix. The intent of this classification is to assist in interpretation of the quality and value of the information available to prepare the cost estimate and accuracy levels that can be produced. A Class 5 estimate indicates the lowest amount of project information quality and value and a Class 1 estimate indicates the highest amount of project information quality and value. Each class has a different set of possible expected accuracy ranges, which define upper and lower bounds for target costs and account for uncertainty in the predicted costs.

Two estimates have been prepared for the project. The first cost estimate includes the project development costs through design, construction, and commissioning of the project. The second cost estimate includes the future operations and maintenance costs and closure of the facility.

The PMB cost estimate, provided in Appendix E, is based on the technical and functional requirements and the design-build performance specification for the project. It covers project management, development of project documentation, and design and construction of the vault system and supporting infrastructure.

The project PMB estimate is a Class 3 cost estimate, as defined by the Association for the Advancement of Cost Engineering. It will have an expected accuracy range of $-10 \%$ to $+15 \%$, allowed through more refined estimates of design and construction costs by subcontractors. This approach is presented and discussed in Section 4.4.

The cost estimate provided Appendix E includes total estimated cost (TEC), other project costs (OPC), and management reserve to cover cost estimate uncertainty. However, it does not represent TPC, because it does not include risk-based management reserve, DOE-held contingency, or other Federal Costs. Risk-based management reserve is presented in Table 5 and calculated in Appendix A of the Risk Management Plan. Contingency is presented in Table 6 and is also calculated in Appendix A of the Risk Management Plan. Other Federal Costs include costs for items to be paid out directly through DOE-ID. These include the costs of installing aquifer monitoring wells, using the services of the US Geological Survey (USGS), and support for the Low-Level Waste Federal Review Group (LFRG). Table 7 summarizes these costs.

TECs are those costs that will be capitalized and apply directly to design and construction of the facility. These costs are funded with line item capital funds. OPCs are those costs that support project 
completion (such as CD support, environmental assessment, disposal authorization, procedure development, training, operational readiness, and facility turnover). These costs are funded with operating funds.

The operations and maintenance cost estimate (9A28-H4), provided in Appendix F, establishes an annual target value of approximately $\$ 4.939 \mathrm{M}$ (not including closure costs). The estimate represents the total operations and maintenance costs for the first 20-years of operations considering the proposed throughput of the facility. Operations and maintenance costs were based on cost information for operation and maintenance of the remote-handled LLW disposal vaults in the SDA and include an estimate of facility monitoring activities needed during the operations period. These costs were validated by the design-build subcontractor, who was requested to provide a target estimate for annual operations and maintenance of the facility. These costs were developed using FY 2012 dollars and were escalated in accordance with current and projected industry trends.

\subsubsection{Risk Costs}

Risk management for this project is addressed in a separate Risk Management Plan (PLN-2451). Risk items identified are logged and maintained in a "living" risk register database. For definitions of the types of risks, refer to PLN-2451. For funding purposes, there are three categories of risks for the RemoteHandled LLW Disposal Project: internal, external, and program portfolio. Internal risks are those that can be managed by BEA within the CBB; external risks are those over which BEA has no control, and are managed by DOE. Costs for responding to mitigated internal risks that still occur are accounted for and are funded with management reserve managed by the project. Costs for responding to mitigated external risks are funded with DOE-held contingency. External Risks which occur outside the control of DOE are termed program portfolio risks and are not funded. Risk mitigations are included in the project baseline; however, costs for responding to the remaining internal or external risks are covered through either management reserve or DOE-held contingency.

4.3.1.1 Management Reserve. Management reserve is the amount of the total project budget withheld for management control purposes by the contractor. Management reserve is established and can only be utilized for the following purposes:

- To incorporate in-scope unknowns into the PMB

- To address emerging internal project risks

- To be used as part of the normal conversion of Planning Packages (PP) or Summary Level Planning Packages (SLPPs)

- To be used to address significant, global rate changes

- To re-baseline at written, customer direction.

Management reserve may not be used for any of the following:

- To retroactively change (historical) budgets for completed work

- As a temporary source of "funding" for added work scope for changes directed by the customer or contractor management.

The application of management reserve is documented by preparing a baseline change proposal. To ensure that the FPD is cognizant of all management reserve utilization, the FPD will 1) be informed in advance of all MR usage and 2) will concur with any single management reserve use $>\$ 200 \mathrm{~K}$ in advance of BCP approval. These change control thresholds are documented in Table 9. The Master Budget Log will be included with all baseline change proposals to inform the FPD of cumulative management reserve usage. The total management reserve is $\$ 7.568 \mathrm{M}$. 
Table 5. Internal risks and associated costs - the basis for risk contribution to management reserve.

\begin{tabular}{|c|c|c|c|}
\hline $\begin{array}{l}\text { Risk } \\
\text { ID \# }\end{array}$ & Risk Description & $\begin{array}{l}\text { Cost Type } \\
\text { (OPC/TEC) }\end{array}$ & $\begin{array}{l}\text { Risk Cost after } \\
\text { Monte Carlo } \\
\quad(\$ K)^{1}\end{array}$ \\
\hline 56 & $\begin{array}{l}\text { If the materials at the Monroe Pit or that are excavated on the project } \\
\text { site are unsuitable for use, then off site materials would need to be } \\
\text { imported. }\end{array}$ & TEC & $\$ 311$ \\
\hline 35 & $\begin{array}{l}\text { If performance specifications or the Code of Record to be included in } \\
\text { contract documents are not specific enough or mature enough or must } \\
\text { change, resulting in missing, changed or new requirements, OR the } \\
\text { design-build subcontractor fails to correctly interpret the } \\
\text { requirements, then changes greater than the expected or average } \\
\text { design error/change thresholds will be required - requiring additional } \\
\text { analysis and possible design rework or construction impacts, resulting } \\
\text { in additional cost and delayed schedule. }\end{array}$ & TEC & $\$ 2,020$ \\
\hline 48 & $\begin{array}{l}\text { If design-builder does not execute the project with an integrated team } \\
\text { philosophy (owner, } \mathrm{A} / \mathrm{E} \text {, construction subcontractor work as } \\
\text { integrated team), then owner's expectations will not be met, resulting } \\
\text { in additional cost and delay due to litigation or change orders. }\end{array}$ & TEC & $\$ 1,301$ \\
\hline 40 & $\begin{array}{l}\text { If a work-related fatality or serious construction injury occurs within } \\
\text { the project or elsewhere on the INL, that results in a work stoppage, } \\
\text { then delays to the project could arise, impacting cost and schedule. }\end{array}$ & TEC & $\$ 489$ \\
\hline 60 & $\begin{array}{l}\text { If the design-build subcontractor's design differs significantly from } \\
\text { the conceptual design analyzed in the PA (i.e., the PA assumptions } \\
\text { are not feasible to design and build; or construction is delayed } \\
\text { resulting in unavailable as-built performance data and interpretation } \\
\text { to support LFRG issuance of the final DAS), it could: 1) affect the } \\
\text { conditional DAS already issued by the LFRG, 2) require the } \\
\text { subcontractor to revise the design resulting in a schedule delay and } \\
\text { associated costs, and/or 3) require updates to the PA, waste } \\
\text { acceptance criteria (WAC), and CA, and, at a minimum, will likely } \\
\text { require additional review materials to be presented to the LFRG. }\end{array}$ & OPC & $\$ 716$ \\
\hline 44 & $\begin{array}{l}\text { If construction does not pass inspection (quality control issues), then } \\
\text { resulting rework will mean cost and schedule overruns. }\end{array}$ & TEC & $\$ 236$ \\
\hline 68 & $\begin{array}{l}\text { If the design-build subcontractor proposes an accelerated schedule } \\
\text { that does not accommodate the DOE-required hold points and the } \\
\text { funding cycle, then the subcontractor will have to adjust their } \\
\text { schedule, resulting in increased costs to BEA. }\end{array}$ & OPC & $\$ 352$ \\
\hline 71 & $\begin{array}{l}\text { If the design/build vendor provides CVAS units that will not be } \\
\text { adequate to safely shield against the anticipated radiation levels, then } \\
\text { the project will have to direct the vendor to provide a more suitable } \\
\text { CVAS design. }\end{array}$ & TEC & $\$ 332$ \\
\hline $5 \mathrm{~b}$ & $\begin{array}{l}\text { If there is a delay in completing nuclear safety documentation (e.g., } \\
\text { preliminary documented safety analysis/ documented safety analysis } \\
\text { and the associated SRC review), then an overall project delay and an } \\
\text { increase in costs would occur. }\end{array}$ & $\mathrm{OPC}$ & $\$ 73$ \\
\hline 9 & $\begin{array}{l}\text { If weather prevents weather-sensitive work from being completed } \\
\text { (e.g., concrete work during winter or excavation work during an } \\
\text { extremely wet or flooding spring), then delays and increased cost } \\
\text { could result. }\end{array}$ & TEC & $\$ 79$ \\
\hline 52 & If construction is delayed and as-built performance data and & OPC & $\$ 69$ \\
\hline
\end{tabular}


Table 5. (continued).

\begin{tabular}{|c|c|c|c|}
\hline $\begin{array}{l}\text { Risk } \\
\text { ID \# }\end{array}$ & Risk Description & $\begin{array}{c}\text { Cost Type } \\
\text { (OPC/TEC) }\end{array}$ & $\begin{array}{l}\text { Risk Cost after } \\
\text { Monte Carlo } \\
\text { (\$K) })^{1}\end{array}$ \\
\hline & $\begin{array}{l}\text { interpretation cannot be available to support LFRG issuance of the } \\
\text { final DAS, there will be a schedule delay and additional cost will be } \\
\text { incurred to convince the LFRG that facility can perform as analyzed } \\
\text { in the PA. (During execution, normal escalation/price increases are } \\
\text { subsumed by the DB subcontractor. Unanticipated cost increases } \\
\text { beyond what is normally expected, will be covered by management } \\
\text { reserve.) }\end{array}$ & & \\
\hline 55 & $\begin{array}{l}\text { If the design-build subcontractor encounters differing site conditions } \\
\text { (e.g. underground obstructions, bedrock shallower than anticipated, } \\
\text { contamination, etc.) then the cost of construction could be increased. }\end{array}$ & TEC & $\$ 82$ \\
\hline 59 & $\begin{array}{l}\text { If disposal vaults fail the first-unit compliance testing (e.g., mockup } \\
\text { and fit tests), then additional vaults will have to be fabricated and the } \\
\text { tests repeated, resulting in schedule delays and additional costs. }\end{array}$ & TEC & $\$ 186$ \\
\hline 38 & $\begin{array}{l}\text { If there is insufficient internal functional integration for the project } \\
\text { (e.g., a lack of inter-organizational coordination and agreement } \\
\text { concerning project execution), then design requirements may be } \\
\text { difficult to stabilize due to inconsistent and rigid functional oversight. } \\
\text { For example, the BEA design review processes could introduce scope } \\
\text { changes due to excessive functional reviews and lack of familiarity } \\
\text { with the performance-based specification. }\end{array}$ & TEC & $\$ 118$ \\
\hline \multicolumn{3}{|c|}{ Management reserve contribution for internal risk residual cost impacts } & $\$ 6,364$ \\
\hline \multicolumn{3}{|c|}{ Management reserve contribution for cost estimate accuracy (cost estimate) } & $\$ 1,204$ \\
\hline \multicolumn{3}{|c|}{ Total Management Reserve } & $\$ 7,568$ \\
\hline
\end{tabular}

1. Residual risk cost impact calculated in Appendix A of the risk management plan (PLN-2541).

The residual risk impact cost contribution was developed using a Monte Carlo simulation. This residual risk impact cost was the result of analyzing each of the affected risk items in Table 5 and totaling their costs. The process used to calculate these costs is presented in Appendix A of the risk management plan (PLN-2541). The analysis performed to assess and account for cost estimate accuracy and assign management reserve to this analysis is provided with the project cost estimate in Appendix E.

4.3.1.2. Department of Energy-held contingency. Like management reserve, DOE-held contingency was determined using a quantitative approach to estimate the potential costs associated with risks external to the contract budget base. DOE program portfolio risks, such as reductions in appropriations or extended continuing resolutions, are excluded from the project's contingency, because the impacts affect all DOE program elements equally. The residual risk (risk that remains after planned mitigations) cost impact from external risks also are detailed in Appendix A of the Risk Management Plan (PLN-2541) and are summarized in Table 6. The total recommended DOE-held contingency is \$3.712M.

The design-build request for proposals utilized a "build to budget" approach. Consequently, there is potential for scope variability. The primary risk is presented as Risk\#43 in Table 6. Contingency identified with Risk \#43 addresses the potential for design differences that could require funding requests for equitable adjustments from the subcontractor, including cost escalation (beyond the commodity indices included in the design-build subcontract). 


\subsubsection{Total Estimated Cost}

The project total estimated cost (TEC) is $\$ 53.813 \mathrm{M}$ (see Table 7). The TEC includes all engineering design costs (after conceptual design), facility construction costs and other costs specifically related to those construction efforts. It includes design and construction of the disposal facility using a design-build delivery method. Included within design and construction TEC are all costs associated with the disposal vaults and required facility infrastructure. NRF will provide transportation and facility interface equipment for all NRF waste. TEC also includes INL oversight of the subcontractors, development of final nuclear safety documentation, and project management and reporting during project design and construction.

\subsubsection{Other Project Costs}

Other project costs (OPC) is estimated at $\$ 23.763 \mathrm{M}$ (see Table 7). OPC include all other costs related to a project that are not included in the TEC. Specifically, it includes costs associated with development of the project concept; preparation of required NEPA documentation; preparation of safeguards and security documentation; development of the performance specification and RFP for the design-build contract; development of the project performance baseline; procurement and installation of monitoring wells; development of the radiological performance assessment and composite analysis (and supporting documentation) necessary to obtain a disposal authorization statement per DOE Order 435.1; development of maintenance and operations procedures; operations training; completion of the contractor management self-assessment and contractor and DOE ORRs; and obtaining CD-4 approval.

Table 6. External risks and associated costs - the basis of a recommendation for Department of Energy-held contingency.

\begin{tabular}{|c|c|c|c|}
\hline $\begin{array}{l}\text { Risk } \\
\text { ID \# }\end{array}$ & Risk Description & $\begin{array}{c}\text { Cost Type } \\
\text { (OPC/TEC) }\end{array}$ & $\begin{array}{l}\text { Risk Cost after } \\
\text { Monte Carlo } \\
\quad(\$ K)^{1}\end{array}$ \\
\hline 43 & $\begin{array}{l}\text { If design issues identified by the project Reconciliation Plan and } \\
\text { Report are realized, then additional funding will be needed to } \\
\text { fund requests for equitable adjustments, including cost } \\
\text { escalation (beyond the commodity indices included in the } \\
\text { design-build contract). }\end{array}$ & TEC & $\$ 3,077$ \\
\hline 26 & $\begin{array}{l}\text { If the project completion is later than planned, due to delays in } \\
\text { DOE-ID and/or DOE-HQ approval of ORR and startup, as } \\
\text { required for a Category } 2 \text { Nuclear Facility, then additional costs } \\
\text { will be incurred. }\end{array}$ & $\mathrm{OPC}$ & $\$ 232$ \\
\hline $5 a$ & $\begin{array}{l}\text { If there is a delay in DOE approving nuclear safety } \\
\text { documentation (e.g., preliminary documented safety analysis/ } \\
\text { documented safety analysis and the associated SRC review), } \\
\text { then an overall project delay and an increase in costs would } \\
\text { occur. }\end{array}$ & $\mathrm{OPC}$ & $\$ 73$ \\
\hline 70 & $\begin{array}{l}\text { If the Acquisition Executive deems there is a need for one or } \\
\text { more "For Cause" Project Review(s), then there will be schedule } \\
\text { slip and additional cost associated with the review(s). }\end{array}$ & $\mathrm{OPC}$ & $\$ 84$ \\
\hline 22 & $\begin{array}{l}\text { If security access control requirements change due to changes in } \\
\text { design and/or final Security Vulnerability Analysis, then cost } \\
\text { and schedule impacts will result. }\end{array}$ & TEC & $\$ 96$ \\
\hline 45 & $\begin{array}{l}\text { If an unexpected force majeure event occurs (other than a } \\
\text { serious injury or death, e.g., union strikes, severe weather, } \\
\text { natural disasters, or brush fires), that results in a work stoppage, } \\
\text { then delays to the project could arise, impacting cost and }\end{array}$ & TEC & $\$ 60$ \\
\hline
\end{tabular}




\begin{tabular}{|l|l|c||c|}
\hline $\begin{array}{l}\text { Risk } \\
\text { ID \# }\end{array}$ & \multicolumn{1}{|c||}{ Risk Description } & $\begin{array}{c}\text { Cost Type } \\
\text { (OPC/TEC) }\end{array}$ & $\begin{array}{c}\text { Risk Cost after } \\
\text { Monte Carlo } \\
\text { (\$K) }\end{array}$ \\
\hline \hline & schedule. & & $\$ 49$ \\
\hline 69 & $\begin{array}{l}\text { If there is a greater than or equal to 20\% increase to the seismic } \\
\text { response criteria from the USGS then this could impact the } \\
\text { current design requirements for a PC-2 structure or the vault } \\
\text { design to SDC-1 with a limit state of C. }\end{array}$ & TEC & \$16 \\
\hline 57 & $\begin{array}{l}\text { If the facility design and construction impact the archeological } \\
\text { findings location identified in SPC-1437, then BEA will have to } \\
\text { mitigate the impact through documentation and preserving some } \\
\text { of the artifacts }\end{array}$ & OPC & \\
\hline 19 & $\begin{array}{l}\text { If DOE Order 435.1 requirements change, then the need for } \\
\text { additional design features at the disposal facility could result. }\end{array}$ & OPC & $\$ 25$ \\
\hline \hline
\end{tabular}

1. Residual risk cost impact calculated in Appendix A of the risk management plan (PLN-2541).

\subsubsection{Total Project Cost}

The total project cost (TPC) is the total of all project costs between CD-0 and CD-4. TPC includes all project capital (TEC) and operating costs (OPC). TPC for the design, siting, construction, and turnover to operations is $\$ 77.576 \mathrm{M}$ (see Table 7). Figure 5 represents the project funding profile reflected in the performance baseline. This funding profile was developed from the cost estimate and is used to develop and refine the project budget.

Unrealized external risks will be retired as the project progresses. Depending on the remaining risk portfolio, DOE may elect to utilize contingency associated with retired risks to fund contingent scope presented in Table 3.

Table 7. Cost summary. (Dollars in thousands)

\begin{tabular}{|c|c|c|c|}
\hline Description $^{\mathrm{a}}$ & $\begin{array}{l}\text { Total } \\
\text { Estimated } \\
\text { Costs }^{\mathrm{b}} \\
\text { (TEC) }\end{array}$ & $\begin{array}{l}\text { Other } \\
\text { Project } \\
\text { Costs }^{\mathrm{c}} \\
\text { (OPC) }\end{array}$ & Total \\
\hline Performance Measurement Baseline $^{\mathrm{d}}$ (PMB) & $\$ 44,877$ & $\$ 20,646$ & $\$ 65,523$ \\
\hline Management Reserve $e^{e}$ & $\$ 5,655$ & $\$ 1,913$ & $\$ 7,568$ \\
\hline Contract Budget Base ${ }^{f}$ (CBB) & $\$ 50,532$ & $\$ 22,559$ & $\$ 73,091$ \\
\hline Contingency $^{9}$ & $\$ 3,281$ & $\$ 431$ & $\$ 3,712$ \\
\hline Other Federal Costs ${ }^{i}$ & $\$ 0$ & $\$ 773$ & $\$ 773$ \\
\hline Total & $\$ 53,813$ & $\$ 23,763$ & \\
\hline Total Project Cost ${ }^{\mathrm{h}}$ (TPC) & & & $\$ 77,576$ \\
\hline
\end{tabular}


c. Other Project Costs (OPC) include all other costs related to a project that are not included in the TEC, such as conceptual design, startup and commissioning, siting, permitting, NEPA, and disposal authorization.

d. The performance measurement baseline (PMB) is the time-phased cost of all work and planning packages in the WBS. Undistributed management reserve and contingency, profit, fee and DOE direct costs are not included. The PMB is currently estimated based on a time-phasing of the project cost estimate.

e. See section 4.3.1.1 for further discussion.

f. The Contract Budget Base (CBB) includes PMB and management reserve costs that together represent INL's contractual baseline for the project $(\mathrm{CBB}=\mathrm{PMB}+\mathrm{MR})$.

g. Contingency is the portion of the project budget that is available for risk uncertainty within the project scope, but outside of INL's contract. Contingency is controlled by DOE.

h. The Total Project Cost (TPC) is the total of all project costs between CD-0 and CD-4. The TPC includes TEC, OPC, management reserve, contingency, and other federal costs $(\mathrm{TPC}=\mathrm{CBB}+$ contingency + Other Federal Costs).

i. Other federal costs, typically referred to as other direct costs (ODCs), include costs managed by DOE-ID outside of the CBB, but within the TPC. These include the costs of installing aquifer monitoring wells, using the services of the US Geological Survey (USGS), and support for the Low-Level Waste Federal Review Group (LFRG).

\subsection{Funding/Spending Profile}

The historical costs (FY 2009 - FY 2013), the cost estimate (9A87-F), approved budgets (FY 2014), and the FY 2015 President's Budget Request and project data sheet were used to develop the funding/spending profiles. They provide the basis for the funding request represented in the project data sheets and the PMB. The funding profile incorporates a forward funding approach. Using this approach, sufficient funds were requested to sustain project activities for at least 3 months during a federal continuing resolution, in addition to providing adequate funding for management reserve and contingency. However, the design phase of the facility design-build subcontract could not be awarded until the FY 2014 funding was received. The construction phase cannot be awarded until sufficient FY 2015 capital funding is received to complete the subcontract. Sufficient funding is anticipated to support construction authorization by March 2015.

The funding profile of Figure 5 supports the performance baseline. This funding profile identifies operating and capital funds needed to support the execution phase of the project. The funding profile includes management reserve and DOE-held contingency. It is based on:

1) Actual costs from FY 2009 to FY 2013, including Other Federal Costs;

2) Funding appropriated in the FY 2014 Budget;

3) Funding requested in the FY 2015 President's Budget Request and project data sheet;

4) Remaining baseline costs.

The spending profile is based on a time-phasing of the cost estimate, with activity costs lumped in the year they start. Other federal costs, risk-based management reserve, and DOE-held contingency have been added in the appropriate years.

The project funding profile reflects funding required to support the PB. Capital appropriations received in FY 2014 support the final design of the facility infrastructure and vaults, initiation of infrastructure construction, and funds the majority of identified management reserve and contingency. The FY 2015 President's Budget Request was submitted and represents funding needed to construct the vault system and complete infrastructure construction. 


\section{INL Remote-Handled Low-Level Waste Disposal Project Total Funding}

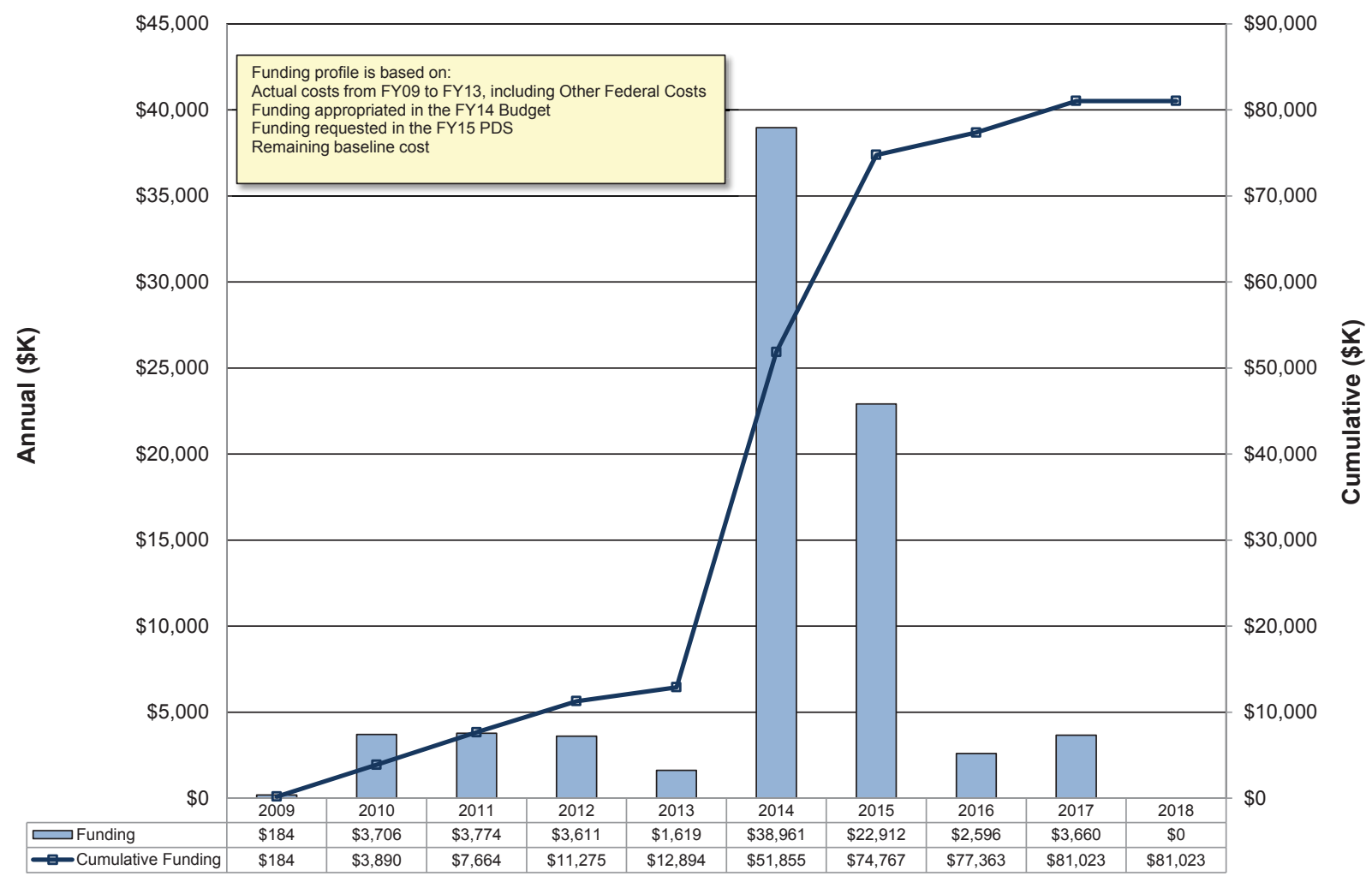

Fiscal Year

Figure 5. Project funding profile.

As required by DOE Order 413.3B, the Secretarial Acquisition Executive must endorse any reduction in funding that could adversely affect the project's approved funding profile after approval of the performance baseline. The Secretarial Acquisition Executive and Office of Acquisition and Project Management will be notified of all:

- Schedule delays that breach the original performance baseline by greater than 12 months

- Termination of this project post-CD-2

- If the capital asset project is no longer able to meet the objective of DOE Order 413.3B (i.e., the delivery of the project at the original performance baseline - DOE Order 413.3B, Appendix A, Paragraph 1).

The Remote-Handled LLW Disposal Project is jointly funded and sponsored by DOE-NE and DOE-NR. Figure 6 graphically presents agreed upon cost sharing between NE and NR. 


\section{INL Remote-Handled Low-Level Waste Disposal Project NE/NR Proposed Funds Sharing}

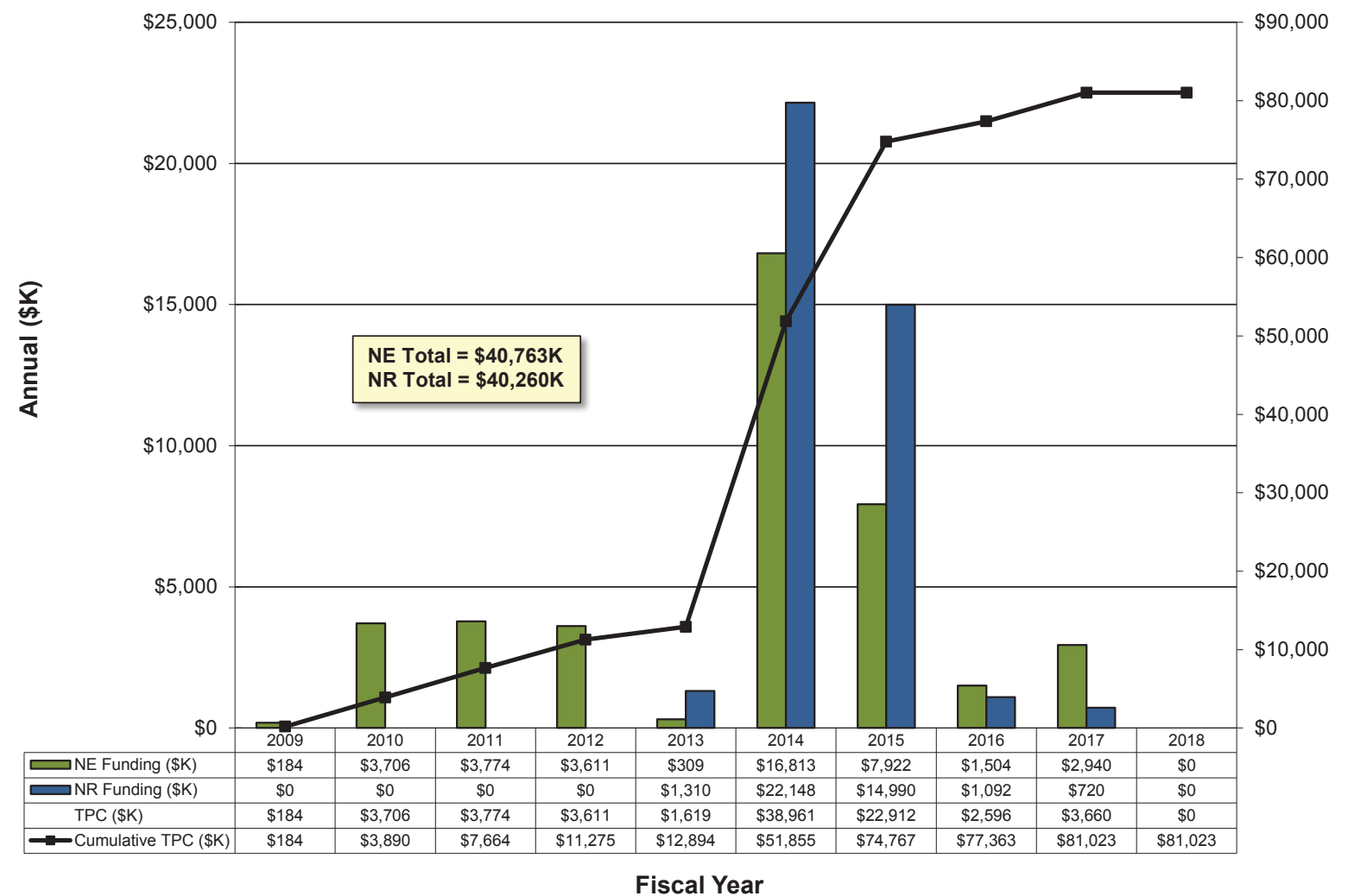

Figure 6. Naval Reactors/Office of Nuclear Energy proposed cost sharing (includes Department of Energy-held contingency).

\subsection{Life-Cycle Cost}

The life-cycle cost for the new disposal facility is the sum of the direct, indirect, recurring, nonrecurring, and other related costs incurred or estimated in the project. These costs span the design, development, production, operation, maintenance, support, and final disposition of the facility. Life-cycle cost includes TPC, 20 years of operations, and costs associated with closure of the disposal facility (assumed to occur FY 2036 through FY 2038). The facility infrastructure, including buildings, security features, access roads, and utilities is designed to operate up to 50 years, but to support disposal beyond 20 years, additional vault capacity will be needed. Total 20 -year life-cycle cost is estimated to be $\$ 187.209 \mathrm{M}$, including the project PB, 20 years of operations and maintenance, and facility closure. Operations and maintenance costs are estimated at $\$ 98.783 \mathrm{M}$; facility closure costs are estimated at $\$ 10.850 \mathrm{M}$ (see Appendix F). Operations costs were validated with target annual operations and maintenance costs provided in the design-build subcontract offers.

\subsection{Direct, Indirect, and Overhead Rates}

In developing the project cost estimate, direct, indirect, and overhead rates are applied to cost elements, as appropriate. These rates are explained as follows:

- Construction direct costs are detailed and summarized in the cost estimate detail item reports. Direct costs include material, equipment, and direct construction labor costs. Construction labor rates are in accordance with the INL Site Stabilization Agreement and include payroll, taxes, and insurance. 
Direct costs also include construction supervision, construction site trailers, trucks, and direct construction support personnel (e.g., non-working supervisors, safety representatives, field engineers, and mechanics).

- Construction indirect costs include home office costs, management, accounting, and legal and are included in the overhead markup rate applied to the direct cost total (e.g., labor, material, and equipment). Construction indirect costs also include the subcontractor profit fee. The profit fee is calculated as a separate markup rate and is applied to the direct costs total.

- INL direct costs are the labor, material, and equipment costs expended to perform the identified work scope. The direct labor rates are provided by INL's Business Management organization.

- INL indirect costs are included and accounted for in the total burdened labor rate used by INL Cost Estimating in the project estimates. INL Cost Estimating adds an appropriate amount of indirect markup, as provided by INL Business Management, to the direct labor rates. The indirect markup includes organizational adders and general and administrative adders. The resulting labor rate used for estimating purposes includes direct labor rates and the indirect labor markups.

- Average charge out rate adjustment is included as a separate summary entry near the end of the cost estimate and represents an increase in overall labor rates, commencing in 2015 and proceeding through the end of the project. This adjustment represents a significant change to INL's approved rate structure.

The integration of the planning, scheduling, budgeting, work authorization, and cost accumulation management processes provides the basis for establishing the performance baseline. The performance baseline is the total time-phased budget against which project performance is measured. It is the schedule for expenditure of the resources allocated to accomplish project scope and schedule objectives and is formed by the budgets assigned to control accounts. The performance baseline also includes budget for future effort assigned as planning packages to WBS levels.

Performance baseline reviews are conducted to ensure that the performance baseline is complete, traceable, and reasonable in terms of schedules, milestones, and budget. The reviews ensure that scope is adequately detailed at each stage of the project. The reviews also will ensure that priorities and issues can be identified and key performance criteria can be met. Baseline reviews also assess the acquisition strategy/plan, life-cycle costs, project risks/hazards, and the implementation of an earned value management system.

The performance baseline is established at approval of CD-2/3.It will be maintained in accordance with INL baseline change control procedures.

\subsubsection{Independent Project Reviews and Annual Reviews}

As required by DOE Order $413.3 \mathrm{~B}$, project reviews will be conducted at CD points. Table 8 identifies the key reviews.

Because the TPC is less than $\$ 100 \mathrm{M}$, an External Independent Review is not required. Rather, an independent project review will be conducted where reviewers from within DOE, but outside the specific project being reviewed, will perform the review. The program sponsor, may request, authorize, or conduct Independent Project Reviews at any time. Reviews are part of the project management process and are used to assist INL, the FPD, and upper-level management in understanding project plans and verifying that the project is being executed within the established performance baseline. Reviews provide information to help make decisions and demonstrate and confirm project accomplishments at various stages. Directed reviews will be completed by an independent review team as needed during project execution. Rather than being scheduled in the baseline, reviews are identified in the risk register as a cost risk and contribute to contingency. 
Table 8. Remote-Handled Low-Level Waste Disposal Project reviews.

\begin{tabular}{|c|c|}
\hline Critical Decision & Review \\
\hline $\begin{array}{l}\text { CD-1, Approve Alternative } \\
\text { Selection and Cost Range }\end{array}$ & $\begin{array}{l}\text { - Conceptual design review by reviewers external to the project. } \\
\text { - Independent project review to ensure early integration of safety } \\
\text { into the design process. }\end{array}$ \\
\hline $\begin{array}{l}\text { CD-2/3, Approve Performance } \\
\text { Baseline/Start of Construction/ } \\
\text { Execution }\end{array}$ & $\begin{array}{l}\text { - Federal Design Review of Design-Build Procurement Package } \\
\text { - } \\
\text { - } \text { Larned Value Management System Validation } \\
\text { - Independent Cost Review to validate the project cost estimate. } \\
\text { - Independent Project Review by the Project Management Support } \\
\text { - } \text { Office to validate the performance baseline. } \\
\text { - } \text { dechnical Independent Project Review for nuclear safety } \\
\text { - Construction hold point reviews. }\end{array}$ \\
\hline CD-4, Approve Start of Operations & $\begin{array}{l}\text { - Reviews as directed by the AE to verify project execution within } \\
\text { the performance baseline. } \\
\text { - ORR, with approval of DOE-NE. }\end{array}$ \\
\hline
\end{tabular}

\subsubsection{Earned Value Management}

NE certified INL's earned value management system after receiving a recommendation from the DOE Office of Acquisitions and Project Management. This project is among the first to be managed under the INL certified earned value management system. The INL system will be used to manage the performance baseline for the project. Cost and schedule performance are updated and analyzed against the performance baseline on a monthly basis. Work activities are assessed using earned value methods as established in PDD-7002, "Earned Value Management System Description."

Although a control account can potentially have more than one earned value method applied, to the extent feasible, each project control account will be assessed and the appropriate method applied for the type and duration of the activity. The earned value method will be determined in accordance with MCP-7345, "Project Baseline Schedule Development and Management." The following earned value methods will be used, as appropriate, based on the schedule activity type, for discrete efforts:

- Discrete Effort - 0/100, 50/50, where the numerator indicates the accomplishment credit (\%) taken at the beginning of the activity and the denominator indicates the credit ( $\%$ balance) taken at the end of the activity

- Weighted Milestone with percent complete or 0/100 - a weighted portion of performance credit is taken for the milestone based on assessed percent complete.

- Percent complete - predefined earning methodology based on detailed earned value plans established for each activity using this methodology.

- Apportioned Effort - effort represented is directly related to and dependent on the performance of another discretely measured scheduled activity.

- Level-of-effort - performance taken based on scheduled completion. Used where non-task specific support is needed of project and control account managers in reporting, interfaces with stakeholders, and completing other general support activities. 
Work progress is assessed monthly to obtain schedule status. Schedule status is the input used to measure progress. Work completed is assessed using the established earned value method. Progress is assessed on all scheduled activities. In addition, a critical path analysis (float analysis included) is performed, as warranted, to ensure the most time-constraining activities are being completed as planned and in the correct sequence. Schedule assessment techniques include monitoring activities that fall on the project critical path, comparing planned durations with actual durations, and comparing planned and forecast dates for activities and milestones. Earned value for the primary design-build construction project will be assessed with an earned value plan established in the subcontract. Following subcontract award, this plan will be further detailed and negotiated with the subcontractor prior to the start of subcontract work.

An objective assessment of the project cost and schedule performance will be performed on a monthly basis by comparing the following elements (expressed in terms of dollars):

- Budgeted Cost for Work Scheduled - budget calculated from the approved, resource-loaded baseline schedule and is represented in terms of budgeted dollars. It represents the estimated value of the work scheduled.

- Actual Cost of Work Performed - actual cost charged to the project, plus accruals for work completed, but for which associated payments have not yet been finalized. This information is collected in the INL financial management system.

- Budgeted Cost for Work Performed - also known as earned value, it represents progress completed against planned work. Earned value is the estimated dollar value of the work performed in relation to the budgeted cost for work scheduled. The earned value is determined from schedule status.

The process of accumulating and comparing performance measurement data results in the identification of favorable (positive) and unfavorable (negative) variances at the control account level. This performance analysis process provides visibility to potential problems, impacts, and alternative courses of action. The variance analysis is documented on the variance analysis report identified in MCP-7348, "Project Data Accumulation, Reporting, and Variance Analysis," if thresholds are exceeded. Variance reporting thresholds for this project are as follows:

\begin{tabular}{|l|l|}
\hline \multicolumn{1}{|c|}{ Type of Variance } & \multicolumn{1}{c|}{ Variance Threshold } \\
\hline Current period schedule & $\pm \$ 15,000$ and $10 \%$ \\
\hline Current period cost & $\pm \$ 15,000$ and $10 \%$ \\
\hline Cumulative-to-date schedule & $\pm \$ 25,000$ and $10 \%$ \\
\hline Cumulative-to-date cost & $\pm \$ 25,000$ and $10 \%$ \\
\hline At-completion & $\pm \$ 75,000$ and $10 \%$ \\
\hline
\end{tabular}

\subsection{Baseline Change Control}

The objective of an effective baseline change control process is to provide an orderly and efficient method of incorporating approved changes into the baseline. Project baseline changes require coordination with DOE-ID before initiation, and approval before changes are implemented. Baseline changes are controlled in a formal, documented, and auditable process. Changes to the performance baseline (i.e., scope, schedule, and budget) and associated funding assignment will be identified, controlled, and managed through INL's formal, documented change control process, as defined in MCP-7400, "Project Baseline Change Management." 
Baseline change proposals will be used to provide DOE a consistent process for baseline change management. Baseline changes may be proposed by the contractor or directed by DOE-ID. However, only the Contracting Officer can authorize changes to the project performance baseline.

As required by DOE Order 413.3B, the change control process will begin after CD-1 for design (i.e., scope/budget/ schedule) and after CD-2 for the PMB. Table 9 identifies the change control thresholds that will be used for this project.

\section{PROJECT MANAGEMENT/OVERSIGHT (STRATEGY) 5.1 Project Management Approach}

To accommodate the design-build method used for the project, the $\mathrm{CD}$ process has been tailored by combination of CD-2 and CD-3 in to a single CD. The decisions were combined to facilitate use of the design-build delivery method. The design-build delivery method is justified in the proven technology of the disposal vault design and allows for cost-effective construction of the support infrastructure. In place of a formal CD-3, a hold point at the start of vault construction has been established to validate incorporation of long-term facility performance and nuclear safety design requirements into the facility final design.

The design-build subcontract for the project was competitively procured and awarded in FY 2014. The procurement was established as firm fixed price, using a build-to-budget approach with a $\$ 35 \mathrm{M}$ ceiling. The subcontractor will provide a full 20 years of disposal capacity, identified as KPP \#1.

It will be the responsibility of the design-build subcontractor to complete the design and construction of the facility to the requirements of the performance specification and the technical and functional requirements.

It is anticipated that smaller subcontracts may be used for certain aspects of the project. When outside sources are sought by INL, services will be solicited only from qualified firms via RFP. Dependent on the action, selection will be based on technical merits and price considerations, as provided for in the DOEapproved procurement procedures manual.

The subcontract formation group, comprised of members from support organizations with input into the RFP, established required procedural documents for inclusion in the design-build RFP. The following support organizations were involved in development of the procurement packages and evaluation of proposals received in response to the RFP: engineering, quality assurance, procurement, safety, construction management, and nuclear safety engineering.

The technical scope, cost baseline, and schedule baseline establish the basis for measurement of project performance. The project PMB will consist of the schedule and time-phased budget required to execute the project scope.

The PMB will be established by the project, reviewed by the IPT, and approved by the Federal Project Director. The PB is approved by the Acquisition Executive through approval of the Project Execution Plan. The PB establishes the benchmark by which the project is controlled and performance is measured. The PMB will be used to measure cost and schedule performance. During all project phases, including planning, work must receive authorization from the proper authority. Formal work authorization is management approval of the expenditure of project resources by a responsible organization to accomplish a specified scope of work within the agreed budget, schedule, and technical objectives. It provides a means for effective internal coordination, communication, and a process to obtain the required management approvals before initiating work. MCP-7344, "Project Work Definition, Assignment, and Authorization," defines the processes, responsibilities, and work authorization documents used by INL for authorizing work on the project. 
Table 9. Change control thresholds.

\begin{tabular}{|c|c|c|c|c|}
\hline \multirow[b]{2}{*}{$\begin{array}{l}\text { Change } \\
\text { Type }\end{array}$} & \multicolumn{4}{|c|}{ Line Item Construction Project Summary Baseline Change Control Thresholds ${ }^{(1)}$} \\
\hline & $\begin{array}{c}\text { Deputy Secretary } \\
\text { Level } 0\end{array}$ & $\begin{array}{c}\text { Acquisition Executive }^{(2)} \\
\text { Level } 1\end{array}$ & $\begin{array}{l}\text { DOE FPD } \\
\text { Level } 2\end{array}$ & $\begin{array}{l}\text { BEA Project } \\
\text { Manager }^{(3)} \\
\text { Level } 3\end{array}$ \\
\hline Scope & $\begin{array}{l}\text { Any change in scope } \\
\text { and/or technical } \\
\text { ability that impacts the } \\
\text { project's ability to } \\
\text { satisfy the mission } \\
\text { need. }\end{array}$ & $\begin{array}{l}\text { A change in scope that impacts } \\
\text { the Threshold KPPs or } \\
\text { changes the funding profile } \\
\text { reflected in the project data } \\
\text { sheet. }\end{array}$ & $\begin{array}{l}\text { Any scope change } \\
\text { that alters the PMB } \\
\text { but does not affect } \\
\text { Threshold KPPs. }\end{array}$ & $\begin{array}{l}\text { Any scope change } \\
\text { that does not alter } \\
\text { the PMB. }\end{array}$ \\
\hline Schedule & $\begin{array}{l}\text { Notification of any } \\
\text { schedule delays that } \\
\text { breach the } \\
\text { performance baseline } \\
\text { by greater than } 12 \\
\text { months }\end{array}$ & $\begin{array}{l}\text { Any changes to a Level } 1 \\
\text { milestone date or the } \\
\text { performance baseline } \\
\text { completion schedule. } \\
\text { Level } 1 \text { milestones are those } \\
\text { that require AE approval, such } \\
\text { as CD approvals or approval to } \\
\text { lift project hold points prior to } \\
\text { construction. }\end{array}$ & $\begin{array}{l}\text { Any change to a Level } \\
2 \text { milestone or the } \\
\text { contract budget } \\
\text { baseline completion } \\
\text { schedule. } \\
\text { Level } 2 \text { milestones are } \\
\text { those that require } \\
\text { DOE action below the } \\
\text { AE, such as submittal } \\
\text { of the performance } \\
\text { assessment to the } \\
\text { LFRG or DOE } \\
\text { approval of nuclear } \\
\text { safety documentation. }\end{array}$ & $\begin{array}{l}\text { Any change to a } \\
\text { Level } 3 \text { milestone } \\
\text { that does not alter } \\
\text { the PMB } \\
\text { completion } \\
\text { schedule. } \\
\text { Level } 3 \text { milestones } \\
\text { are all that are not } \\
\text { Level } 1 \text { or } 2 .\end{array}$ \\
\hline Cost & $\begin{array}{l}\text { Any cumulative } \\
\text { increase in excess of } \\
50 \% \text { of the original } \\
\text { CD- } 2 \text { cost baseline. }\end{array}$ & Any increase in TPC or TEC. & $\begin{array}{l}\text { Changes that } \\
\text { authorize the use of } \\
\text { DOE-held } \\
\text { contingency. }\end{array}$ & $\begin{array}{l}\text { Any change within } \\
\text { the approved } \\
\text { Contract Budget } \\
\text { Baseline } \\
\text { FPD will be } \\
\text { notified of all } \\
\text { management } \\
\text { reserve usage and } \\
\text { will concur with } \\
\text { any single use of } \\
\text { management } \\
\text { reserve }>\$ 200 \mathrm{~K} \text { in } \\
\text { advance of } \mathrm{BCP} \\
\text { approval. }\end{array}$ \\
\hline
\end{tabular}

(1) The change control thresholds will be effective upon approval of the performance baseline.

(2) Level 1 baseline change proposals and Level 2 baseline change proposals involving the use of DOE contingency will be performed in accordance with DOE processes.

(3) Level 3 baseline change proposals will be evaluated in accordance with MCP-7400, "Project Baseline Change Management." In accordance with MCP-7400, all Level 3 baseline changes will be reviewed/approved by both the BEA project manager and the BEA Change Control Board (CCB). The DOE FPD will be informed of all Level 3 changes to the PMB and will concur on all changes using greater than $\$ 200 \mathrm{~K}$ in management reserve. 
The DOE FPD, through the DOE Contracting Officer, is responsible for granting authority to perform project work scope for this project. Upon approval of CD-2/3, DOE will issue written authorization for INL to perform work consistent with the approved PB. INL will then prepare and submit a baseline change proposal to DOE for approval to establish the PMB that aligns with the approved PB. In addition to establishing the PMB approved at CD-2/3, a detailed design schedule of values, negotiated with the design-build subcontractor following a post-CD-2/3 notice-to-proceed, will be incorporated via the baseline change proposal. Any adjustments to the PMB resulting from incorporation of the design-build subcontractor's detailed design schedule, the actual cost and schedule for obtaining CD-2/3 approval, and other minor adjustments will be addressed by adding or subtracting management reserve from the CBB.

This will ensure that the PB is maintained as approved by the Acquisition Executive at CD-2/3. Following completion of the design phase and release of the construction hold point, a second baseline change proposal to the PMB will be approved and implemented to establish a construction schedule of values.

Once the project work authorization is received from DOE and funding allocations have been made, the PMB will be established and project work will be performed consistent with the established project schedule and budget. The INL project manager will issue the required project work authorization document(s) to allow work to proceed in accordance with MCP-7344. The work authorization document provides written authorization for performing organizations to execute work.

\subsubsection{Project Reporting}

The INL reporting system reflects project cost and schedule performance, and tracks changes to the PMB. All costs are collected and reported through the WBS. The system has the capability to report capital costs, operating costs, and estimate-to-completion. The system also provides cost and schedule variance information based on predetermined thresholds at multiple levels of the WBS. The WBS is established, maintained, and controlled through IPS2000 (a web based interface for management reports). The WBS provides the framework for project estimating, scheduling, budgeting, execution, management, and reporting. The INL cost and schedule control tools include hardware and software used to collect, process, and report project funding, budget, schedule, and performance data. Each system addresses a specific project control function. Collectively, these systems provide information and capabilities for the following:

- Developing project schedule and allocating resources

- Establishing cost estimates and performance baselines

- Monitoring procurement of subcontracts, equipment, and materials

- Tracking changes to project scope, schedule, and budget

- Monitoring labor hours, costs, and commitments against available funds

- Measuring and reporting project performance

- Monthly Status Reporting in PARS-II

Monthly project reports are prepared in accordance with MCP-7348, "Project Data Accumulation, Reporting, and Data Analysis." The monthly status report addresses work performed, major accomplishments, status of key milestones, significant issues and their corrective actions, and cost and schedule performance data. The performance reporting will include monthly and cumulative year-to-date cost and schedule variances, along with analysis of those variances. The INL Business Systems will output performance data that can be directly input to the DOE Project Assessment and Reporting System (PARS-II). Qualitative status reporting was initiated in PARS-II at CD-0. Earned Value Management System status reporting in PARS-II will commence at CD-2. 
Project performance will be addressed with the FPD in both informal and formal monthly project reviews, commencing at the release of capital funding and proceeding through CD-4 approval. Quarterly Acquisition Executive reviews will be held as required by DOE O 413.3B or as determined necessary.

\subsubsection{Risk Management}

A risk management plan (PLN-2541) has been prepared for the project. The plan defines the scope, responsibilities, and methodology for identifying, assessing the impacts of, and managing risks that could affect successful completion of the project. The risk management plan has been prepared in accordance with MCP-7350, "Project Risk Management," DOE Order 413.3B, and DOE Guide 413.3-7, "Risk Management Guide." The plan was initiated to support the CD process and will be modified, as required, throughout the life of the project. The results of uncertainty analyses are documented in two informal risk analysis reports that are included as Appendix A (for cost) and Appendix C (for schedule) to PLN-2541. Appendix B to PLN-2541 contains the cost estimate that provided the basis for the cost risk analysis in Appendix A. Appendix A also includes risk cost funding and drawdown tables and profiles. Appendix D to PLN-2541 provides an analysis that demonstrates that the costs associated with schedule uncertainty, schedule reserve, and schedule contingency are adequately covered by management reserve and DOE-held contingency. The risk register contained in the plan will be revisited periodically by scheduled meetings of the risk management team, where all identified risks will be updated and reevaluated to maintain current consequence and impact analyses. Emerging risks will be added to the register and evaluated for consequence, impact, and planned mitigation strategies. The risk register identifies the potential cost impact (along with the likelihood and potential schedule and technical impacts) for the purpose of assessing (scoring and ranking) the risks as low, medium, or high. The residual risk cost impacts in the risk register serve as the basis for recommending contribution to management reserve and DOE-held contingency.

The project uncertainties listed in Section 1.2.1 were developed and evaluated as part of the project risk register. They will be revisited and managed as described above.

The project team reviewed and applied the lessons learned from several completed design-build projects at INL, other DOE sites, and private industry. These lessons learned were tabulated and compared to the risks already in the current risk management plan. Lessons learned risks not previously identified were added to the risk register.

In addition, a design-build Proposal Reconciliation Report (INLg) was issued to evaluate the differences between the assumed facility concept and the awarded concept. From these differences, residual risk impacts were calculated and added to the risk register. These impacts were added to management reserve or contingency as appropriate.

\subsubsection{Engineering and Technology Readiness}

Engineering and technology employed in the design and construction of the remote-handled LLW disposal facility is well understood and has been successfully applied for many years. Neither new, untested technologies nor required technology development is anticipated for its successful completion.

\subsubsection{Alternatives Analysis and Selection}

An alternatives analysis (INLb) and a siting study (INLc) were performed. A preferred alternative of onsite disposal, with a specific location southwest of the ATR Complex was identified through the NEPA process.

\subsubsection{Environment, Safety, and Health}

As the INL prime contractor, BEA is required to meet the requirements of 10 CFR 851, "Worker Safety and Health Program." INL has established a DOE-approved Worker Safety and Health Program to reduce or prevent occupational injuries, illnesses, and accidental losses by providing DOE contractors and 
their workers with safe and healthful workplaces. INL's Worker Safety and Health Program is comprised of multiple documents contained in Manual 14C. The program is a high-level overview, implemented primarily through numerous existing procedures that address safety in the workplace and safe performance of work activities. All INL employees and subcontractors are expected to work under appropriate procedures.

Safety and health protection during construction will be in accordance with the requirements of 29 CFR Part 1926, "Safety and Health Regulations for Construction;" applicable sections of 29 CFR 1910, "Occupational Safety and Health Standards;" construction management subcontract documents, INL's Integrated Safety Management System, and the construction project safety and health plan that is in place for all INL construction subcontractors. All work at INL will be conducted in accordance with INL's DOE-approved Integrated Safety Management System. The objective of the Integrated Safety Management System is to provide a safe workplace to perform work while protecting the worker, the public, and the environment by incorporating safety into management and work practices at all levels and by addressing all types of work and all types of hazards. "Safety" encompasses safety and health, quality assurance, and the environment, including pollution prevention and waste minimization.

Construction activities will be covered under a task-specific job safety analysis, which will be prepared by the subcontractor and approved by construction management. The project supports stop work authority and all team members, whether INL employees or subcontractors, have the responsibility and authority to initiate stop work for any environmental, safety, or quality issue.

In addition to compliance with NEPA, construction of a new Remote-Handled LLW Disposal Project facility will comply with environmental laws and regulations and, as such, may require completion of a permit-to-construct under the Clean Air Act. An Air Permit Applicability Determination will be completed to determine the need. It also has also been determined that the disposal facility is within the storm water corridor, requiring compliance with the National Pollutant Discharge Elimination System general permit requirement. Because the facility is not to be used for disposal of hazardous waste, a Resource Conservation and Recovery Act permit is not required.

All radioactive waste management activities at DOE facilities are governed by DOE Order 435.1. The objective of this order is to ensure that all DOE radioactive waste is managed in a manner that is protective of worker and public health, safety, and the environment. As a LLW disposal facility, the remote-handled LLW disposal facility must be sited, designed, operated, maintained, and closed so that a reasonable expectation exists that the specified performance objectives will be met. Compliance with the requirements of the order is demonstrated via the radiological performance assessment, liner alternatives analysis, composite analysis, closure plan, and monitoring plan.

This documentation is reviewed by the LFRG and a preliminary disposal authorization statement must be issued before construction of the facility commences. The radiological performance assessment has been completed and approved and the preliminary disposal authorization statement has been issued. The final disposal authorization statement must be issued prior to commencing facility operations. The LFRG will review preliminary performance data and analysis, verifying that the final design and as-built facility continues to support long-term performance. Figure 7 depicts the interaction of required NEPA documentation and DOE Order 435.1 documentation in the CD process for a design-build acquisition strategy. All project activities will comply with LWP-8000, "Environmental Instructions for Facilities, Processes, Materials and Equipment."

In accordance with Executive Orders 13423 and 13514, the project will conduct its environmental, transportation, and energy-related activities in an economically sound, efficient, and environmentally sustainable manner. As a management system is developed to support remote-handled LLW disposal facility operations, it will include consideration for planning, environmental policy, performance, objectives, and targets, in accordance with ISO 14001. Construction activities will be conducted in accordance with LWP-7201, "INL Construction," which establishes a minimum set of controls for all 
construction with application of a risk-based, graded approach to establish greater control and rigor where needed.

5.1.5.1 Integrated safety management. All personnel on the project, whether direct hire or subcontract, are expected to participate in achieving a goal of performing work in a safe, compliant, and environmentally responsible manner, and to actively care for their safety and the safety of others. All employees have the obligation to stop work at any time if an unsafe work condition is identified as directed in LWP-14002, "Time Out and Stop Work Authority" for BEA personnel and RD-1003, "General Information and Requirements" for subcontractors. The project manager and first line supervision will be notified immediately if a stop work is initiated. Efforts will be directed to immediately correct any unsafe condition.

5.1.5.2 Industrial safety and occupational health. Industrial safety and health protection during field work activities will be in accordance with the requirements identified in BEA Laboratory-wide Manuals 14A, Vol. I and II, "Safety, Fire Protection, and Industrial Hygiene," for work performed by BEA personnel or the INL Subcontractor Requirements Manual for work performed by a subcontractor. These manuals incorporate requirements from 29 CFR 1910, 29 CFR 1926, and other contractually required standards. Work activities will be directed through work documents and approved by safety and health professionals that will identify associated work hazards and required mitigation, as required by LWP-6200, "Maintenance Integrated Work Control Process," for BEA work activities and RD-2000, "Work Coordination and Hazard Control," for subcontractors. A stand-alone health and safety plan is not anticipated.

5.1.5.3 Nuclear safety. In accordance with the requirements of DOE Order 413.3B, safety must be integrated into the design process for new or major modifications to DOE Hazard Category 1, 2, and 3 nuclear facilities. The intended purpose of this requirement involves the handling of hazardous materials, both radiological and chemical, in a way that provides adequate protection to the public, workers, and the environment. Requirements provided in DOE Order 413.3B, 10 CFR 830, and DOE Order 420.1C, "Facility Safety," and the expectations of DOE-STD-1189-2008 provide for identification of hazards early in the project and use of an integrated team approach to design safety into the facility. The basic safety-in-design precepts are as follows:

- Appropriate and reasonably conservative safety structures, systems, and components are selected early in the project designs

- Project cost estimates include these structures, systems, and components

- Project risks associated with selections of safety structures, systems, and components are specified for informed risk decision making by the project approval authorities.

The provisions of DOE-STD-1189-2008, when implemented in conjunction with DOE Order 413.3B and its guidance documents, are consistent with the core functions and guiding principles of the Integrated Safety Management System, as described in DOE Policy 450.4A, "Integrated Safety Management Policy."

5.1.5.4 Hazard analysis. A preliminary safety design report has been developed to support the Remote-Handled LLW Disposal Project. This document is the third in a prescribed evolution of safety-related documentation of the project. The preliminary safety design report will validate that the final facility design meets the nuclear safety requirements. A construction hold point at the start of vault construction has been established until a safety evaluation report is issued. A final DSA will be issued prior to commencing facility operations. 


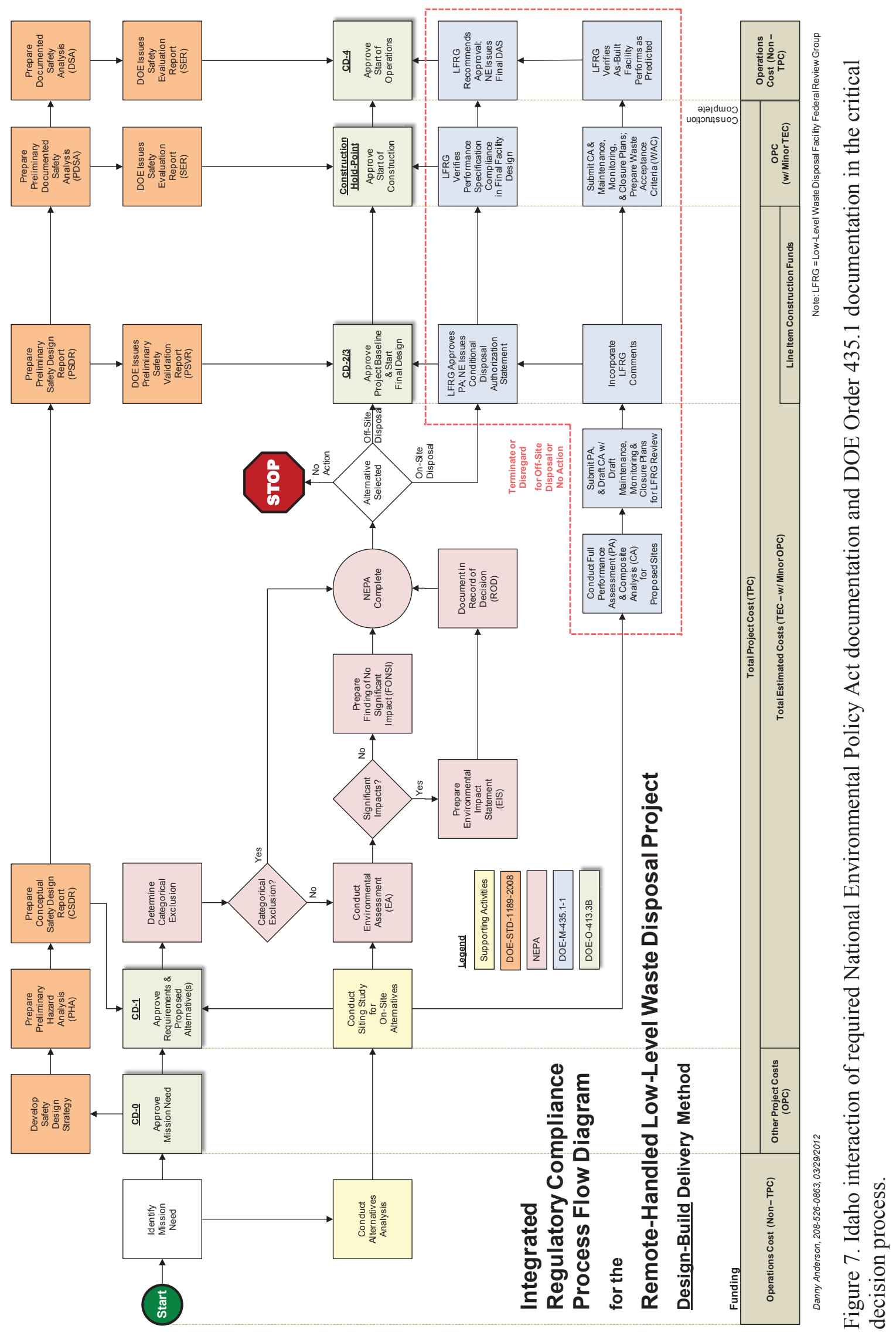


5.1.5.5 Value engineering and management. Value engineering techniques will be used in all phases of the project to achieve the lowest life-cycle cost to accomplish the project technical and functional requirements. Value engineering is a formal method of evaluating alternatives to ensure optimum value. In development of the conceptual design, a number of alternatives to achieve project goals were considered. In all cases, minimizing project cost (both near-term and life-cycle) while meeting project requirements was a primary discriminator in selecting the path forward. For example, this process was used to refine and detail design requirements that roll down to the performance specification from the technical and functional requirements. Value engineering will be used throughout the project life cycle, as applicable and necessary, to guide decisions to optimize sub-functions and sub-processes. Because the design is closely modeled on the existing INL disposal capability and practices, use of value engineering in this project will in large part build on this practical experience and lessons learned from current operations.

\subsubsection{Safeguards and Security}

The project is located within geographic areas designated for asset protection. Because of its location, a preliminary security vulnerability assessment was performed by INL Security and Emergency Services. This document (INL/INT-11-21259) is classified as "Official Use Only" and is available for review and use as needed. This assessment evaluates the facility and recommends protection strategy and requirements to ensure proper protection of the waste material. A final security vulnerability assessment will be issued and a project review of requirements implementation will be completed as prerequisites to commencing facility operations.

\subsubsection{Configuration Management}

Configuration management provides identification and documentation of the configuration of the end products and controlling changes to the configuration during the life cycle. For the remote-handled LLW disposal project, configuration management will include identifying, allocating, and managing requirements; establishing and maintaining facilities configuration information; and managing work control and change control. In general, configuration management will be conducted in accordance with LRD-10501, "Configuration Management Requirements." For this project, configuration management of documents supporting disposal authorization is described in Section 4.12.11 of the quality assurance program plan (PLN-3359).

Configuration management of facility design documentation will be the responsibility of the design-build subcontractor and identified in the subcontractor's quality assurance program plan. This includes control and delivery of selected facility as-built drawings and appropriate supporting documentation. These drawings currently include those identified as "Master Facility Drawings" or "Essential Drawings" and are listed in Section 4.2 of the performance specification (SPC-1437).

Configuration management of safety basis and supporting CD documentation is performed in the INL Electronic Data Management System and is maintained under project number 31055.

\subsubsection{Records Management/Document Control}

A project records and controlled documents system was established for the project. A formal project file and document control system that preserves and controls project records is maintained. The system complies with LWP-1202, "Records Management." Additional records management requirements defined in LWP-7201 will be addressed during the construction phase of the project. Uniform file codes, disposition authority, and retention periods will be established. Document configuration control will be conducted in accordance with LWP-1201, "Document Management."

\subsubsection{Systems Engineering}

A decision was made, in coordination between DOE and INL project management, that a systems engineering management plan was not required for this project. Nevertheless, systems engineering 
principles have been and will continue to be applied. A Certified Systems Engineering Professional is assigned to the project to assist with requirements identification and management, risk management, interface control, and integration.

\subsubsection{Quality Assurance}

The primary quality assurance objective is to ensure that the project operates in a safe, secure, and environmentally conscientious manner. INL has implemented a DOE-approved quality assurance program (Manuals 13A \& B) designed to comply with DOE Order 414.1D Admin Chg 1 and 10 CFR Part 830, Subpart A, "Quality Assurance Requirements.” To comply with DOE O 413.3B, the project quality assurance program plan also addresses requirements of ASME NQA-1-2008 and 1A-2009 Addenda, "Quality Assurance Requirements for Nuclear Facility Applications.” The design-build subcontractor's Quality Program was verified to be compliant with these requirements.

The project Quality Assurance Program Plan (PLN-3359) provides documentation of the procedures and processes used for assuring the quality of products and services in support of the project. A graded approach will be applied for quality assurance through the assignment of quality levels to items and activities at the earliest time consistent with the application of appropriate controls. Quality engineering will be responsible for defining the quality level(s) of the project work scope. The quality engineer will aid in development of the required subcontract procurement packages and prepare surveillance plans to monitor subcontractor-performed tests and inspections. The engineer will ensure required surveillances are performed and will coordinate all work with construction management. Facility quality engineering and system engineering will define quality processes that must be in place to comply with the safety basis documentation for the nuclear facility based on the facility hazard category.

\subsubsection{Communications Management Plan}

A public involvement plan (PLN-3378) was developed to address how the public and other stakeholders will be kept informed of progress on the project. This plan serves as the communications management plan and has been developed in coordination with DOE-ID Communications staff.

\subsubsection{Testing and Evaluation}

In this project, testing and evaluation activities primarily focus on verification that the facility meets all design requirements and to support safe operation as a nuclear facility. These areas of focus are as follows:

1. Quality control inspection of construction activities. For infrastructure construction and vault installation, quality inspection plans will be developed to ensure that construction materials and workmanship meet design requirements.

2. Functional testing of all operational systems necessary to support use of the facility, including, but not limited to, water, septic, electrical, and security systems.

3. Materials verification, assembly, and fit-up of vault components. Quality inspection of the vault system will occur to ensure that all safety design requirements are implemented.

4. All software used to analyze and verify facility design performance will meet quality requirements established in the Quality Assurance Program Plan.

These areas of focus will be applied to activities verifying that the design, finished facility, and planned operations personnel comply with all KPPs. To verify success in achieving all key parameters, Table 3 identifies each KPP, the verification method used to ensure compliance (analysis, inspection, and demonstration), and the detailed methods that will be employed to verify compliance. Table 3 will form the high-level basis for success in measuring design compliance and for verifying that operational readiness has been achieved. 


\subsubsection{Project Reviews}

Internal project status reviews may be conducted at any management level within the project, but will primarily be held by INL and the DOE-ID FPD. Status reviews between INL and the DOE-ID FPD will be held at least monthly (more frequently if determined necessary) to provide for discussion of project technical, cost, and schedule progress; performance trends; specific variances to project WBS activities; other issues; and recovery plans implemented to avoid project slips or delays. Formal project reviews that use the Project Definition Rating Index will be completed prior to CD-2/3 and CD-4 approvals.

\subsubsection{Transition to Operations}

Transition to operations begins with turnover and acceptance planning during the conceptual design phase and is finalized at CD-4. Operations transition activities are considered OPC and include facility operations and maintenance procedures development, functional testing of all facility systems and equipment, operations personnel training, spare parts procurement, operational readiness review activities, and facility commissioning. A significant amount of the turnover and acceptance work will begin before construction completion. Systems testing and personnel training can be initiated after physical completion of the facilities. Transition-to-operations and commissioning plans will be developed and completed to support submittal of the CD-4 approval request. These plans will clearly define the basis for attaining initial and full operating capability and will include the following:

- KPPs and project completion criteria

- Clear definition of CD-4 and post CD-4 activities and deliverables

- Identification of responsibility for post CD-4 activities and deliverables, between operations and the project, including funding source

- Staffing

- Project Interfaces (operations, project management, and subcontractor)

- Identification of operations budget (i.e., OPER cost post CD-4)

- Agreed-to readiness activities to startup operation (management self-assessment, contractor ORR and DOE ORR as determined using MCP-9902 and Form TEM-9902-A)

- Systems Testing - to include Safeguards and Security, Life Safety Systems, Emergency Preparedness, and Operations/Maintenance systems

- Project inspection and acceptance documentation (i.e., equipment, systems, facility checklists, Code of Record Compliance)

- Development of operations and maintenance manuals

- As-built drawings

- Procurement of materials, including operational spares required for initial operations

- Project closeout checklist activities.

Rough order-of-magnitude estimates to operate the facility have been requested from design-build subcontractors. If INL elects to have the design-builder operate the facility, a contract will be established prior to operational transition. These specific actions are outside of project scope but must be completed to support operational readiness and transition to operations.

The design-build subcontractor will assist in preparations for facility turnover. Project turnover and acceptance will be conducted in accordance with MCP-7460, "Project Turnover and Acceptance." A management self-assessment, as well as contractor and DOE ORRs will be completed in accordance with 
LWP-9903, "Performing Management Self-Assessments for Readiness," and DOE Order 425.1D, "Startup and Restart of Nuclear Facilities." The management self-assessment, contractor ORR, and DOE ORR will be completed in sequence. DOE Order 425.1D requires the operating contractor to notify DOE that readiness to startup has been verified by an ORR prior to initiation of the DOE ORR.

Upon successful completion of the DOE ORR and closeout of all pre-start findings, DOE will authorize startup. Startup approval authority for new Hazard Category 2 facilities currently resides with the Secretary of Energy. It is possible this authority may be delegated to NE prior to facility startup. Upon receipt of DOE's authorization to start operations, a draft project closure plan and project completion report will be developed. The draft plan and report will describe follow-on commitments and requirements (i.e., post project) needed to complete project closure. This documentation will be appended to the (already submitted) CD-4 documentation in order to allow AE approval of CD-4.

Outside of project scope (following CD-4 approval), a checklist of closeout activities will be prepared and a schedule to complete project closeout (physically, contractually, and financially) within 6 months after the data of the final project transfer will be established. A final project closure plan will be issued. A formal transfer of all documents, materials, equipment, manpower, and responsibilities will be completed. Financial data will be provided to DOE to support preparation of the "Prior Years Construction Report." Final project closure will also include issuing a lessons learned document.

\section{REFERENCES}

10 CFR 830, Subpart A, "Quality Assurance Requirements," Code of Federal Regulations, Office of the Federal Register.

10 CFR 835, "Occupational Radiation Protection," Code of Federal Regulations, Office of the Federal Register.

10 CFR 851, "Worker Safety and Health Program," Code of Federal Regulations, Office of the Federal Register.

29 CFR 1910, “Occupational Safety and Health Standards," Code of Federal Regulations, Office of the Federal Register.

29 CFR 1926, "Safety and Health Regulations for Construction," Code of Federal Regulations, Office of the Federal Register.

42 USC $§ 4321$ et seq., "National Environmental Policy Act of 1969 (NEPA)," United States Code.

42 USC § 9601 et seq., "Comprehensive Environmental Response, Compensation, and Liability Act (CERCLA)," United States Code.

ASME NQA-1-2008 and 1A-2009 Addenda, “Quality Assurance Requirements for Nuclear Facility Applications," American Society of Mechanical Engineers.

DOE, 2004, "Quality Assurance Requirements and Descriptions," DOE/RW-033P, Rev. 16,

U.S. Department of Energy, Office of Civilian Radioactive Waste Management.

DOE, 2011, Environmental Assessment for the Replacement Capability for Disposal of Remote-Handled Low-Level Radioactive Waste Generated at the Department of Energy's Idaho Site (Including FONSI), DOE/EA-1793, Final, December 2011. 
DOE-ID, 2011, Acquisition Strategy for the Idaho National Laboratory Remote-Handled Low-Level Waste Disposition Project, DOE/ID-11368, Idaho National Laboratory.

DOE Guide 413.3-3A, "Safeguards and Security for Program and Project Management”, U.S. Department of Energy.

DOE Guide 413.3-7, “Risk Management Guide,” U.S. Department of Energy.

DOE Manual 435.1-1, "Radioactive Waste Management Manual," Change 1, U.S. Department of Energy.

DOE Order 413.3B, "Program and Project Management for Acquisition of Capital Assets," U.S. Department of Energy.

DOE Order 414.1D Admin Chg 1, “Quality Assurance,” U.S. Department of Energy.

DOE Order 420.1C, “Facility Safety,” U.S. Department of Energy.

DOE Order 425.1D, “Startup and Restart of Nuclear Facilities,” U.S. Department of Energy.

DOE Order 435.1, "Radioactive Waste Management," Change 1, U.S. Department of Energy.

DOE Order458.1, Change 2, "Radiation Protection of the Public and the Environment," Change 2, U.S. Department of Energy.

DOE Policy 450.4A, “Safety Management System Policy,” U.S. Department of Energy.

DOE-STD-1020-2012, "Natural Phenomena Hazards Analysis and Design Criteria for Department of Energy Facilities," U.S. Department of Energy.

DOE-STD-1027-92, Chg.1, "Hazard Categorization and Accident Analysis Techniques for Compliance with DOE Order 5480.23, Nuclear Safety Analysis Reports,” U.S. Department of Energy.

DOE-STD-1189-2008, “Integration of Safety into the Design Process,” U.S. Department of Energy.

Executive Order 13423, "Strengthening Federal Environmental, Energy, and Transportation Management," January 24, 2007.

Executive Order 13514, "Federal Leadership in Environmental, Energy, and Economic Performance," October 5, 2009.

INLa, Conceptual Design Report for the Remote-Handled Low-Level Waste Disposal Project, INL/EXT-07-12901, Idaho National Laboratory.

INLb, Alternative Analysis for the Remote-Handled Low-Level Waste Disposal Facility, INL/EXT-09-17152, Idaho National Laboratory.

INLc, Siting Study for the Remote-Handled Low-Level Waste Disposal Facility, INL/EXT-07-12092, Idaho National Laboratory.

INLd, Conceptual Safety Design Report for the Remote-Handled Low-Level Waste Disposal Facility, INL/EXT-09-17427, Idaho National Laboratory. 
INLe, Preliminary Hazards Analysis for the Remote-Handled Low-Level Waste Disposal Facility, INL/EXT-07-12903, Idaho National Laboratory.

INLf, Remote-Handled Low-Level Waste Disposal Facility Code of Record, INL/EXT-11-20044, Idaho National Laboratory.

INLg, Proposal Reconciliation Report, INL/EXT-12-26370, Idaho National Laboratory.

ISO 14001, 2004, “Environmental Management Systems,” International Organization for Standardization.

LRD-10501, “Configuration Management Requirements,” Idaho National Laboratory.

LWP-1201, “Document Management,” Idaho National Laboratory.

LWP-1202, “Records Management,” Idaho National Laboratory.

LWP-6200, “Maintenance Integrated Work Control Process,” Idaho National Laboratory.

LWP-7201, “INL Construction,” Idaho National Laboratory.

LWP-8000, "Environmental Instructions for Facilities, Processes, Materials and Equipment," Idaho National Laboratory.

LWP-9903, "Performing Management Self-Assessments for Readiness," Idaho National Laboratory.

LWP-14002, “Timeout and Stop Work Authority,” Idaho National Laboratory.

Manual 11A, “S\&S Program Management,” Idaho National Laboratory.

Manual 13A, "Quality Assurance Program Requirements Documents,” Idaho National Laboratory.

Manual 14A, "Safety, Fire Protection, and Industrial Hygiene," Idaho National Laboratory.

Manual 14C, "Worker Safety and Health Program, 10 CFR 851,” Idaho National Laboratory.

MCP-7344, "Project Work Definition, Assignment, and Authorization," Idaho National Laboratory.

MCP-7345, "Project Baseline Schedule Development and Management," Idaho National Laboratory.

MCP-7346, "Project Budgeting and Baseline Schedule Development," Idaho National Laboratory.

MCP-7347, "Project Material and Subcontract Management,” Idaho National Laboratory.

MCP-7348, "Project Data Accumulation, Reporting, and Data Analysis," Idaho National Laboratory.

MCP-7349, "Project Estimate to Complete and Estimate at Completion Development', Idaho National Laboratory.

MCP-7350, "Project Risk Management,” Idaho National Laboratory.

MCP-7400, "Baseline Change Management," Idaho National Laboratory. 
MCP-7460, “Project Turnover, Acceptance, and Closeout,” Idaho National Laboratory.

PDD-10000, “Conduct of Engineering,” Idaho National Laboratory.

PLN-2541, "Risk Management Plan for Remote-Handled Low-Level Waste Disposal Project," Idaho National Laboratory.

PLN-3359, "Quality Assurance Program Plan for the Remote-Handled Low-Level Waste Disposal Project," Idaho National Laboratory.

PLN-3378, "Public Involvement Plan: Environmental Assessment of the Replacement Capability for Disposal of Remote-Handled Low-Level Waste Generated at the Department of Energy's Idaho Site," Idaho National Laboratory.

PLN-4089, "General Environmental Requirements Plan for the Remote-Handled Low-Level Radioactive Waste Disposal Facility at the Idaho National Laboratory Site," Idaho National Laboratory.

PLN-7315, “Earned Value Management System Description,” Idaho National Laboratory.

RD-1003, “General Information and Requirements,” Idaho National Laboratory.

RD-2000, "Work Coordination and Hazard Control," Idaho National Laboratory.

SAR-4, "Radioactive Waste Management Complex Safety Analysis Report," Idaho Cleanup Project.

SPC-1437, "Design-Build-Operate Performance Specification for the Remote-Handled Low-Level Waste Disposal Project," Idaho National Laboratory.

State of Idaho, 1995, "Settlement Agreement and Consent Order to fully resolve all issues in the actions Public Service Co. of Colorado v. Batt, No. CV 91-0035-S-EJL (D. Id.) and United States v. Batt, No. CV-91-0065-S-EJL (D. Id.),” Executed October 16, 1995.

State of Idaho, 2008, "Addendum to the Settlement Agreement and Consent Order in Public Service Co. of Colorado v. Batt, No. CV-91-0035-S-EJL (D. Id.) and United States v. Batt, No. CV-91-0054S-EJL (D. Id.)," Executed June 4, 2008.

TFR-483, "Technical and Functional Requirements for the Remote-Handled Low-Level Waste Disposal Project," Idaho National Laboratory. 
Appendix A

Integrated Project Team Charter 



\section{Idaho National Laboratory Remote-Handled Low-Level Waste Disposal Project Integrated Project Team Charter \\ April 29, 2014}

\section{BACKGROUND and OBJECTIVE}

The Idaho National Laboratory (INL) faces a shortfall in Remote-Handled (RH) Low-Level Waste (LLW) disposal capability. The current LLW disposal facility, located at the INL's Subsurface Disposal Area (SDA), will reach capacity or close in order to cap the SDA in support of final remediation. As an integral part of INL operations, RH LLW will continue to be generated after closure of the existing LLW disposal facility. The purpose of this project is to develop the capital assets necessary to ensure INL's LLW generators have continued access to disposal capacity. The Total Project Cost (TPC) is estimated to be less than $\$ 100 \mathrm{M}$. The Office of Nuclear Energy Deputy Assistant Secretary for Operations (NE-3) currently functions as the Acquisition Executive.

\section{PURPOSE AND OBJECTIVE}

The purpose of this charter is to accomplish the projective objectives, as defined in the RH LLW Disposal Project Execution Plan by establishing clear lines of authority; duties; roles and responsibilities; and interfaces between project and members of the Integrated Project Team (IPT). The charter also provides guidelines for effective project management and federal stewardship.

The objective of the IPT is to bring the necessary disciplines and organizational elements together to form a unit that shares information; balances conflicting priorities and ideologies; and jointly plans and executes the project.

\section{PERIOD OF PERFORMANCE}

The IPT will be in effect from conceptualization of the project through Critical Decision 4.

\section{PROJECT ROLES, RESPONSIBILITIES, AND AUTHORITIES}

Upon approval of CD-1, the Acquisition Executive appointed a Level 2 Federal Project Director (FPD) to provide oversight of the project development and execution. The IPT will support the FPD to ensure the project is executed safely and effectively in accordance with DOE requirements and applicable Federal and State laws and regulations.

The FPD's responsibilities include interface with the Idaho Branch Office of Naval Reactors; defining project objectives including scope, cost and schedule; risk management and providing project oversight. The FPD is responsible to deliver the project scope within the established cost and schedule. The FPD with assistance from the IPT, shall monitor progress and report project performance. The DOE-ID Principal Deputy Manager (PDM) for Nuclear Energy will function as the Contracting Officers Representative until the project receives congressional approval through line item appropriations. Upon receipt of line item appropriations, the FPD will assume COR responsibilities. In addition, the DOE-ID Contracting Officer (CO) is a member of the IPT to facilitate clarification and direction to the contractor through the INL Contract, as necessary and serve as the principal point of contact for acquisition and procurement actions.

The IPT represents diverse disciplines that have the knowledge, skills, and abilities necessary to support the successful execution of the RH LLW Disposal Project. Table 1 identifies the functional responsibilities of each team member. In their functional capacity, IPT members are authorized to represent their respective organizations in advising the FPD; facilitate effective communications and 
coordination of project activities; provide subject matter expertise and, monitor project progress. IPT composition and membership will vary depending on the phase and needs of the project.

As the primary sponsor, the Office of Nuclear Energy assigns a representative from NE-32 to the IPT. A representative of the Naval Reactors Idaho Branch Office (IBO) participates on the IPT in an advisory capacity. IBO's Naval Reactors Facility (NRF) is the principal generator of RH LLW at the Idaho Site. IBO represents the Office of Naval Reactors on the IPT whom co-funds the project with NE.

\section{MEMBERSHIP}

The IPT is organized by functional areas (Figure 1). The composition of the IPT is based on the project's requirements as it progresses from formulation through implementation. DOE-ID members are assigned based on their expertise and responsibilities. Table 1 lists current IPT members and their functional areas of responsibility. IPT members represent their respective organizations and provide a conduit for two-way communication between the project and each functional area. IPT members provide advice and guidance to the FPD to ensure successful project completion.

IPT participation is a collateral duty, typically ranging from 2 to 80 hours per month depending on the project's phase of development, member's responsibilities, and project activity. Sub-teams will be used as needed to access needed expertise. The use of sub-teams will allow the IPT to remain a manageable size and access necessary expertise.

\section{MEETINGS and REPORTING}

IPT meetings are conducted as required, typically once a month. The FPD will send out a notification and proposed agenda in advance of the meetings.

Upon CD-2 approval, the contractor will upload EVMS information in PARS-II. The contractor shall review the EVMS data with the FPD and deputy FPD prior to uploading data into PARS-II.

Upon CD-1 approval, the INL Project Manager will provide monthly Earned Value Management System (EVMS) and Project status reports to the FPD and the Acquisition Advisory Board Chairman. In addition, the INL Project Manager shall verbally report "real-time" status at IPT meetings. This report shall include any upcoming actions, both contractor and federal that may be required of the IPT. IPT members will provide a functional area status as necessary. Status reports shall include: progress/activities occurring in the last month; recent developments affecting the project; issues; action items, and upcoming activities.

\section{OPERATING GUIDANCE}

Typically, the IPT functions in a collaborative/consensus mode of operation (e.g. no significant objections of any member). In situations where a decision is required but a consensus cannot be reached, the FPD shall determine the course of action, taking IPT member input under consideration.

The FPD coordinates with the PDM for Nuclear Energy, as the responsible Contracting Officer's Representative (COR) to provide clarifications, technical instructions, or guidance within the INL's existing contract scope. Upon approval of CD-2, the FPD will assume COR responsibilities for the project. CO direction is required when the cost, scope, schedule, contractual requirements, or INL Performance Evaluation Measurement Plan may be affected. 
Table 1. INL RH LLW Disposal Project IPT Membership

\begin{tabular}{|c|c|c|}
\hline Organization & Member & Functional Area of Responsibility \\
\hline DOE-ID Infrastructure Projects & Julie Conner & $\begin{array}{l}\text { Federal Project Director \& } \\
\text { Risk Management. }\end{array}$ \\
\hline DOE-ID Infrastructure Projects & Gerardo Islas Rivera & Deputy Federal Project Director \\
\hline NE-31 & Kim Petry & PSO - Program Sponsor \\
\hline NE-31 & Mary McCune & PSO - Program Sponsor \\
\hline DOE Naval Reactors - IBO & Christopher Henvit & Naval Reactors (Advisory Capacity) \\
\hline DOE-ID Contract Management & Suzette Olson & Contracting Officer \\
\hline $\begin{array}{l}\text { DOE-ID Environmental } \\
\text { Compliance }\end{array}$ & Vanica Dugger & Environmental SME \\
\hline DOE-ID Public Affairs & Timothy Jackson & Public Affairs \& Communications \\
\hline DOE-ID Budget Services & Faye Alexander & Budgets, Planning and Project Controls \\
\hline DOE-ID Nuclear Safety & $\begin{array}{l}\text { Primary: Roger } \\
\text { Harshbarger } \\
\text { Secondary: Charles } \\
\text { Maggart }\end{array}$ & Nuclear Safety SME \\
\hline DOE-ID Quality \& Safety & Chris Beaman & Quality Assurance SME \\
\hline $\begin{array}{l}\text { DOE-ID Facility } \\
\text { Representative }\end{array}$ & $\begin{array}{l}\text { Steve Karns / John } \\
\text { Martin }\end{array}$ & Facility Operations SME \\
\hline DOE-ID Industrial Safety & Mike Hicks & Transportation SME \\
\hline DOE-ID Design/Engineering & Greg Bass & Civil Engineer/STSM \\
\hline DOE-ID Chief Counsel & Erin Walkowiak & Legal \& Regulatory \\
\hline DOE-ID Industrial Safety & Kyle A. Morrison & Fire Protection SME \\
\hline DOE-ID Industrial Safety & James B. Lovejoy & $\begin{array}{l}\text { Construction Safety and Hoisting and Rigging } \\
\text { Safety SME }\end{array}$ \\
\hline INL Manager & Philip J. Breidenbach & BEA Nuclear Operations Manager \\
\hline INL Project Manager & David Duncan & BEA Project Manager \\
\hline $\begin{array}{l}\text { INL MFC Hazardous Waste } \\
\text { Treatment and Storage }\end{array}$ & Vince Bowen & $\begin{array}{l}\text { Manager, MFC Spent Fuel } \\
\text { Treatment/Disposal Facilities }\end{array}$ \\
\hline INL ATR Canal Operations & Scott Ullsperger & ATR Canal Operations Manager \\
\hline Design Authority & Gary Tarbet & INL Design Authority \\
\hline
\end{tabular}


Figure 1. INL RH LLW Disposal Project Organization

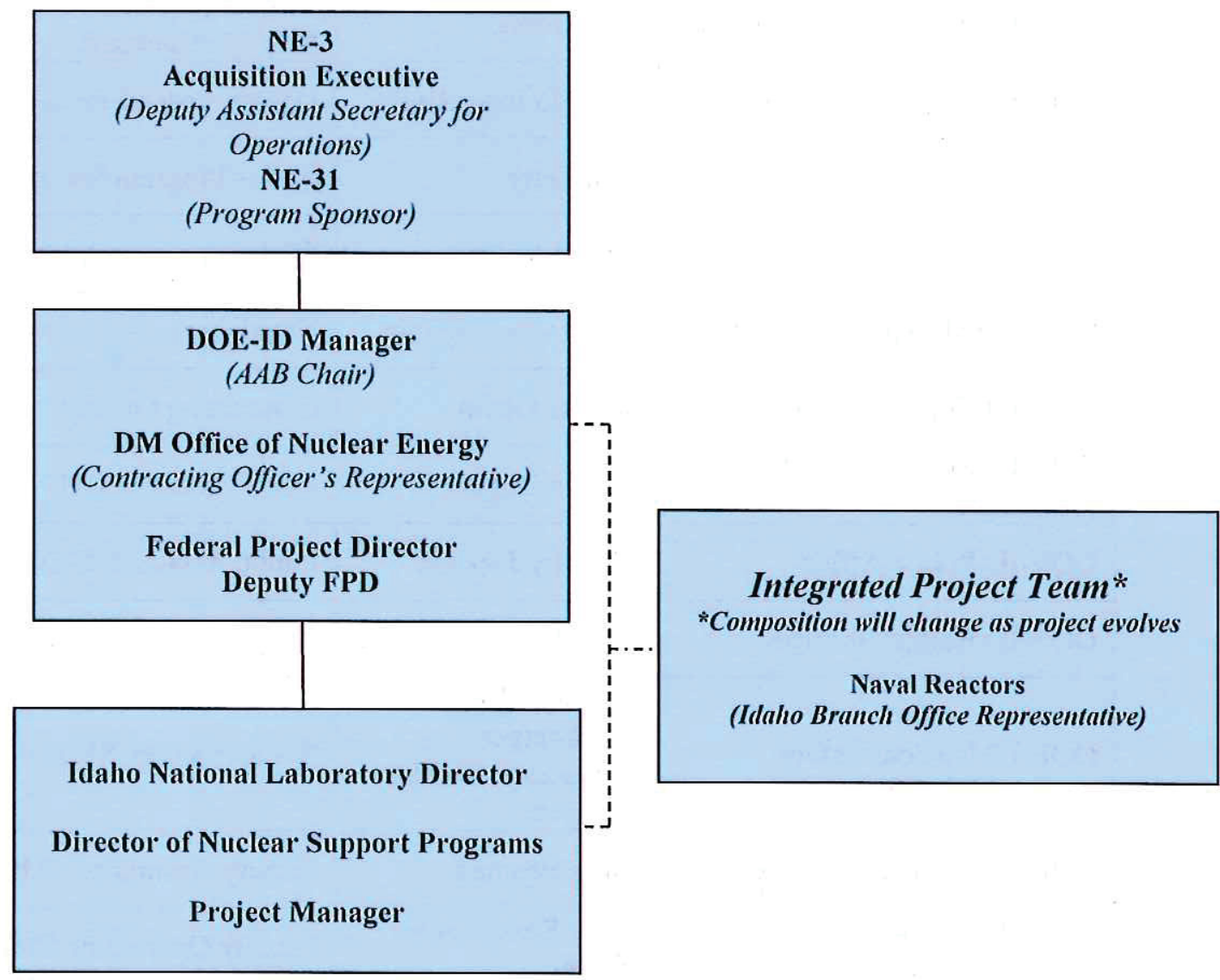

The original charter was approved on July 13, 2011 by Dr. Peter Lyons, Acquisition Executive via approval of the Project Execution Plan. The charter has been updated to reflect current project status and conditions.

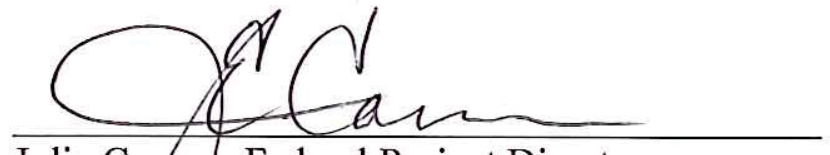

Julie Couner, Federal Project Director

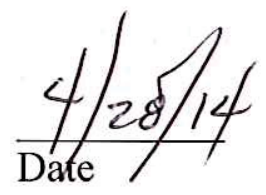


Appendix B

\section{Hold Point Review Checklist}





\section{Appendix B \\ RH LLW Disposal Project \\ Hold Point Pre-Release Verification Checklist}

\begin{tabular}{|c|c|}
\hline $\begin{array}{l}\text { Hold Point } \\
\text { Release } \\
\text { Requirement }\end{array}$ & $\begin{array}{l}\text { To Release } \\
\text { Vault System/CVAS } \\
\text { Hold Point }\end{array}$ \\
\hline \multirow{2}{*}{ Compliance Review } & $\square$ V1a. The vaults and identified transportation equipment interface appropriately. \\
\hline & $\begin{array}{l}\text { V1b. The Acquisition Executive approved any final document changes. } \\
\text {. }\end{array}$ \\
\hline Final Design Report & $\begin{array}{l}\square \text { V2. The designs of the vaults and the Cask/Vault Adapter System (CVAS) are } \\
\text { complete. }\end{array}$ \\
\hline Constructability & $\begin{array}{l}\text { The vaults can be constructed and the CVAS can be fabricated within the } \\
\square \text { V3. bounds of the baseline budget and schedule. }\end{array}$ \\
\hline Code of Record & $\begin{array}{l}\text { The Code of Record (COR) is current and consistent with the vault and } \\
\square \text { V4. CVAS final designs, and all post-CD-2 changes to the COR were reviewed } \\
\text { and approved by the Design Authority. }\end{array}$ \\
\hline $\begin{array}{l}\text { Security Vulnerability } \\
\text { Assessment (SVA) and } \\
\text { Emergency Management } \\
\text { requirements }\end{array}$ & $\begin{array}{l}\text { The SVAR is revised and consistent with the final vault and CVAS designs, } \\
\square \text { V5. and applicable security and emergency management requirements are } \\
\text { implemented in accordance with DOE O } 473.3 \text { and DOE G 413.3-3. }\end{array}$ \\
\hline $\begin{array}{l}\text { Environmental } \\
\text { Assessment (EA) }\end{array}$ & $\mathrm{N} / \mathrm{A}$ \\
\hline \multirow{2}{*}{$\begin{array}{l}\text { Quality Assurance Project } \\
\text { Plan (QAPP) }\end{array}$} & $\begin{array}{l}\text { The QAPP is updated and addresses construction, field design changes, } \\
\square \text { V7a. procurement activities and any the appropriate disposition of quality issues } \\
\text { that may occur post CD-3. }\end{array}$ \\
\hline & $\begin{array}{l}\square \text { V7b. The QAPP is consistent with guidance provided in DOE G 413.3-2, and any } \\
\text { exceptions to the guidance are justified. }\end{array}$ \\
\hline $\begin{array}{l}\text { Construction Safety and } \\
\text { Health Plan (CHSP) }\end{array}$ & $\begin{array}{l}\text { The CSHP is developed in accordance with the requirements of } 10 \text { CFR } \\
\text { Part } 851 \text {, Appendix A, Section (d) and meets the requirements of the } \\
\text { performance specification. }\end{array}$ \\
\hline $\begin{array}{l}\text { Preliminary Disposal } \\
\text { Authorization Statement } \\
\text { (PDAS) }\end{array}$ & $\begin{array}{l}\text { The Low-Level Waste Federal Review Group (LFRG) Co-Chairmen } \\
\square \text { V9. reviewed the final design and concurs that the final vault and CVAS designs } \\
\text { meet the conditions of the PDAS. }\end{array}$ \\
\hline \multirow{3}{*}{$\begin{array}{l}\text { Safety Design Strategy } \\
\text { (SDS), Preliminary } \\
\text { Documented Safety } \\
\text { Analysis (PDSA), \&Safety } \\
\text { Evaluation Report (SER) }\end{array}$} & $\begin{array}{l}\text { T V10a. The SDS is updated to reflect any changes to the security/nuclear safety } \\
\text { approach since CD-2. }\end{array}$ \\
\hline & $\square$ V10b. The PDSA is based on the final vault and CVAS designs. \\
\hline & $\begin{array}{l}\text { V V10c. The SER was issued in accordance with DOE STD } 1189 \text { and DOE O } \\
\text { 420.1C. }\end{array}$ \\
\hline \multirow{3}{*}{$\begin{array}{l}\text { Start-Up Planning and } \\
\text { Operational Readiness }\end{array}$} & $\begin{array}{l}\text { The Start-Up and Transition-to-Operations Plan was developed and } \\
\square \text { V11a. accurately reflects the final designs for infrastructure and disposal vault } \\
\text { system. }\end{array}$ \\
\hline & $\begin{array}{l}\square \text { V11b. The Start-Up and Operational Readiness Plan addresses the } \\
\text { recommendations of DOE G 413.3-9. }\end{array}$ \\
\hline & $\square$ V11c. A draft Plan of Action is developed to address the ORR. \\
\hline
\end{tabular}




\section{Appendix C}

\section{Summary Work Breakdown Structure Dictionary}





\section{Remote-Handled Low-Level Waste (RH LLW) Disposal Project}

\section{Work Breakdown Structure (WBS) \\ Dictionary}

July 2014 


\section{LWBS: C.R.60.20 Remote-Handled Low-Level Waste Disposal Project}

\section{Scope of Work}

The scope of the Remote- Handled Low-Level Waste Disposal Project (RHLLWDP) is to design, permit, construct, and transition a facility ready to perform RHLLW disposal operations. To achieve this scope, the project will complete such high level activities as: obtaining critical decision approval of each project phase; obtaining disposal authorization for the facility; design and construction of all facility Infrastructure; design, fabrication and installation of the disposal vault system; design and fabrication of all necessary waste handling interfaces/ equipment; achieving operational readiness and turnover of the facility to INL operations.

This scope is executed through 5 sub-projects each assigned a portion of the total project scope. Presented below is each subproject and a summary of its assigned scope:

C.R.60.20.01 Project Definition: This subproject is closed down. This subproject includes work scope leading up to completion of CD-1 approval.

C.R.60.20.02 Project Management: This subproject will complete all activities needed to obtain critical decision approval, complete earned value management certification, complete project independent reviews, achieve operational readiness, and complete project close-out.

C.R.60.20.03 Support Documents: This subproject will complete all documentation required to achieve funding approvals and authorize waste disposal. It also includes scope for a separate LFRG review support of the Composite Analysis (CA).

C.R.60.20.04 Infrastructure: This subproject will complete procurement, design, and construction of the supporting infrastructure for the facility, including roads, utilities, security, buildings, disposal area excavation, support of the design authority and design authority mentor in completion of the design-build process, and final finish of the disposal facility.

C.R.60.20.05 Vaults: This subproject will complete design, fabrication, and installation of the vault system. Also included is al safety documentation, including a refined shielding analysis of the vault plug, which is required to verify safety of the design.

\section{Major Deliverables and Milestones}

\section{Products and Deliverables}

Completed RHLLW Disposal Facility, ready for operations.

See individual control accounts for discrete products and deliverables.

\section{Milestones}

CD-2/3 Approved- RH4630- see schedule and control accounts for all interim milestones necessary to support this milestone. CD-4 Approved- RH4710-_see schedule and control accounts for all interim milestones necessary to support this milestone.

\section{Bounding Planning Assumptions (Conditions that bound the scope and associated cost estimate)}

The INL has been directed by DOE-ID to execute the project design and construction activities using the design-build delivery method. Because this project includes the design and construction of a nuclear facility, the design-build approach will be modified to mitigate the risks inherent in nuclear facility design and construction.

\section{Specific Scope Exclusions}

See individual sub-projects/control accounts for specific scope exclusions.

Baseline Execution Risk Summary (Describe the primary baseline execution risks identified and how they will be mitigated) See the Risk Management Plan PLN-2541 for a detailed register of risks and planned mitigations. 


\section{LWBS: C.R.60.20.02 Project Management}

\section{Scope of Work}

This subproject includes all activity by project management and other resources, necessary to manage project execution, obtain all project critical decisions, complete EVMS certification, declare operational readiness, complete facility turnover to operations, and complete all closeout activities.

Four control accounts have been established to address this scope:

C.R.60.20.02.01 Critical Decision Support: This consists of project data sheets and CD-2/3 and CD-4 package submittals.

C.R.60.20.02.02 Project Management Support: This consists of project management support (Level of Effort) and EVMS certification.

C.R.60.20.02.03 Operational Readiness: This consists of personnel training/Qualifications, operations and maintenance procedures, operational readiness review, and operations turnover.

C.R.60.20.02.04 Close-Out: This consists of closing out the plan and report for CD-4 which includes project file/record disposition and equipment transfers necessary for closure, and preparing a draft closeout report for the project.

\section{Major Deliverables and Milestones}

Products and Deliverables

See individual control accounts for discrete products and deliverables.

Milestones

See individual control accounts for discrete milestones.

Bounding Planning Assumptions (Conditions that bound the scope and associated cost estimate)

Much of the project's successful execution is dependent upon interface and support from the entire DOE integrated project team. This schedule and project deliverables were developed based on the assumption that medium and high risks outside of project control would be mitigated using DOE-held contingency.

\section{Specific Scope Exclusions}

None

Baseline Execution Risk Summary (Describe the primary baseline execution risks identified and how they will be mitigated)

Execution Risks include:

a. Funding requests and congressional approvals must coincide with the critical decision process to ensure project success. These approvals are outside project control.

b. See the Risk Management Plan PLN-2541 for a detailed register of risks and planned mitigations. 


\section{LWBS: C.R.60.20.02.01 Critical Decision Support}

\section{Scope of Work}

This Control account includes activities to support the creation and update of project data sheets during all critical decision approval request submittals and during annual update activities. This scope also supports the preparation of critical decision approval request packages and collection/ incorporation of comments from DOE following their submittal.

This control account includes work packages for project data sheet updates and CD approval request package assembly and comment resolution. This is for effort required to communicate with the customer and ensure that critical decision approval request documentation is correct and adequate. PM and CAMs are assumed to be the primary resources used for the duration of each update activity.

C.R.60.20.02.01.01 Project Data Sheet Updates: This work package includes scope to review, update, and issue project data sheets for the project.

C.R.60.20.02.01.02 CD-2/3 Package Assembly and Comment Resolution: This work package includes scope to assemble, submit and receive approval of CD-2/3 which involves the following: 1- cost estimate updates; 2- independent cost estimate review (ICE); 3- Independent project review (IPR); 4- CD-2/3 package submittal, review, and approval process, with final approval from DOE-ESAAB.

C.R.60.20.02.01.04 PP-CD-4 Package Assembly and Comment Resolution: This planning package includes scope to finalize the CD-4 package/lessons learned, and the review and approval process for CD-4 by DOE-ESAAB.

\section{Major Deliverables and Milestones}

\section{Products and Deliverables}

CD-2/3, and CD-4 approval Requests. Also includes yearly updates of the project data sheets for submittal to DOE.

\section{Milestones}

Complete performance baseline and request approval :

Submit and review CD-2/3 Approval Request- RH5145- see project schedule

Submit and review CD-4 Approval request -RH4700- see project schedule

RHLLW Project Complete - RH3000- see project schedule

Bounding Planning Assumptions (Conditions that bound the scope and associated cost estimate)

For each critical decision, different review and approval times are assumed. For CD-2/3, approximately 3.5 months is assumed on an accelerated schedule. For CD-4, 5 months is assumed and included in the baseline. Extenuating circumstances, political conditions, and election years have been accounted for, to some extent, in other activities in the schedule, but the critical decision approval process has not been modified for those circumstances. These approval times are currently estimated by DOE and will require significant coordination and cooperation from all review organizations to achieve.

\section{Specific Scope Exclusions}

CD-0 and CD-1 approvals are obtained and are excluded from the current scope.

Baseline Execution Risk Summary (Describe the primary baseline execution risks identified and how they will be mitigated)

Execution Risks include:

a. Funding requests and congressional approvals must coincide with the critical decision process to ensure project success. Approvals by external authority are outside project control.

b. See the Risk Management Plan PLN-2541 for a detailed register of risks and planned mitigations. 


\section{LWBS: C.R.60.20.02.02 Project Management Support}

\section{Scope of Work}

This control account includes LOE and activity-specific work packages to provide general project management support and specific support for the DOE Earned Value Management System Certification Process.

This control account includes work packages for general management of the project by control account managers and the PM. The CAM work included in this control account is that specifically to support annual planning and work package development, which includes development of budgets and schedules supporting each work package developed during the "rolling wave" planning process. It also includes full time support by a project financial controls specialist and part time support by a project scheduler and a cost estimator.

C.R.60.20.02.02.01 Project Management Support: This work package includes (LOE) level of effort project management support for the lifecycle of the project. The scope included involves project management, project financial controls, and project scheduling and estimating support. Scope includes oversight management of cost, schedule, baseline change controls, funding analysis, travel, monthly reporting (including PARS), and all other administrative aspects of project oversight.

C.R.60.20.02.02.02 EVMS Certification: This work package involves all activities related to achieving EVMS certification by Office of Engineering and Construction Management (OECM). The scope includes utilizing an outside subcontractor in support of the certification process.

\section{Major Deliverables and Milestones}

Products and Deliverables

1. Detailed work packages developed from planning packages, as the rolling wave planning process is executed for the project

2. Cost performance, status, and other required reports to execute and closeout the project

3. Documentation approving the project performance measurement baseline and certifying the project to EVMS.

Milestones:

None

Bounding Planning Assumptions (Conditions that bound the scope and associated cost estimate)

For each critical decision, different review and approval times are assumed. For CD-2/3, approximately 3.5 months is assumed on an accelerated schedule. For CD-4, 5 months is assumed and included in the baseline. . Extenuating circumstances, political conditions, and election years have been accounted for to some extent in other activities in the schedule, but the critical decision approval process has not been modified for those circumstances. These approval times are currently estimated by DOE and will require significant coordination and cooperation from all review organizations to achieve.

Also assumed is the amount of time needed by OAPM to support ongoing EVMS surveillance activity. Surveillance activities have not yet been planned by OAPM and/or PMSO.

\section{Specific Scope Exclusions}

CD-0 and CD-1 approvals are obtained and are excluded from current scope.

Baseline Execution Risk Summary (Describe the primary baseline execution risks identified and how they will be mitigated) Execution Risks include:

a. Funding requests and congressional approvals must coincide with the critical decision process to ensure project success. Many of these activities are outside project control.

b. See the Risk Management Plan PLN-2541 for a detailed register of risks and planned mitigations. 
LWBS: C.R.60.20.02.03 Operational Readiness

\section{Scope of Work}

This control account includes work packages to provide support to complete operational readiness activities for the project, specifically including preparations for, and completion of a DOE-directed Operational Readiness Review (ORR). These packages detail the specific activities needed to develop training and procedures, complete personnel qualification, develop maintenance procedures and qualifications, prepare for and execute all appropriate readiness reviews including the DOE ORR, and complete a turnover of the completed project to INL nuclear operations to conduct emplacement operations.

This Control account includes 5 time-phased work packages to achieve project operational readiness. The work packages included are:

C.R.60.20.02.03.01 PP- Personnel Training/Qualifications: This planning package includes scope to develop training plans and qualifications, and provide training to personnel in preparations for operational readiness.

C.R.60.20.02.03.02 PP- Operations and Maintenance Procedures: This planning package includes the following scope: 1completion of the checkout/testing/and commissioning plan for CD-4; 2- completion of the operations and maintenance plans and procedures for CD-4. This also involves documentation and review process in preparation for the MSA and RA in regards to the Plan of Actions, Implementation Plans, and evidence binders.

C.R.60.20.02.03.03 PP- Operational Readiness Review: This planning package includes the following scope: 1- Management Self-Assessment; 2- Contractor Readiness Assessment; and 3- DOE Operational Readiness Assessment. Each assessment involves the following: conducting the assessment; identifying and performing corrective actions (pre-start and post-start findings); final reporting and approval; documentation into Labway.

C.R.60.20.02.03.04 PP- Operations Turnover: This planning package includes scope to turn over the facility to operations. This includes the following: facility acceptance; and turnover of all operating and maintenance procedures.

\section{Major Deliverables and Milestones}

\section{Products and Deliverables}

Training plans, operating procedures, maintenance procedures, and personnel qualification records for each individual trained to emplace waste in the facility

Operation Readiness Review Report

Milestones

Personnel Training/ Qualification Complete- RH5850- see project schedule

Operations and Maintenance Procedures Complete- RH5840- see project schedule

Commence Management Self-Assessment- RH4690- see project schedule

Contractor ORR Complete- RH5860- see project schedule

DOE ORR Complete- RH8200- see project schedule

Bounding Planning Assumptions (Conditions that bound the scope and associated cost estimate)

For critical decision -4 a 5-month approval is assumed for DOE. Extenuating circumstances, political conditions, and election years have been accounted for to some extent in other activities in the schedule, but the critical decision approval process has not been modified for those circumstances.

\section{Specific Scope Exclusions}

This scope does not include work to prepare and submit the CD-4 approval request.

Baseline Execution Risk Summary (Describe the primary baseline execution risks identified and how they will be mitigated)

Execution Risks include: 
RH LLW Disposal Project

a. Funding requests and congressional approvals must coincide with the critical decision process to ensure project success. Many of these activities are outside project control.

b. See the Risk Management Plan PLN-2541 for a detailed register of risks and planned mitigations. 


\section{LWBS: C.R.60.20.02.04 Close-Out}

\section{Scope of Work}

The work in this control account includes the development of the draft closure report and organization of activities and effort necessary to achieve a "closed" status for the project. All equipment mobilized to support project execution is stored, excessed, or transferred to another project. All project files and records are dispositioned and/or established as permanent. Lessons learned for the project are issued and used to assist in the execution of future projects. The work packages include the following:

C.R.60.20.02.04.01 PP- Close-Out Plan: This planning package includes the scope to develop a closeout plan in preparation to closing out the project. This includes project file/record disposition and equipment transfers necessary for closure.

C.R.60.20.02.04.02 PP- Close-Out Report: This planning package includes the scope to prepare a draft closeout report for the project. The final closeout report will be issued outside of the project TPC to allow for financial closure of all obligations and charge number closeout.

Major Deliverables and Milestones

\section{Products and Deliverables}

Draft Closure Report, including project lessons learned.

\section{Milestones}

None.

Bounding Planning Assumptions (Conditions that bound the scope and associated cost estimate)

The issuance of the final closure report, which occurs following financial closure of all commitments and obligations, is not included in the scope of the project.

\section{Specific Scope Exclusions}

Activities excluded from this control account and from the scope of the project are financial closure of the project, completion of all financial commitments, and receipt/payment of all invoices.

Baseline Execution Risk Summary (Describe the primary baseline execution risks identified and how they will be mitigated) None. 


\section{LWBS: C.R.60.20.03 Project Support Documents}

\section{Scope of Work}

Project Support Documents is a subproject of the Remote-Handled LLW Disposal Project. This subproject covers development and delivery of general project support documentation. These documents are defined as those that apply to the whole project, as opposed to those that apply only to specific subsystems (e.g., performance specifications). Project Support Documents include those required by DOE Order 413.3, DOE Order 435.1, and the National Environmental Policy Act of 1969 (NEPA). The subproject work scope involved in completing these documents includes writing, reviewing, revising, printing, and submitting the documents. It also includes management of these documentation activities, where such management is separate and distinct from general project management work scope. There is a Level-of-Effort (LOE) Control Account for management of the Project Support Documents work scope, and there is a Control Account for documents associated with each Critical Decision (CD). Documents are organized into Work Packages based on their driver (DOE Order 413.3 vs. DOE Order 435.1 and NEPA).

Open Control Accounts include:

C.R.60.20.03.01 Project Support Document Management: This control account consists of LOE oversight support in managing all documentation activities in support of $C D$ deliverables.

C.R.60.20.03.02 CD-1 Documents (Closed). Work scope was in support of CD-1 documentation approval.

C.R.60.20.03.03 CD-2/3 Documents: This control account consists of the following work scope: 435.1 \& NEPA documentation for CD-2/3; and 413.3 documentation for CD-2/3.

C.R.60.20.03.05 CD-4 Documents: This control account consists of the following work scope: 413.3 documentation for CD-4; 435.1 \& NEPA documentation for CD-4; and Waste Acceptance Criteria.

See the Control Account IWADS for further explanation of the scope, budget, and schedule.

Major Deliverables and Milestones

Products and Deliverables

DOE Order 413.3 Documents

DOE Order 435.1 Documents

NEPA Documents

Waste Acceptance Criteria (WAC)

See individual control accounts for discrete products and deliverables.

Milestones

See individual control accounts for discreet milestones.

Bounding Planning Assumptions (Conditions that bound the scope and associated cost estimate)

See the Control Account IWADs for Bounding Planning Assumptions.

\section{Specific Scope Exclusions}

See individual control accounts for specific scope exclusions.

Baseline Execution Risk Summary (Describe the primary baseline execution risks identified and how they will be mitigated)

See the Control Account IWADs for specific Baseline Execution Risks.

See the Risk Management Plan PLN-2541 for a detailed register of risks and planned mitigations. 
LWBS: C.R.60.20.03.01 Project Support Document Management

\section{Scope of Work}

Project Support Documents is a subproject of the Remote-Handled LLW Disposal Project. This subproject covers development and delivery of general project support documentation. These documents are defined as those that apply to the whole project, as opposed to those that apply only to specific subsystems (e.g., performance specifications). Project Support Documents include those required by DOE Order 413.3, DOE Order 435.1, and the National Environmental Policy Act of 1969 (NEPA). The subproject work scope involved in completing these documents includes writing, reviewing, revising, printing, and submitting the documents. It also includes management of these documentation activities, where such management is separate and distinct from general project management work scope. This control account is the Level-ofEffort (LOE) Account for management of the Support Documents work scope.

Work Packages included in the Support Document Management Control Account include:

- C.R.60.20.03.01.01 Support Documentation Management: This LOE work package provides oversight support in managing all documentation activities (including writing, reviewing, revising, printing, and submission) in support of project completion through CD-4.

\section{Major Deliverables and Milestones}

Products and Deliverables

None (LOE)

Milestones

None (LOE)

Bounding Planning Assumptions (Conditions that bound the scope and associated cost estimate)

This control account covers document support LOE effort for one CAM at $40 \%$ for the duration of the project.

Specific Scope Exclusions

N/A

Baseline Execution Risk Summary (Describe the primary baseline execution risks identified and how they will be mitigated) $\mathrm{N} / \mathrm{A}$ 
LWBS: C.R.60.20.03.03 CD-2/3 Documents

\section{Scope of Work}

Project Support Documents is a subproject of the Remote-Handled LLW Disposal Project. This subproject covers development and delivery of general project support documentation. These documents are defined as those that apply to the whole project, as opposed to those that apply only to specific subsystems (e.g., performance specifications). Project Support Documents include those required by DOE Order 413.3, DOE Order 435.1, and the National Environmental Policy Act of 1969 (NEPA). The subproject work scope involved in completing these documents includes writing, reviewing, revising, printing, and submitting the documents. It also includes management of these documentation activities, where such management is separate and distinct from general project management work scope. This control account contains the works cope associated with CD-2/3 documentation and reviews. Documents are organized into Work Packages based on their driver (DOE Order 413.3 vs. DOE Order 435.1 and NEPA).

Work Packages included in the CD-2/3 Documents Control Account:

- C.R.60.20.03.03.01 435.1 \& NEPA Documents (CD-2/3): This work package includes the following work scope: preparing and submitting performance assessment (PA) to LFRG; preparing the FONSI (Finding of No Significant Impact); updating the PA and finalizing a draft of the CA and 3 plans; LFRG review of CA and 3 plans; support of the LFRG reviews; and LFRG review of the vault design.

- C.R.60.20.03.03.02 413.3 Documents (CD-2/3) - Closed: This work package included scope in support of CD-2/3 approval which consisted of the following: Preliminary Safety Design Report (PSDR); Quality Assurance Program Plan

(QAPP);Construction Project Safety and Health Plan; Risk Management Plan (RMP); Project Execution Plan (PEP); Final Hazard Categorization; Hazard and Accident Analysis; review and approval of the PSDR and issuing the PSVR; and developing initial draft preliminary documented safety analysis (PDSA).

The single LFRG review has been split into two reviews, requiring BEA support throughout the duration of each. The Performance Assessment (PA) review will be performed first, to support the accelerated CD-2/3. The LFRG will then reconvene at a later date to review the Composite Analysis (CA). Originally, DOE requested that Savannah River personnel be funded to support the LFRG reviews ( $\$ 70 \mathrm{~K})$. However, the second review was removed for the Composite Analysis, at DOE's request. DOE opted to fund Savannah River support outside of the PMB.

Major Deliverables and Milestones

Products and Deliverables

Documents to be submitted for CD-2/3 or before CD-4 submittal, including:

- Performance Assessment (PA)

- Composite Analysis (CA)

- PA/CA Maintenance Plan

- Closure Plan

- Monitoring Plan

- Environmental Assessment (EA)

- Risk Management Plan (RMP)

- Preliminary Safety Design Report (PSDR)

- Safety Design Strategy (SDS)

- Project Execution Plan (PEP)

- Quality Assurance Project Plan (QAPP)

- Code of Record

Milestones

RH5750 Receive EA FONSI

RH6000 Submit CA \& 3 Plans to LFRG

RH5780 DOE Issue PSVR

RH5760 LFRG Review Final Design (Vault) Complete

Bounding Planning Assumptions (Conditions that bound the scope and associated cost estimate)

Assume that there will be a hold point prior to start of vault construction and that the PDSA and SDS will not be approved until this hold point Assume the SDS will be submitted only once prior to CD-2/3. (Normally, it would be submitted at CD-2 and again at CD-3.) Assume that the T\&FR is complete and requires no revision. If revisions are required, they will be addressed through Infrastructure work scope. Assume that a Final DAS is not required until ORR (CD-4).

\section{Specific Scope Exclusions}


RH LLW Disposal Project

initial delivery of the CD-2/3 package. Project Management supports comment resolution and resubmission.

Baseline Execution Risk Summary (Describe the primary baseline execution risks identified and how they will be mitigated) See the Risk Management Plan PLN-2541 for a detailed register of risks and planned mitigations. 


\section{LWBS: C.R.60.20.03.05 CD-4 Documents}

\section{Scope of Work}

Project Support Documents is a subproject of the Remote-Handled LLW Disposal Project. This subproject covers development and delivery of general project support documentation. These documents are defined as those that apply to the whole project, as opposed to those that apply only to specific subsystems (e.g., performance specifications). Project Support Documents include those required by DOE Order 413.3, DOE Order 435.1, and the National Environmental Policy Act of 1969 (NEPA). The subproject work scope involved in completing these documents includes writing, reviewing, revising, printing, and submitting the documents. It also includes management of these documentation activities, where such management is separate and distinct from general project management work scope. This WBS Element is a Summary Level Planning Package for CD-4 Documents. Documents are organized into Work Packages (or Planning Packages) based on their driver (DOE Order 413.3 vs. DOE Order 435.1 and NEPA).

Work and Planning Packages included in the CD-4 Documents Control Account:

- C.R.60.20.03.05.01 PP -413.3 Document (CD-4): This planning package consists of the following work scope: internal and external updates, reviews, and approval of the Preliminary Documented Safety Analysis (PDSA); issuance and approval of the Safety Evaluation Report (SER); updating/ approval of the Fire Hazards Analysis (FHA); updating and finalization of the Risk Management Plan (RMP), Quality Assurance Plan (QAP), and Documented Safety Analysis (DSA); review and approval of the DSA.

- C.R.60.20.03.05.02 435.1 \& NEPA Documents (CD-4): This work package consists of the following work scope: performing lithological analysis; analyzing/baseline aquifer trends; developing inventory tracking tools to support the waste acceptance criteria; monitoring, analyzing, and reporting of vault performance; updating the performance assessment model; updating the PA and CA interacting with LFRG; supporting LFRG in preparing and approving a final DAS.

- C.R.60.20.03.05.03 Waste Acceptance Criteria (New for CD-2/3 Approval BCP): This work package consists of drafting, reviewing, and finalizing the waste acceptance criteria.

(The Hazard Analysis Report is a table in the DSA. It was removed as distinct work scope. It was decided that a Construction Project Safety and Health Plan is not a stand-alone project document requiring specific work scope.)

Major Deliverables and Milestones

Products and Deliverables

Documents to be submitted for (or before) CD-4, including:

C.R.60.20.03.05.01

- Risk Management Plan (RMP)

- Fire Hazards Analysis (FHA)

- Documented Safety Analysis (DSA)

- Quality Assurance Plan (QAP)

- Safety Evaluation Report (SER) from DOE

C.R.60.20.03.05.02

- Performance Assessment (PA)

- Composite Analysis (CA)

- Monitoring Plan

- Closure Plan

- PA/CA Maintenance Plan

- Disposal Authorization Statement (DAS) from the LFRG

C.R.60.20.03.05.03

- Waste Acceptance Criteria (WAC)

Milestones

C.R.60.20.03.05.01

- RH5790 PDSA Submitted to DOE

- RH5800 DOE Issue Safety Evaluation Report (SER)

- RH5810 Issue Documented Safety Analysis (DSA) to DOE

- RH5820 DOE Approve Final Documented Safety Analysis

- RH8240 DOE Issue SER

C.R.60.20.03.05.02

- RH8500 DAS Approved (New for CD-2/3 Approval BCP)

C.R.60.20.03.05.03

- N/A

Bounding Planning Assumptions (Conditions that bound the scope and associated cost estimate)

Assume that there will be only one review cycle (DOE-ID/DOE-HQ). Assume that the PA, CA, and associated plans will only have to be reviewed/updated once during the period between approval of CD-2/3 and approval of CD-4. 
RH LLW Disposal Project

Specific Scope Exclusions

None

Baseline Execution Risk Summary (Describe the primary baseline execution risks identified and how they will be mitigated)

C.R.60.20.03.05.01

Risk that CD-4 approval will be delayed or that it will not be approved after the first review cycle. Risk that Final DAS will not be approved in time. Risk \#5b addresses the possibility of a delay in completing nuclear safety documentation (e.g., preliminary documented safety analysis/documented safety analysis and the associated SRC review). Risk \#5a addresses the possibility of a delay in DOE approving nuclear safety documentation (e.g., preliminary documented safety analysis/documented safety analysis and the associated SRC review).

C.R.60.20.03.05.02

Risk \#19 addresses the possibility of DOE Order 435.1 requirements changing, leading to additional design features at the disposal facility. Risk \#52 addresses a delay in construction, resulting in as-built performance data and interpretation not being available to convince the LFRG that the facility can perform as analyzed in the PA, thus delaying issuance of the final DAS. Risk \#60 addresses the possibility that the design/build contractor's design differs significantly from the conceptual design analyzed in the PA (i.e., the PA assumptions are not feasible to design and build. This could: 1) affect the conditional DAS already issued by the LFRG, 2) require the contractor to revise the design resulting in a schedule delay and associated costs, and/or 3) require updates to the PA, waste acceptance criteria (WAC), CA, and at a minimum will likely require additional review materials to be presented to the LFRG.

C.R.60.20.03.05.03

There is a risk in the project risk register (\#60) that addresses the possibility of having to revise the WAC if the design/build contractor's design differs significantly from the conceptual design analyzed in the PA.

See the Risk Management Plan PLN-2541 for a detailed register of risks and planned mitigations. 
LWBS: C.R.60.20.04 Infrastructure

\section{Scope of Work}

This subproject includes all infrastructure which must be constructed on the Idaho National Laboratory (INL) as part of the Remote-Handled Low-Level Waste (RH-LLW) Disposal Project, and project activities which support definition of the infrastructure requirements. This project is being installed on a green field site near, but separate from, the ATR Complex. The majority of the infrastructure will be designed and constructed utilizing a design-build subcontractor. This subproject contains five control accounts which consist of the following:

C.R.60.20.04.01 Infrastructure RFPs: This control account consists of the following work scope: developing and issuance of performance specifications; request for proposal of the design build contract; review and approval of the design build (DB) subcontract; issuance of stipends to unsuccessful bidders.

C.R.60.20.04.02 Infrastructure: This control account consists of the following work scope: infrastructure design; infrastructure construction; retained utility tie-ins; and infrastructure subcontract management.

C.R.60.20.04.03 Monitoring Wells: This control account consists of the following work scope: BEA support for the design of the facility monitoring wells and taking samples in the aquifer monitoring wells to demonstrate that an acceptable baseline has been established prior to startup of the RH-LLW Disposal Facility.

C.R.60.20.04.04 Equipment: This control account consists of the following work scope: procurement of equipment (emergency management supplies, industrial safety, radiological support, office building, maintenance shop, and hoisting/rigging equipment).

C.R.60.20.04.05 Infrastructure Liner Alternatives Analyses: This control account consists of the following work scope: parameterize Near-Field Vault Model; developing and analyzing concrete mix design; interpreting hydraulic data provided by the DB subcontractor; and addressing LFRG liner alternatives issues.

\section{Major Deliverables and Milestones}

\section{Products and Deliverables}

See individual control accounts for discrete products and deliverables.

\section{Milestones}

See individual control accounts for discrete milestones

Bounding Planning Assumptions (Conditions that bound the scope and associated cost estimate)

See PEP DOE/ID-11466

\section{Specific Scope Exclusions}

Project management activities are in the Project Management subproject.

Development of Performance Specification for Infrastructure is in the Vaults Subproject.

All RHLLW Disposal Project Start up activities are in the Project Management subproject.

Project Documentation is in the Documents Subproject.

Baseline Execution Risk Summary (Describe the primary baseline execution risks identified and how they will be mitigated)

A risk management plan is established and maintained for the project in the Project Management subproject (see risk management plan, PLN-2541). 


\section{LWBS: C.R.60.20.04.01 Infrastructure RFPs}

\section{Scope of Work}

This control account contains one work package. The scope includes development of the Request for Proposals for the design-build subcontract for the infrastructure and vaults. The scope also includes support from a design-build consultant, and a design authority mentor.

Work package included:

C.R.60.20.04.01.01 Performance Specifications: Consists of the following work scope: developing and issuance of performance specifications ( engineering design requirements, ESH requirements, Quality requirements, safety analysis interface requirements, Ops and Maintenance requirements, special conditions, vendor data schedule requirements); request for proposal of the design build contract; review and approval of the design build (DB) subcontract; issuance of stipends to unsuccessful bidders.

\section{Major Deliverables and Milestones}

\section{Products and Deliverables}

1. RH-LLW Disposal Project specific training for development and management of a design-build subcontract, and development of the design-build subcontract strategy/plan

2. Final RFP for the Infrastructure and Vaults design-build subcontract

\section{Milestones}

N/A

\section{Bounding Planning Assumptions (Conditions that bound the scope and associated cost estimate)}

The rough draft of the Infrastructure performance specification developed to date by Northwind will not require significant changes. BEA Engineering has been engaged in the project and a design authority and a project engineer are assigned.

BEA Engineering and other functional organization resources will be made available to the project as identified in the baseline schedule.

An initial value engineering session which acquainted the INL SMEs with the project was conducted in FY2010 and those results were made available to Northwind and BEA Engineering.

An initial draft of the requirements roll down matrix in DOORs was developed in FY-2010 and will continue to be used as the basis for the project requirements tracking system.

An initial draft of the FDD was developed in FY-2010 and will continue to be used as the basis for the project facility or systems design document.

A Level 3 cost estimate for the project was developed in to support the development of the project baseline. DOE has formally committed that this work will be performed as design-build and this has been accepted by INL project management. BEA Management has accepted the design-build acquisition strategy.

The scope of the Infrastructure will be based on the preferred location option identified in the approved CD-1 submittal.

The BEA management approval process for the final RFP will not require additional project funded resources or time over that in the baseline.

Project funding will be provided as identified in the baseline DBIA project specific training for the project identified the need to revise the RFP development process; new activities/resources were added and existing activities/resources were adjusted to ensure successful development of the RFP.

All supply chain labor costs to support the development of the RFP, the pre-RFP marketing research, the management and DOE reviews of the RFP, the formal bidding and subcontractor bid review and selection process will be charged to the Supply Chain service center. 
RH LLW Disposal Project

Development of the Infrastructure and Vault performance specification and programming sheets, if necessary, is included in the Vault subproject.

All functional organization training on the design build acquisition strategy and all involvement by functional organization management will be paid for by those functional organizations.

There is no funding for travel or materials, computer support, personnel training, etc., in this control account.

Overhead charges will be the same as used in the cost estimate for the project baseline.

Baseline Execution Risk Summary (Describe the primary baseline execution risks identified and how they will be mitigated)

A risk management plan is established and maintained for the project in the Project Management subproject (see risk management plan, PLN-2541). 
LWBS: C.R.60.20.04.02 Infrastructure

\section{Scope of Work}

This control account includes all work to complete the design and construction of the Infrastructure portion of the RH-LLW facility. It contains the following packages: 1) Infrastructure Design, 2) Infrastructure Construction, 3) BEA Retained Utilities Tie-ins, and 4) Infrastructure Subcontract Management. The Conceptual Design Report approved as part of the CD-1 package, TFR-483, and SPC-1437 are the basis of scope for the infrastructure work scope as further defined by the baseline cost estimate. A design authority mentor experienced with design-build projects will assist the design authority during the infrastructure design and construction.

C.R.60.20.04.02.01 Infrastructure Design: The infrastructure design scope includes the development of the final design for the infrastructure work assigned to the design build subcontractor. This includes all design activities including development of design drawings and specifications, completion of supporting design and analysis calculations, establishment and maintenance of a requirements tracking system and the facility design document, support of design reviews by BEA functional organizations, issuing design drawings and specifications for construction, maintaining up to date redlines as construction progresses and providing completed final as-built drawings, and maintaining the design baseline. The requirements for the design activities will be defined in the design build RFP and will be based on the INL Engineering Program. This scope also includes the Supply Chain charges for the infrastructure/vault design build contract.

C.R.60.20.04.02.02 PP -Infrastructure Construction: The Infrastructure Construction planning package includes all construction work for the infrastructure assigned to the design build subcontractor. This work includes equipment mobilization and demobilization, INL specific training for construction personnel, development of the access road, site area clearing and grubbing, excavation of the hole for the vaults and backfilling, constructing buildings (maintenance shop and administration building), installation of thirteen (13) facility monitoring wells in and around the disposal vault arrays, final site grading and landscaping, fence installation, final road and site paving, installation of the utilities (fire water, electrical distribution, telecommunications, security, potable water, sanitary sewer, and subcontractor turnover. An incentive fee for the subcontractor is also included.

C.R.60.20.04.02.04 PP -BEA Retained Utilities Tie-ins: The BEA Retained Utilities Tie-Ins planning package includes preparation of work orders by BEA personnel to the sewer tie-in, the fire water tie-in, the potable water tie-in, the electrical outage, and for the IT work.

C.R.60.20.04.02.05 PP- Infrastructure Subcontract Management: The Infrastructure Subcontract Management planning package includes the BEA subcontract management activities, operations support during construction, BEA construction management, safety oversight, and subsurface investigations prior to excavations and wall or floor penetrations, and unexploded ordinance surveys prior to any new area work.

\section{Major Deliverables and Milestones}

\section{Products and Deliverables}

1. Final design documents

2. Infrastructure construction which includes the following:

a. Initial construction site access roadway and site preparations

b. Excavation of hole for safe installation the vaults

c. Utilities (fire, sewer, potable water, electrical), and communications (security, emergency communications and internet) from ATR

d. Two support buildings (administrative and maintenance)

e. Final site landscaping, access road buildup, grading, and paving

f. Perimeter security fence

3. Installation of thirteen (13) facility monitoring wells in and around the disposal vault arrays

4. All subcontractor vendor data

5. Subcontract management documentation 
RH LLW Disposal Project

Milestones

RH4660 -Facility Design Complete

RH4670 -Commence Infrastructure Construction

RH4680 -Construction Complete

Bounding Planning Assumptions (Conditions that bound the scope and associated cost estimate)

Design-build subcontract award is made as shown in schedule.

Scope of the design-build subcontract is as described in the RHLLW Conceptual Design Report, TFR-483, and SPC-1437.

Details of the scope are found in the baseline cost estimate.

Design and construction funding for the Infrastructure will be available as depicted in the Project Execution Plan so the baseline schedule can be met.

Design approval by DOE will support construction initiation as shown in schedule.

Infrastructure construction can be completed as shown in project schedule.

See PEP DOE/ID-11466 for overall project assumptions.

Specific Scope Exclusions

Project management activities are in the Project Management subproject.

Review and finalization of the final RFP and performance specification is in the Infrastructure RFP control account and the Vault subproject.

The work to issue RFIs, to issue the RFPs, to review the subcontractor proposals, and to issue the subcontract is in the Infrastructure RFP control account.

Startup activities are in the Project Management subproject.

Project documentation is in the Documents subproject.

Baseline Execution Risk Summary (Describe the primary baseline execution risks identified and how they will be mitigated)

A risk management plan is established and maintained for the project in the Project Management subproject. See risk management plan, PLN-2541. 


\section{LWBS: C.R.60.20.04.03 Monitoring Wells}

\section{Scope of Work}

This control account is in support for the design of the facility monitoring wells and taking samples in the aquifer monitoring wells to demonstrate that an acceptable baseline has been established prior to startup of the RH-LLW Disposal Facility. There is one planning package associated with the control account.

C.R.60.20.04.03.02 PP- Monitoring Well Installation/Testing: The scope includes BEA support for the design of the facility monitoring wells and taking samples in the aquifer monitoring wells to demonstrate that an acceptable baseline has been established prior to startup of the RH-LLW Disposal Facility.

Major Deliverables and Milestones

Products and Deliverables

1. BEA support for the design of the facility monitoring wells

2. Established monitoring wells baseline

Milestones

N/A

Bounding Planning Assumptions (Conditions that bound the scope and associated cost estimate)

Monitoring the wells cannot begin until the wells have been installed by the design-build subcontractor. Monitoring the wells will be performed by a subcontractor separate from the main design-build subcontractor, and can be performed on a schedule which isn't dictated by the design-build subcontractor schedule, once wells are installed.

Monitoring activities will be under direction of Regulatory and Monitoring Organization and will be incorporated into the BEA monitoring program. The wells are needed to be installed immediately after the first vaults installation to ensure that sufficient data is collected analyzed to support issuance of a final DAS. Monitoring must occur through at least two wetting/draining cycles.

\section{Specific Scope Exclusions}

None

Baseline Execution Risk Summary (Describe the primary baseline execution risks identified and how they will be mitigated)

A risk management plan is established and maintained for the project in the Project Management subproject. See risk management plan, PLN-2541. 
RH LLW Disposal Project

LWBS: C.R.60.20.04.04 Equipment

\section{Scope of Work}

This control account includes all procurement of all equipment and building furnishings required for initial startup of the $\mathrm{RH}-$ LLW. It consists of one planning package:

C.R.60.20.04.04.02 PP- Equipment Procurement: This planning package consists of the following work scope: procurement of equipment (emergency management supplies, industrial safety, radiological support, office building, maintenance shop, and hoisting/rigging equipment).

\section{Major Deliverables and Milestones}

\section{Products and Deliverables}

1. Office and Maintenance building furnishings

2. Radiological Support instrumentation and equipment

3. Maintenance building tools, cabinets, and equipment

4. Environmental monitoring instrumentation

5. Other miscellaneous equipment as dictated by the design

Milestones

N/A

Bounding Planning Assumptions (Conditions that bound the scope and associated cost estimate)

Final equipment list has not yet been completed. The equipment included in this control account is based on a preliminary evaluation of the facility needs during the value engineering meeting held at the end of August 2010. Input was received from the SMEs at that meeting. More or different equipment may be identified during design.

The Manitowoc 3900W crane currently in use at RWMC will be not be available for re-utilization at the new facility until its use at the RWMC SDA is completed in FY 2020.

\section{Specific Scope Exclusions}

The equipment list identified in the cost estimate limits the scope of this control account.

Refurbishment of the existing 3900W Manitowoc crane in use at RWMC is not included in this control account or the project.

Baseline Execution Risk Summary (Describe the primary baseline execution risks identified and how they will be mitigated)

A risk management plan is established and maintained for the project in the Project Management subproject. See risk management plan, PLN-2541. 


\section{LWBS: C.R.60.20.04.05 Infrastructure Liner Alternatives Analyses}

\section{Scope of Work}

This control account includes a single work package for development and issuance of a liner alternatives analysis which addresses the effect on performance of the proposed RHLLW facility of various liner alternatives. Miscellaneous modeling and simulation work is also included in this scope. The work package included is:

C.R.60.20.04.05.01 Liner Alternatives Analyses: work scope included: parameterize Near-Field Vault Model; developing and analyzing concrete mix design; interpreting hydraulic data provided by the DB subcontractor; and addressing LFRG liner alternatives issues.

\section{Major Deliverables and Milestones}

\section{Products and Deliverables}

1. Final alternatives analysis appendix for the Performance Assessment Document

2 Interim deliverable - Issue Kd experiments results

3. Interim deliverable - Complete Geochemical Model

4. Interim deliverable - Complete conceptual designs for liner alternatives

5. Addressing the comments from the independent review of the Final Alternatives Analysis.

6. Activities supporting final vault design required for intermediate LFRG review of the construction hold point.

Milestones (see project schedule for dates)

N/A

Bounding Planning Assumptions (Conditions that bound the scope and associated cost estimate)

A listing of potential liner alternatives was developed in FY-2010, and a down select process was performed at the beginning of FY-2011 to no more than 4 alternatives. These alternatives were evaluated based on a preliminary source term definition and a conceptual design.

The alternatives analysis was based on the approach that the performance of the alternatives could be evaluated using the new hydro-geochemical model.

Resources for the liner alternatives analysis have been defined and agreed upon.

The results of the liner alternatives analysis was placed in a new document separate from the Performance Assessment document; this is based on guidance from the Federal Project Director.

The Liner Alternatives Analysis Report will be updated and finalized after a final design and a final source term definition are available.

\section{Specific Scope Exclusions}

None

Baseline Execution Risk Summary (Describe the primary baseline execution risks identified and how they will be mitigated)

A risk management plan is established and maintained for the project in the Project Management subproject. See risk management plan, PLN-2541. 
LWBS: C.R.60.20.05 Vaults

\section{Scope of Work}

This subproject includes the design and construction of the remote handled low-level waste disposal vaults. The design and construction of the remote handled low-level waste disposal vaults as described in the current project Conceptual Design Report, TFR-483, and SPC-1437. The waste disposal capacity of the facility is described in the Project Execution Plan (DOE/ID-11466).

Control accounts in this subproject include:

C.R.60.20.05.02 Vault Performance (Closed): This control account included criticality shielding analysis, geotechnical testing, and vault performance specifications.

C.R.60.20.05.03 Vault Design: This control account includes the following work scope: vault design; preparing final design report of vaults and Cask Vault Adapting Structure (CVASs); reviews and award of final design; DOE hold point requirements review of the design; hold point for starting of vault construction and CVAS fabrication; and design compliance test plan for vaults and cask systems planned for use at the facility.

C.R.60.20.05.04 Vault Construction: This control account includes the following work scope: first units compliance testing and approval for fabrication; 55-Ton cask system vault construction; NRF Large Concept Cask System Vaults construction; MFC HFEF-5 /ATR Activated Metals Cask System Vaults construction; Modified FTC Vaults construction; and ATR Resin (NuPac 14-210L) Cask System Vaults Construction.

\section{Major Deliverables and Milestones}

\section{Products and Deliverables}

See individual control accounts for discrete products and deliverables.

\section{Milestones}

See individual control accounts for discrete milestones

Bounding Planning Assumptions (Conditions that bound the scope and associated cost estimate)

The basis of the cost estimate and planned schedule comes from average historical costs, recent work performed at the INL, and project management experience. The schedule and cost estimate bound the work scope.

\section{Specific Scope Exclusions}

General project management, document support, infrastructure design/testing/construction, excavation for vaults, and transportation cask design/testing/construction

Baseline Execution Risk Summary (Describe the primary baseline execution risks identified and how they will be mitigated) See Risk Management Plan (PLN-2541). 
LWBS: C.R.60.20.05.03 Vault Design

\section{Scope of Work}

This control account covers final design of the concrete vault system including the cask vault adapting system (CVAS). The vault design and the design compliance test plan will be based on the requirements from the current project Conceptual Design Report, TFR-483, and SPC-1437. The waste disposal capacity of the facility will be as described in the Project Execution Plan (DOE/ID-11466). The vault design review is for BEA to make sure that the design-build contractor understands the design and what is expected. A final design review report will insure that the final design is compliant with INL requirements. The design compliance test plan will be developed to ensure that, during fabrication of the vaults, the vaults are built according to the required design. Packages include the following:

C.R.60.20.05.03.01 Vault Design: This work package includes the following work scope: kickoff meeting with the design-build subcontractor; design of the vault and CVAS with a 90\% design review; completion of final design for the vaults and CVAS's; and updating engineering calculation and analysis reports (ECARS) for shielding and dose.

C.R.60.20.05.03.02 Final Design Report: This work package includes the following work scope: final design review and comment resolution (vaults/CVASs); issuance of the final design report with a DOE hold point for requirements review; hold point for the vault construction/CVAS fabrication (for Safety Evaluation Report (SER) and LFRG review); and awarding the DB subcontractor incentive fee for the design.

C.R.60.20.05.03.03 Design Compliance Test Plan: This work package includes the following work scope: developing compliance testing criteria for vaults; develop plans to test the first units; and review and comment incorporation of vault test plans.

Major Deliverables and Milestones

Products and Deliverables

Vault design review, final design review report, and a design compliance test plan.

Milestones

RHVCHP -HOLD POINT - Vault Construction/CVAS Fabrication

Bounding Planning Assumptions (Conditions that bound the scope and associated cost estimate)

The basis of the cost estimate and planned schedule comes from historical costs, recent work performed at the INL, and project management experience. The schedule and cost estimate bound work scope. Also, the first unit compliance tests for each of the different vault types are assumed to be successful on the first attempt.

\section{Specific Scope Exclusions}

Infrastructure design/testing

Baseline Execution Risk Summary (Describe the primary baseline execution risks identified and how they will be mitigated) 


\section{LWBS: C.R.60.20.05.04 Vault Construction}

\section{Scope of Work}

This control account involves construction of the vault system. The vault construction and first units compliance testing will be based on the requirements from the current project Conceptual Design Report, TFR-483, and SPC-1437. The waste disposal capacity of the facility will be as described in the Project Execution Plan (DOE/ID-11466). The first unit compliance testing will prove the design of each vault system and develop a fabrication strategy to ensure that the remaining vaults are properly constructed. The various vault construction work packages for the various vault designs will fabricate, deliver, and install the vaults. A design authority mentor experienced with design-build projects will assist the design authority during vault construction.

Planning packages include:

C.R.60.20.05.04.01 PP- First Units Compliance tests: This planning package consists of the following work scope: testing of the $1^{\text {st }}$ vault systems (NRF Large Concept cask, NRF 55-Ton Scrap cask, MFC HFEF-5/ ATR Activated Metals cask, ATR resin (NuPac 14-210L) cask, and Modified FTC); review and approval of test results for each of the cask system vaults.

C.R.60.20.05.04.02 PP- 55-ton Cask System Vaults Construction: (includes both the NRF 55-Ton Scrap and the NRF Large Concept cask system vaults). This planning package consists of the following work scope: developing fabrication drawings for each of the identified systems; review and approval of the fabrication drawings; fabrication of the cask system vaults and cask vault adapting system (CVAS); shipping of cask system vaults; installation and backfill of vault systems; and design authority support during installation.

C.R.60.20.05.04.03 PP -MFC/ATR Activated Metals Cask System Vaults Construction: (includes both MFC HFEF-5, Modified FTC, and ATR HFEF-5 cask system vaults). This planning package consists of the following work scope: developing fabrication drawings for each of the identified vault systems; review and approval of the fabrication drawings; fabrication of the cask system vaults and cask vault adapting system (CVAS); shipping of cask system vaults; installation and backfill of vault systems; and design authority support during installation.

C.R.60.20.05.04.04 PP -ATR Resin Cask System Vaults Construction: includes ATR Resin (NuPac 14-210L) Cask System Vault). This planning package consists of the following work scope: developing fabrication drawings for the identified vault system; review and approval of the fabrication drawings; fabrication of the cask system vaults and cask vault adapting system (CVAS); shipping of cask system vaults; installation and backfill of vault systems; and design authority support during installation.

\section{Major Deliverables and Milestones}

Products and Deliverables

Testing each vault system design and 3 different vault arrays that will hold the required waste from various INL sites.

Milestones

RH2960 -BEA Approve Vault Fabrication Drawings (ATR Resin)

RH2920 -BEA Approve Vault Fabrication Drawings (HFEF-5)

RHA173 -BEA Approve Vault Fabrication Drawings (Modified FTC)

RH2750 -BEA Approve Vault Fabrication Drawings (NRF 55-Ton)

RHA143 -BEA Approve Vault Fabrication Drawings (NRF Large Concept)

RH2670 -BEA Approve Fabrication for Remaining Vaults (NRF 55-Ton)

RH2700 -BEA Approve Fabrication for Remaining Vaults (HFEF-5)

RH2730 -BEA Approve Fabrication for Remaining Vaults (ATR Resin)

RHA152 -BEA Approve Fabrication for Remaining Vaults (NRF Large Concept)

RHA162 -BEA Approve Fabrication for Remaining Vaults (Modified FTC)

RH5830 -Vault Installation Complete

\section{Bounding Planning Assumptions (Conditions that bound the scope and associated cost estimate)}

The basis of the cost estimate and planned schedule comes from historical costs, recent work performed at the INL, and project management experience. The schedule and cost estimate bound the work scope.

\section{Specific Scope Exclusions}


RH LLW Disposal Project

Baseline Execution Risk Summary (Describe the primary baseline execution risks identified and how they will be mitigated) See Risk Management Plan (PLN-2541) 
Appendix D

Schedule 



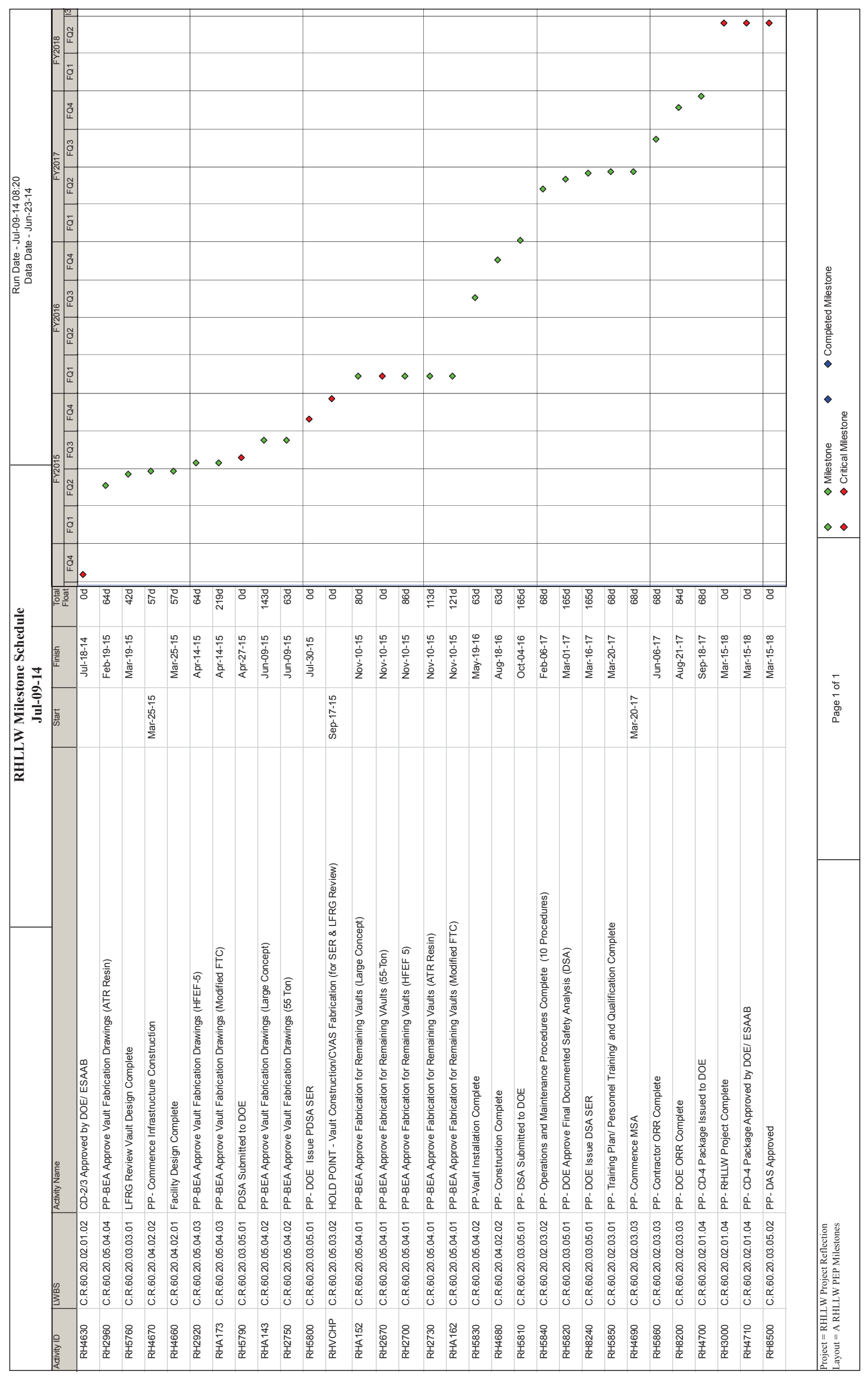




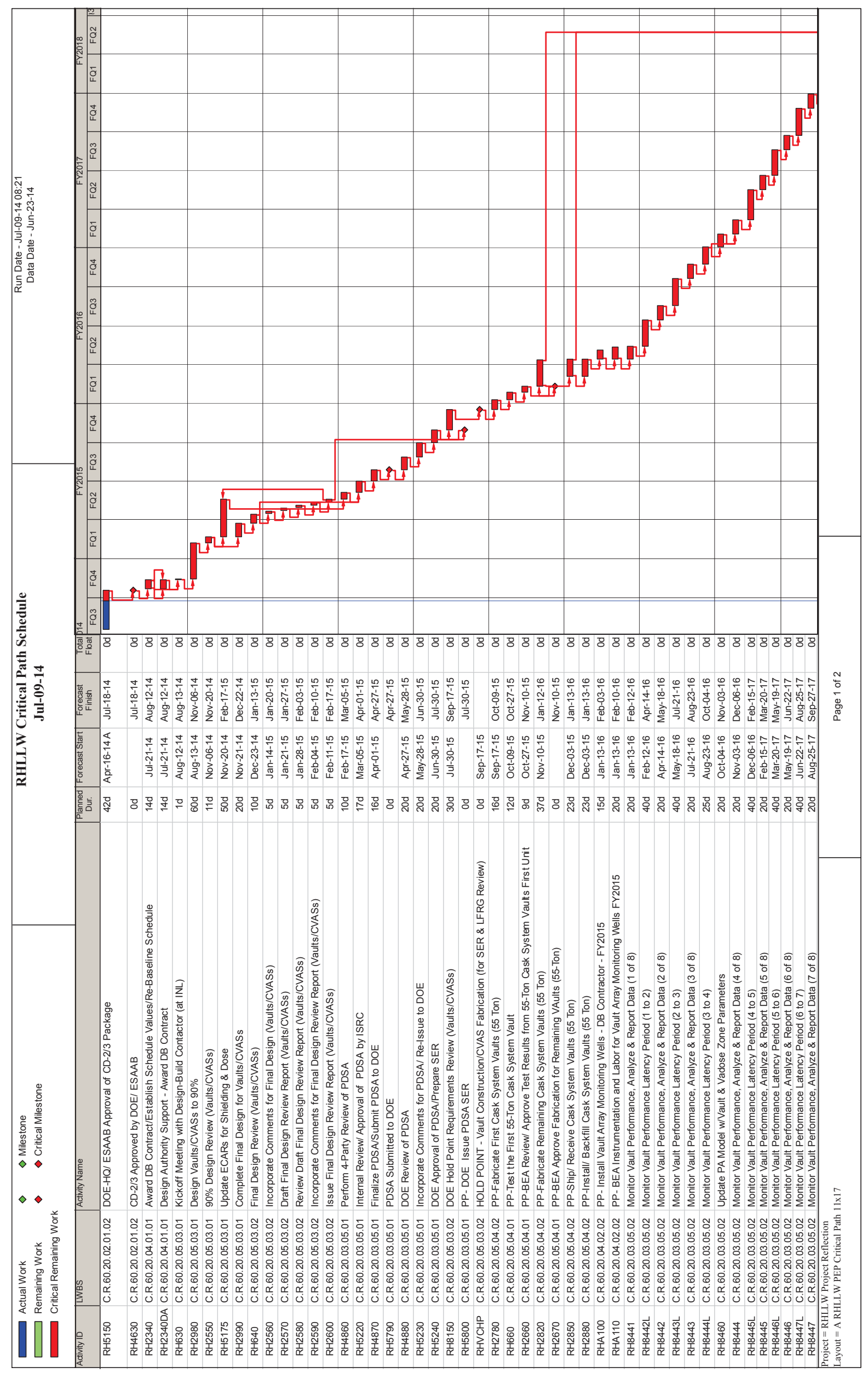




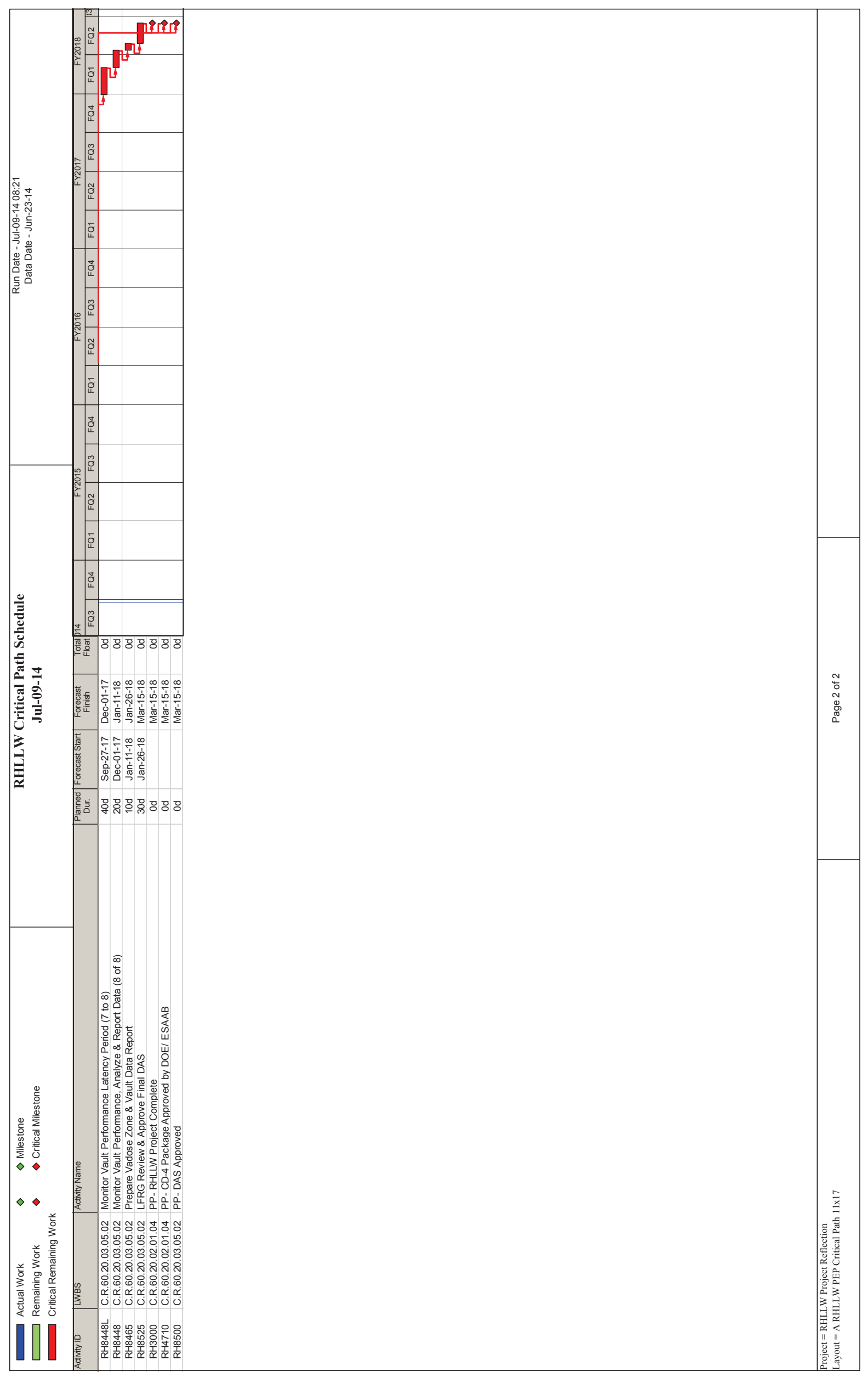




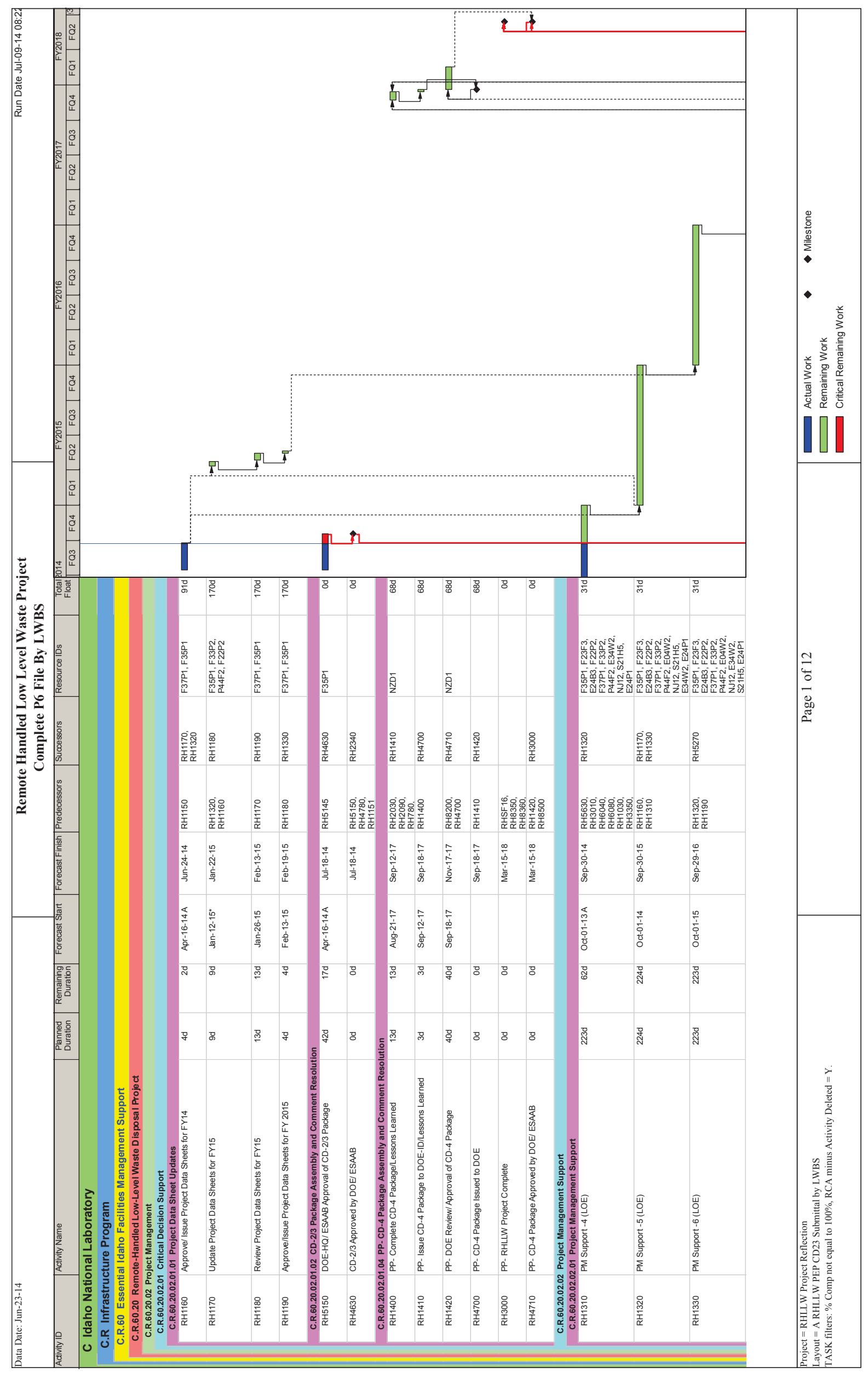




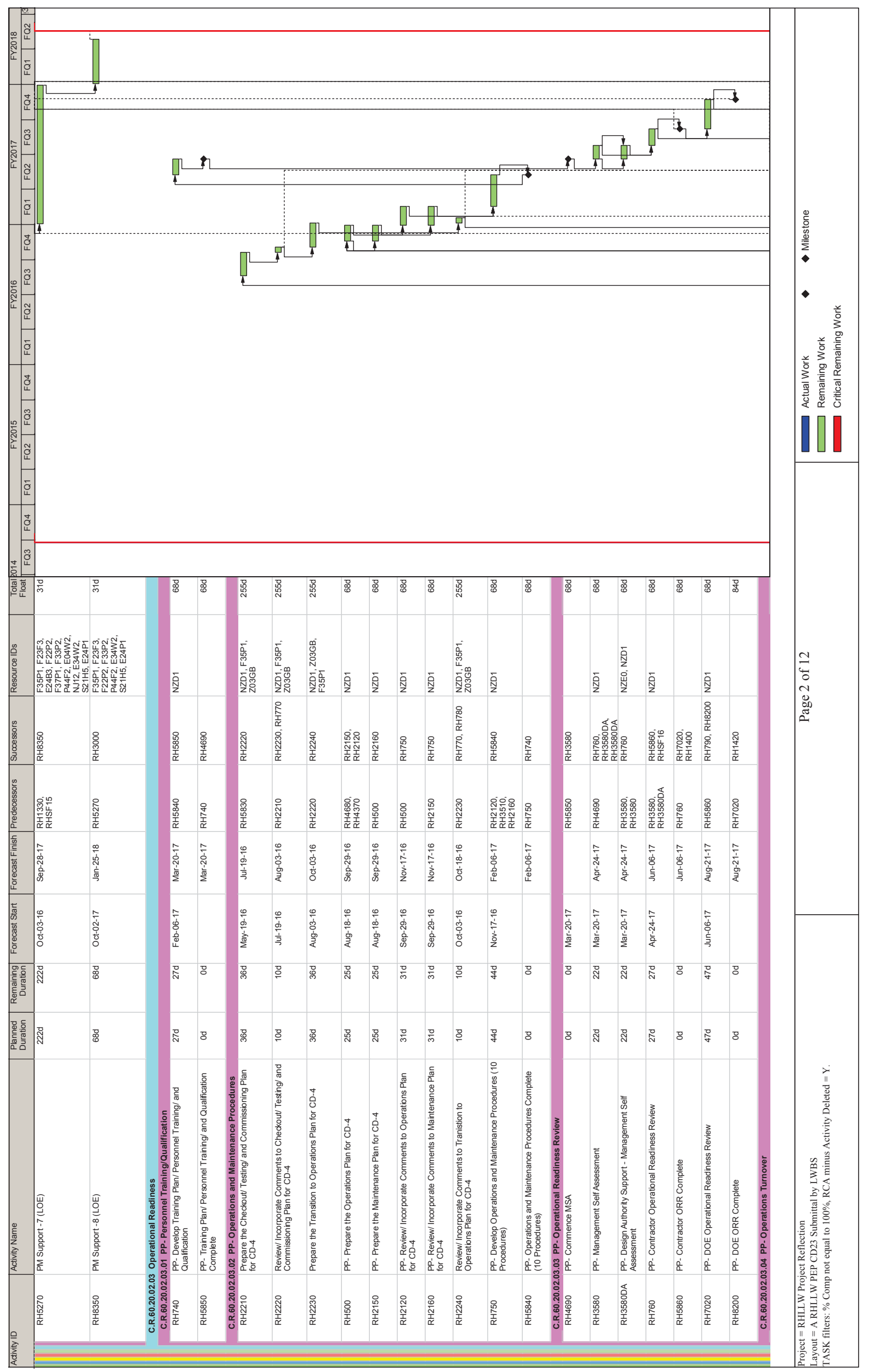




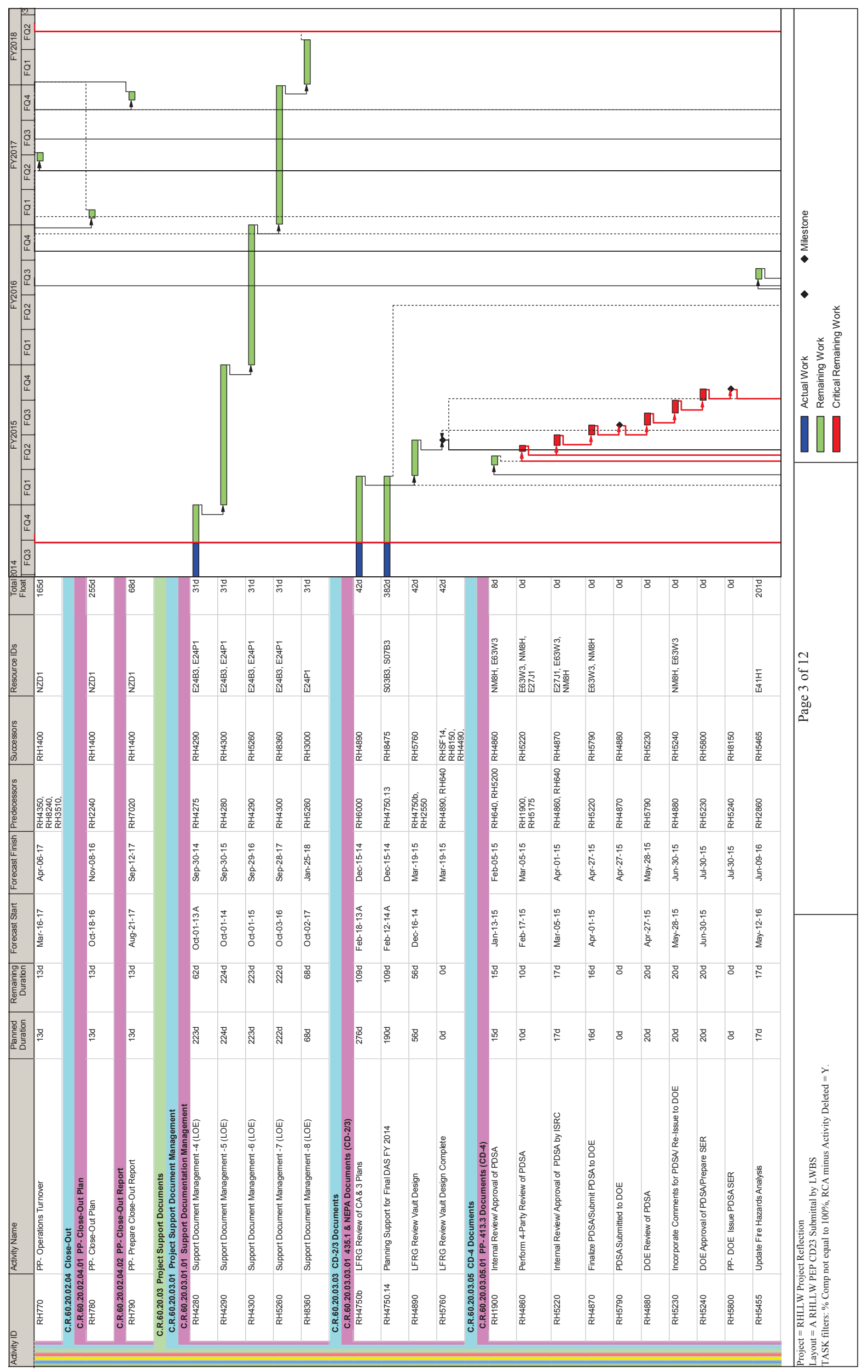




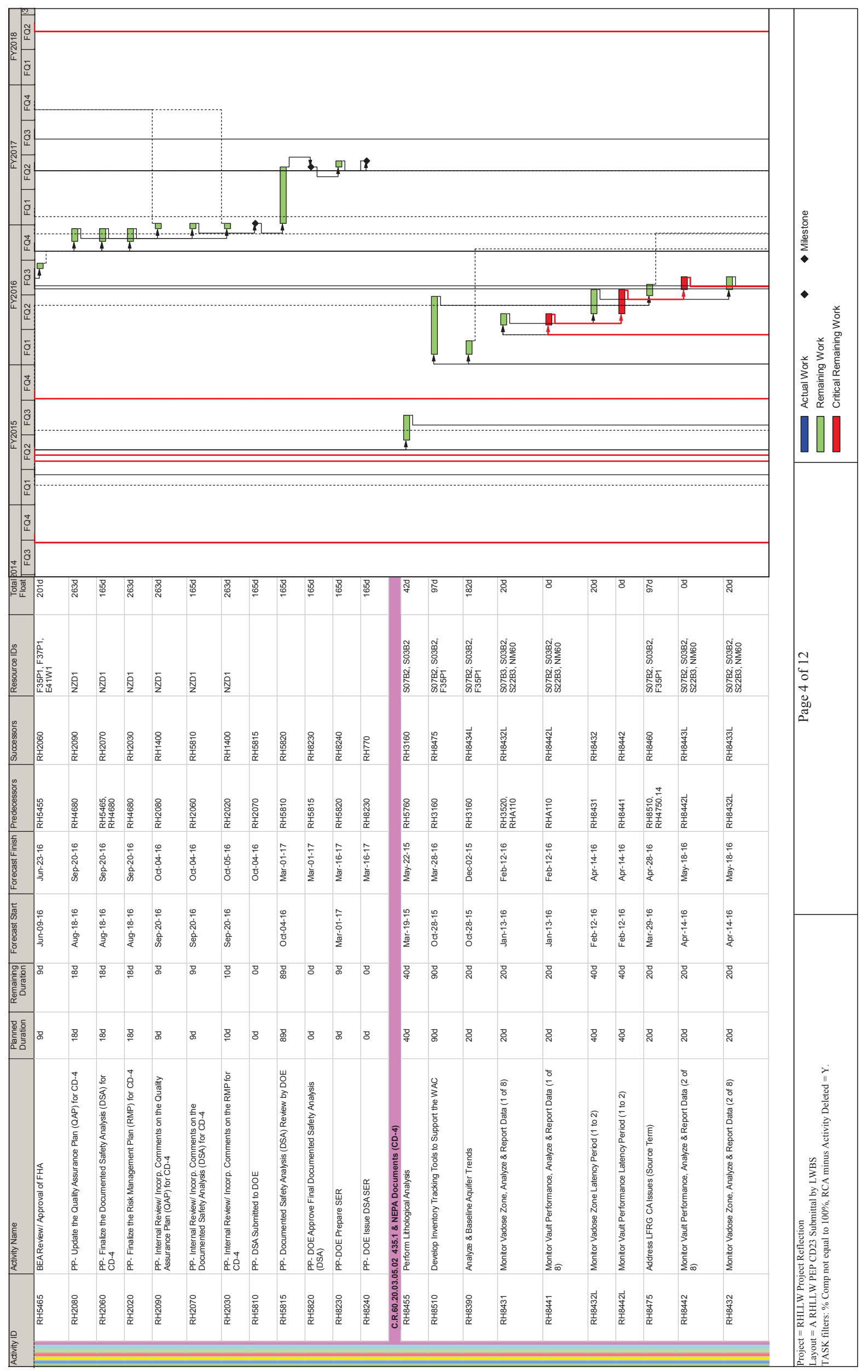




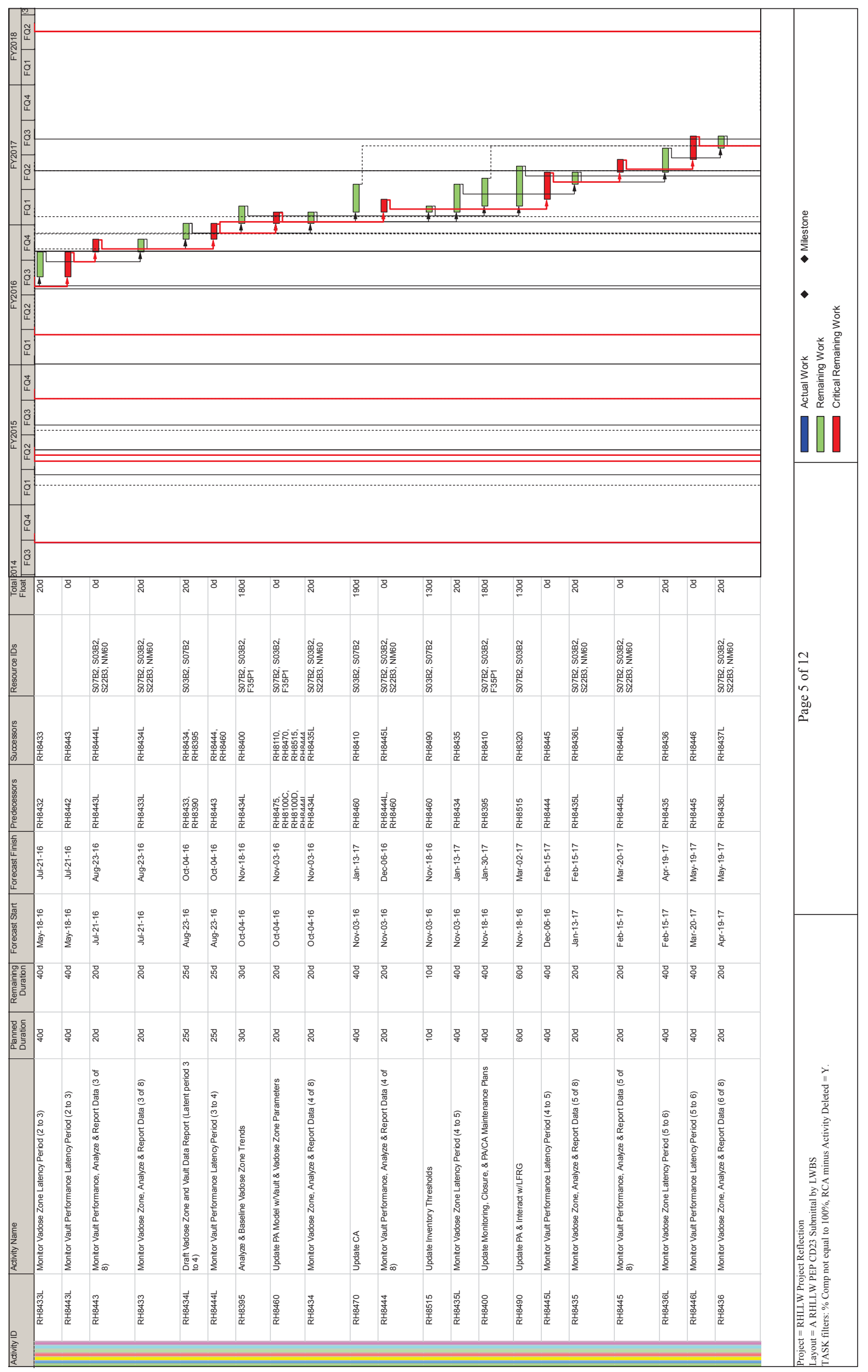




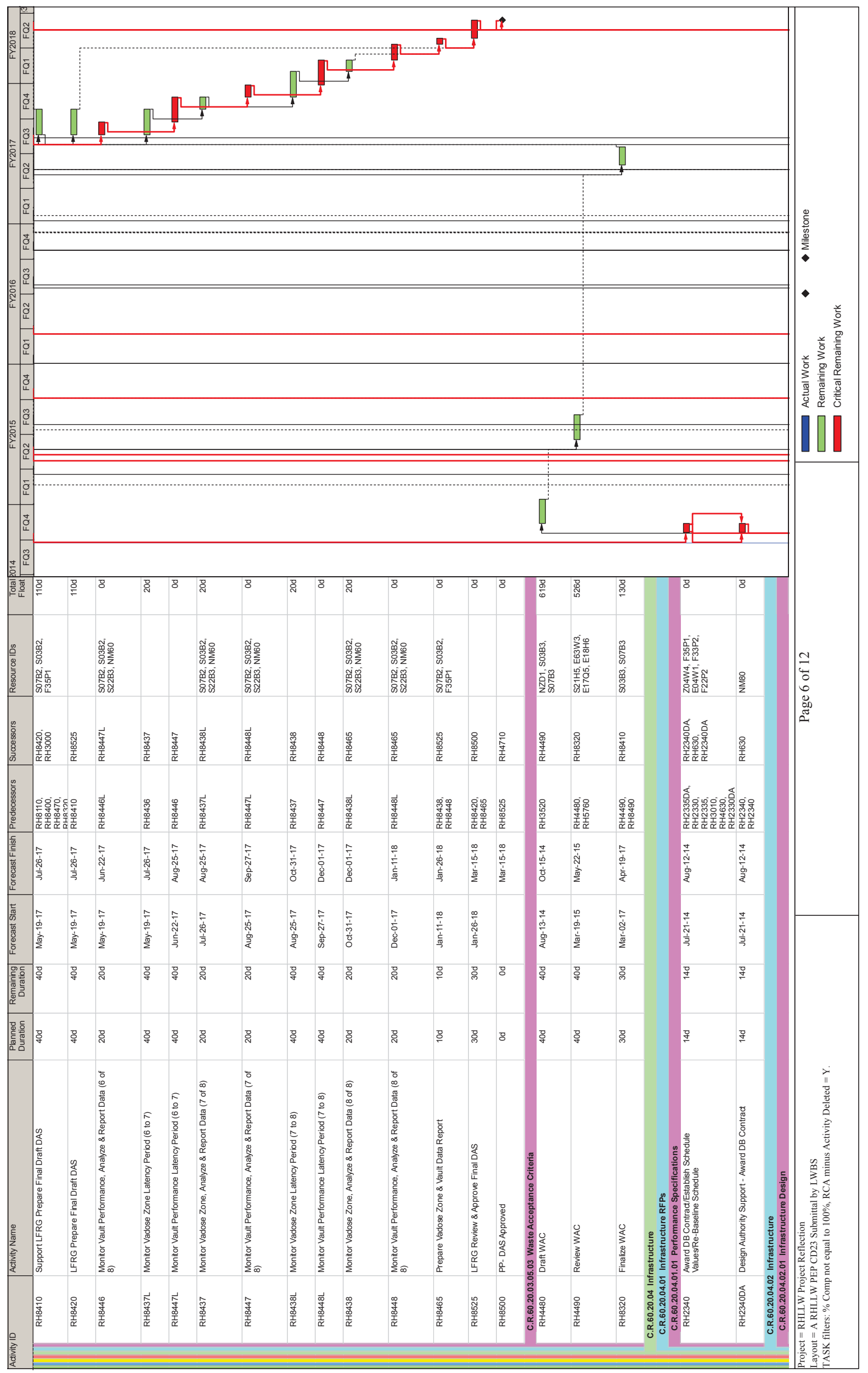




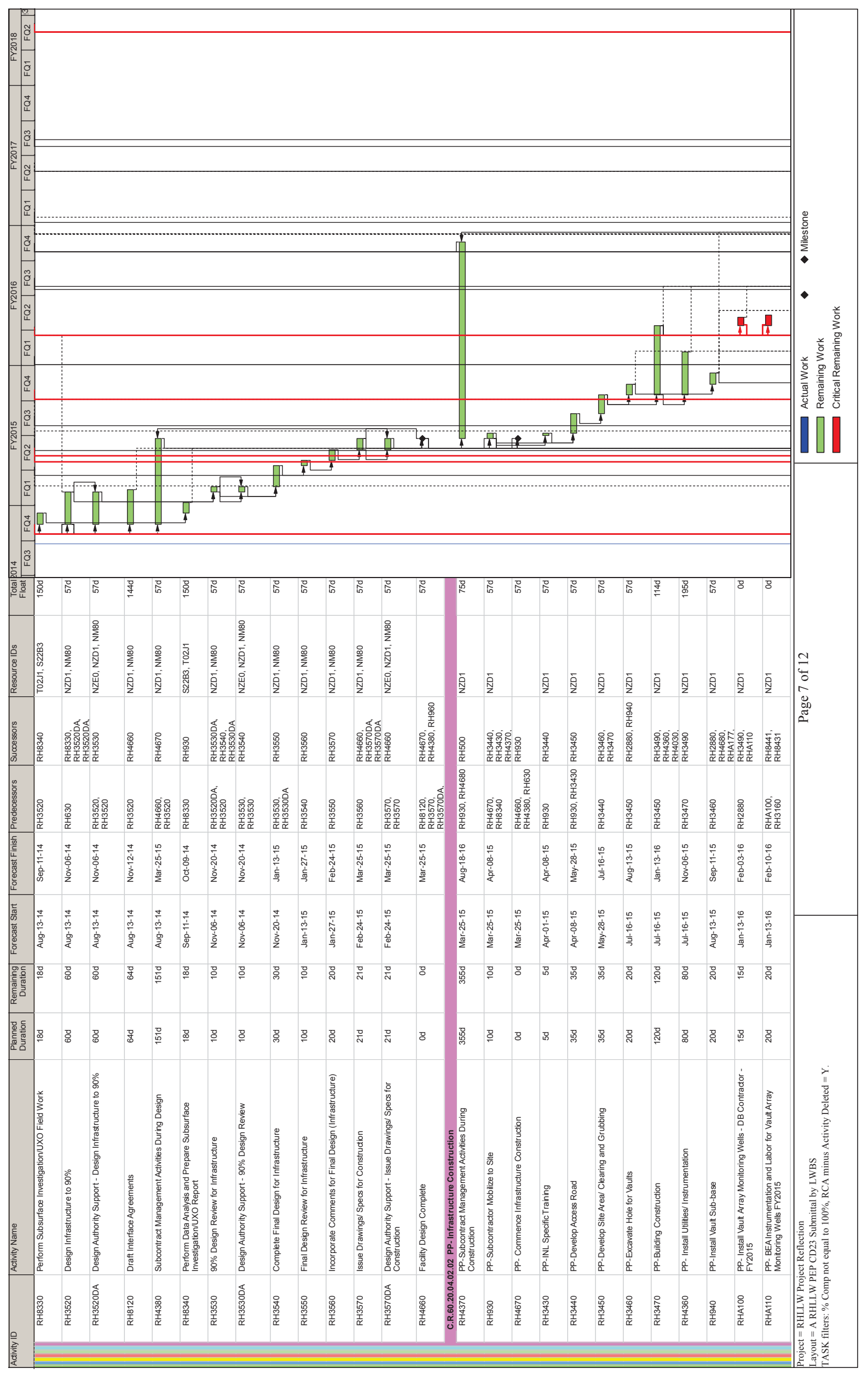




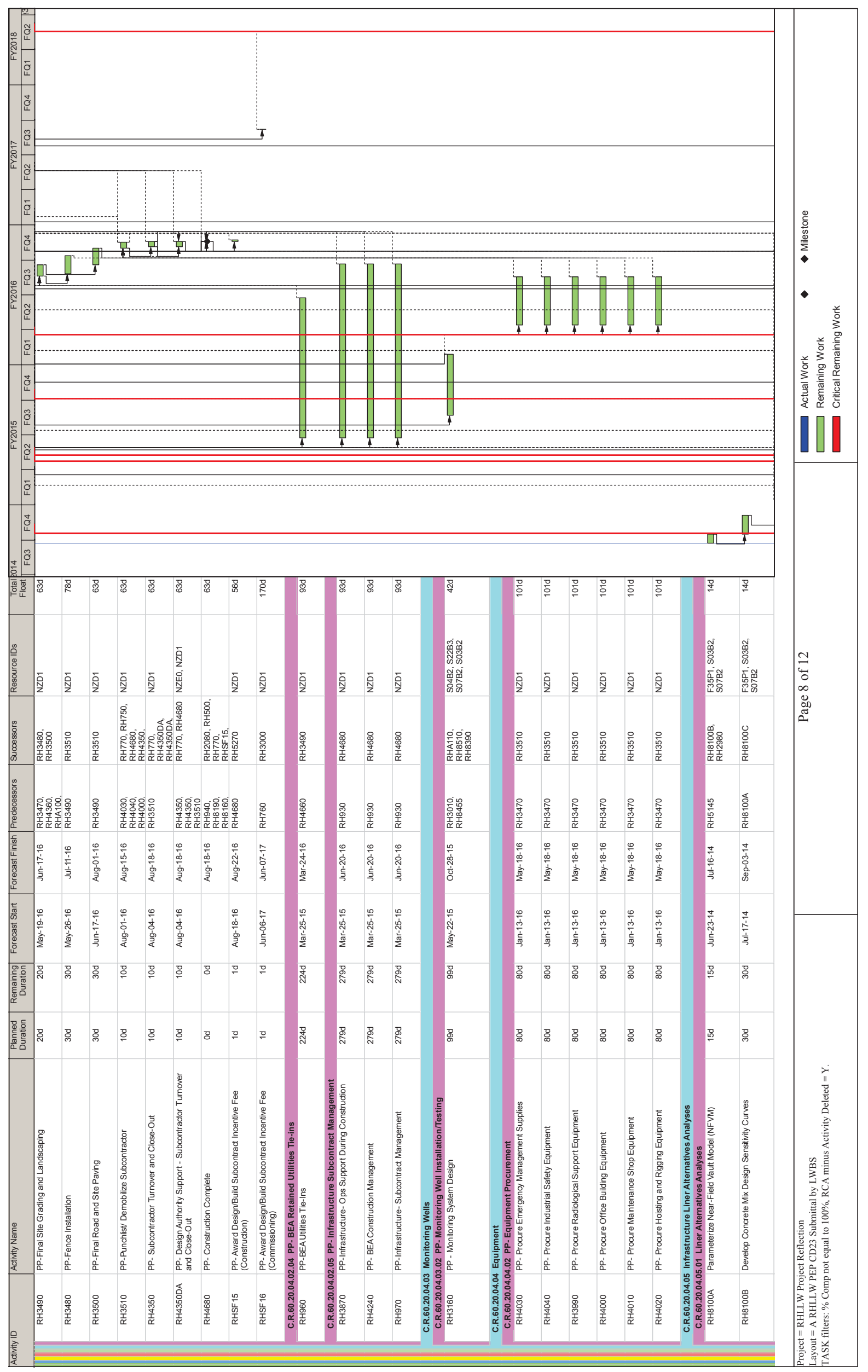




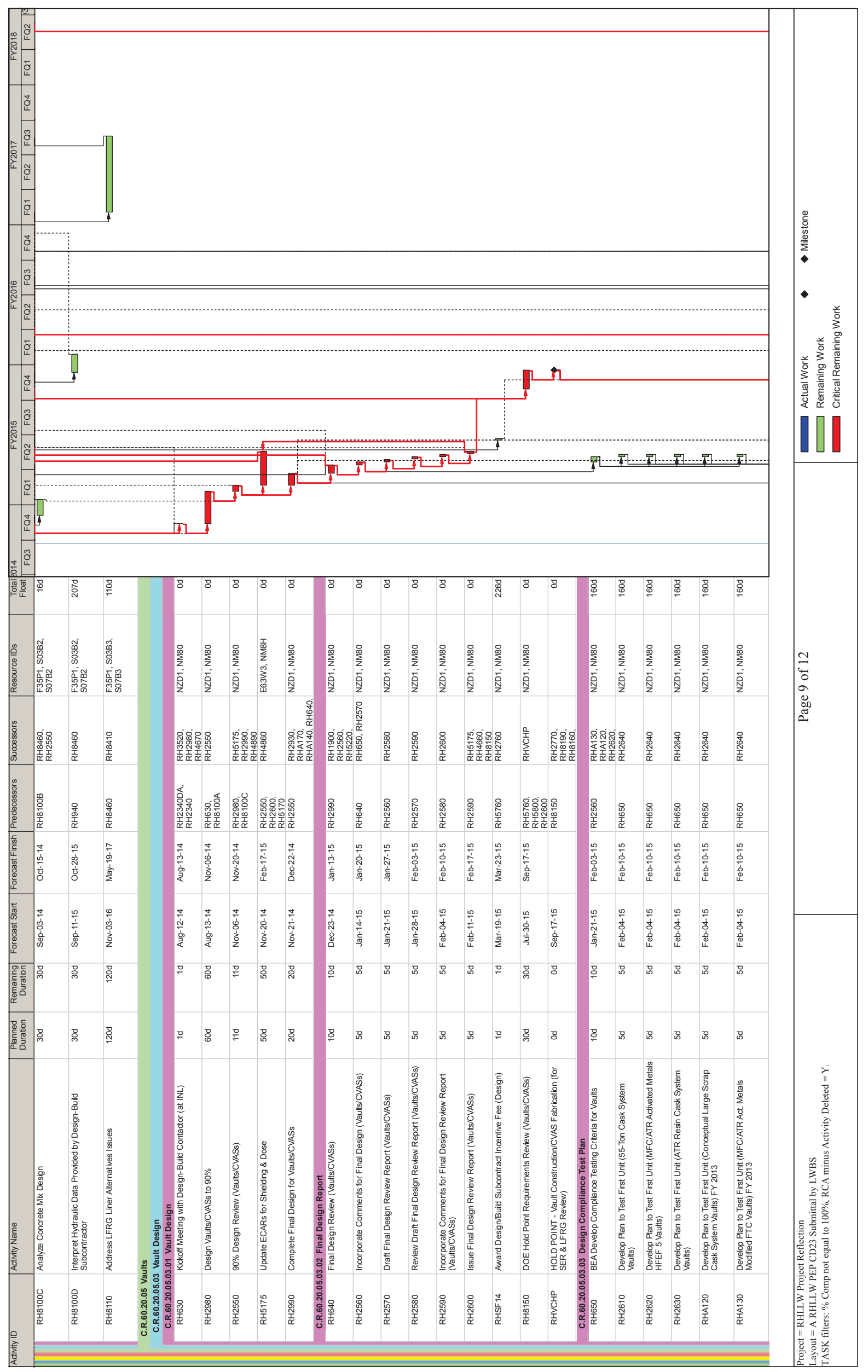




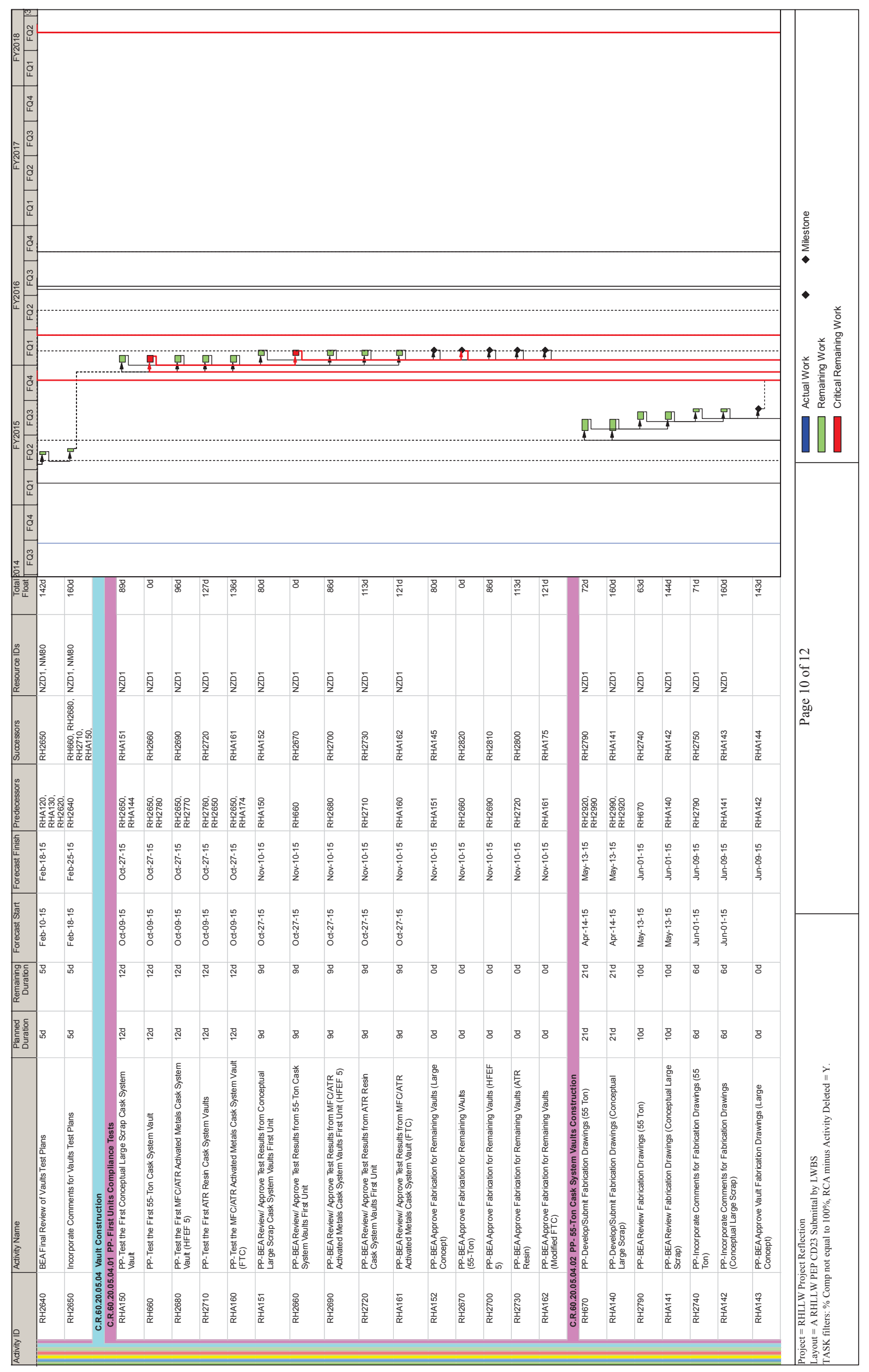




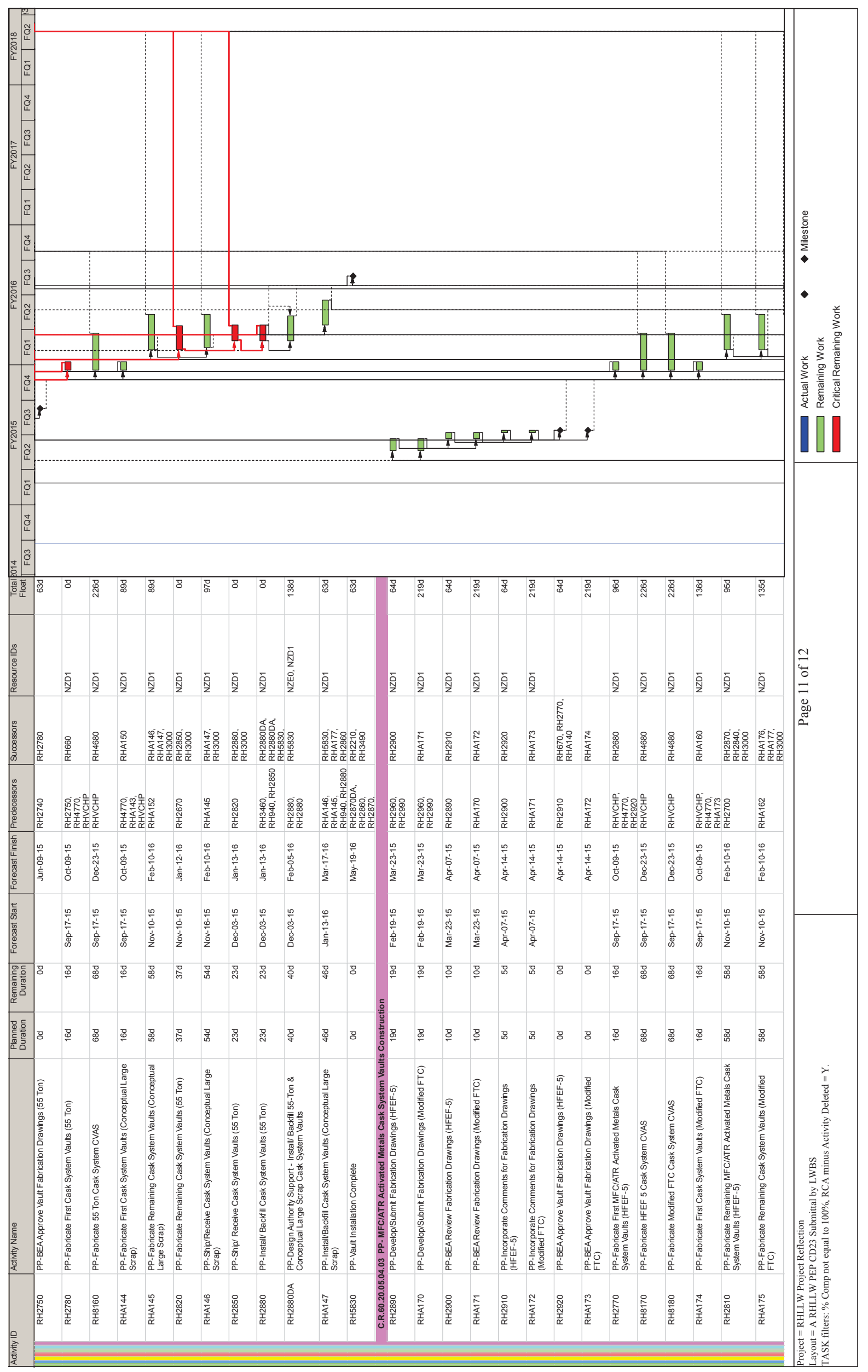




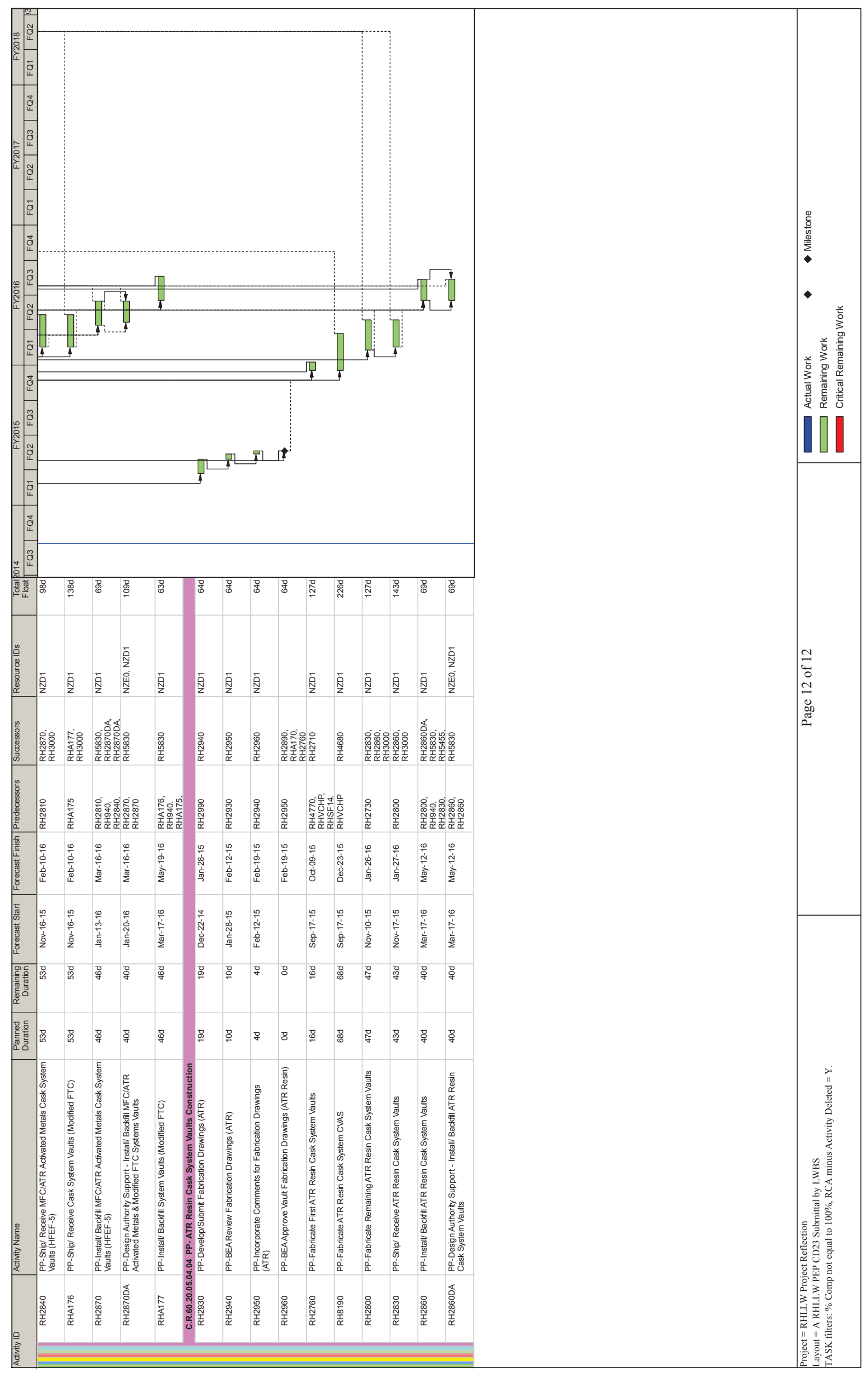




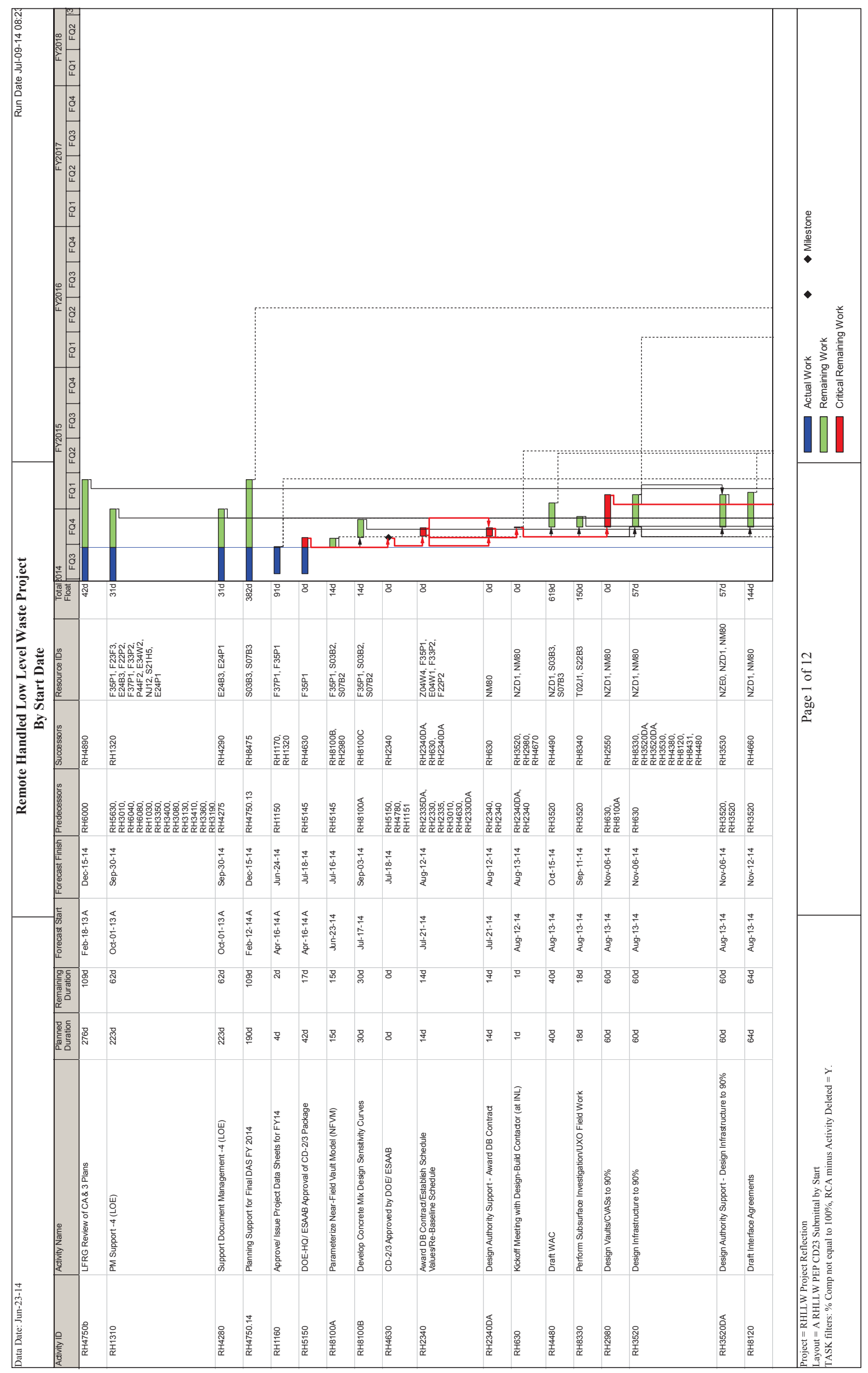




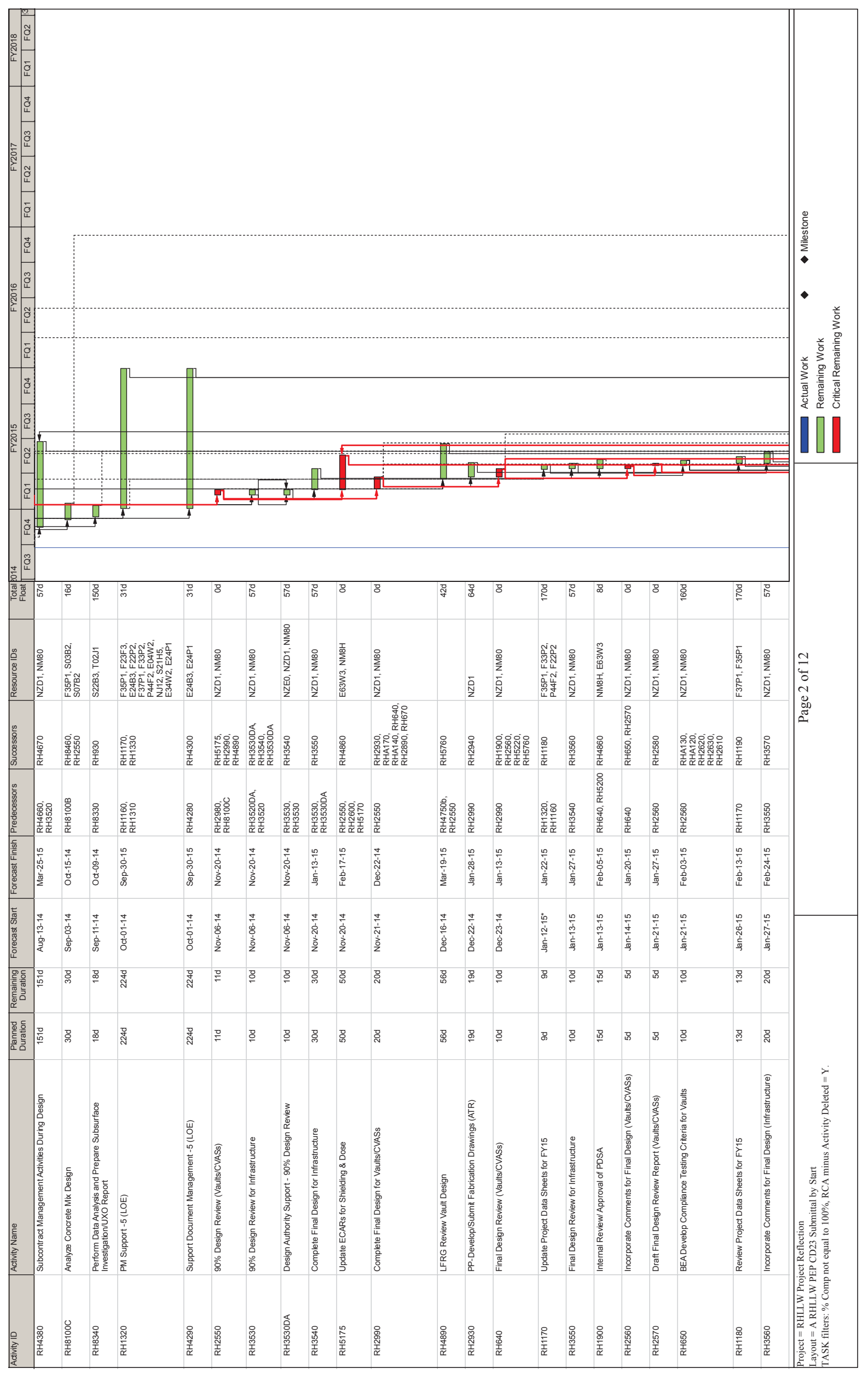




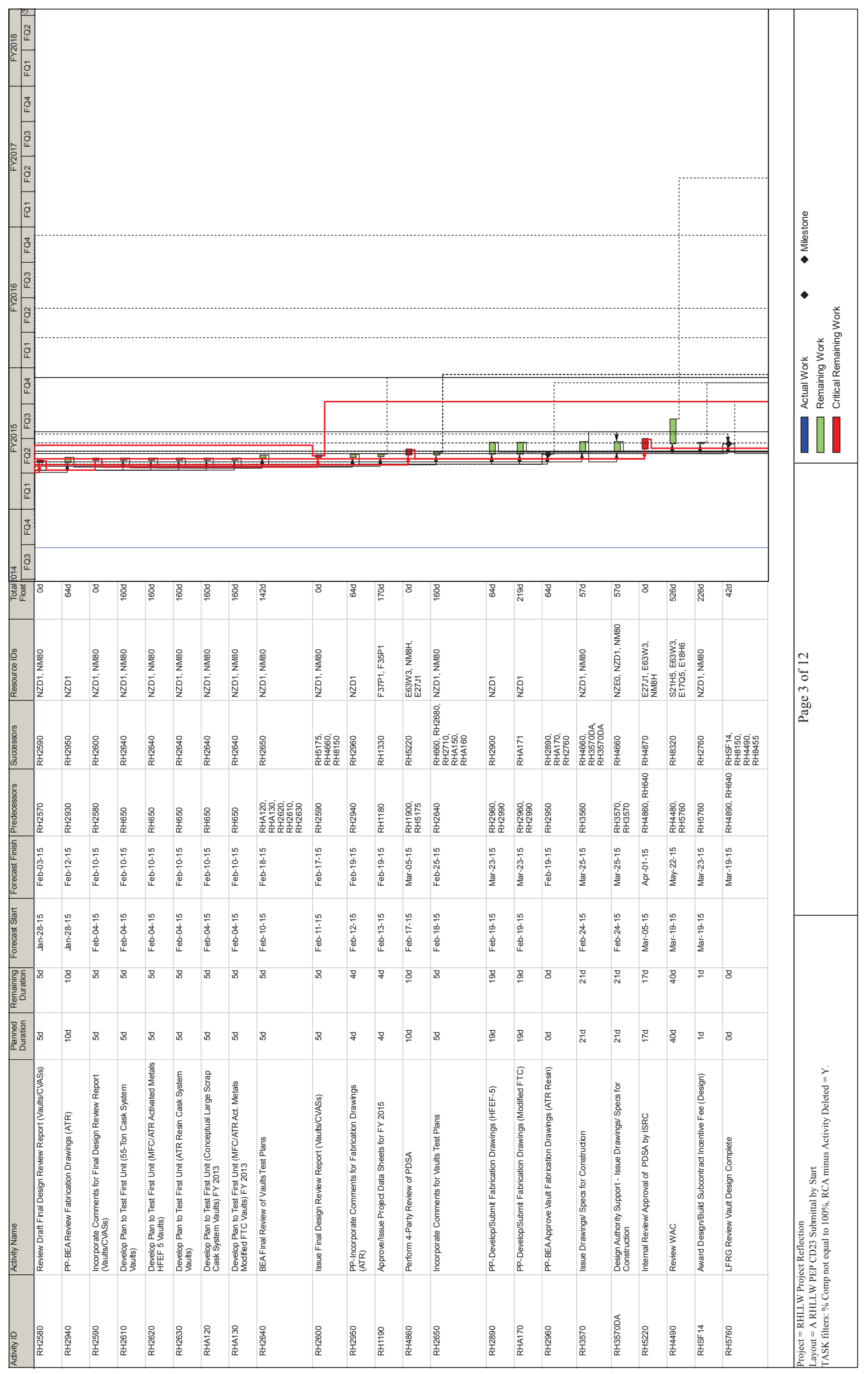




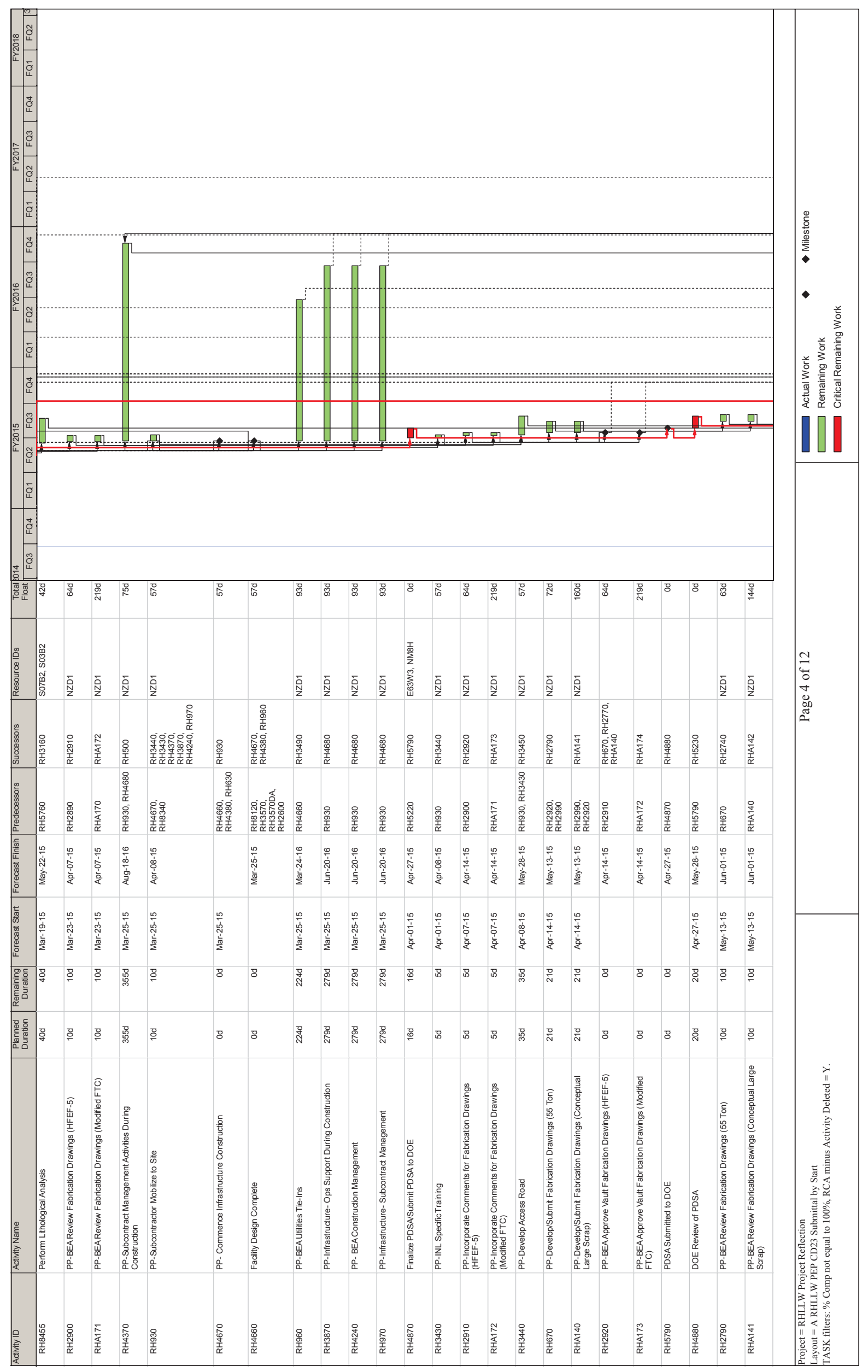




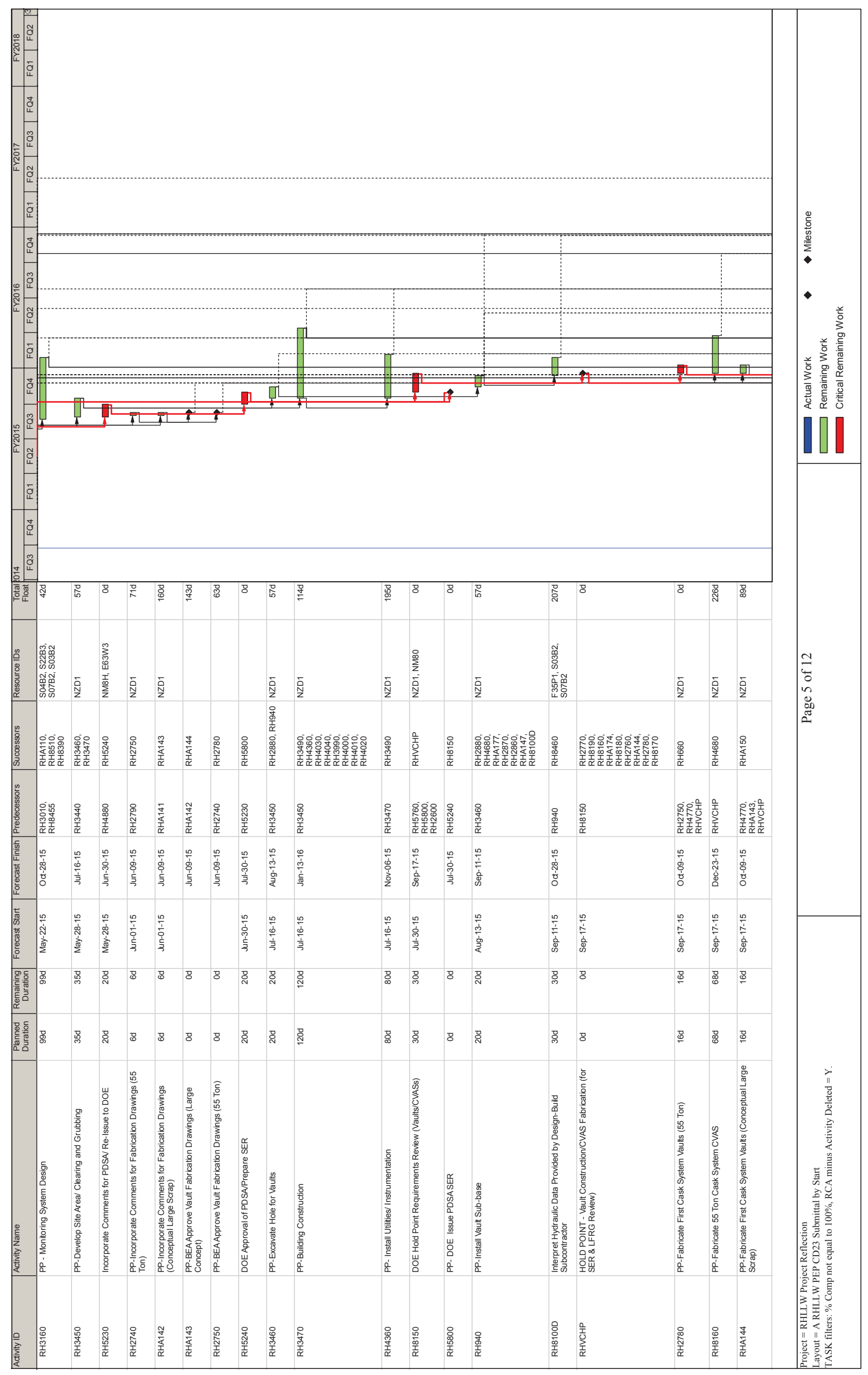




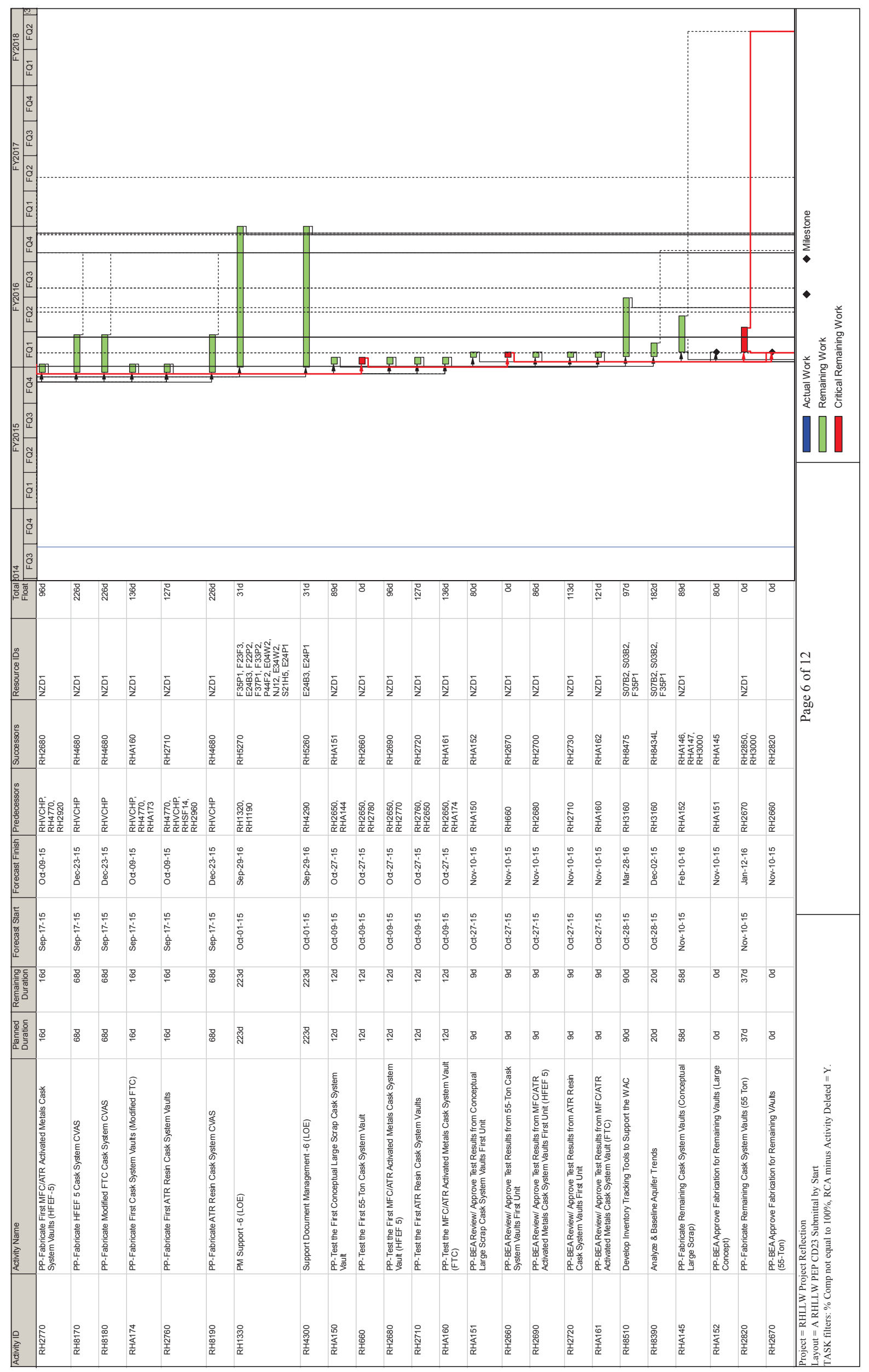




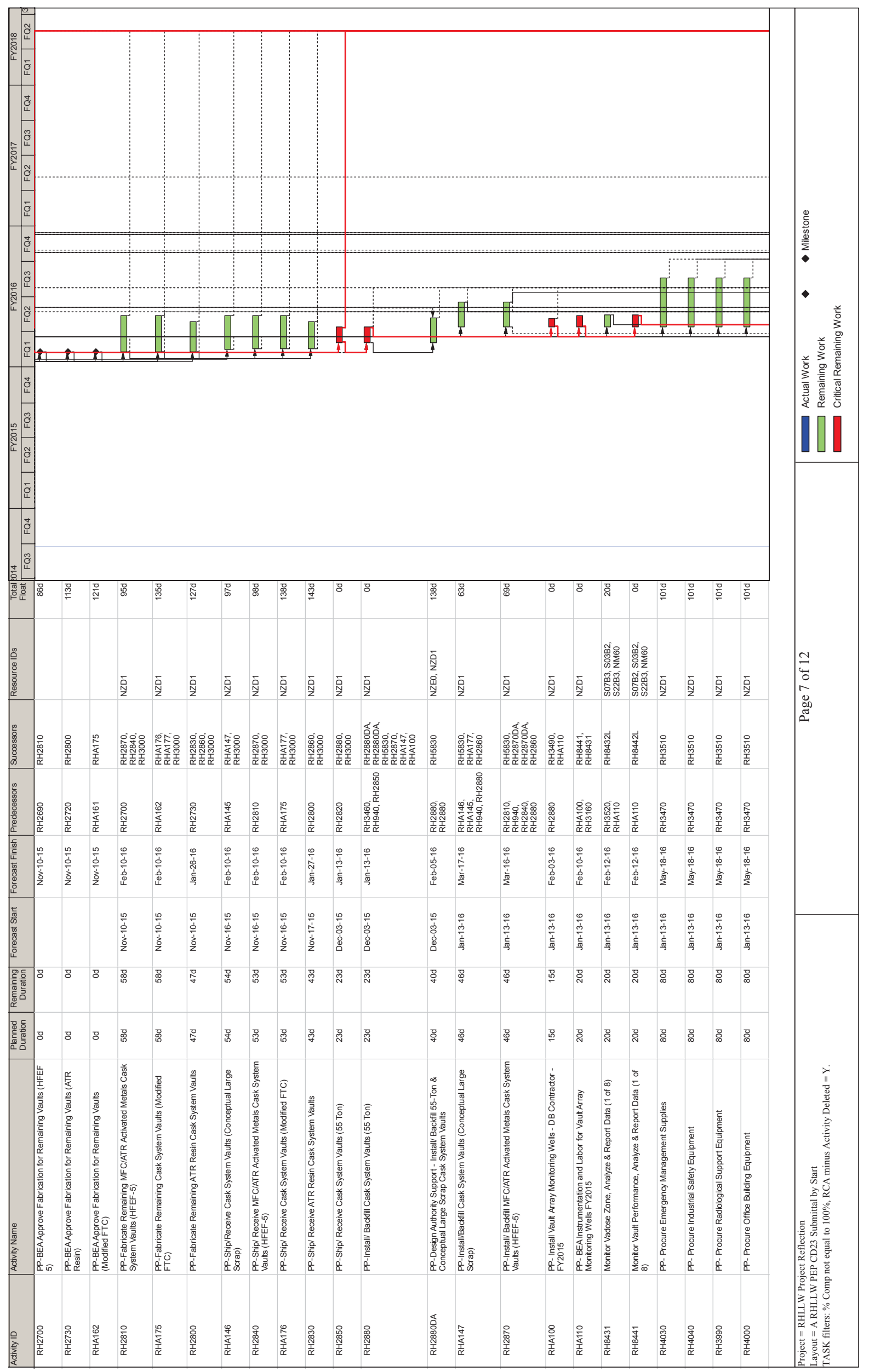




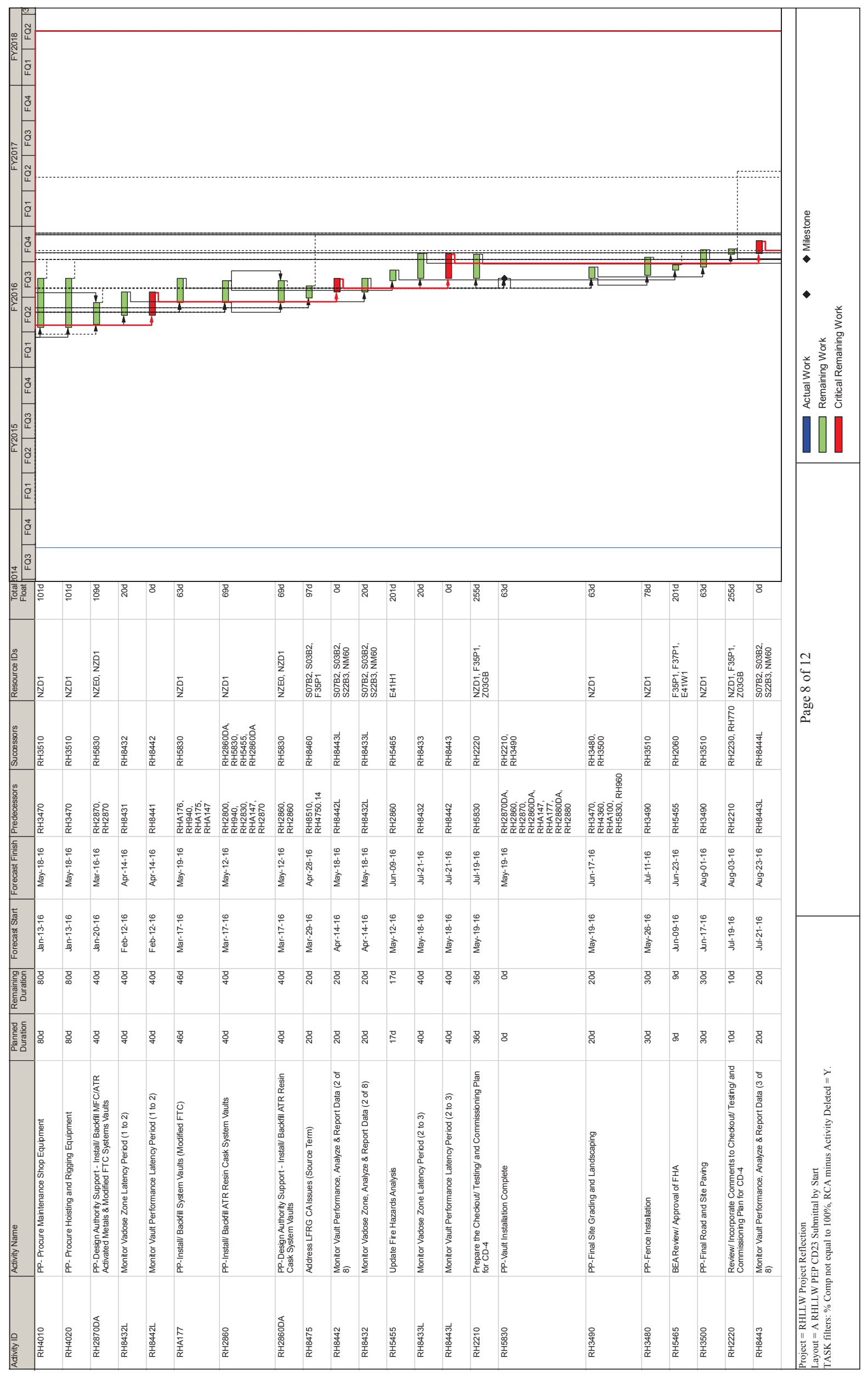




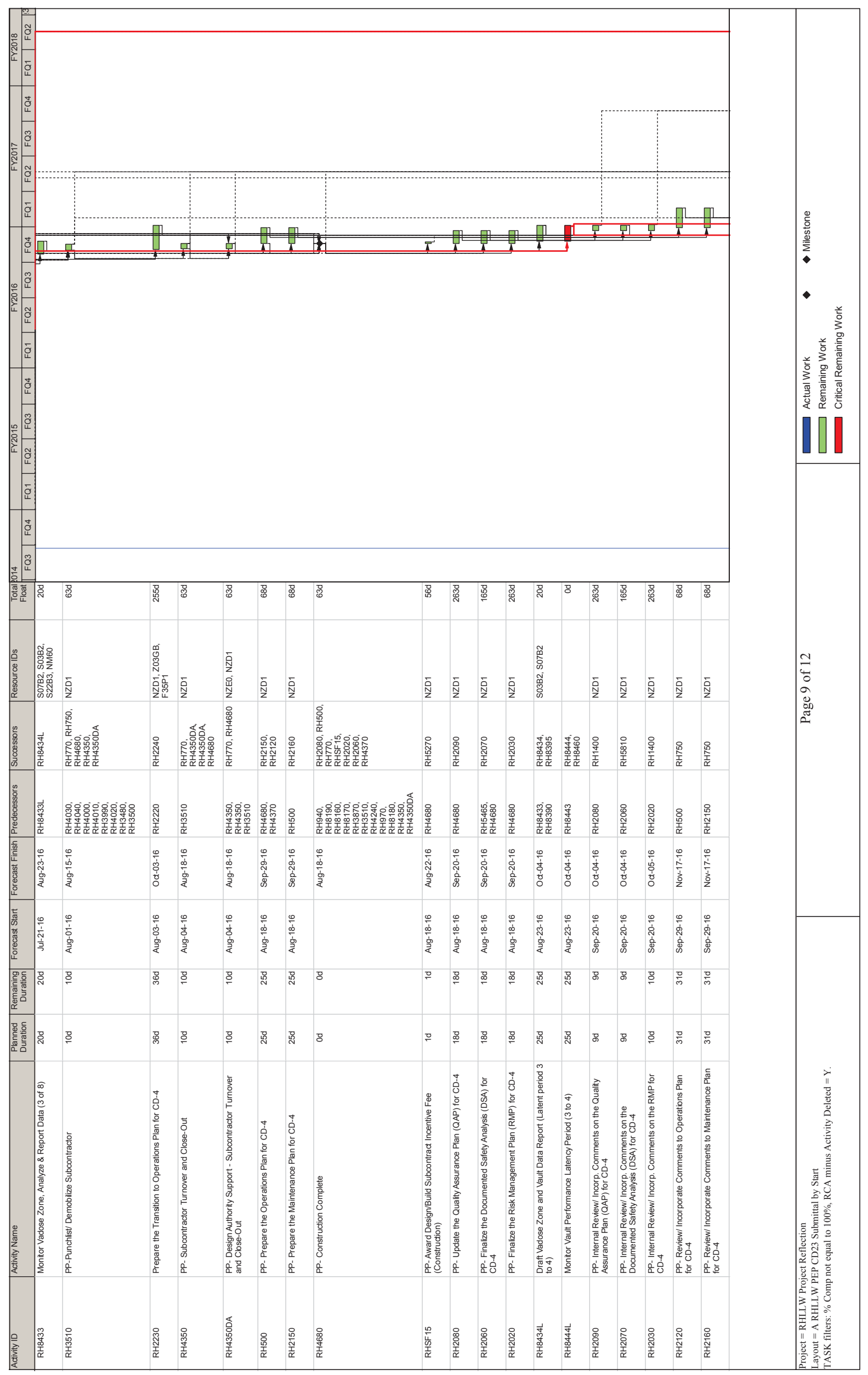




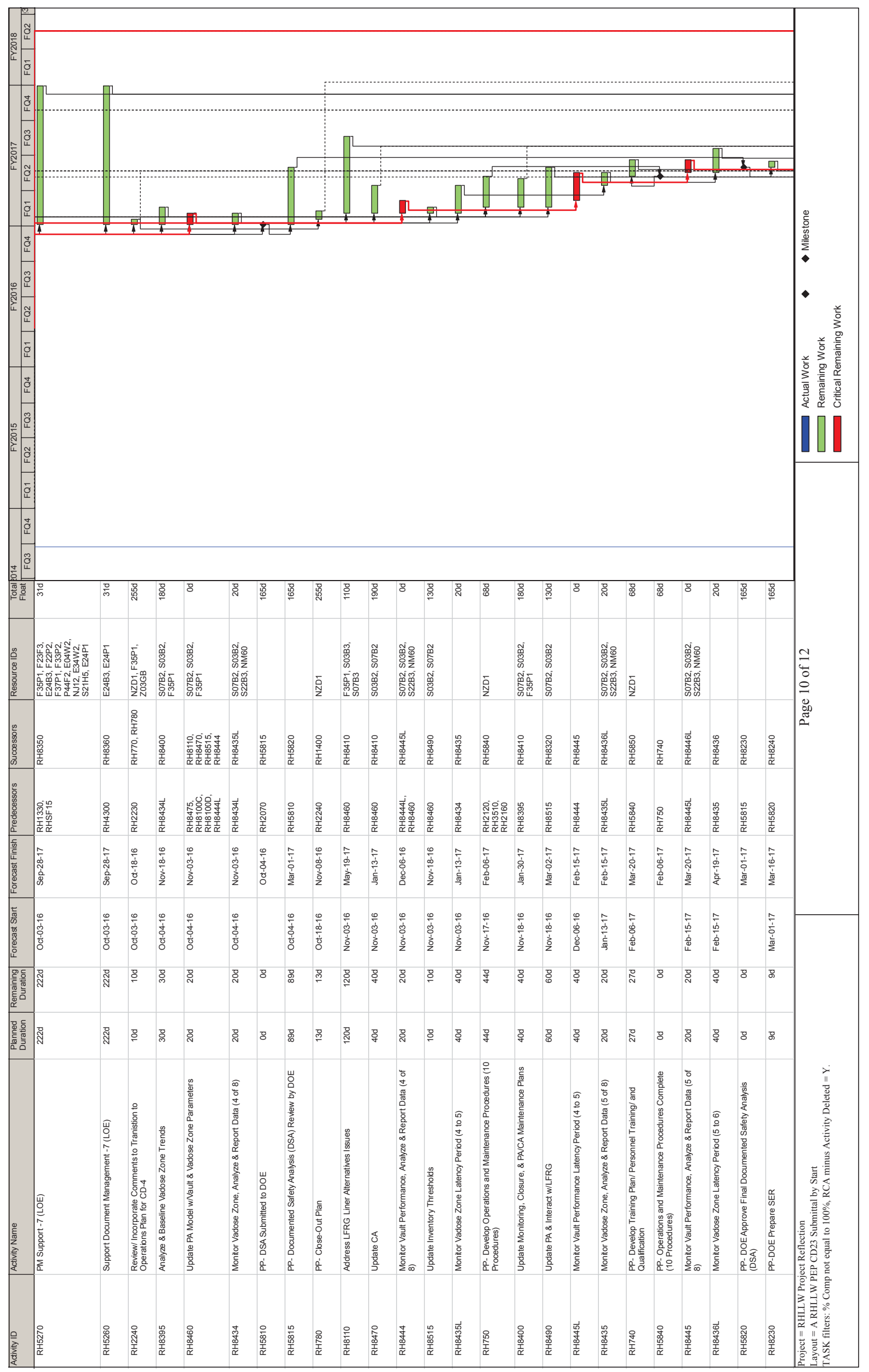




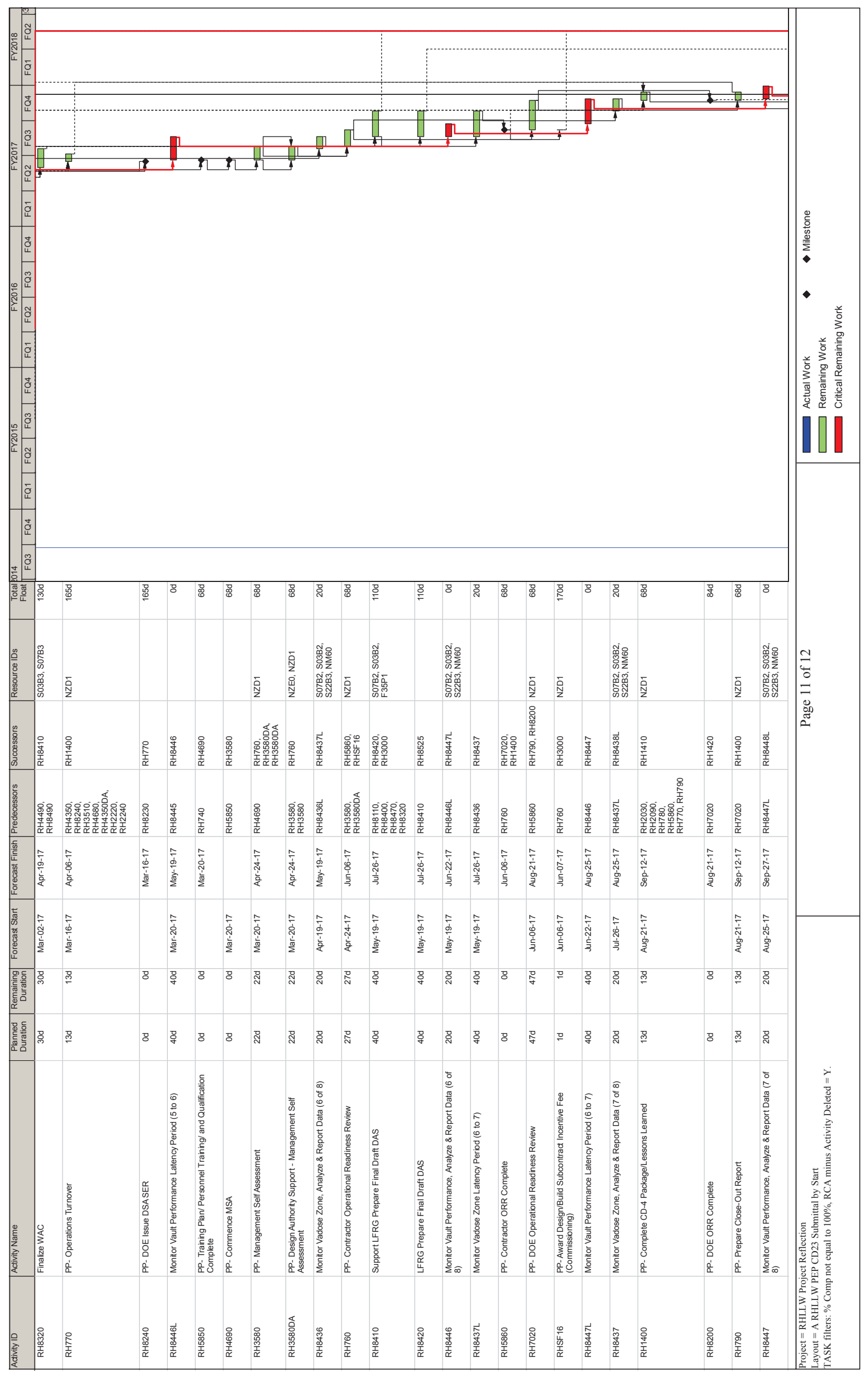




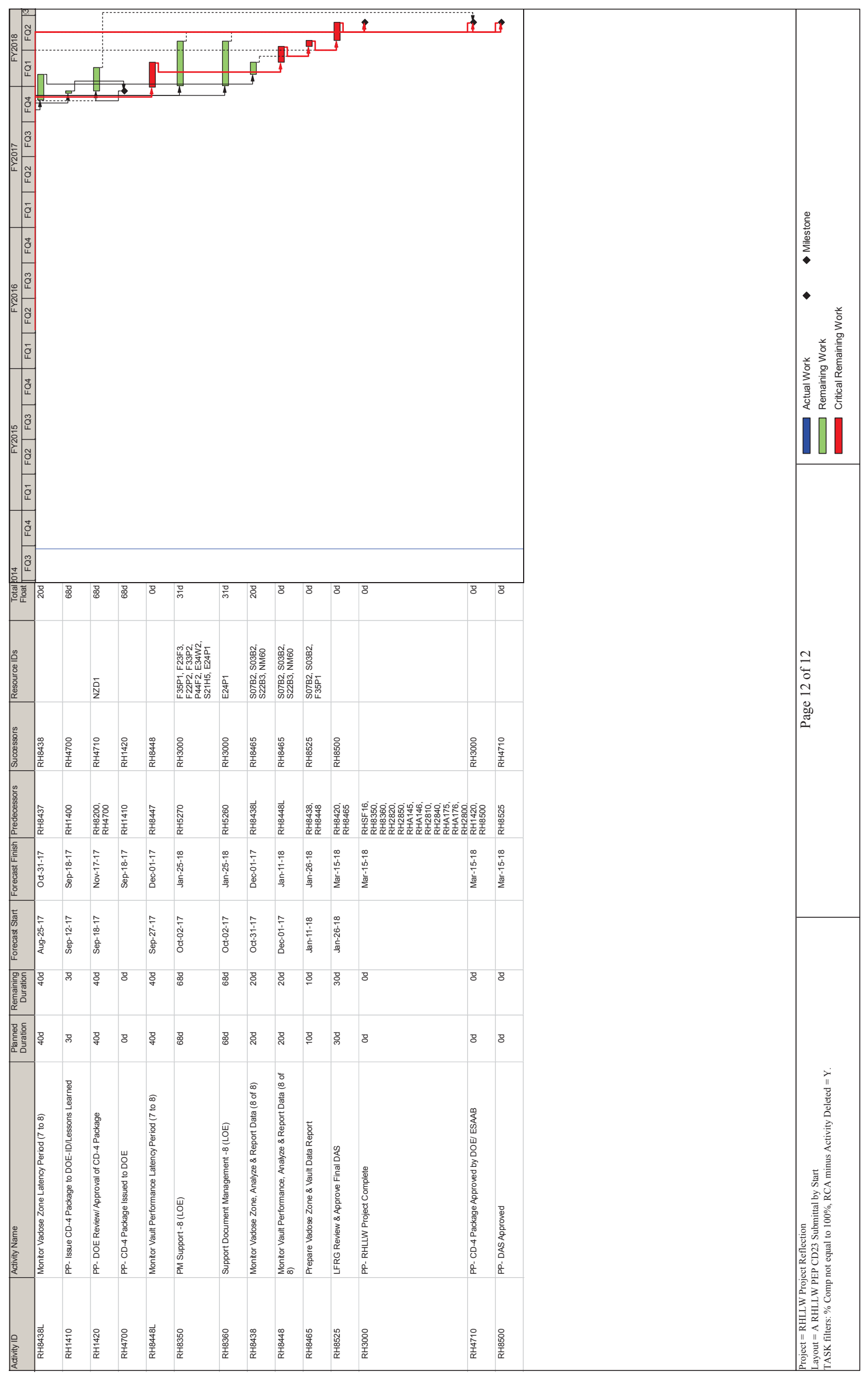




\section{Appendix E}

\section{Cost Estimate Summary for Total Estimated Cost and Other Project Cost (9A87)}

Full cost estimate details are included on CD. 

Date: $\quad$ July 2, 2014

To: $\quad$ D. S. Duncan, Project Manager

From: $\quad$ T. L. Julius, fost Estimator

Subject: $\quad$ Remote Handled Low Level Waste Disposal Project

Reference: Previous Estimate File \#9A87-D

Per your request, Cost Estimating prepared a revised cost estimate (Class 3 ) package for the abovementioned subject. The estimated cost, including escalation and management reserve, is $\$ 66,700,000$.

The estimate File 9A87-D was published on May 23, 2014, and submitted with critical decision (CD)2/3 submittal package to Department of Energy Idaho Operations Office (DOE-ID). A funding reduction was requested and the transportation equipment was eliminated.

This version of the estimate (9A87-F) incorporates the following changes:

1. Removed the cost of the transportation equipment including the new shipping cask, trailer, shield bell, and auxiliary equipment.

2. Reduced the hours for the cost account manager (CAM) for the transportation equipment from 2,551 to 393 .

3. Modified C.R. 60.20.02.6 Costs Spent to Date (Oct 2013 to March 2014) FY 2014 to read C.R. 60.20.02.6 Costs Spent to Date (Oct 2013 to June 2014) FY 2014 and added $\$ 574,011$ to the previous dollars to update actual costs spent to date.

4. Added C.R. 60.20.02.7 Costs Projected for July 2014

5. Deleted from the work breakdown structure as actual costs for work completed accrued in item 3 above as follows:

a. C.R.60.20.01.7 Projected Costs through CD-2/3 Approval (April to June) FY 2014

b. DOE-HQ/ ESAAB Review/Approval of CD-2/3 Package FY 2014

c. RH8130 Acquisition Executive (AE) Design Review FY 2015 to the infrastructure hold point.

6. Specifically deleted from the work breakdown structure to accommodate the deletion of the cask and transportation equipment as follows:

a. C.R.60.20.06 Cask

b. C.R.60.20.06.2.1 PP-Subcontract System subcontract Award, Hardware Fab and Delivery

c. C.R.60.20.06.2.2 Cask System Final Design

RH830 PP-First Unit Cask System Final Design FY 2015

RH8140 PP- Acquisition Executive (AE) Design Review FY 2015

RH8270 Issue Transportation System RFP \& SOW to Bidders FY 2014

RH8280 Vendors Develop Transportation System Bids/Submit to BEA FY 2014

RH8290 BEA Review Transportation Systems Bids \& Select System Bidder-

Milestone

RH8300 Issue Conditional Award to Winning Transportation System Bidder FY 2014 
D. S. Duncan

July 2, 2014

Page 2

RH8310 Incorporate Detail Schedule and Detail SOV into Transportation WBS FY 2014

d. C.R.60.20.06.2.3 Casks Fabrication/ Completion

RH840 PP-First Unit Cask Fabrication FY 2015

e. C.R.60.20.06.2.4 Ancillary Equipment Design / Fab.

RH850 PP-Ancillary Equipment Design FY 2015

RH850-2 PP-Ancillary Equipment Design / Fab FY 2015

RH850-2-1 HFEF-5, PP-BEA Ancillary Equipment Design FY 2015

RH850-2-2 Shield Bell - PP-BEA Ancillary Equipment Design FY 2015

RH851 PP-Ancillary Equipment Fabrication FY 2015

RH851-2 PP-BEA Ancillary Equipment Fabrication FY 2015

RH851-2-1 HFEF-5, PP-BEA Ancillary Equipment Fab FY 2015

RH851-2-2 Shield Bell-PP-BEA Ancillary Equipment Fab FY 2015

f. C.R.60.20.06.2.5 Transportation System Fit Up

RH860 PP-Transportation System Fit Up FY 2016

g. C.R.60.20.06.2.6 Transportation System / Ancillary Equip. Hardware Delivery

RH870 PP-Transportation System/Ancillary Equip. Delivery FY 2016

h. C.R.60.20.06.3 Subcontract G\&A for Cask FY 2015

7. Changed WBS number to match the schedule for the following :

RH4240 PP-BEA Construction Management FY 2016 FY 2015

CM01 Develop Special Conditions FY 2015 Changed CM01 to RH4240-1

CM02 Develop 540.10C FY $2015 \quad$ Changed CM02 to RH4240-2

CM03 Develop Nine Block Revision FY 2015 Changed CM03 to RH4240-3

CM04 Review Final Design FY 2015 Changed CM05 to RH4240-4

CM05 BEA Construction Management FY 2015 Changed CM05 to RH4240-5

CM05.1 BEA - Provide CM Supervision Changed CM05 .1 to RH4240-5.1

CM05.2 Provide CM Support - LOE Changed CM05.2 to RH4240-5.2

CM05.3 Provide Safety, IH, \& Radcon - LOE Changed CM05.3 to RH4240-5.3

CM06 Perform Subsurface Investigations FY 2015 Changed CM06 to RH4240-6

CM07 BEA CM Adjustment for Priority -1 Scope FY 2015 Changed CM07 to RH4240-7

CM08 Rad Survey Prior to Commence Construction FY 2015Changed CM08 to RH4240-8

8. Deleted the following:

a. C.R.60.20.03.3.1.1 Performance Assessment (PA) was used as place holder and carried no dollars.

b. RH1140 Update Project Data Sheets for FY 2014 as these cost are now expended.

c. RH1150 Review Project Data Sheets for FY 2014 as these cost are now expended. 
D. S. Duncan

July 2, 2014

Page 3

A. Per the project manager, this work will be direct funded. General and Administrative (G\&A) costs are included in this estimate.

B. Per the project manager, this scope of work is a capital asset project.

C. This cost estimate has been evaluated using the INL Cost Estimate Class Determination Matrix (Form 415.44) as a Class 3 estimate. The primary and secondary characteristics used in this matrix to define the classification category is the degree of project definition at this time. The intent of this classification is to assist in the interpretation of the quality and maturity of the information available to prepare this cost estimate and the expected accuracy levels that can be produced. Per this matrix, a Preliminary Class 5 and Class 5 per the Association for the Advancement of Cost Engineering (AACE) indicate the lowest amount of project information quality and maturity with a graded approach to a Class 1 , which indicates the highest amount of project information quality and maturity. Project deliverables that do not meet the minimum maturity requirements will drive the classification of that estimate as unable to classify. Estimates of this type that are unable to classify add very little credibility to the planning process and should be cautiously used.

D. A review of this cost estimate was held on June 27, 2014 with the project team, project manager and this cost estimator. This review allowed the team to discuss, in detail, the perceived scope, basis of estimates, assumptions, project risks, and the resources that make up this cost estimate. Comments from this review have been incorporated into this estimate to reflect a project team consensus of this document.

E. This project has been identified by INL Construction Management, R. E. Strong, as a Block 2 in the INL Construction Commercial Practices Evaluation for the purpose of construction scope, management, and field oversight.

Refer to the cost estimating summary, detail, markup, and labor sheets with the cost breakdowns. Also included for your use are the cost estimate recapitulation sheets describing the basis, assumptions, risk identification, and other pertinent information used in development of this estimate.

This estimate, the work, and the work breakdown structure are based on the information perceived by this estimator as to the scope of work to be completed. Any changes to the methodology used to prepare this estimate could have a significant effect on the cost estimate and should be reviewed by me. If you have any questions or comments, do not hesitate to contact me at 524-2286 or e-mail terry.julius@walshengr.com.

Attachments

cc: Estimate File 9A87-FC

Uniform File Code: $\underline{8309}$

Disposition Authority: A16-1.5-b 
D. S. Duncan

July 2, 2014

Page 4

Retention Schedule: Cut off at the end of each fiscal year. Destroy 10 years after cutoff.

NOTE: Original disposition authority, retention schedule, and Uniform Filing Code applied by the sender may not be appropriate for all recipients. Make adjustments as needed. 

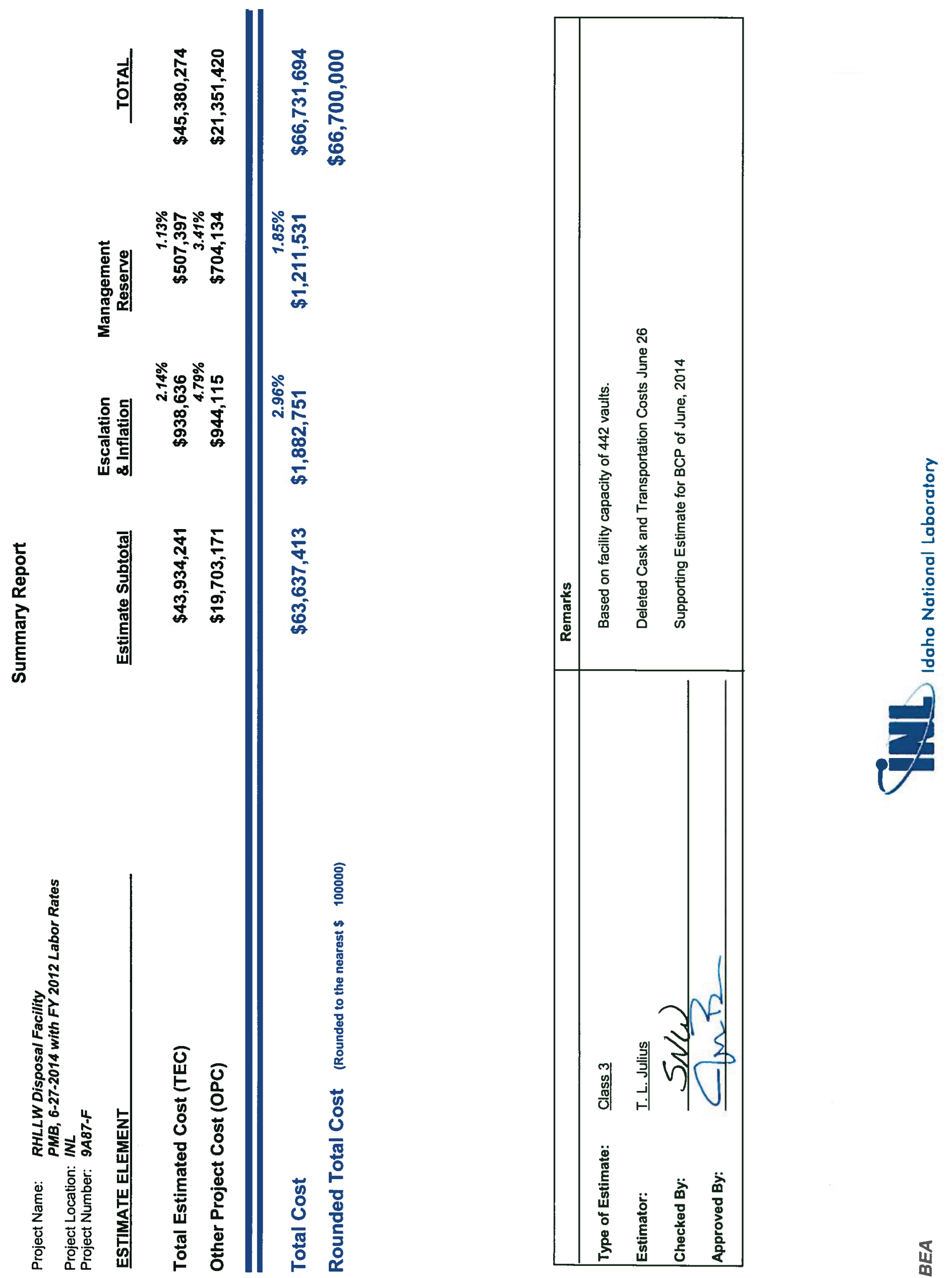

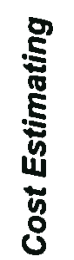




\section{FORMAL COST ESTIMATE SUPPORT DATA RECAPITULATION}

Project Title: $\quad$ Remote Handled Low Level Waste (RH LLW) Disposal Project - PMB

Estimator: T. L. Julius

Date: July 2, 2014

Estimate Type: Class 3

File: $\quad 9$ A87-F

Approved By: Page 1 of 15

I. PURPOSE: Brief description from the requester of the intent of how the estimate is to be used, i.e., for engineering study, comparative analysis, request for funding, proposal, etc.

This estimate determines a cost for the scope of work as stated below. This estimate will be used to support Critical Decision (CD)-2/3 approval for this project, per Department of Energy (DOE) CD Process for Capital Asset Projects. Upon CD-2/3 approval, this estimate will be used to support the Performance Measurement Baseline (PMB) for this project. This estimate supports a PMB schedule and work breakdown structure (WBS).

II. SCOPE OF WORK: Brief statement of the project's objective. Thorough overview and description of the proposed project. Identify work to be accomplished, as well as any specific work to be excluded.

\section{A. Objective:}

The objective of this work is to construct a facility within Idaho National Laboratory (INL) that will support disposal of remote-handled low-level waste (RH LLW) transported from the existing facilities at INL.

\section{B. General Introduction:}

This estimate includes costs from CD-0 in fiscal year (FY) 2009 through March FY 2014, identified as costs spent to date (actual) costs. The estimate also includes estimated costs from March FY 2014, to approval of CD-2/3 in June FY 2014. This estimate continues from the end of CD-1 to project completion through FY 2018, as planning package (PP) costs.

The original cost estimate 9A87-A was based on the detailed project description in this recapitulation report. The description is based on Battelle Energy Alliance, LLC. (BEA) Conceptual Design Report INL/EXT-07-19201 Rev 5 dated May, 2011. The project was bid as design-build project RFP \#121414. The submitted bid from AREVA Federal Services LLC (AREVA) was approved in March 2014. All subcontractor costs for the facility construction were removed from this cost estimate and the associated costs were replaced with lump sum values based on the schedule of values (SOV) furnished with the bid. The final design is not complete or submitted to date from AREVA. The facility description is included in this recapitulation report for information only based on AREVA's technical proposal and will be superseded by the AREVA final design. BEA project management (PM), and support management 
FORMAL COST ESTIMATE SUPPORT DATA RECAPITULATION

-Continued-

Project Title: Remote Handled Low Level Waste (RH LLW) Disposal Project - PMB

File: $\quad$ 9A87-D $\quad$ Page 2 of 15

estimated work scopes are included in this estimate. The cask and transportation equipment have been removed from this project.

C. General Project Description:

1. The RH LLW disposal facility infrastructure includes access roads, maintenance building, office building, and utilities to the facilities.

2. The facility infrastructure including the vaults is a design-build (DB) project and will be designed and constructed by subcontractors who will provide the design based on BEA work scope descriptions, as defined by technical and functional requirements and DB performance specification.

3. The RH LLW disposal facility capacity is approximately 442 storage vaults designed for disposal of RH LLW. This cost estimate includes costs to construct the receiving, maintenance facilities, and vault storage area. This total includes vaults of five different diameters to allow for receipt of different types of waste materials, and containers. The activities equate to a 20 year life expectancy for storage of RH LLW.

4. BEA project management will conduct oversight and have review authority during the design and construction process to ensure nuclear safety, environmental compliance, schedule progress, and quality processes.

\section{Included:}

The scope of work required to achieve this objective includes the following:

DB Subcontractor Work Scope for Infrastructure:

1. The DB subcontractor will provide the design and furnish project management, construction management, quality, environmental, safety, and health monitoring during the construction process. The DB subcontractor will manage procurement of materials, equipment, and lower-tier subcontractors to construct the project. The DB engineering and general subcontractor will be part of the team during the construction process, check out, and final acceptance process.

2. The RH LLW facility conceptual footprint has dimensions of $218 \mathrm{ft}$ wide by $1,257 \mathrm{ft}$ long. These dimensions may change as the facility DB subcontractor proceeds to final design.

3. The 2,400 $\mathrm{ft}$ long access road to the RH LLW compound is $30 \mathrm{ft}$ wide on the top with a 4 in. thick asphalt surface, 10 in. thick base of $3 / 4$ in. minus, and 14 in. thick pit run gravel sub-base. The access road will be attached to the existing Monroe Road before it enters into the Advanced Test Reactor (ATR) Complex parking lot with a $45^{\circ}$ turn from Monroe Road and a long turn tee intersection into the compound. The road will be center crowned. Road sides and the areas not built upon will have 3 in. of top soil placed back and seeded with natural seed and mulch. All dirt areas outside the compound with exposed excavation will be reseeded. 
FORMAL COST ESTIMATE SUPPORT DATA RECAPITULATION

-Continued-

Project Title: Remote Handled Low Level Waste (RH LLW) Disposal Project - PMB File: $\quad$ 9A87-D

Page 3 of 15

4. The potable water supply will be from ATR Complex by tapping into a water line within ATR Complex and routing approximately 3,100 ft of 4 in. HDPE water line out to the RH LLW maintenance building. The 4 in. line will have a shut off valve at the ATR Complex site and at the RH LLW site. Install a 1 in. tap and shut off valve for the office building. The water line will be buried approximately $6 \mathrm{ft}$ deep. A potable water return loop, sized the same as the supply line, will be installed from the RH LLW facility to the ATR Complex.

5. The sanitary sewer disposal system at the RH LLW will utilize a septic tank and subsurface drain field. The sanitary sewer disposal system will be located at least 400 feet from the vaults.

6. The fire water supply will be from ATR Complex by tapping into a 12 in. fire water main at ATR Complex and routing a 12 in. fire water line $6 \mathrm{ft}$ underground from ATR Complex to the RH LLW pump house and level control system.

A 12 in. fire water return loop will be installed from the RH LLW to a tie in point within the ATR Complex.

7. The power source for the RH LLW will be a $2.4 \mathrm{kV}$ underground power line tapped from Manhole 108 in the ATR Complex site. A 5kV sectionalizer and a $5 \mathrm{kV}$ fused disconnect switch (FDS) will be installed adjacent to Manhole 108. The electrical subcontractor will tap six conductors in the manhole up to and back down into the manhole for the sectionalizer, install a $750 \mathrm{kcmil}, 5 \mathrm{kV}$ service feeder from the sectionalizer to the FDS, and install approximately $3,000 \mathrm{ft} 5 \mathrm{kV}$ service feeder cables from the FDS to the local 5kV FDS at RH LLW. The service feeders will connect to the new $300 \mathrm{kV}$ transformer to transform power from $2.4 \mathrm{kV}$ to 480 volts. The $5 \mathrm{kV}$ power cables will be installed underground from Manhole 108 to the RH LLW via two 5 in. conduits in a red concrete duct bank. Several hand-holes will be installed along the $3,100 \mathrm{ft}$ long duct bank. The power duct shall have a minimum of 24 in. deep soil cover.

8. The communication system will have one 50 pair copper cable, one 48 conductor single mode fiber optic cable, and one 12 strand single mode fiber optic cable. The cables will be installed underground from a telecom Manhole T-26 in ATR Complex to the RH LLW via two 4 in. conduits and two additional 2 in. conduits in a red concrete duct bank. Install hand holes along the 2,300 foot long duct bank. The duct bank shall have a minimum of 24 inch deep soil cover.

9. The security system will have one 12 fiber optic cable installed. The cables will be installed underground from a security manhole \#4 in ATR Complex to the RH LLW via the communications duct bank. Install hand holes along the 3,100 foot long duct bank. The duct bank shall have a minimum of 24 in. deep soil cover.

10. The RH LLW compound interior roads will be $30 \mathrm{ft}$ wide and loop $1 / 2$ way around and close to the inside of the perimeter fence. The far side lane that will be $30 \mathrm{ft}$ wide and the road surface will be exposed gravel to allow the steel tracked crane to travel up and down and not destroy the asphalt surface. The compound road will be made of 4 in. thick asphalt surface, a 10 in. thick base of $3 / 4$ in. minus, and a 10 in. sub-base of pit run gravel. The roads will slope away from the center vault area. 
FORMAL COST ESTIMATE SUPPORT DATA RECAPITULATION

-Continued-

Project Title: $\quad$ Remote Handled Low Level Waste (RH LLW) Disposal Project - PMB

File: $\quad$ 9A87-D $\quad$ Page 4 of 15

11. The vault area will be excavated down approximately $21 \mathrm{ft}$ with a cut back of 2 to 1 . After the sub-base is installed, the pre-cast concrete vaults will be set in place by a crane located in the pit area. The vaults will be set in-place and compacted around the outside with engineered fill or soils previously removed from the vault excavation. The interior areas between the vaults will be backfilled with sand.

12. The vault area will have a $2 \mathrm{ft}$ thick sub-base installed at the bottom of the entire vault excavation.

13. A stock pile area outside the fenced area approximately $1,000 \mathrm{ft} \times 600 \mathrm{ft}$ will be cleared and grubbed down 4 in. to allow the excavated soils from the vault pit to be stock piled and stored for replacing during construction or for long term disposal of the vault cap after completion of operations. Compact the stockpile area to allow vehicle travel on it.

14. The entire compound area will be surrounded by an $8 \mathrm{ft}$ tall chain link security fence with one $24 \mathrm{ft}$ wide electrically operated gate and $12 \mathrm{ft}$ wide swing gate. The fence will have three rows of barbed wire on top.

15. The fire water system within the compound will consist of two fire hydrants on a 12 in. fire water main.

16. The maintenance building will be $50 \mathrm{ft} \times 100 \mathrm{ft}$ pre-engineered steel building. The building will have a high bay area large enough to house a transport truck and an equipment truck. The high bay will be equipped with one electrically operated high bay doors and five personnel passage doors. The high bay will have high intensity discharge (HID) metal halide lighting and four $480 \mathrm{~V}$ welding outlets for repairs or thawing needs. The high bay floor will be 12 in. reinforced concrete with a $4 \mathrm{ft}$ deep concrete foundation. The entire building will be insulated and heated. The office area will also be air conditioned with a heat pump system. The facility will have a fire alarm system with voice paging and evacuation alarms.

17. The shop area will have a work bench with vise and hanging racks for tools and slings. The shop will house stands for cask lifting and cask connecting tools.

18. The office building will be a $52 \mathrm{ft} \times 77 \mathrm{ft}$ pre-engineered steel building placed on a 6 in. concrete slab with a $4 \mathrm{ft}$ concrete foundation. This building will have four offices, conference room, storage area, two restrooms, shower, locker areas, and a telecom room. The office area will have a suspended ceiling, fluorescent lighting, $120 \mathrm{~V}$ utility outlets throughout, and computer outlets. This entire building will be heated and air conditioned with a heat pump system. The building will have a fire alarm system for monitoring the office area and the maintenance building.

19. Power pedestals will be provided along the outside edge of the vault area in order to supply convenient access to operate the cask unloading units and small power tools.

20. Thirteen monitoring wells of approximately 40 to $60 \mathrm{ft}$ in depth will be installed within and adjacent to the RH LLW disposal vault arrays.

21. A paved parking facility will be provided to accommodate 10 cars. The parking lot will be located in the area next to the office building. The parking will be lighted by building side lights. 
FORMAL COST ESTIMATE SUPPORT DATA RECAPITULATION

-Continued-

Project Title: Remote Handled Low Level Waste (RH LLW) Disposal Project - PMB

File:

9A87-D

Page 5 of 15

22. The fire alarm system will consist of a Notifier fire alarm panel (FAP) located at the main entry of the office building with room smoke detectors, manual pull stations at each door, and a distributed speaker system for fire alarms and voice announcements with flashing strobes in each major area. The maintenance building will have a similar detection and annunciation system and all alarms will be managed and report to the office fire alarm panel. The fire alarm system will connect to the local telecom room to communicate with the ATR network and INL Central Alarm Station.

23. The office building shall include a telecom room with one rack of equipment and a small uninterruptible power supply (UPS). The telecom room will have a back board with punch down blocks for copper splices and a fiber optic splice panel for the fiber network. There will be space in the room for a security rack for the door card reader equipment, closed circuit television, controls, and power supplies. The security system will consist of six card readers located at the main doors of each building and one for the main gate. The card readers will be powered and controlled from the security equipment located in the office building telecom room.

24. The voice paging system will be part of the fire alarm network and utilize the fire alarm speakers for voice announcements.

25. The evacuation system will have two $480 \mathrm{~V}$ evacuation sirens located outside, operated by relays located in the telecom room. The relays will be connected into the ATR Complex alert/evacuation system via the communications network cables. Each building will have local evacuation alarms installed in each major area.

26. The vault area will be lighted with 14 light poles with multiple lights for security purposes.

27. Cost for large capacity fork lift and heavy lifting equipment is included in this estimate.

28. The cost for this work is included in the estimate as AREVA work scope and the previously estimated subcontractor costs were removed and replaced with lump sum costs based on AREVA schedule of values.

\section{DB Subcontractor Vault Work Scope:}

1. As per the BEA conceptual designs, each vault will consist of two or three sections of pre-cast concrete with steel reinforcing. The base is approximately $12 \mathrm{in}$. thick reinforced concrete, hexagonal in shape to match the shape of the top plug. The vault riser sections will be round tubes approximately $8 \mathrm{ft}$ to $18 \mathrm{ft}$ tall and $1.5,3,4$, 6 , or $7 \mathrm{ft}$ inside diameter. The riser section walls will be approximately 6 in. thick reinforced concrete. Each vault component will have a tongue and groove joint to interlock into each other and have lifting lugs to allow assembly. The top plug will be solid concrete, steel reinforced, approximately $5 \mathrm{ft}$ tall sized to fit each riser. The top plug will be hexagonal in shape to match the bottom and have lifting lugs to allow setting and removal. The base and first riser tube will be set in place. 
FORMAL COST ESTIMATE SUPPORT DATA RECAPITULATION

-Continued-

Project Title: Remote Handled Low Level Waste (RH LLW) Disposal Project - PMB

File:

9A87-D

Page 6 of 15

Sand will be placed between the vault sections to provide stabilization. The second riser will be set in place after the sand is placed around the first riser to ensure that the installation remains stable.

2. The vault forms and components will be DB subcontractor constructed and mass produced off site. The vault components will be loaded and delivered to the RH LLW construction lay-down area. The vault components will be transported locally as needed by the construction subcontractor and installed in the vault disposal areas.

3. There are five separate disposal areas within the vault pit area. One area for $1.5,3$, 4,6 , and $7 \mathrm{ft}$ inside diameter vaults. Each assembly is separated from each other by a compacted filled section.

4. The preparation work to receive the vaults such as vault area excavation is included in the infrastructure section of this estimate.

5. The DB subcontractor will complete the design and furnish project management, construction management, quality, environmental, safety, and health monitoring during the construction process. The DB subcontractor will manage procurement of materials, equipment, and lower-tier subcontractors to construct the project. Both the engineering and general subcontractor will be part of the team during construction, check out, and final acceptance processes.

6. BEA project management will conduct oversight and review authority during the design and construction process and to ensure safety, schedule, and quality construction.

7. The vault system will be precast concrete and meet Nuclear Quality Assurance (NQA)-1 requirements for construction, materials, and installation.

8. The vault acceptance process will include building an initial vault of each of the five types and delivering it to a test site to allow testing and validation to ensure they meet requirements. The testing and validation will be provided by the DB subcontractor. The testing will include ground penetrating radar (GPR) to validate the rebar installation, core drills for concrete testing to validate the concrete strength and composition, and assembly to validate the tongue and groove fit and structural integrity.

9. The final testing and vault acceptance will be completed by the DB subcontractor before BEA final acceptance is authorized. After substantial completion, the DB subcontractor shall conduct a final walk-through and demonstration with BEA to prove operation and condition of the vaults and equipment furnished.

10. The vault installation will be completed and made ready for operations in FY 2018.

Subcontractor Work Scope for Casks:

The cask and transportation equipment have been removed from this project. 
FORMAL COST ESTIMATE SUPPORT DATA RECAPITULATION

-Continued-

Project Title: $\quad$ Remote Handled Low Level Waste (RH LLW) Disposal Project - PMB

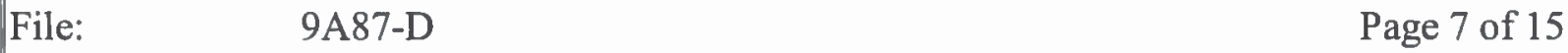

\section{BEA Work Scope for Infrastructure:}

1. BEA has accepted the AREVA proposal for the DB subcontract. BEA has performed initial site surveys such as radiological and unexploded ordnance survey. The cultural resources survey and environmental survey are completed and not included in this estimate. The final subsurface investigations will be completed prior to any excavation.

2. BEA will provide oversight of the DB subcontractor PM, engineering, and construction management (CM) during the design, construction, startup, and testing.

3. BEA will provide oversight of DB safety, quality, environmental, radiological, and procurement services.

4. BEA will provide and install the instrumentation in the monitoring wells that the DB subcontractor provides.

5. BEA will furnished the initial complement for office furniture, lockers, chairs, tables, hand tools, work benches, hand dollies, hand forklifts, small lifting slings, and racks for the shop area and office areas.

\section{BEA Project Management Work Scope:}

1. This work scope addresses the BEA project management costs incurred over the life of the project from conceptual design through the design-build process, testing, final acceptance, and start-up of the facility. These costs are defined as those that apply to the whole project as opposed to those that apply only to specific subprojects. This estimate includes labor hours for general coordination meetings, coordination planning, and scheduling. Other project manager (PM) or control account manager (CAM) costs directly related to each subproject are included in those subproject sections.

2. This project was started in FY 2008 and uses the critical decision process for a line item construction project approved by Congress. This project is a DB project where BEA will oversight the DB subcontractors to accomplish the work. There will be one PM and four CAMs for this project. The CAMs will manage separate and specific subprojects to accomplish the primary project and preparation for startup and long term operations.

3. The infrastructure CAM will manage the design and construction of the infrastructure including roads, buildings, and utilities. The vault CAM will oversight the disposal vault design, construction, and installation. The cask CAM will oversight the design and construction of the facility and transfer equipment. The documentation CAM will manage the subproject support documentation such as the safety analysis report (SAR), hazard analysis (HA) and environmental assessments (EA). The PM CAM will manage the project control systems to ensure they are set-up and operational to report earned value throughout the life of the project. 
FORMAL COST ESTIMATE SUPPORT DATA RECAPITULATION

-Continued-

Project Title: $\quad$ Remote Handled Low Level Waste (RH LLW) Disposal Project - PMB

$\begin{array}{lll}\text { File: } & \text { 9A87-D } & \text { Page } 8 \text { of } 15\end{array}$

4. BEA will conduct project audits or periodic reviews such as Management Self Assessments (MSA), Readiness Assessments (RA), Contractor Operational Readiness Assessment, and assist DOE with an Operational Readiness Review (ORR).

\section{BEA Work Scope for Support Documentation:}

1. The support documents address the general project support documents including those required by DOE Order 413.3, 435.1, National Environmental Policy Act (NEPA) of 1969, and DOE STD-1189. Completing the support documents includes writing, reviewing, revising, printing, tracking, and managing the completion of them until project completion, authorization, and startup. It also includes management of these documentation activities, where such management is separate and distinct from BEA general project management work scope.

2. The PM's and CAM's time that is directly related to support documentation is accounted for in this estimate. This project was started in FY 2008 and uses the critical decision process for a line item construction project approved by Congress.

\section{BEA Work Scope for Casks:}

1. A new cask and transportation equipment have removed from this project. The existing $l$ cask and equipment acceptance will occur after the transportation system fit-up has been successfully completed and system functionality and interface with the vault system has been verified.

\section{E. Excluded:}

This scope of work specifically excludes the following:

1. Operation, facility shutdown, and end-of-life demolition of the facility is addressed in estimate File \#9A28-H4.

2. Costs for long-term, post-closure activities, including sampling of monitoring wells are not included in this estimate.

3. Costs for refurbishment of the existing crane that will be used to support disposition of NRF 55 ton waste canisters are not included in this estimate.

4. Cost of a transportation system for legacy waste stored at the Radioactive Scrap and Waste Facility at MFC is not included in this estimate.

5. Cost for drilling and installing two aquifer monitoring wells is not included in this estimate. Cost of the aquifer wells will be co-funded with USGS and DOE-ID, and is outside the scope of this cost estimate.

6. Costs for annual Project Management Support Office (PMSO) reviews are not included in this estimate.

7. Cost for a new cask, cask design, and transportation equipment associated with a new cask. 


\section{FORMAL COST ESTIMATE SUPPORT DATA RECAPITULATION}

\section{-Continued-}

Project Title: $\quad$ Remote Handled Low Level Waste (RH LLW) Disposal Project - PMB

File: 9A87-D

Page 9 of 15

III. ESTIMATE METHODOLOGY: Overall methodology and rationale of how the estimate was developed, i.e., parametric, forced detail, bottom up, etc. Total dollars/hours and rough order of magnitude (ROM) allocations of the methodologies used to develop the cost estimate.

This estimate was prepared utilizing "forced detail" and "bottom up" methods. The activities and resources were developed by the cost estimator and the project team from engineering and project information that provided the level of detail documented in the estimate. The infrastructure and vault construction/installation portions of the estimate are based upon input from the BEA prepared conceptual design and the Design-Build-Operate Performance Specification for the Remote-Handled Low-Level Waste Disposal Project.

\begin{tabular}{lc}
\hline \multicolumn{1}{c}{ Estimate Methodology } & ROM Percentage (\%) \\
\hline Project Team & 21 \\
Recorded Actuals & 19 \\
Parametric & 0 \\
Vendor Quotes & 50 \\
Other (e.g., RS Means) & 10 \\
\hline TOTAL & 100
\end{tabular}

IV. BASIS OF THE ESTIMATE: Overall explanation of sources for resource quantities, pricing, and schedules.

A. Quantification Basis: The source for the measureable quantities in the estimate that can be used in support of earned value management. Source documents may include drawings, design reports, engineers' notes, and other documentation upon which the estimate is originated.

1. The PM and CAM provided the scope, schedule, labor hours, and materials costs anticipated for the BEA portion of this work.

2. The Statement of Work for the Development of DOE Order 431.5 Documentation for the Proposed Idaho National Laboratory Remote Handled Low Level Waste Disposal Facility, SOW-7611, 7/06/09.

3. The Preliminary Project Execution Plan (PEP) for the Remote Handled Low Level Waste Disposal Project, DOE/ID -11370, issued June 2010.

4. The Conceptual Design for the Remote Handled Low Level Waste Disposal Project, INL/EXT-07-12901, Rev 5, issued May 2011.

5. Performance Specification, SPC-1437, Design-Build-Operate Performance Specification for the Remote-Handled Low-Level Waste Disposal Project, issued January 12, 2012.

6. Technical and Functional Requirements, TFR-483, Remote-Handled Low-Level Waste Disposal Project, issued January 16, 2012. 
FORMAL COST ESTIMATE SUPPORT DATA RECAPITULATION

-Continued-

Project Title: $\quad$ Remote Handled Low Level Waste (RH LLW) Disposal Project - PMB

File:

9A87-D

Page 10 of 15

7. Weekly meetings with the project manager and five project control account managers who were developing the WBS and definitions.

8. Meetings were held with consultants who provided budget estimates for their hours and specific work scope.

9. A "Siting Study for the Remote Handled Low Level Waste Disposal Project" dated October 2010, document number INL/EXT-07-12902, revision 2, was furnished.

10. The project manager and control account managers developed the WBS and definitions.

11. The draft Monitoring-Well Specification for the Remote Handled Low Level Waste Disposal Project, by A.L. Schafer, BEA Earth and Water Resource Science Department.

12. Drawing 448552 ATR Complex Underground Piping Project Underground Water Lines Sheet 7 of 8.

13. Drawing 421002 ATR Complex Underground Ductbanks and Manholes.

14. Drawing 448547 ATR Complex Underground Piping Project Sanitary Sewer and Cold Waste Sheet 1 of 1 .

15. Drawing 421002 ATR Complex Underground Power Distribution Sheet 1 of 2.

16. Google Earth maps and scales.

17. The canister quantities and vault dimensions were provided by vault CAM J. Jacobson in TFR-483, Table 1, RH LLW waste canister scope, revised February 23, 2012.

18. The basis for the RH LLW facility cost is the AREVA subcontractor bid costs and WBS approved March 2014. The AREVA bid including facility and vault design, construction, and commissioning. The previously estimated facility and vault subcontractor costs were removed from the estimate and informed from the DB subcontractors approved bid.

B. Planning Basis: The source for the execution and strategies of the work that can be used to support the project execution plan, identification of long lead item, acquisition strategy, schedules, market conditions, and other documentation upon which the estimate is originated.

1. Project management and engineering activities performed prior to FY 2014 are included in the estimate as costs spent to date.

2. The project management activities will begin in FY 2014 and will be completed by end of FY 2018.

3. BEA will provide oversight for all consultants, engineering, project management resources, and activities.

4. The CD-2/3 approval will be obtained in FY 2014.

5. The DB contract award was March 2014.

6. DB subcontractors will manage, design, and build the infrastructure and vaults.

7. Subcontractor markup rates are based on this estimator's judgment. These rates have been adjusted to reflect the anticipated market conditions. 
FORMAL COST ESTIMATE SUPPORT DATA RECAPITULATION

-Continued-

Project Title: Remote Handled Low Level Waste (RH LLW) Disposal Project - PMB

File: 9A87-D

Page 11 of 15

8. This work will be performed during standard working hours and no premium time will be required for off-shift or weekend work.

9. Work will be able to progress consecutively and will not require delays between work segments.

10. The cost estimate does not consider or address funding or labor resource restrictions. Sufficient funding and labor resources will be available in a manner allowing optimum usage of that funding and resources as estimated.

11. DB subcontractors will design and construct the buildings and utilities, and backfill around the vaults. This project was competitively bid nationally and within the local subcontracting community.

12. The preliminary engineering activities will begin in FY 2014, with the construction acceptance to be completed early FY 2018.

13. DB subcontractors will design and construct the vaults. This project was competitively bid nationally and within the local subcontracting community.

14. The estimate does not include any cost allowances for winter work impacts. Construction may continue during winter months.

C. Cost Basis: The source for the costing on the estimate that can be used in support of earned value management, funding profiles, and schedule of values. Sources may include published costing references, judgment, actual costs, preliminary quotes and lor other documentation upon which the estimate is originated.

1. INL labor rates, fees, and burdens are based on the FY 2012 published rates as provided by BEA Business Management.

2. Craft labor rates are based on information provided by the "INL Site Stabilization Agreement." Adders (such as FICA, SUTA, and federal insurances) are based on an interpretation by Cost Estimating.

3. Estimated escalation rates are based on historical indexes from 1962 to today, as published by RS Means. Five-year, ten-year, and lifecycle trends were developed to estimate the most likely rates that have been used in this estimate. Inflationary and deflationary impacts will be addressed in management reserve. The escalation rates are applied based upon input from the project schedule.

Escalation will not be added to the AREVA subcontractor bid costs unless there is extraordinary inflation for specific materials.

4. Sales tax on materials is based on the current $6 \%$ rate charged by the State of Idaho.

5. Standard published industry references were used to help develop the estimated resources and their productivities and some material costs.

6. The cost basis is identified on the Detail Item Reports using RSM for "RSMeans" in the code column, "catalog" or "VQ" for vendor budget quotes, and "CAM" for the cost account manager input assignment. If the code column has no notation, it was estimator's judgment for item costs or allowances.

7. Preliminary vendor quotes were used to supply some material costs particularly for small hand tools note furnished as part of the subcontractor's bid. 
FORMAL COST ESTIMATE SUPPORT DATA RECAPITULATION

-Continued-

Project Title: $\quad$ Remote Handled Low Level Waste (RH LLW) Disposal Project - PMB

File: 9A87-D

Page 12 of 15

8. The DB subcontractor cost is based on the fixed price award made to AREVA Federal Services, LLC, in March 2014.

V. ESTIMATE OUALITY ASSURANCE: A listing of all estimate reviews that have taken place and the actions taken from those reviews.

A. A review of this estimate was held June 27, through July 2, 2014 with the requester, control account managers, and this cost estimator. This review allowed for the requester and project team to review and comment, in detail, on the perceived scope, basis of estimate, assumptions, project risks, and the resources that make up this cost estimate. Comments from this review have been incorporated into this estimate to reflect a project team consensus of this document.

B. Reviews of the previous versions of this estimate (File \#9A87-A) was held on March 15, 2012, 9A87-C on November 5, 2012, and 9A87-D on May 28, 2014 with the requester, control account managers, and this cost estimator.

C. The draft cost estimate was reviewed by the DOE-ID integrated project team (IPT) and the comments were incorporated into the estimate.

D. An internal organizational check will be performed on this estimate with the purpose of checking the methodology approach used, discussing the document with the estimator, and ensuring the document has been reviewed and discussed with the requester, reflects a team consensus, has adequately documented the basis, assumptions, and risks to the project, and has mitigated those risks

VI. ASSUMPTIONS: Condition statements accepted or supposed true without proof of demonstration; statements adding clarification to scope. An assumption has a direct impact on total estimated cost.

A. The BEA consultants can complete their portion of the documentation in a timely basis and within budget as some of the BEA documents will use the consultant's documents as their basis.

B. Discussions with the ATR Complex electrical engineer, Dave Ferguson, confirmed that the power to the RH LLW shall be $13.8 \mathrm{kV}$ and recommended a sectionalizing cabinet be installed above Manhole 108 and the cables spliced into and routed up to the sectionalizer.

C. No bed rock will be encountered in the vault excavation site as the project has conducted numerous sound depth tests and confirmed soil depth and bed rock locations. Also, it has been assumed that rock will not be encountered in the utility excavations from RH LLW to the ATR Complex.

D. A portion of the earth removed from the vault pit area is reusable as compacted fill around the vault installation site.

E. The utilities at ATR are in good condition and able to supply the additional services to this new site.

F. There will be adequate gravel in the Monroe borrow pit for gravel and the gravel is available at no cost. Transport costs are included in this estimate. 
FORMAL COST ESTIMATE SUPPORT DATA RECAPITULATION

-Continued-

Project Title: Remote Handled Low Level Waste (RH LLW) Disposal Project - PMB

File: $\quad 9 A 87-D$

Page 13 of 15

G. No fire water pumps will be required for the new fire water loop system supplying the RH LLW disposal facility.

H. Activities associated with implementation of transport systems at generator site are the responsibility of the generator and outside the scope of this project.

I. All waste containers considered in operation of the facility are the responsibility of the generator.

Activity-specific assumptions that are considered to also reflect the basis of the estimate have been included within the estimate body (reference cost estimating detail sheets).

\section{MANAGEMENT RESERVE (MR) GUIDELINE IMPLEMENTATION:}

Management Reserve Methodologies: Explanation of methodology used in determining overall management reserve. Identify any specific drivers or items of concern and any inherent risks typical with this type of environment. Inflationary and deflationary impacts are addressed in this section.

At a project risk review for this CD-2/3 Estimate File \#9A87, on March 15, 2012, the project team conducted a review of this cost estimate and assigned high to low impact values based on uncertainty. The resulting high-low range of percentages was then used to perform an analysis using the "@Risk" software. These bounding values were then run through a Monte Carlo sampling simulation to arrive at the additional cost required to address the uncertainty in the cost estimate at various levels of confidence. A confidence level of $85 \%$ was chosen. The appropriate uncertainty amount, represented as a percentage, was added to the estimate to result in the estimated cost, including management reserve. The resulting MR is included in this estimate and represents the cost estimate MR.

Based upon input and findings of the Independent Cost Review, the cost estimate MR calculated by the @Risk analysis and assigned to the work activities of the DB Subcontractor has been removed from this estimate. The removed DB MR has been reassigned to a project risk within the project risk register.

The MR that remains with the DB activities is for MR calculated and applied to BEA costs that are included within the DB activities.

Additional MR for the project risk identified in the project risk register, including schedule risk, and DOE contingencies will be added to the total project budget, but are not included in this estimate.

A. Threats: Uncertain events that are potentially negative or reduce the probability that the desired outcome will happen.

1. Only conceptual designs and preliminary documents exist for this project. Completion of the requirements and design may increase the costs for the 


\section{FORMAL COST ESTIMATE SUPPORT DATA RECAPITULATION}

-Continued-

Project Title: Remote Handled Low Level Waste (RH LLW) Disposal Project - PMB

File:

9A87-D

Page 14 of 15

shipping cask to meet requirements or needs not identified in the scope of this estimate.

2. This project is heavily dependent on limited qualified personnel and subcontractors for nuclear and INL construction work.

3. Preciseness in the forced detail take-offs leaves little room if crews are unable to meet the estimated production rates. Factors could include, but are not limited to, changes to Integrated Safety Management requirements, equipment breakdowns, resource impacts, and/or availability.

4. More than normal adverse weather (cold, snow, rain, and wind) would cause losses in productivity or even stop the work. This loss in productivity or stoppage would still require for the operating contractor's forces to be compensated.

5. Instability in fuel, steel, and concrete prices could increase the construction costs associated with this project.

6. The existing cask and transfer equipment may not be adequate for the different types of RH LLW to be transferred to this facility.

B. Opportunities: Uncertain events that could improve the results or improve the probability that the desired outcome will happen.

1. Well-planned-out work activities and scheduling by the subcontractors could result in increased production, thus producing lower bids and operating contractor oversight costs than what have been estimated.

2. The DB contract will allow marketplace ingenuity to be used.

C. Accepted Risks: Activities with a greater than $50 \%$ and less than $100 \%$ probability of occurrence have been accepted as part of this scope of work.

None

D. Excluded Risks: Risks that have been identified and have a probability of occurrence but are specifically excluded from this estimate.

None

Note: Management reserve does not increase the overall accuracy of the estimate; it does, however, reduce the level of risk associated with the estimate. Management reserve is intended to cover the inadequacies in the complete project scope definition, estimating methods, and estimating data. Management reserve specifically excludes changes in project scope, unexpected work stoppages, (e.g., strikes, disasters, and earthquakes) and excessive and/or unexpected inflation or currency fluctuations. This estimate does not contain any contingencies and has not been evaluated to include any contingencies and has not been evaluated to include any of the risks that pertain to Department of Energy. 
FORMAL COST ESTIMATE SUPPORT DATA RECAPITULATION

-Continued-

Project Title: $\quad$ Remote Handled Low Level Waste (RH LLW) Disposal Project - PMB

File: $\quad$ 9A87-D $\quad$ Page 15 of 15

VIII. OTHER COMMENTS/CONCERNS SPECIFIC TO THE ESTIMATE:

None 


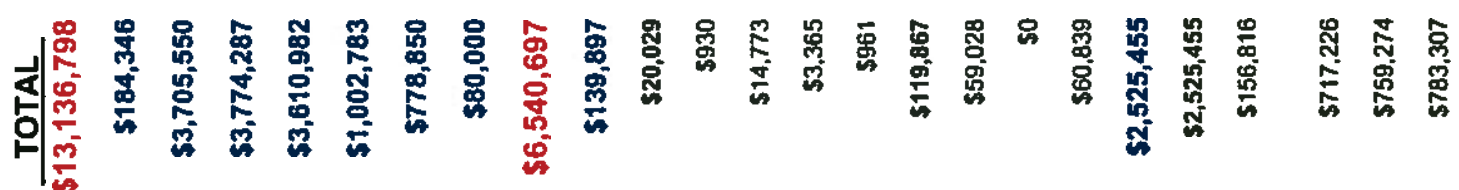

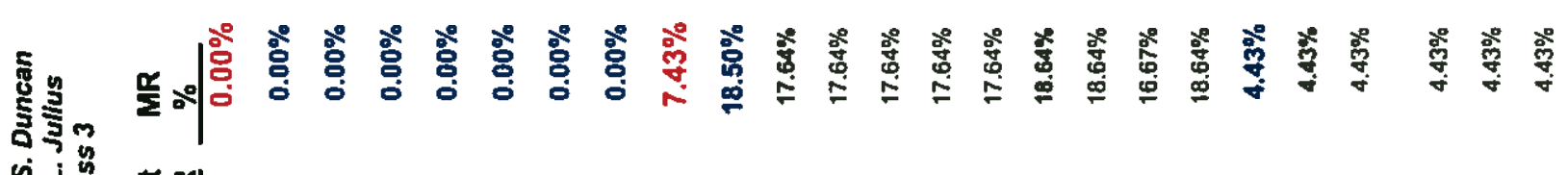

sist

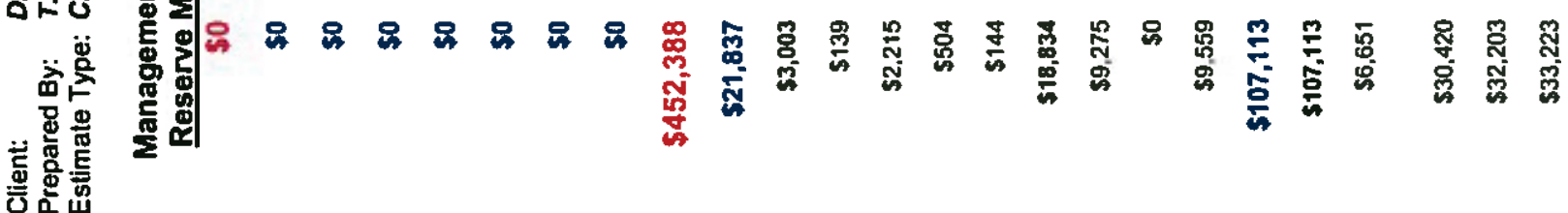

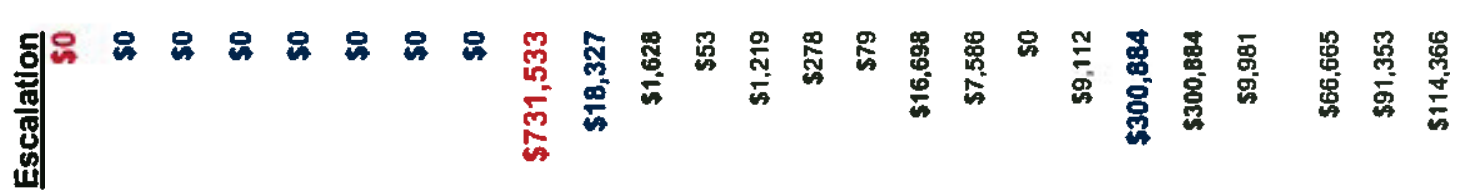

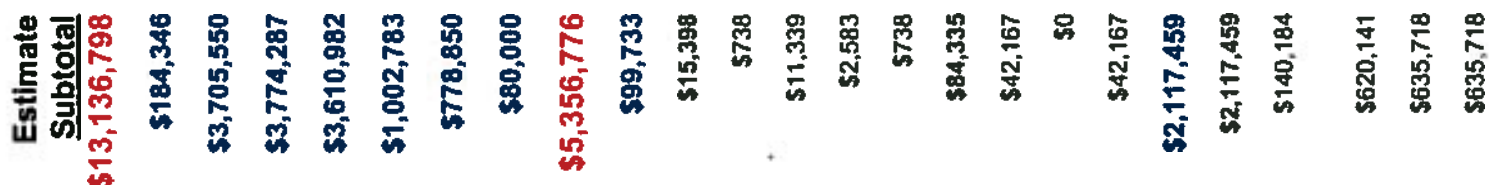

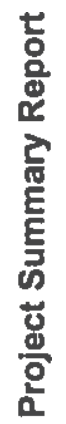




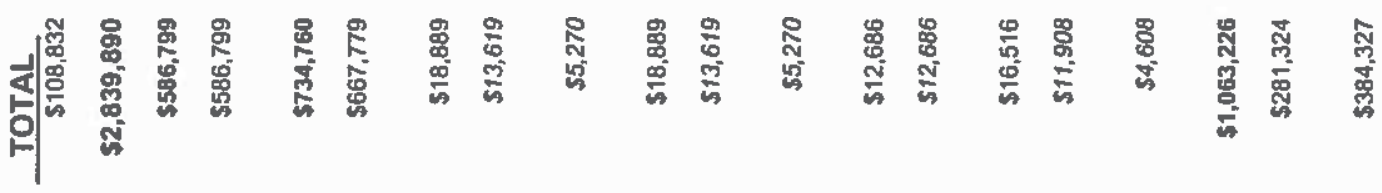

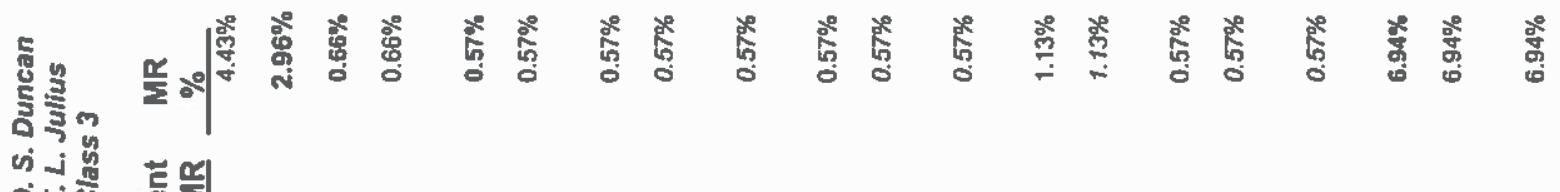

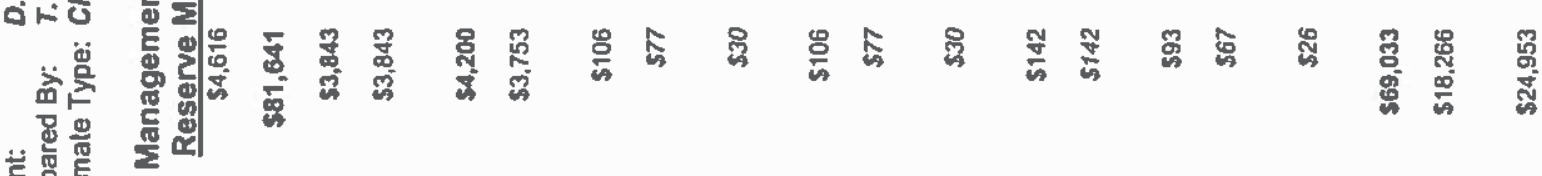

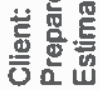

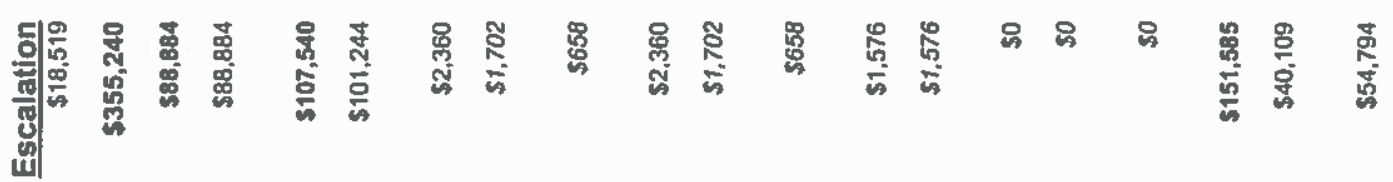

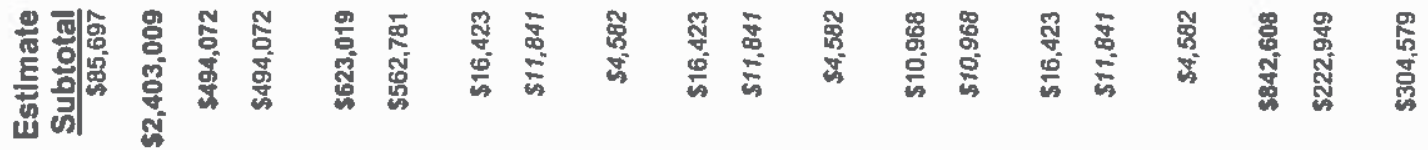

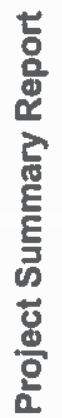

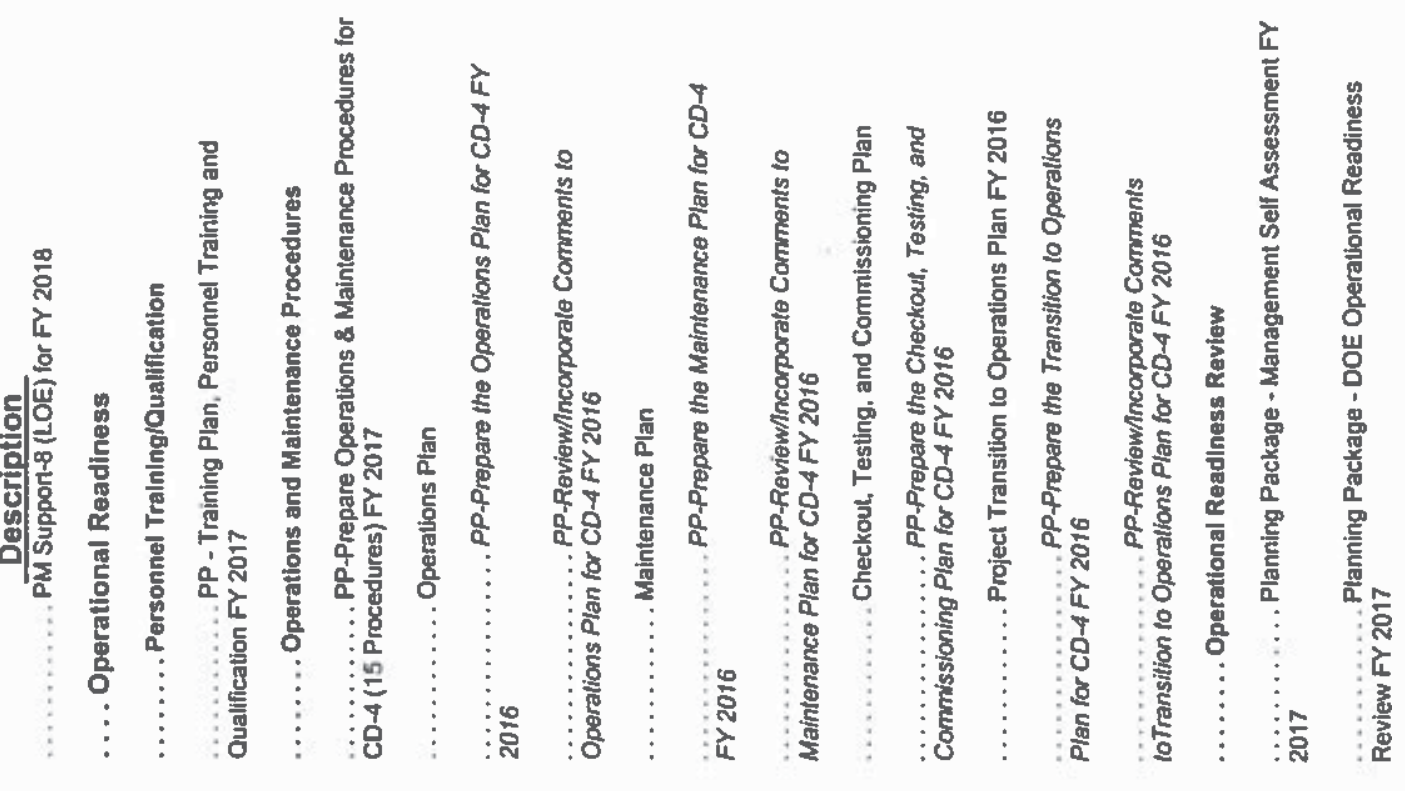

(1)

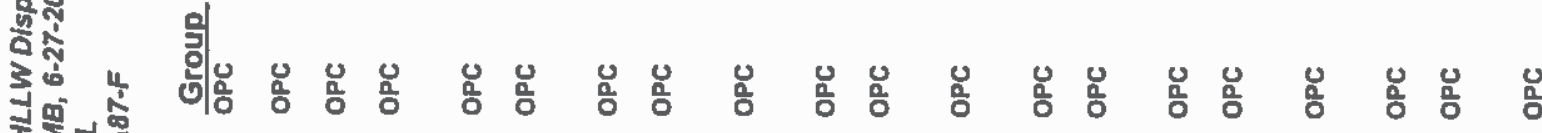

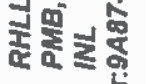

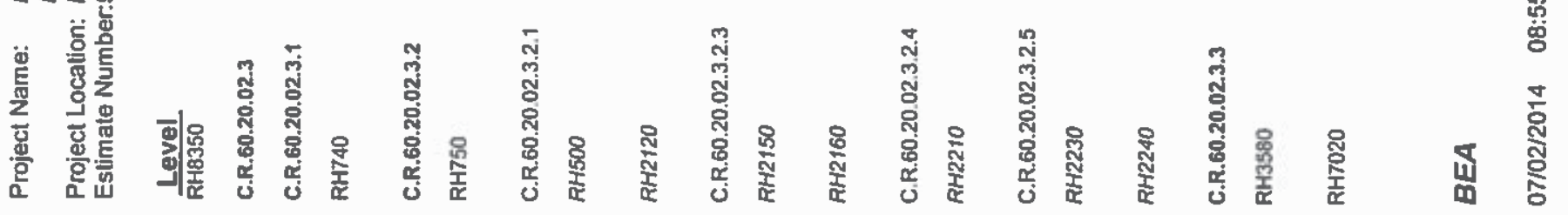




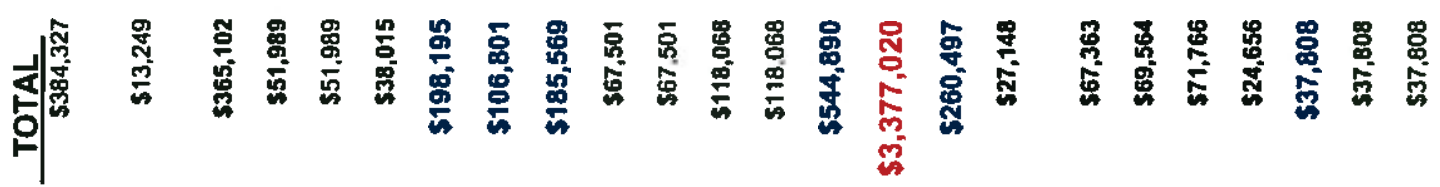

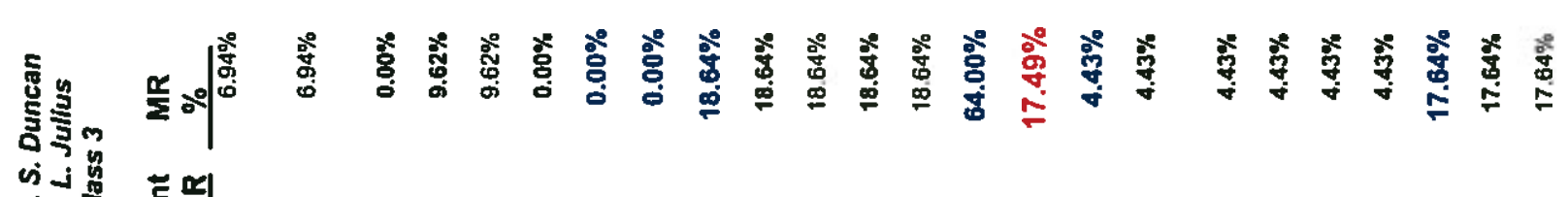

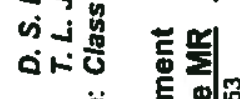

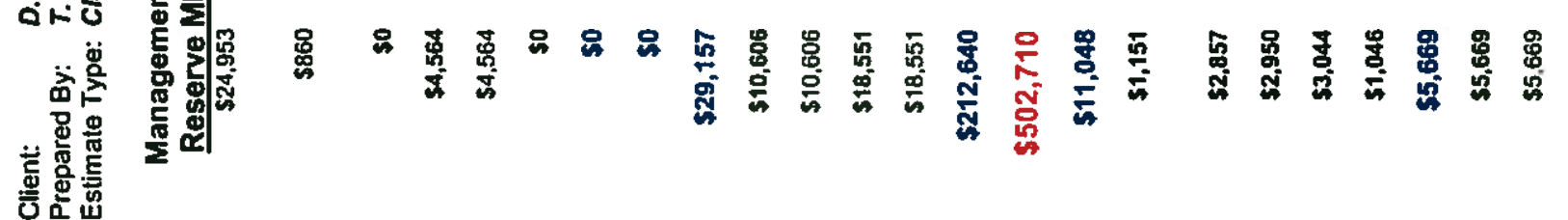

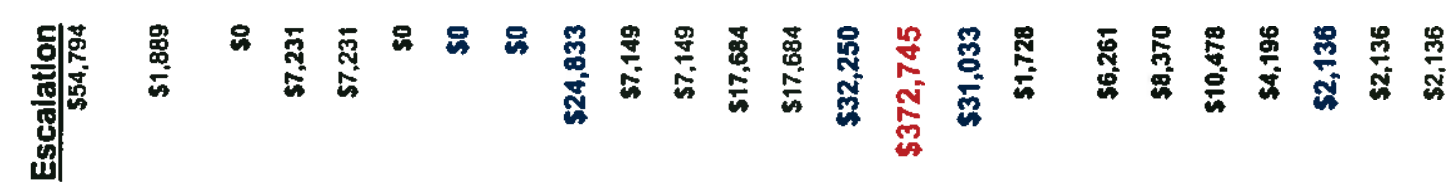

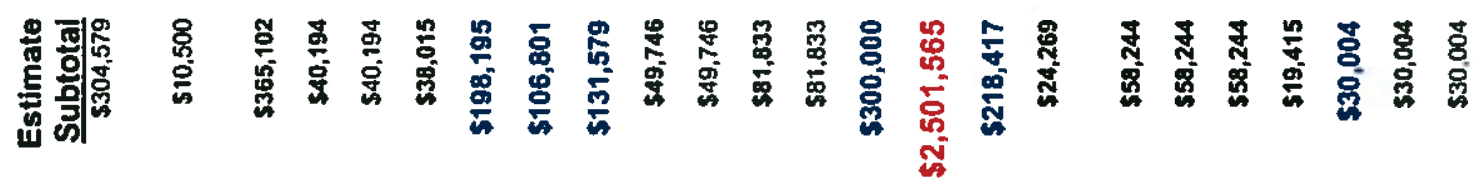

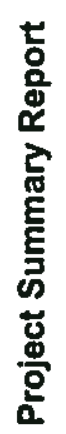
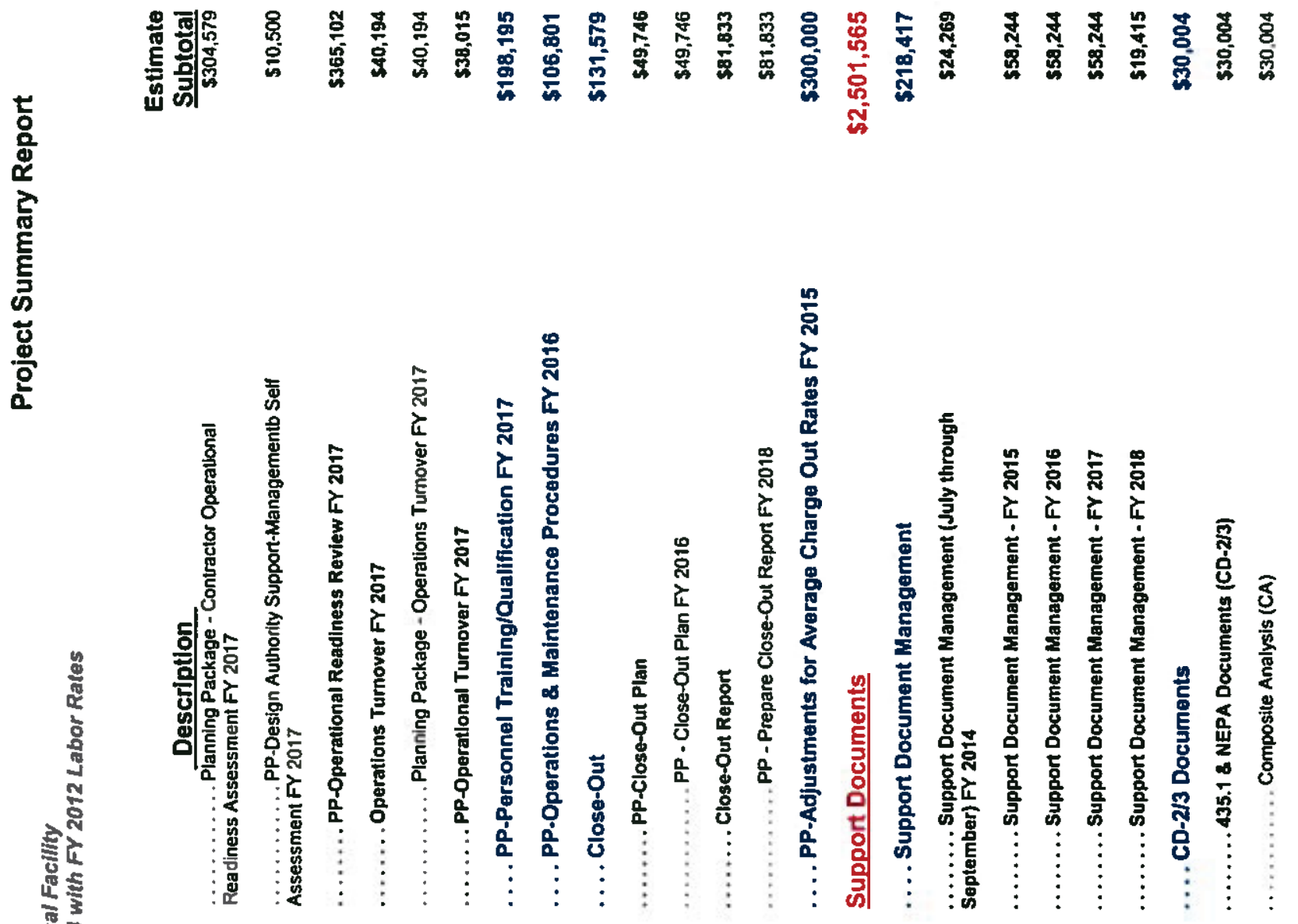

旅

sin

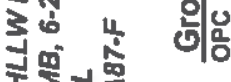

ㅎํ용

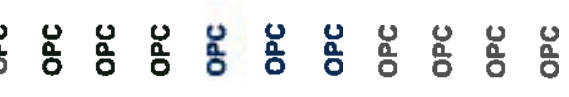

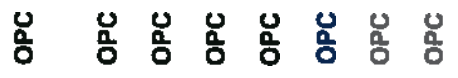

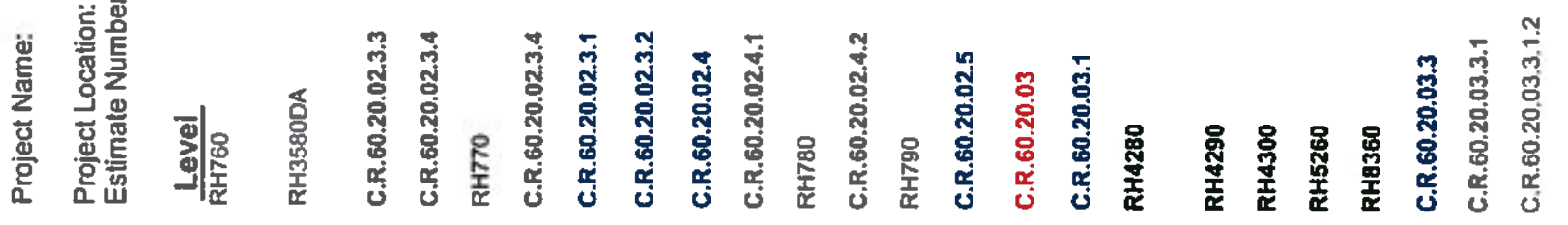




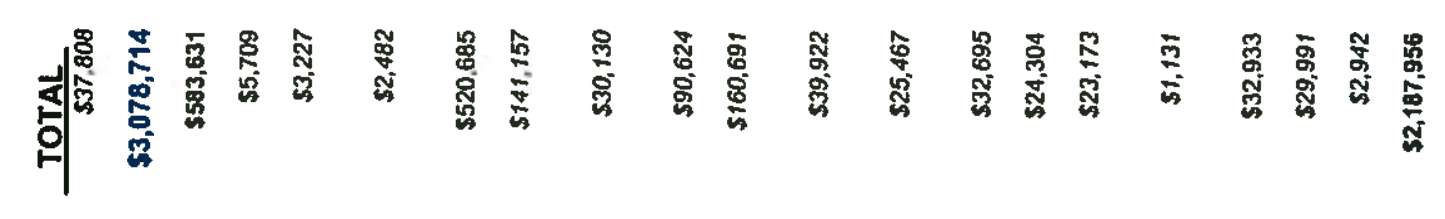

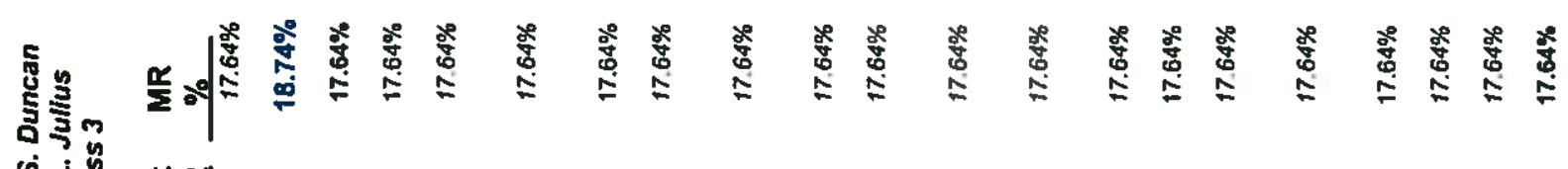
나에

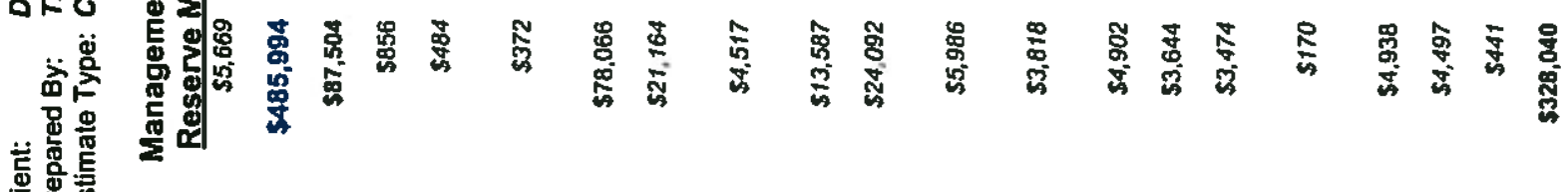

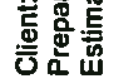

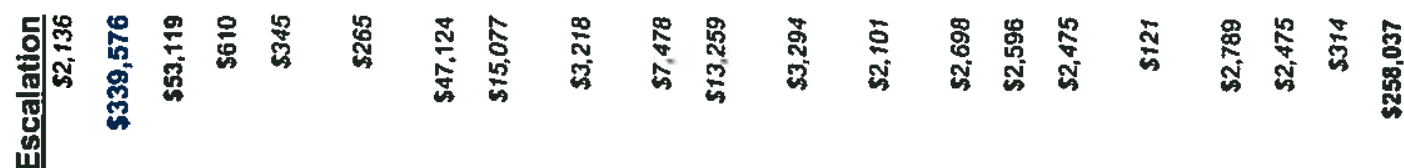

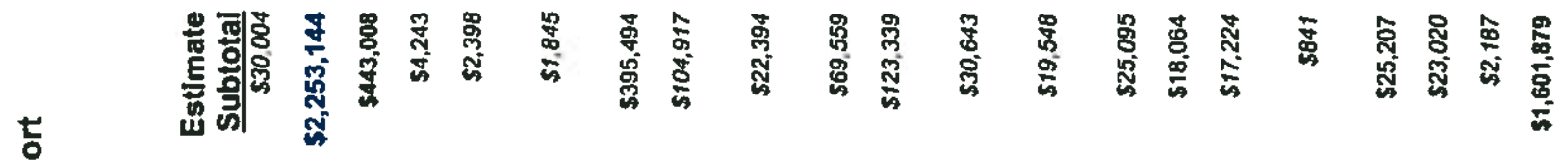

눙

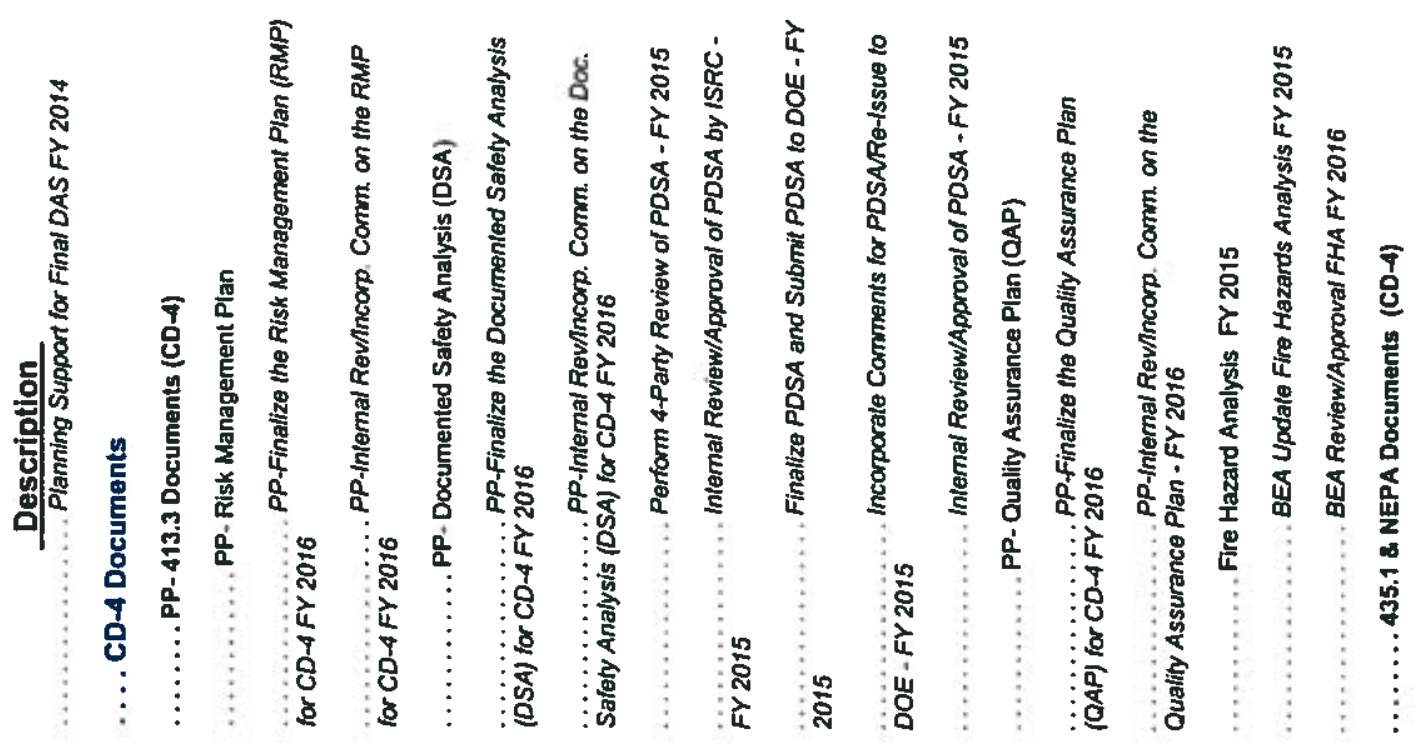

豁

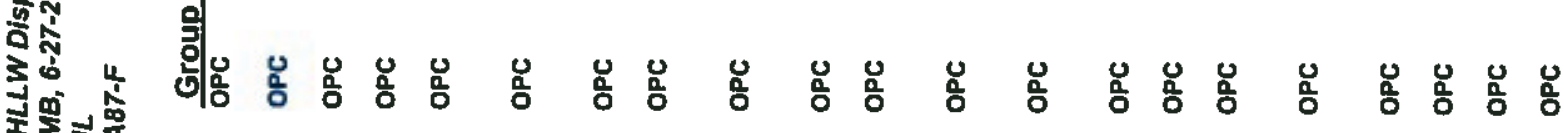

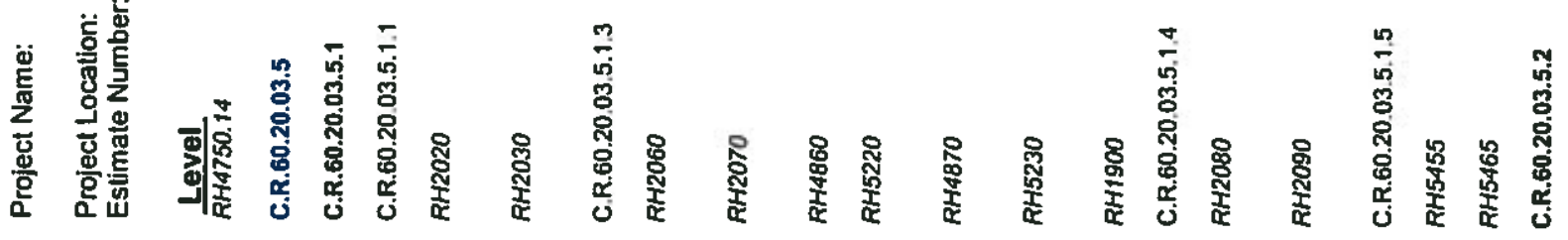




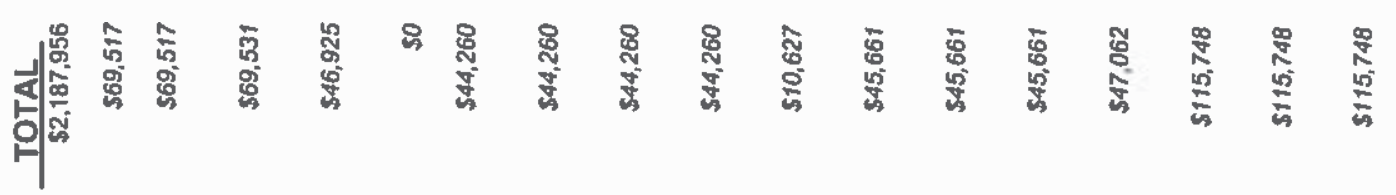

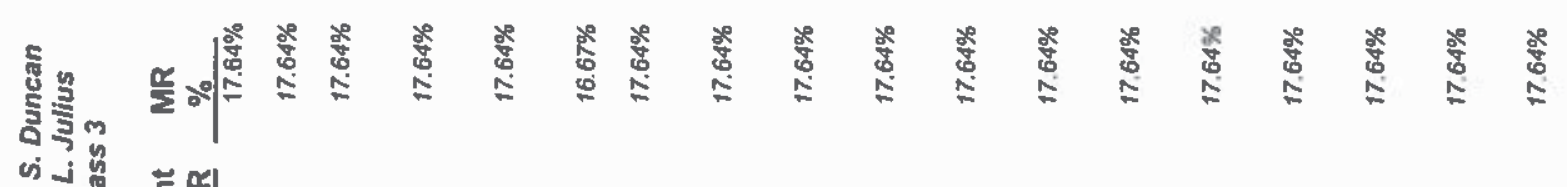

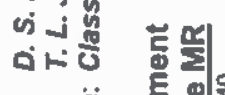

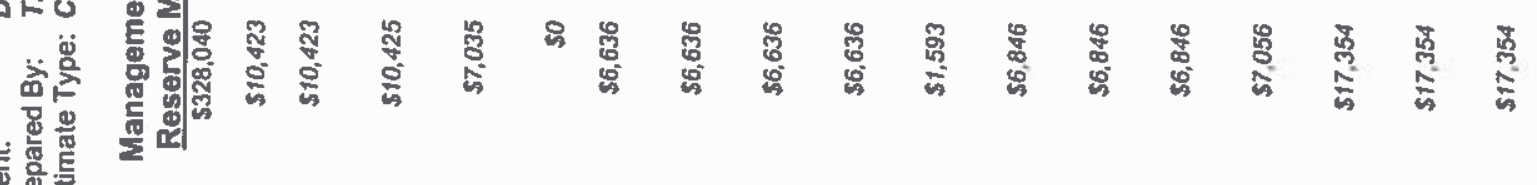

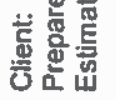

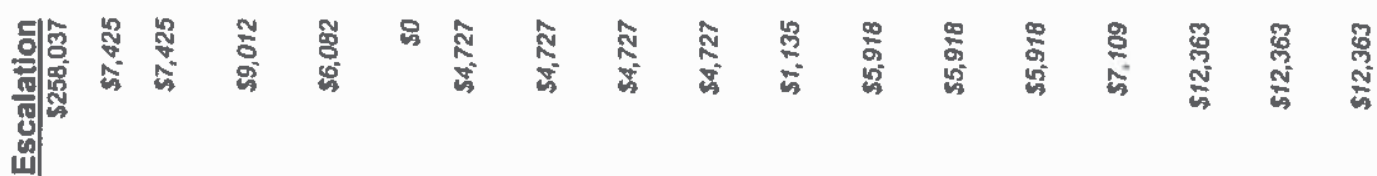

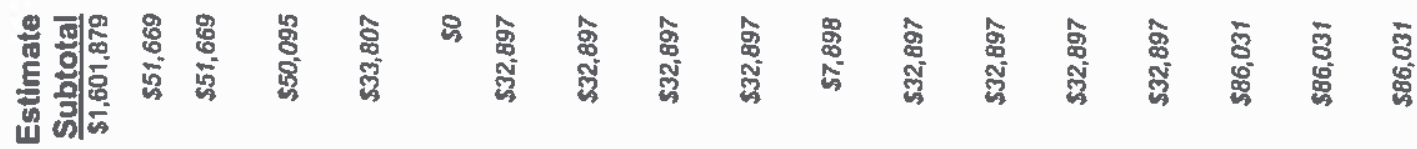

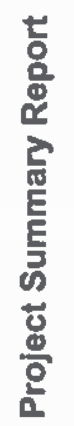

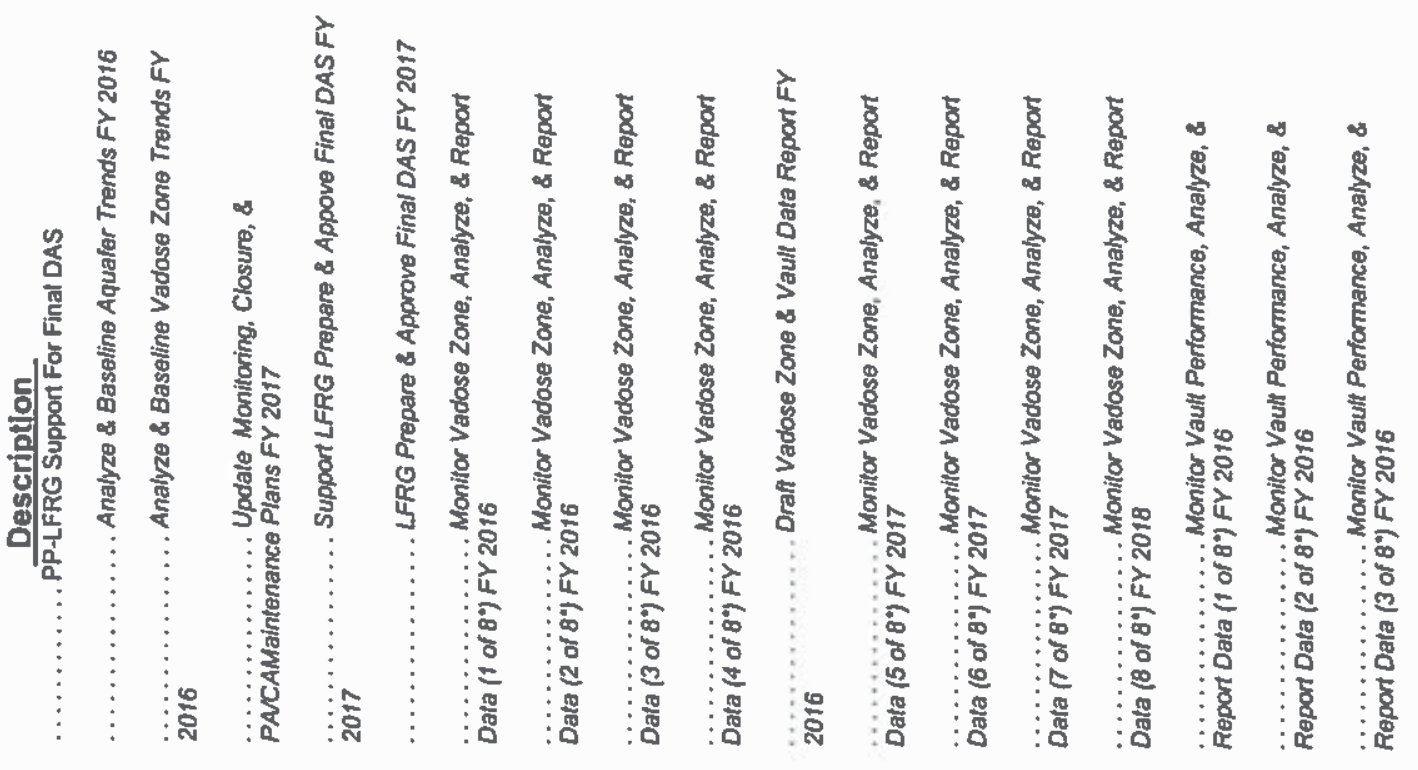

$8 \frac{1}{5}$

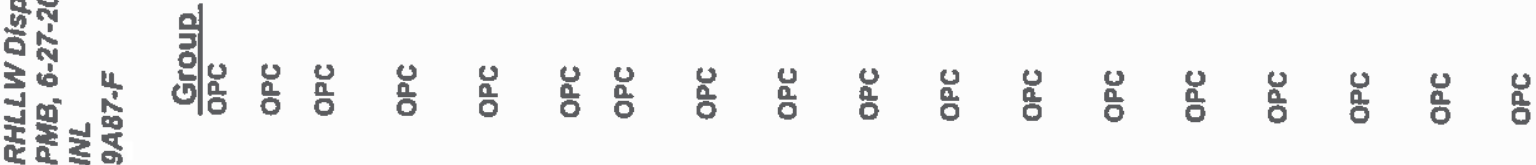

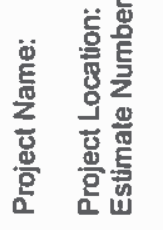
戴唯 


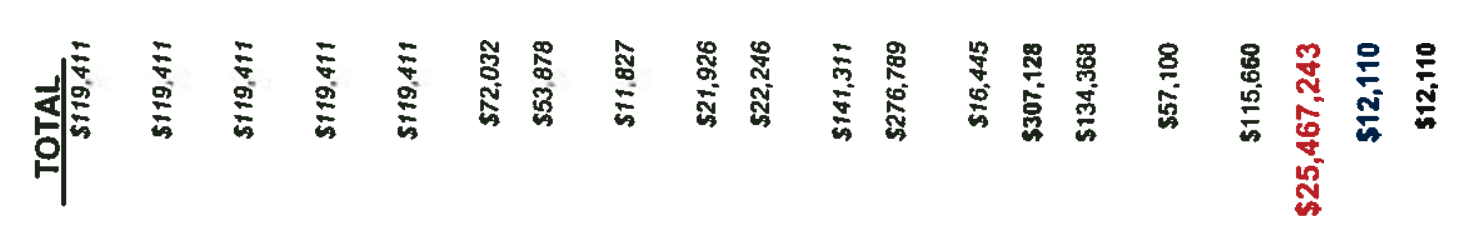

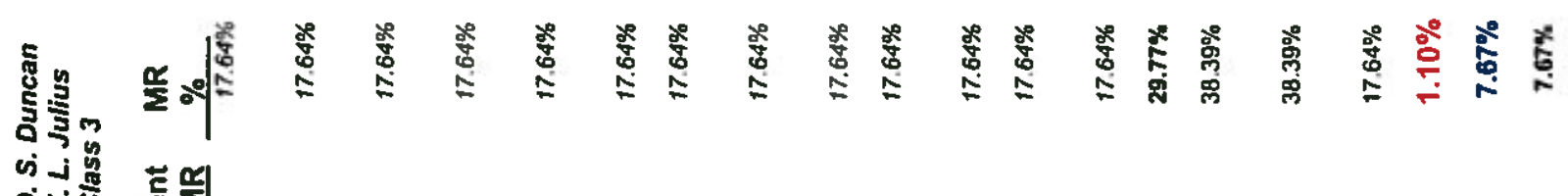

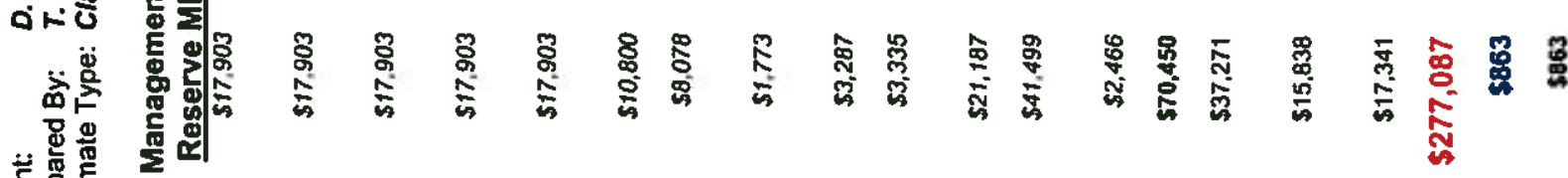

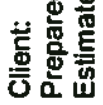

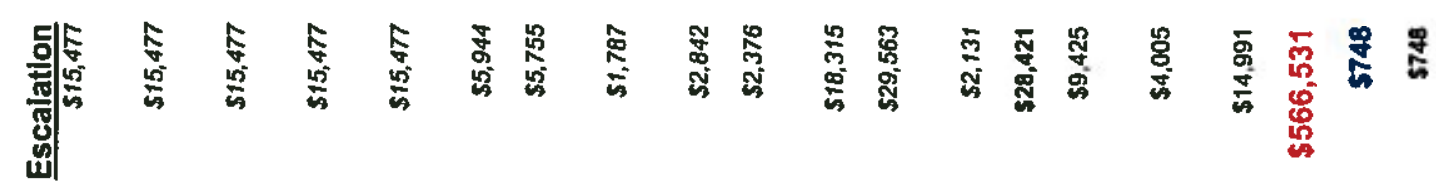

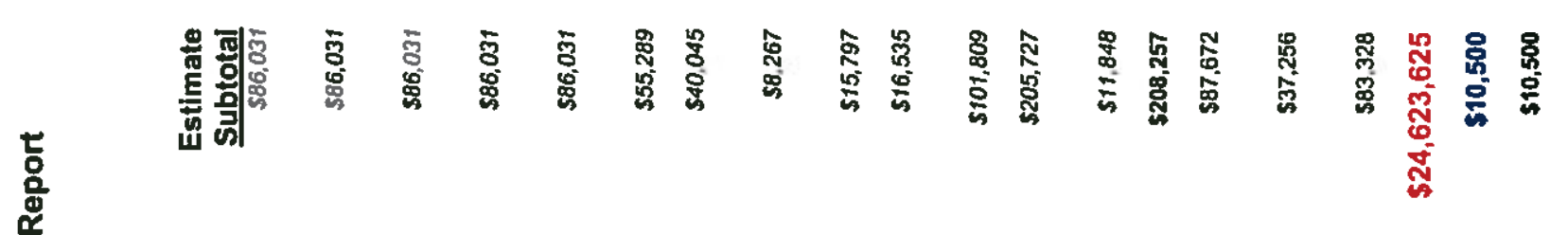

를

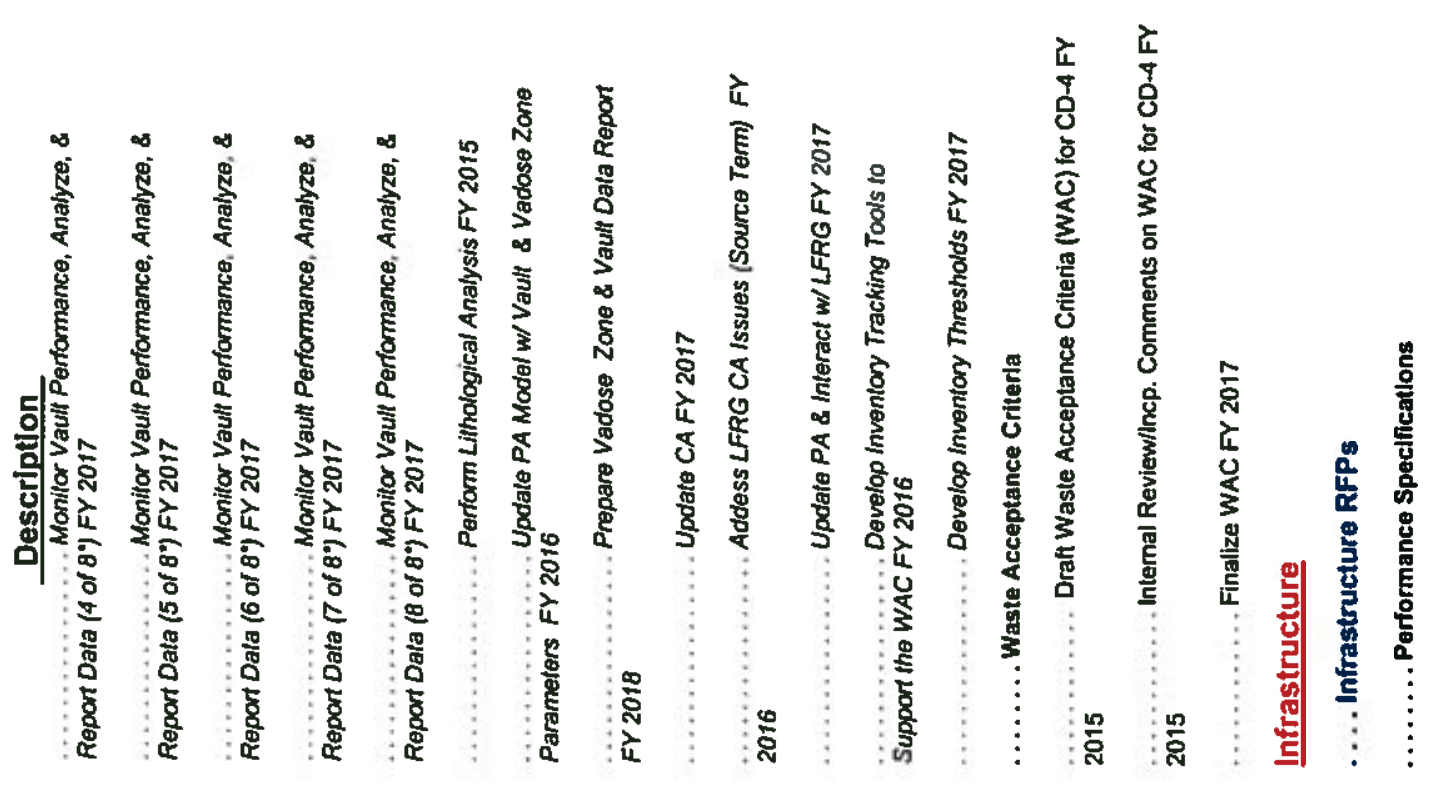

s

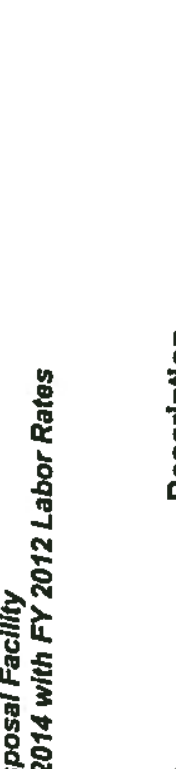

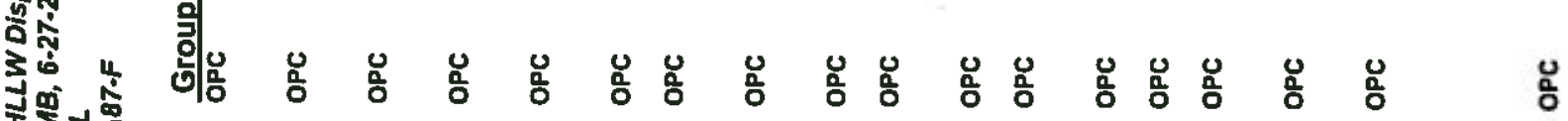

ำ

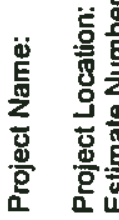




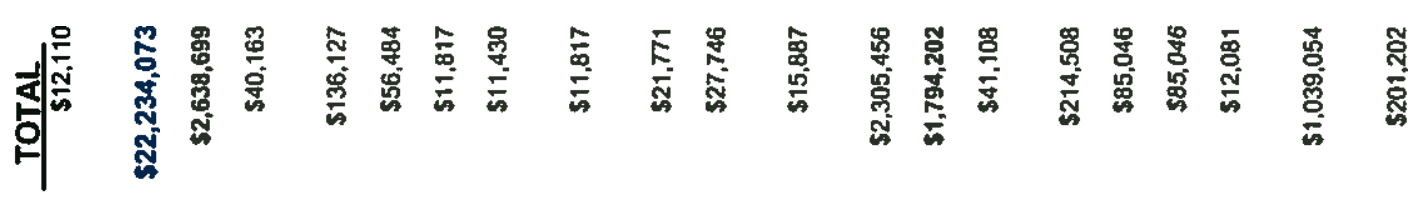

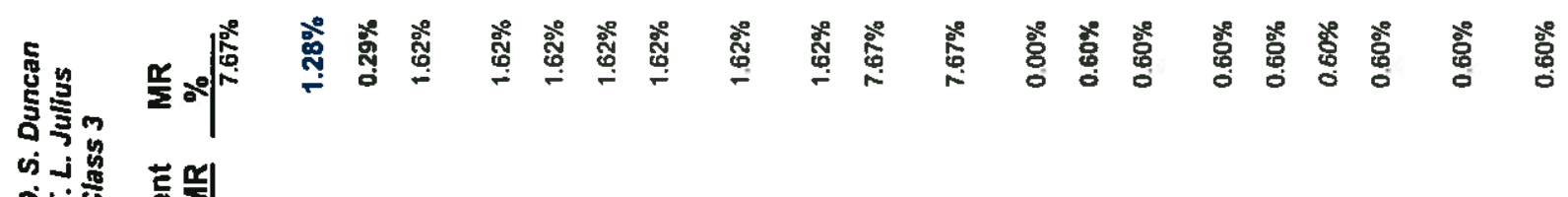

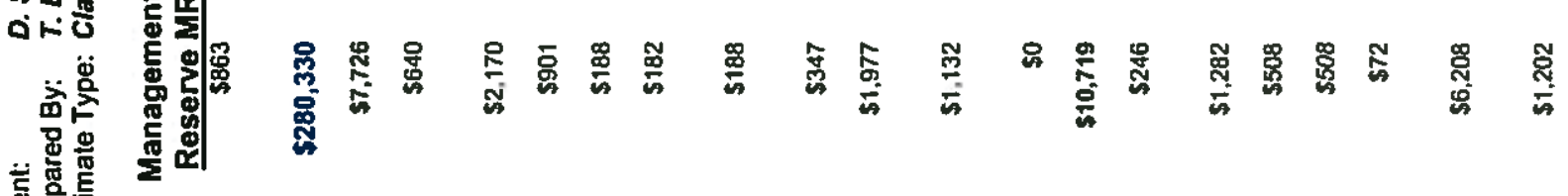

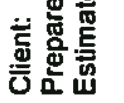

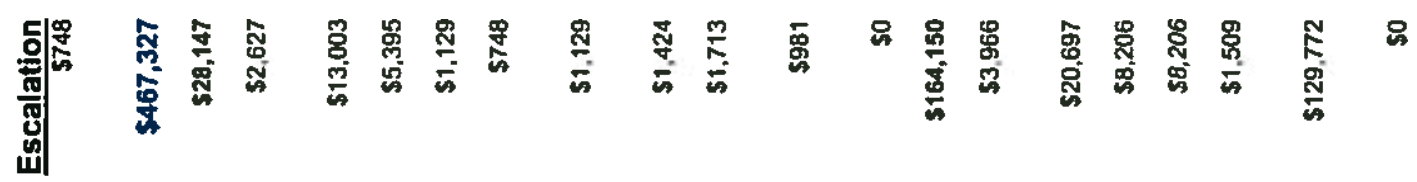

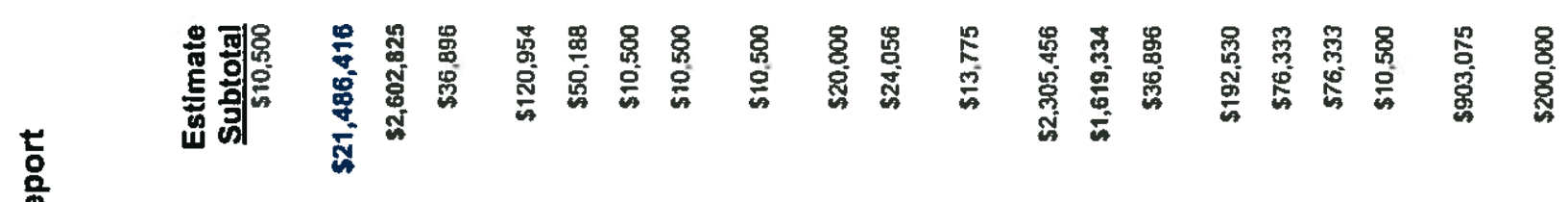

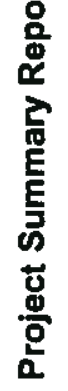

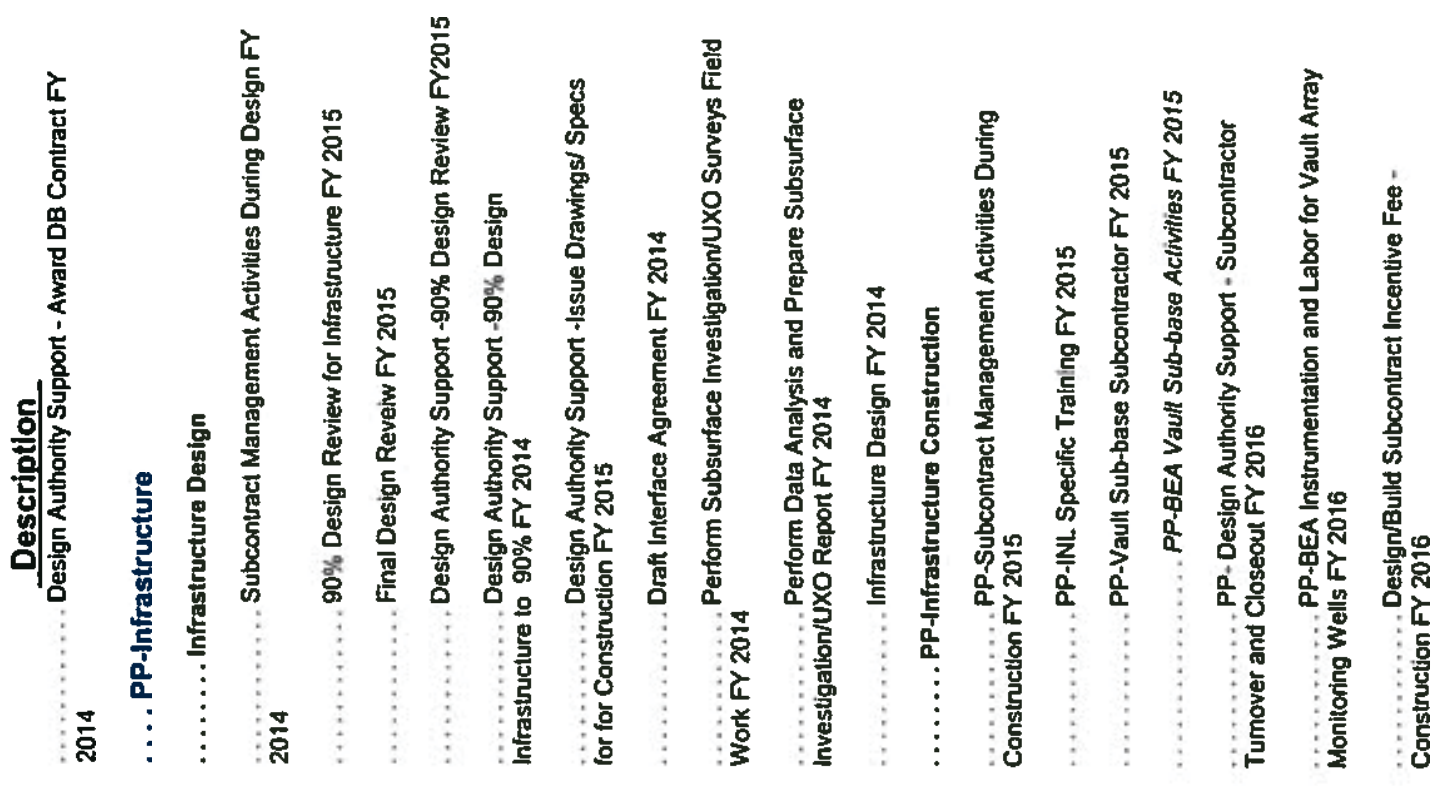

는

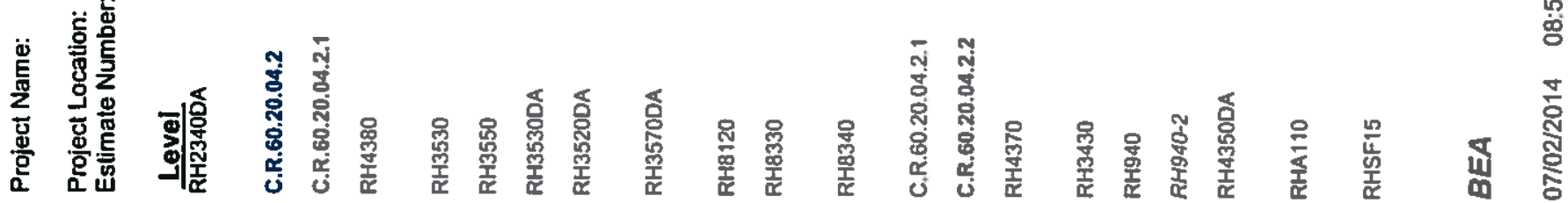




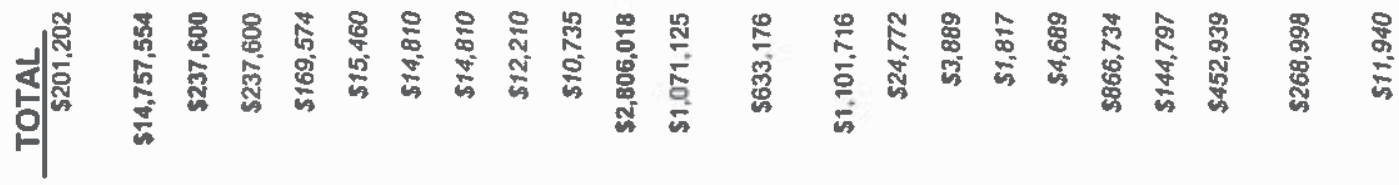

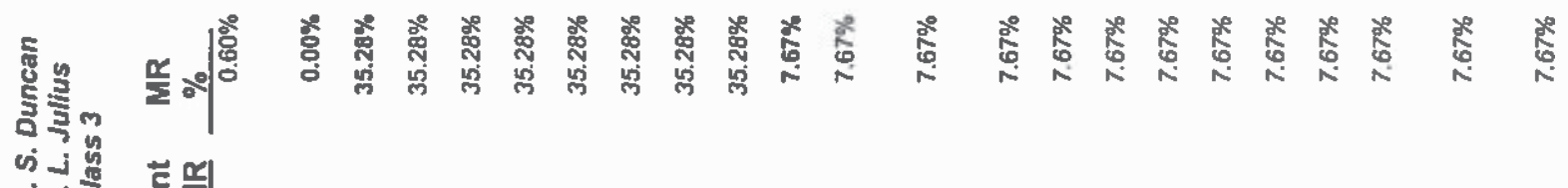

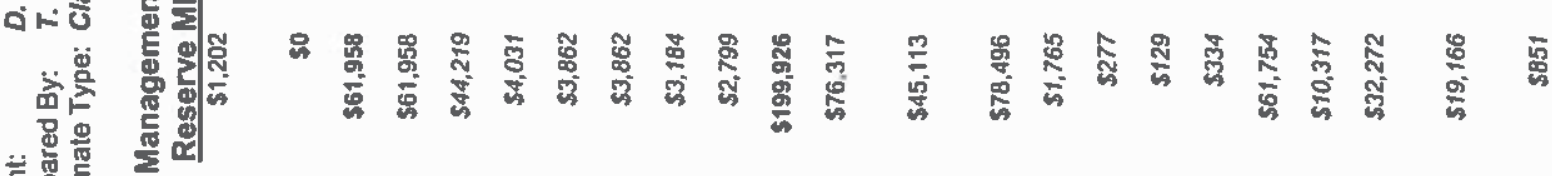
言器票

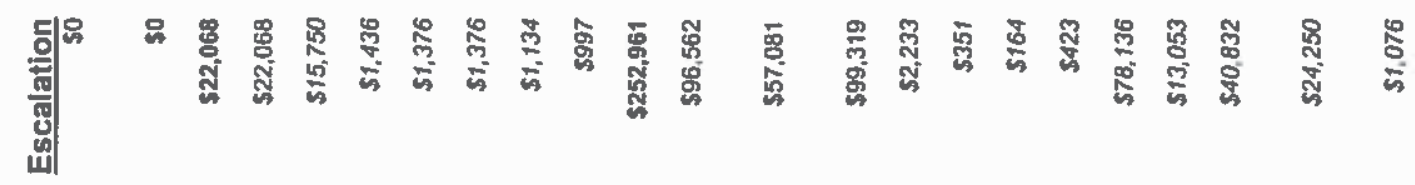

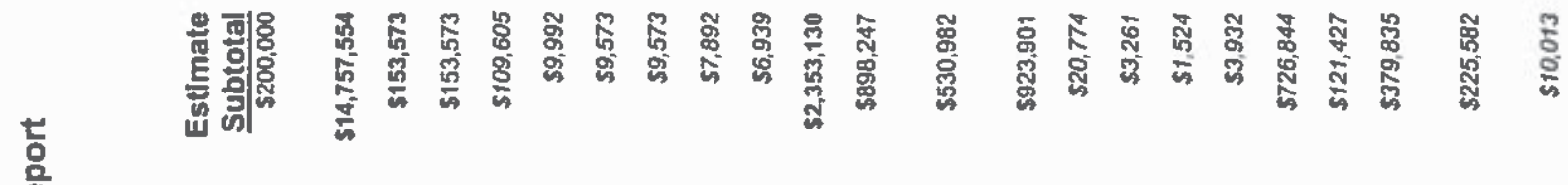

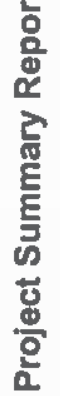

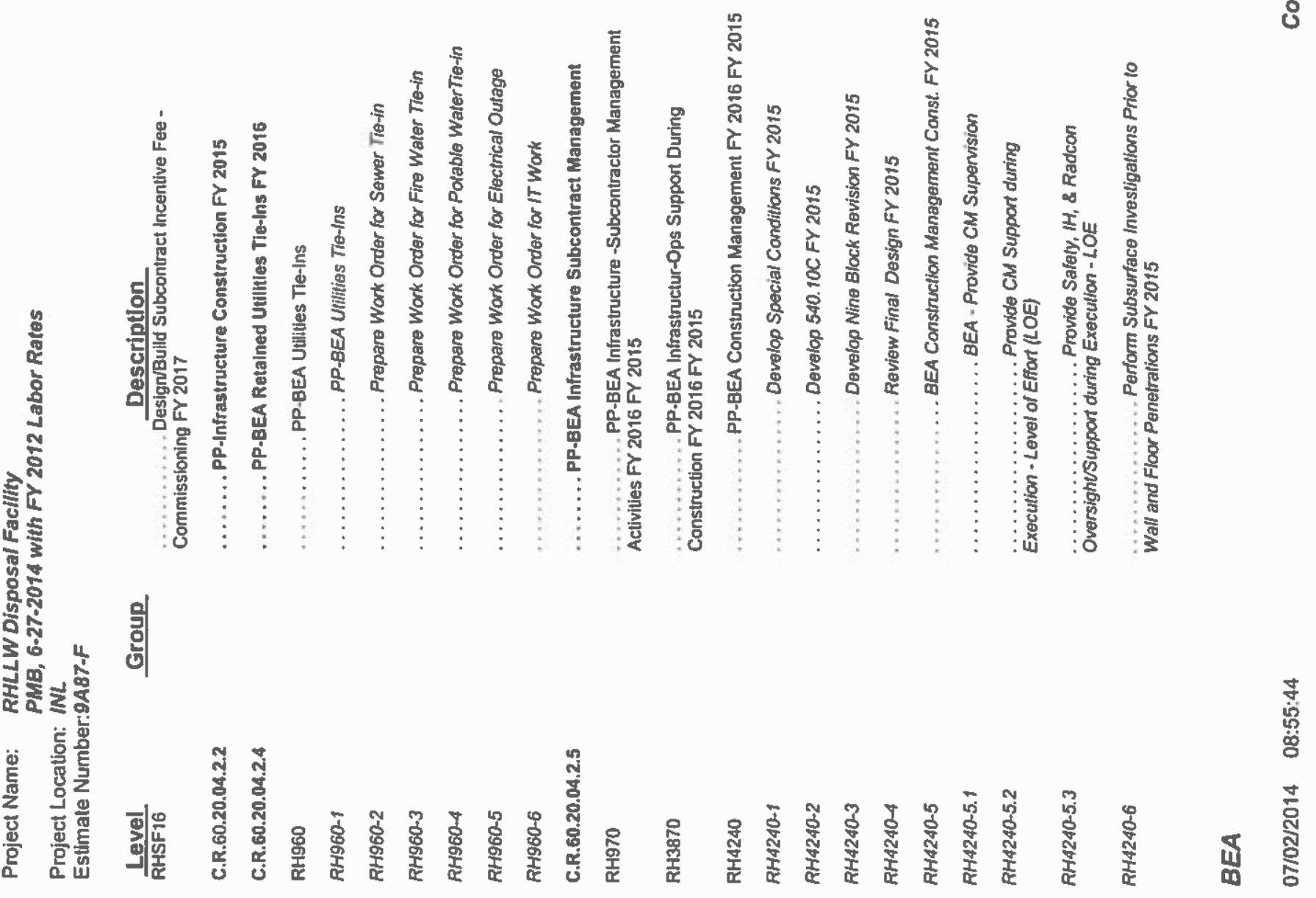




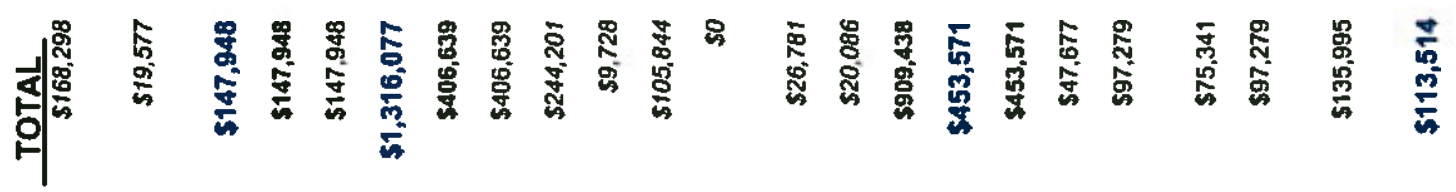

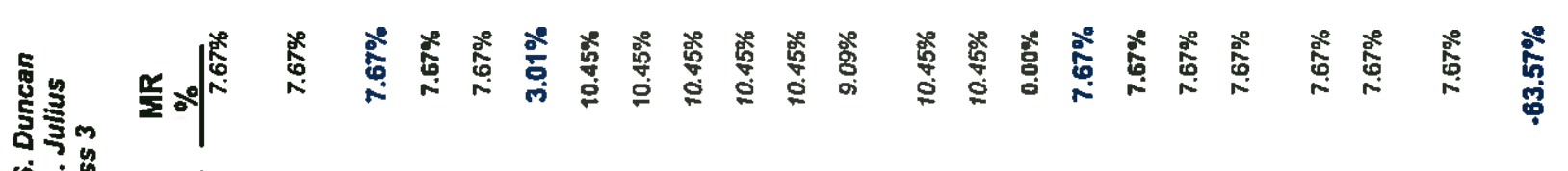

ज十⿱ ⿻上丨

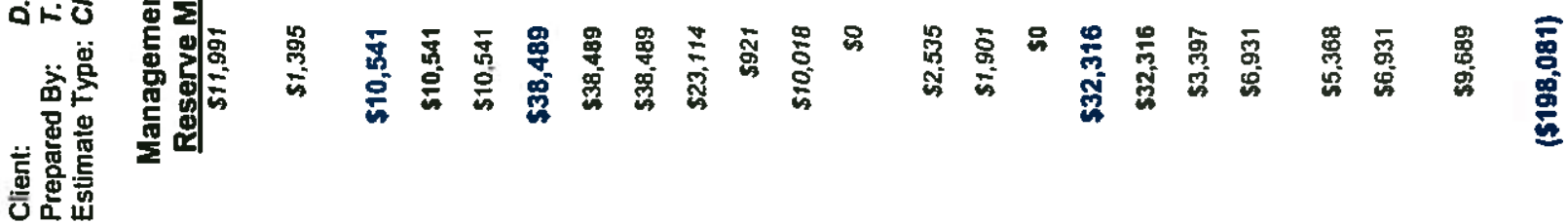

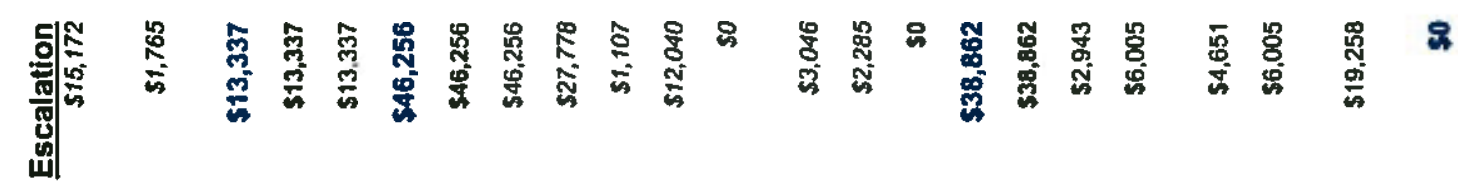

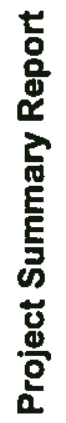

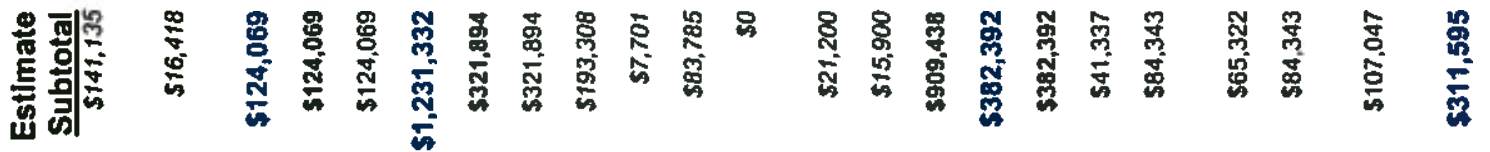

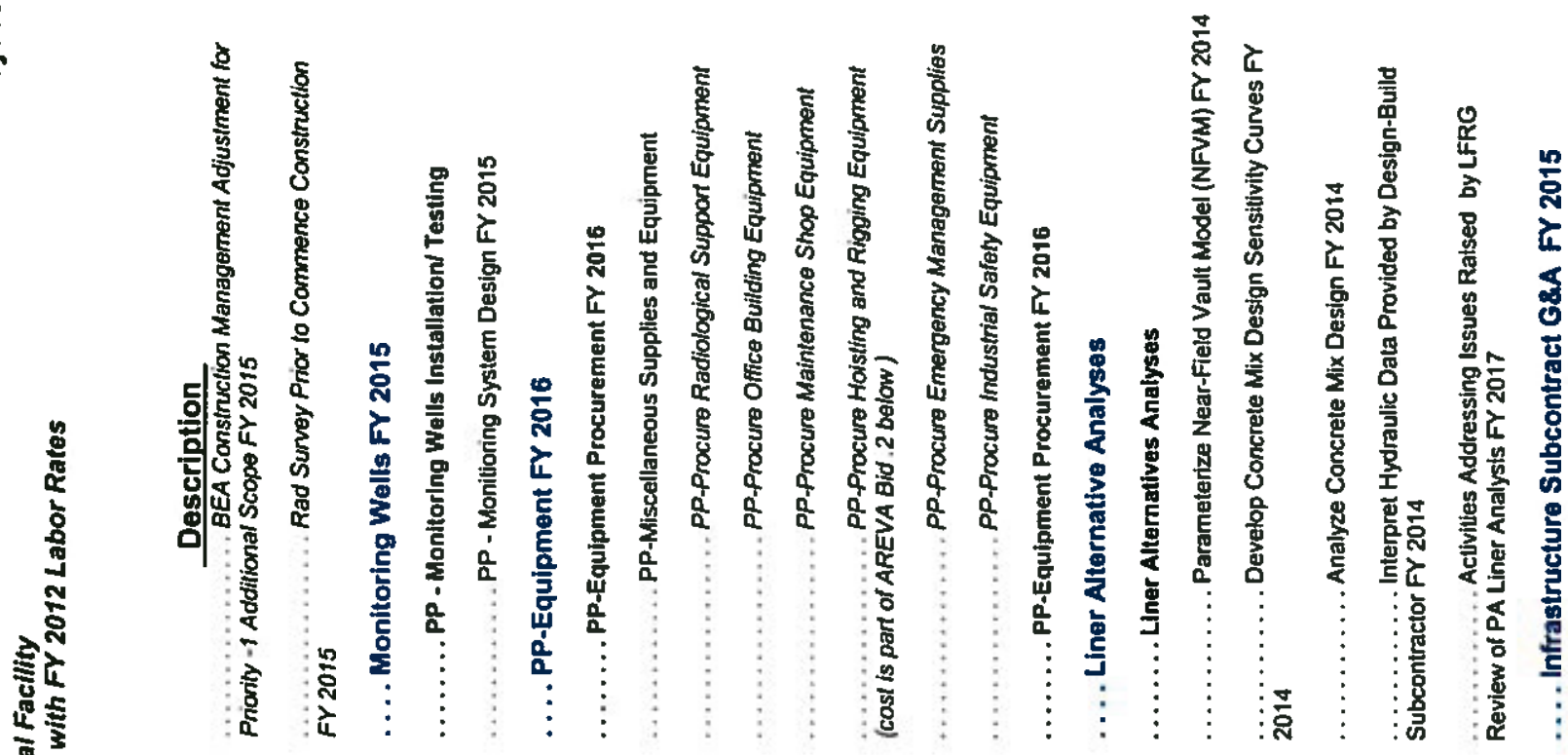

ริํำ

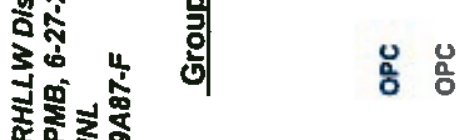

๕

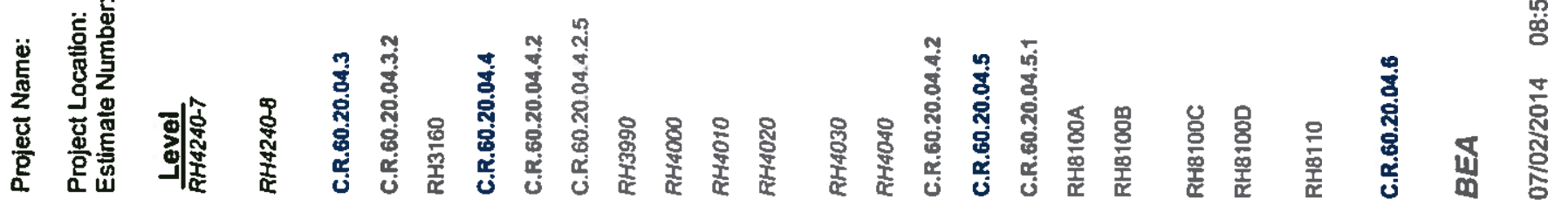




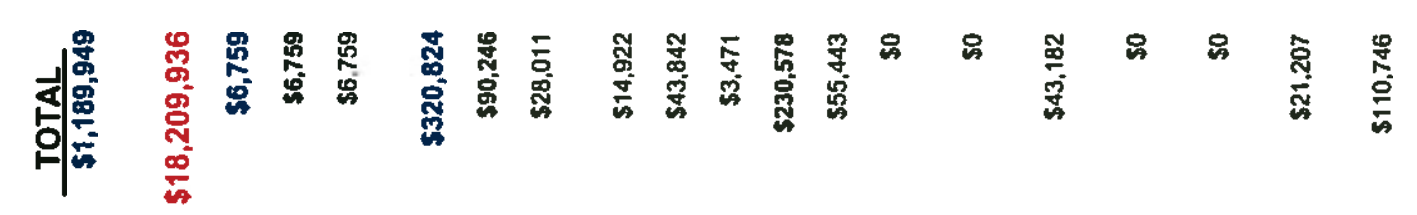

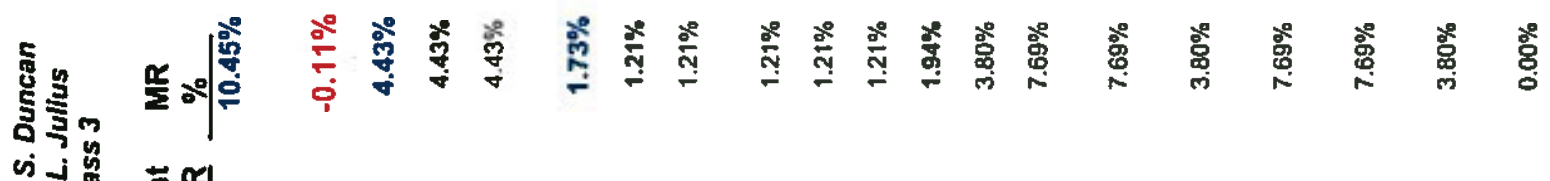

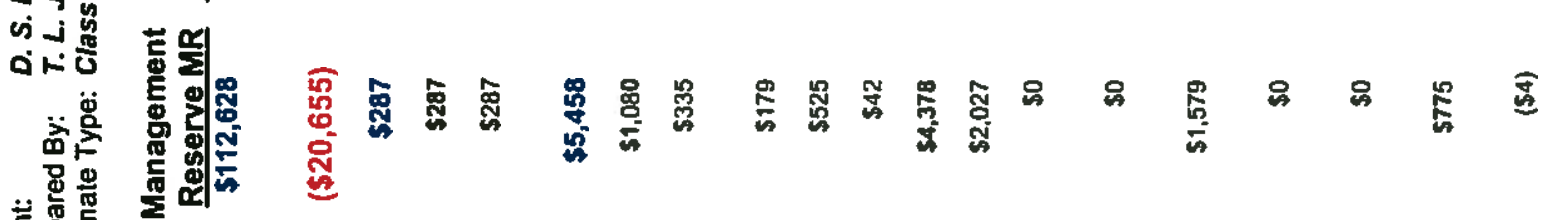

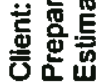

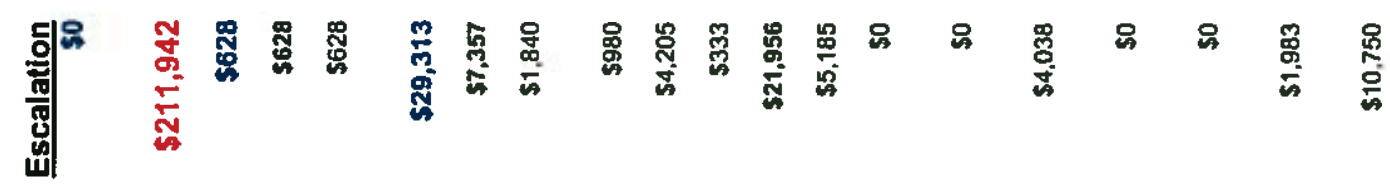

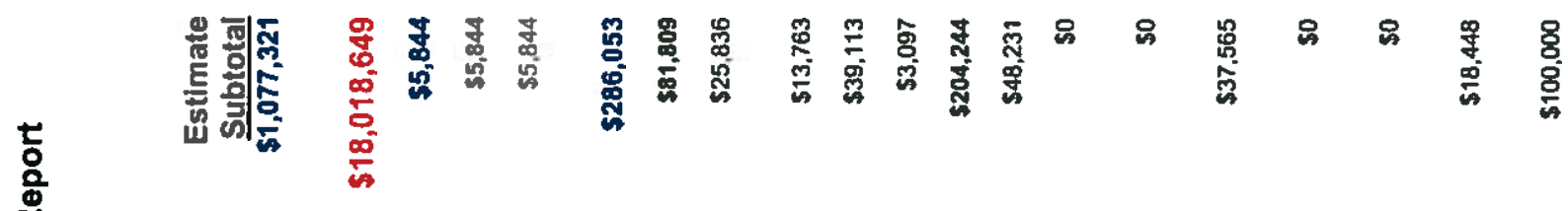

要
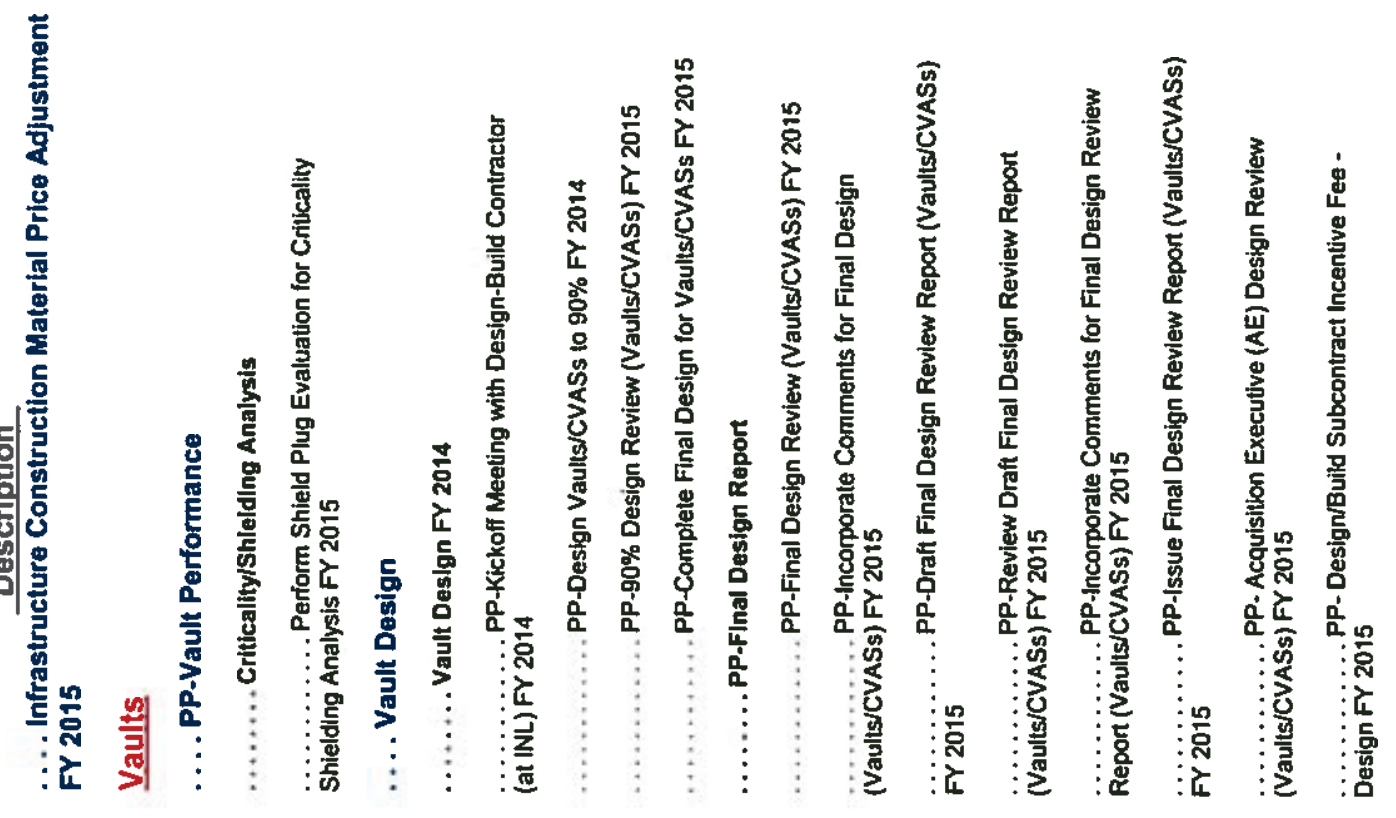

震要

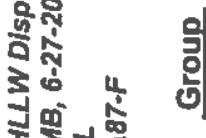

0
$\vdots$

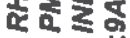

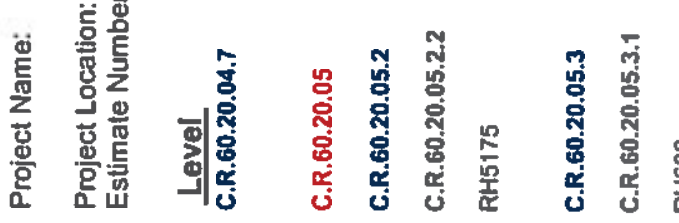

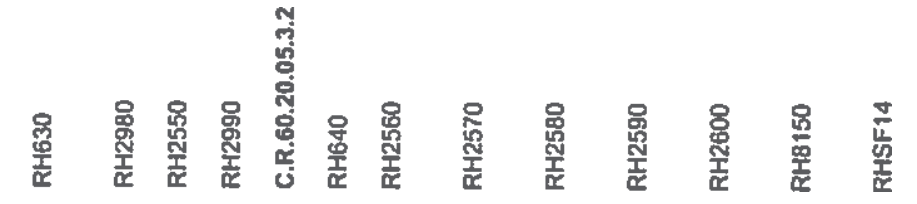




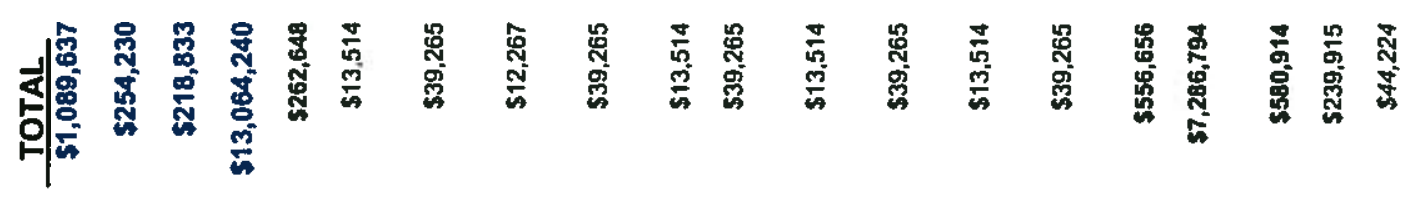

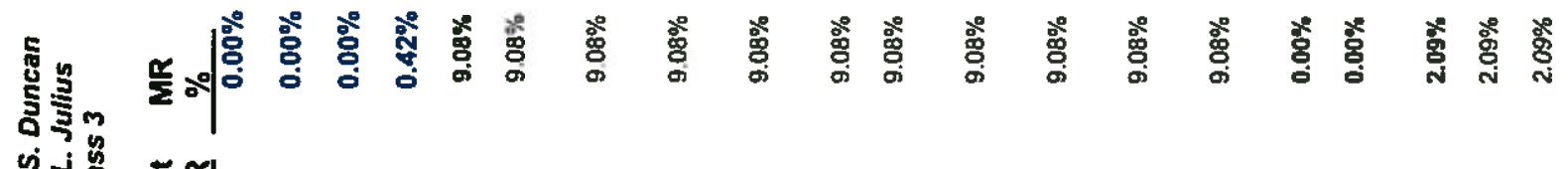

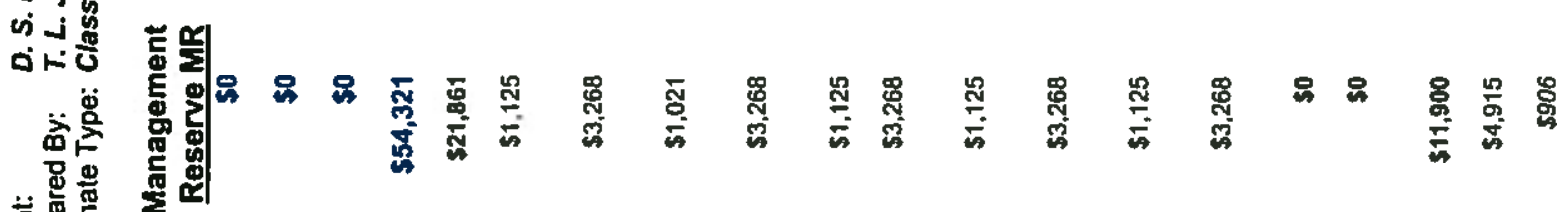
率器咅

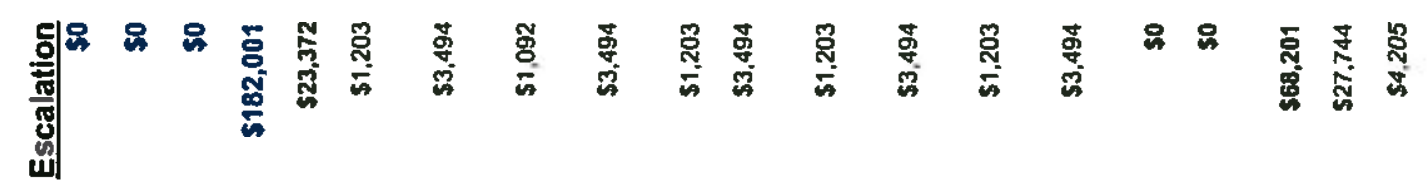

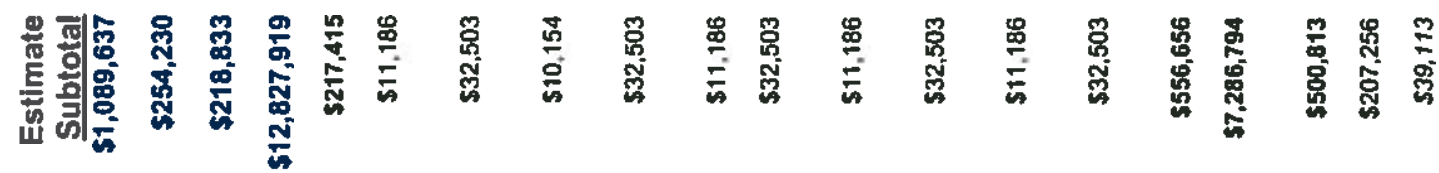

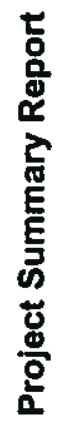
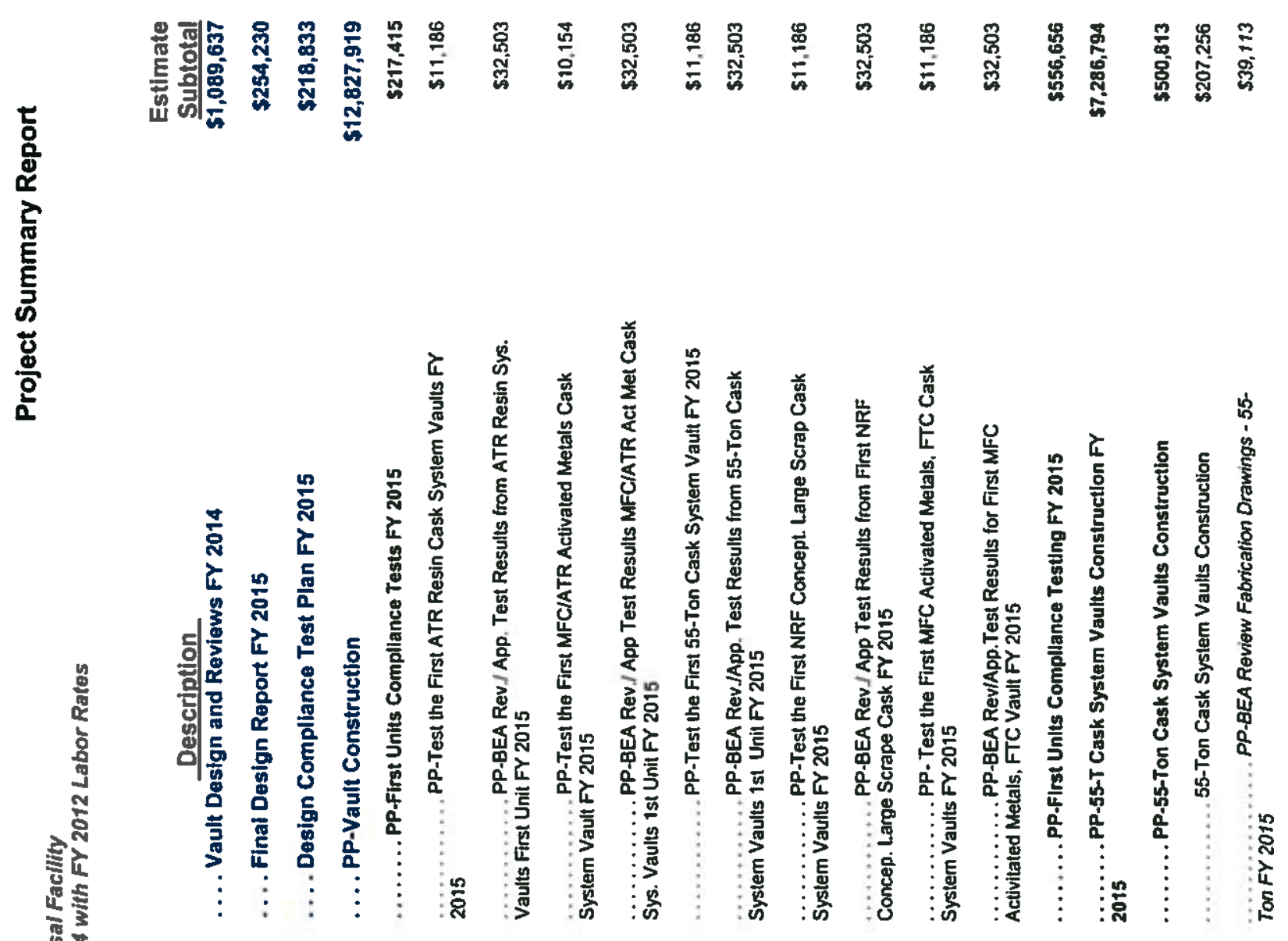

s.

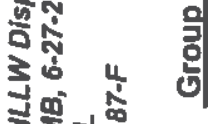<smiles>[CH]1CCCCC1</smiles>

珰 


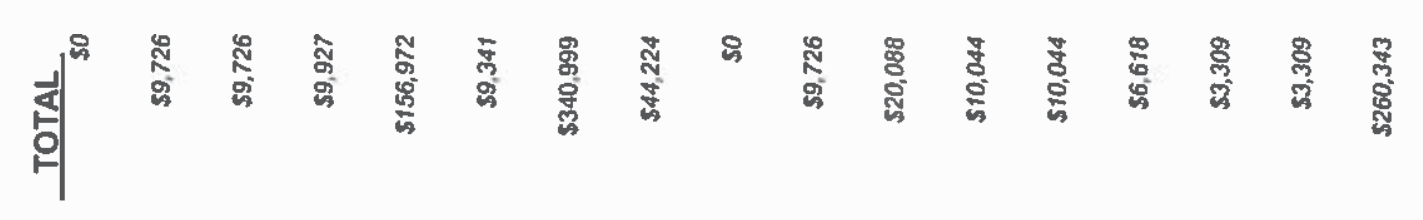

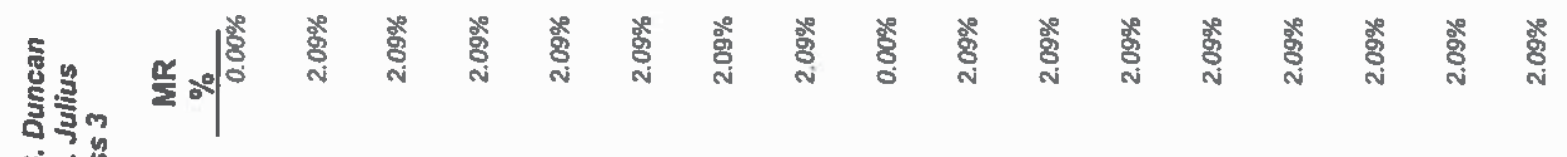

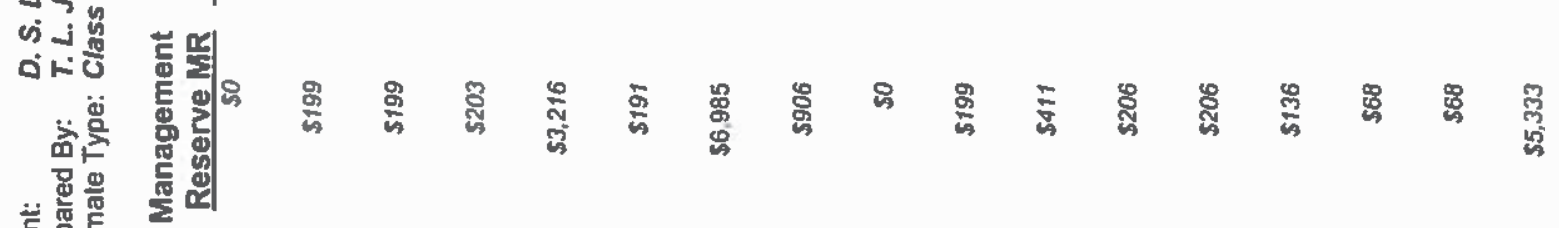
产高高

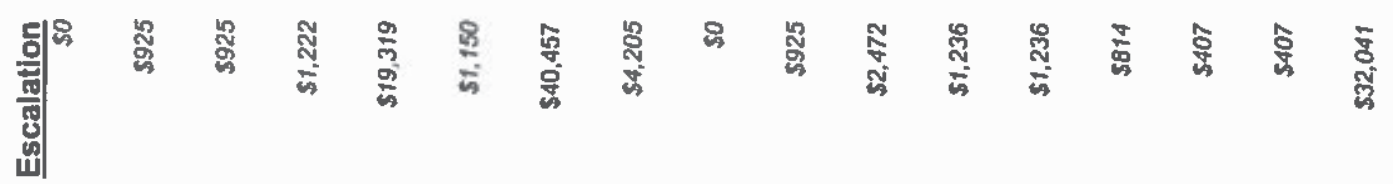

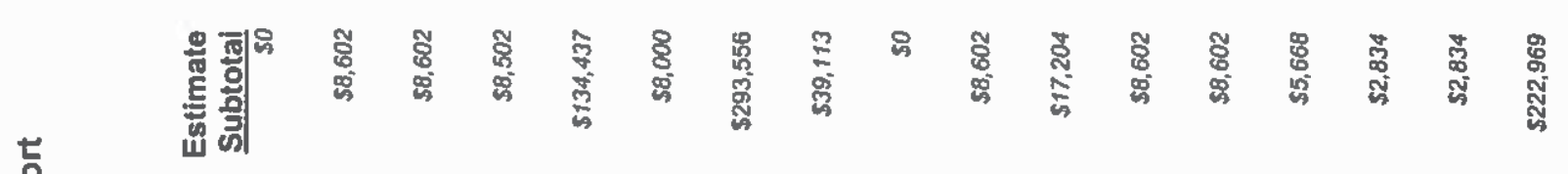

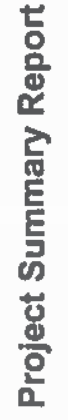

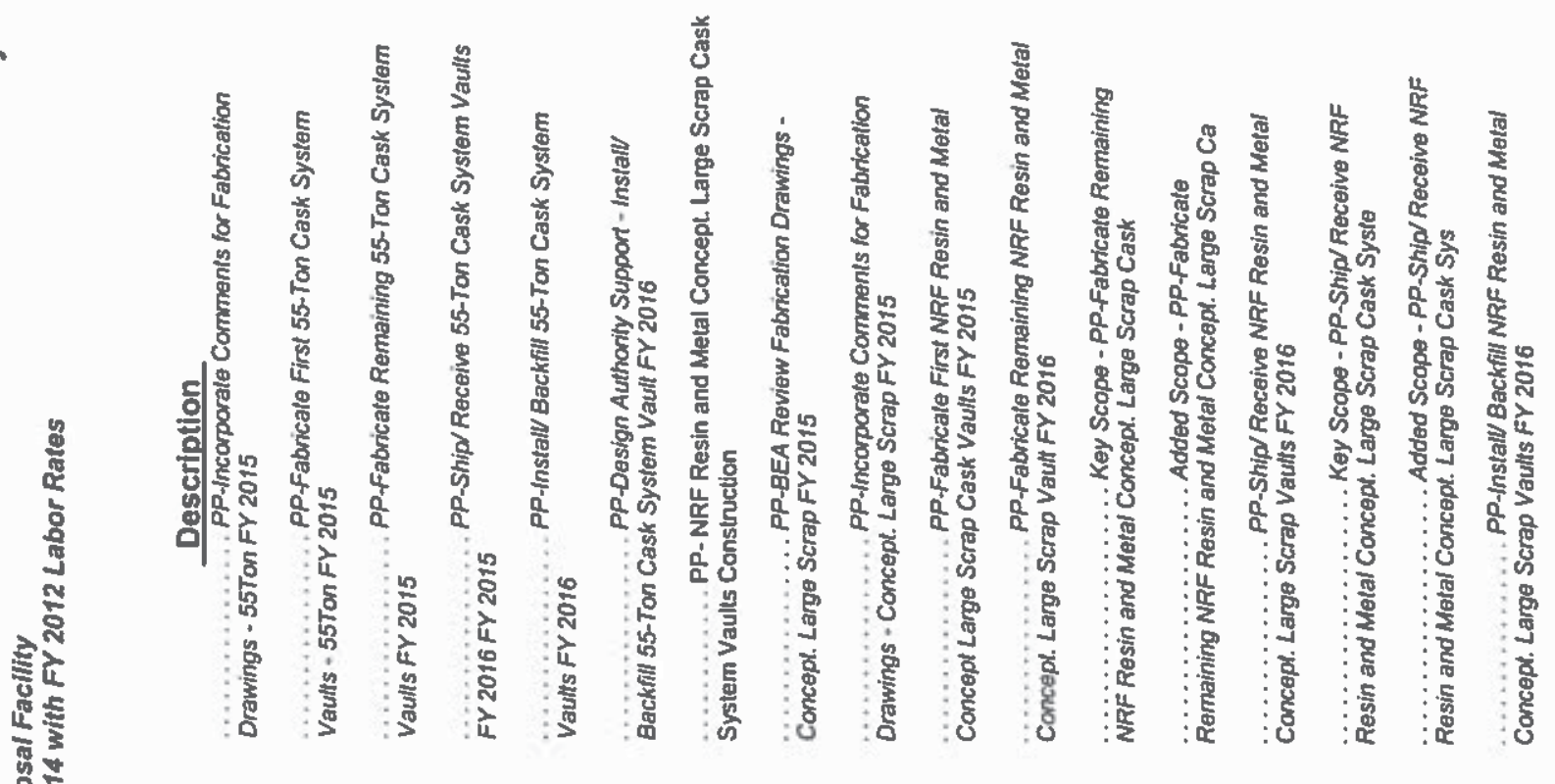

.

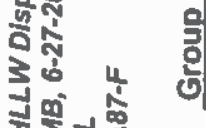

ष्ट

密 害总

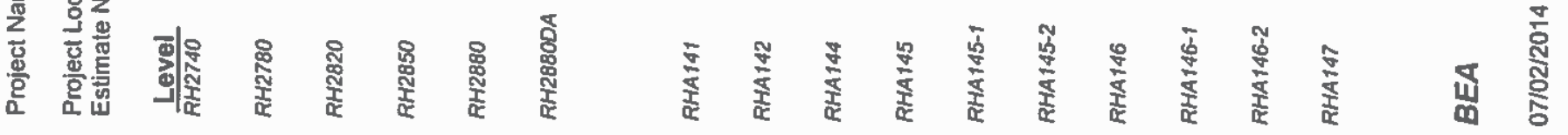




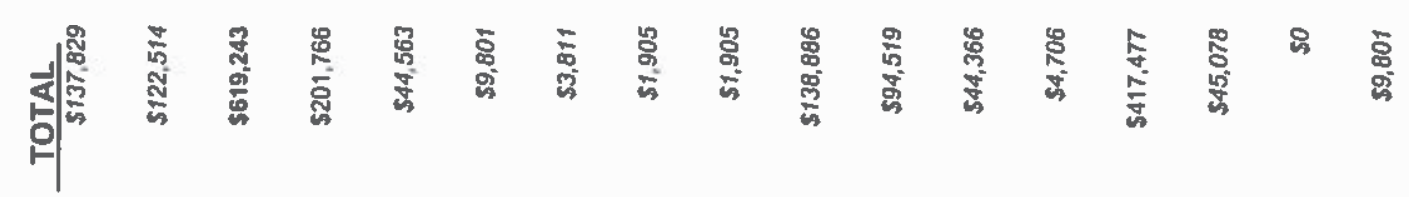

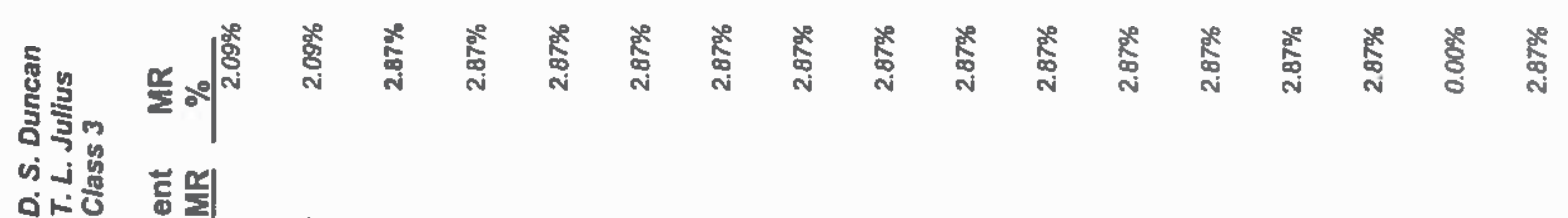

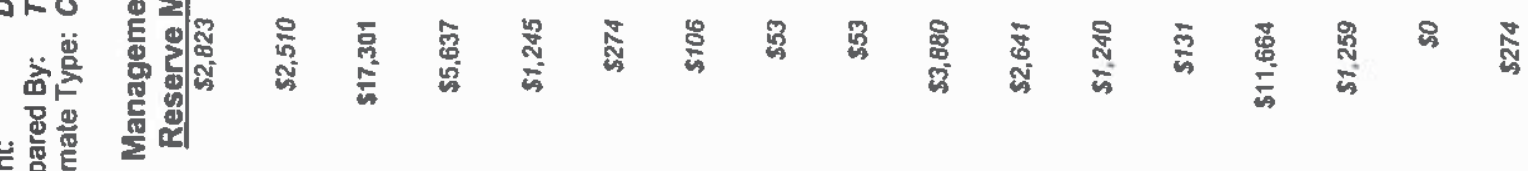

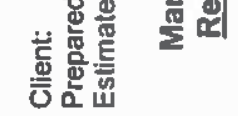

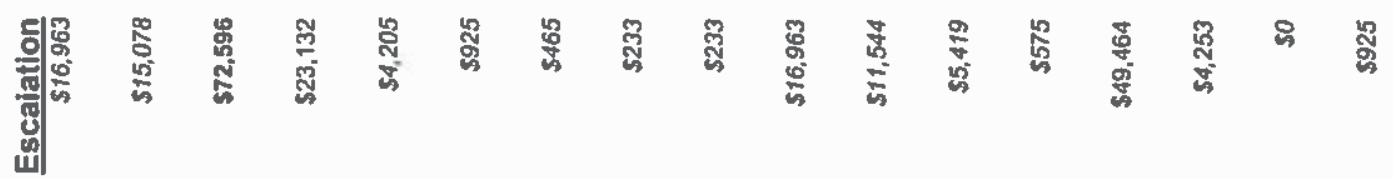

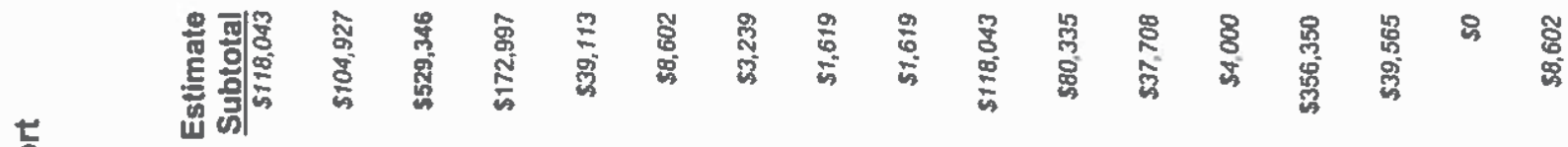

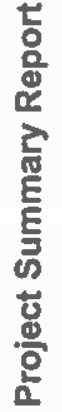

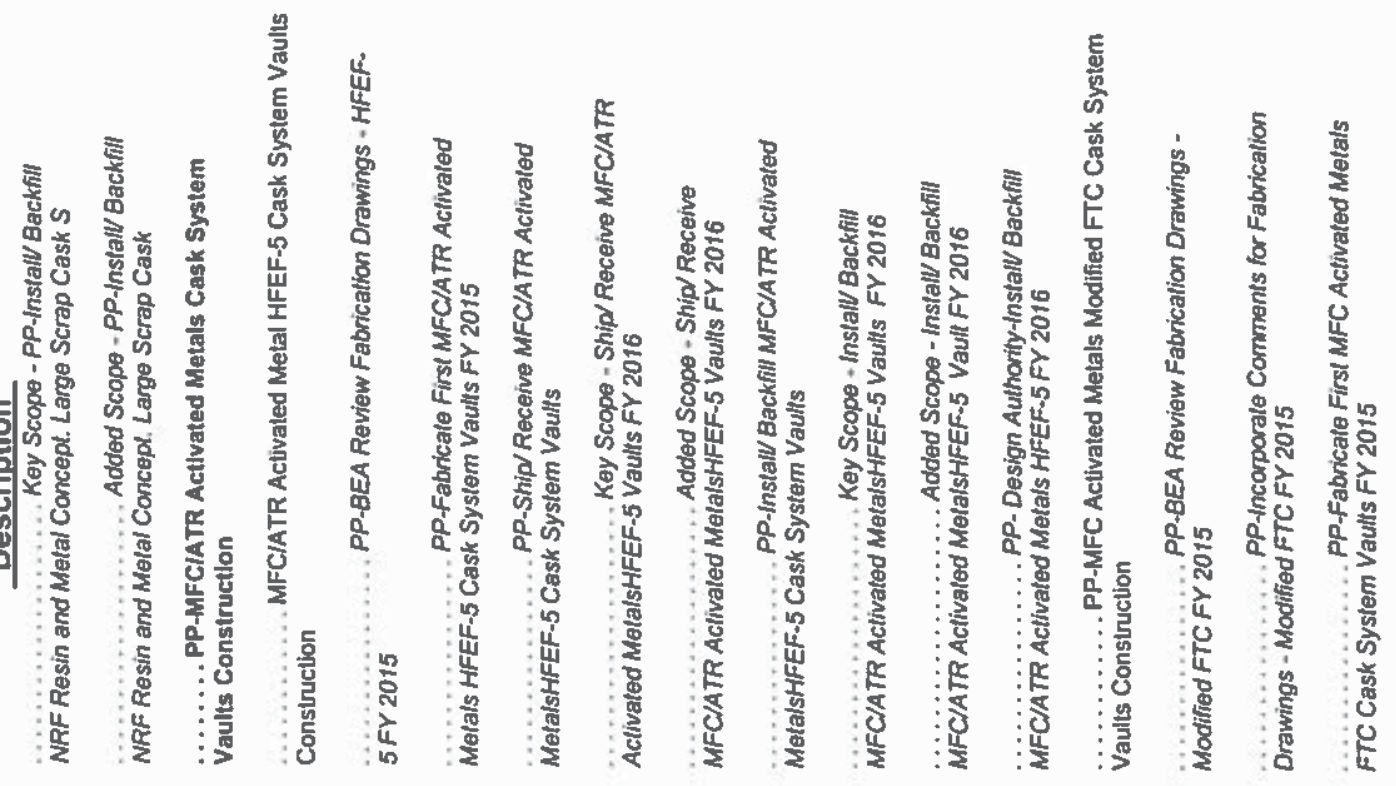

4

ำ

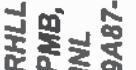

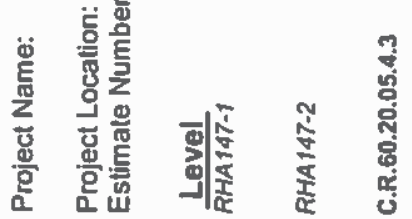

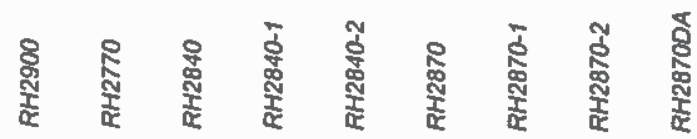

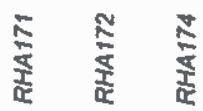




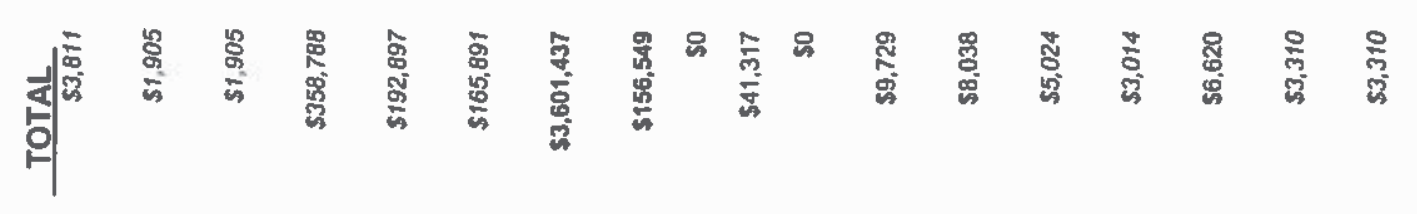

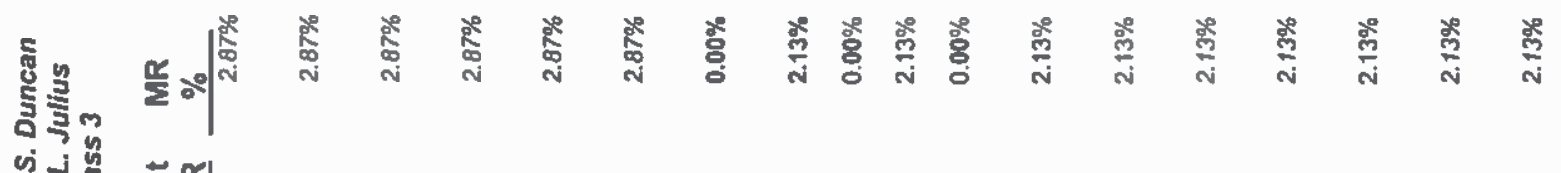

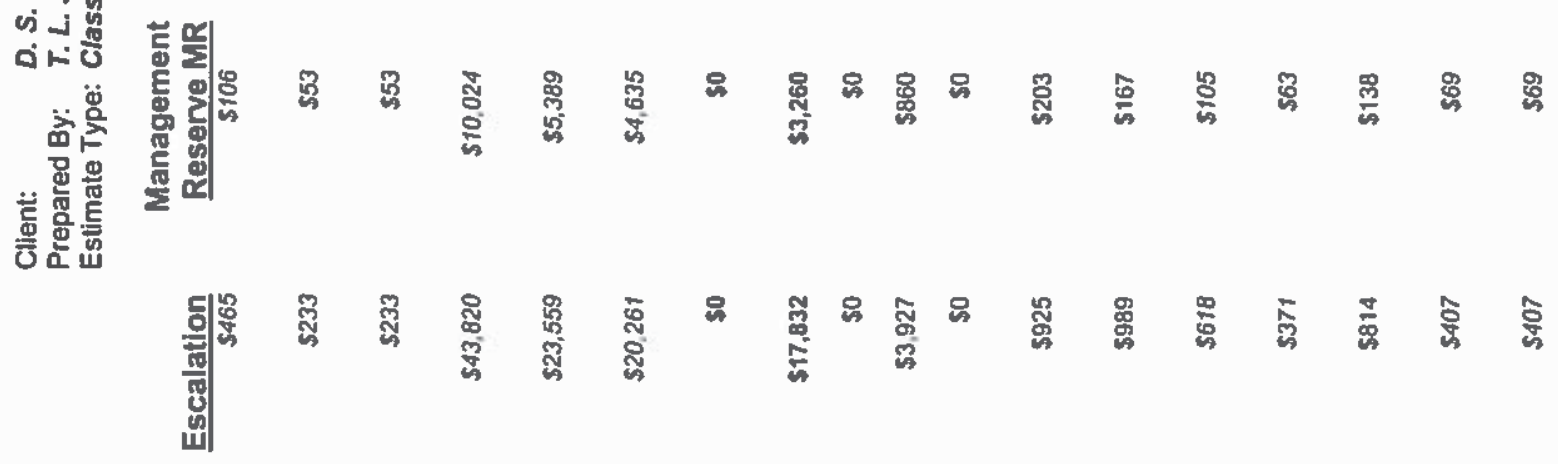

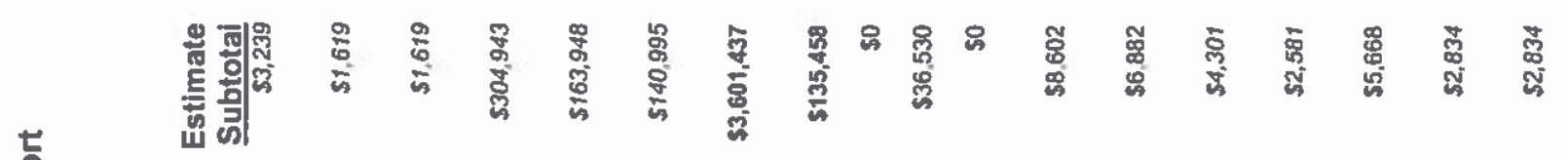

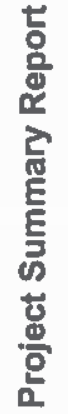

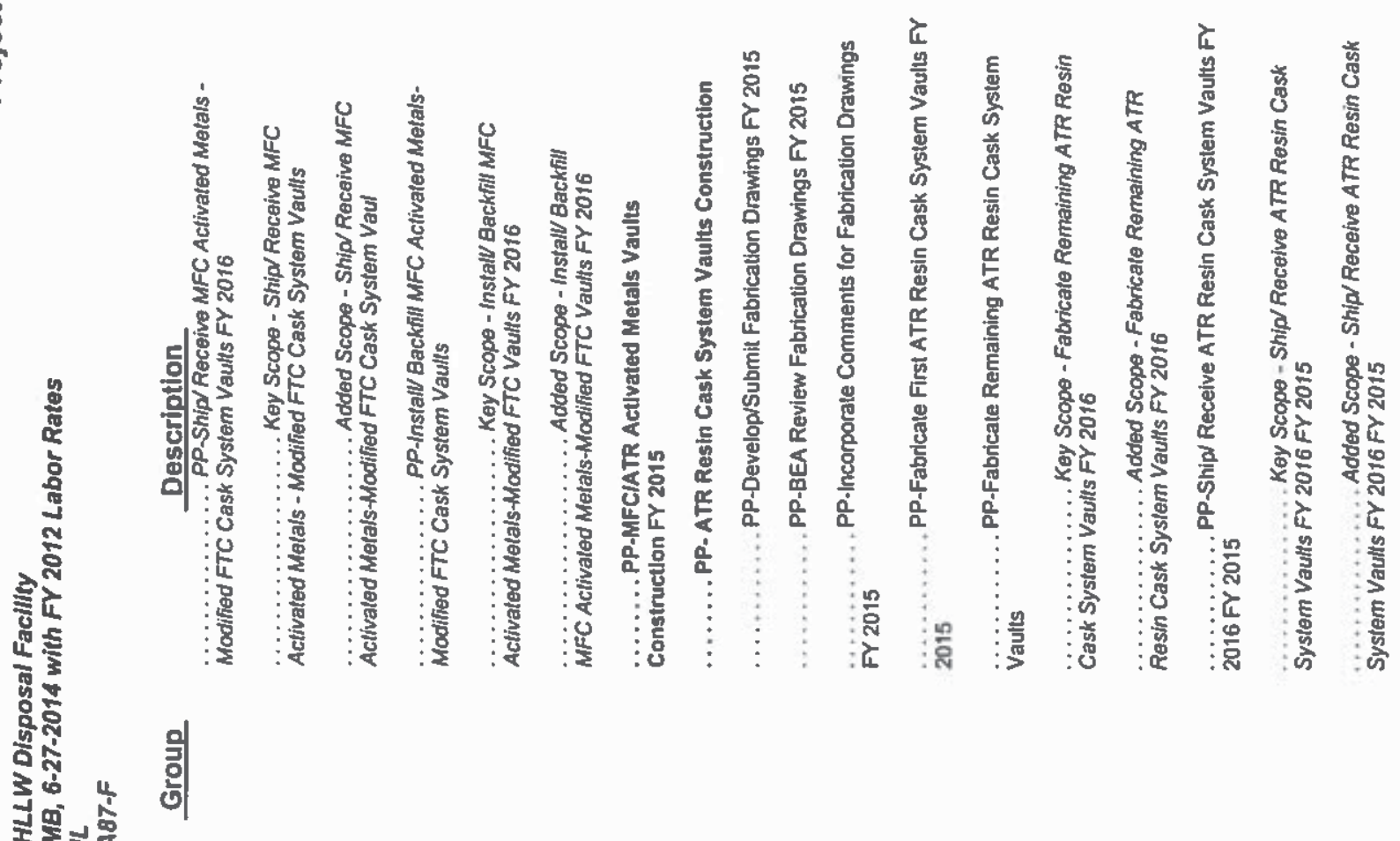




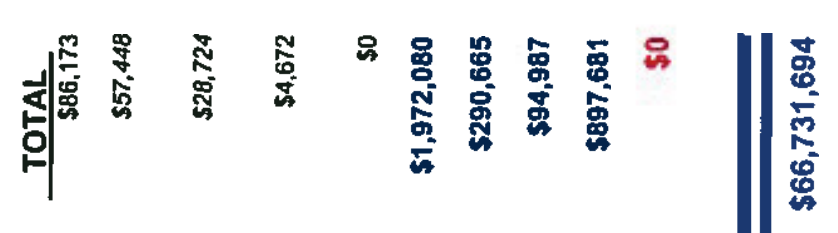

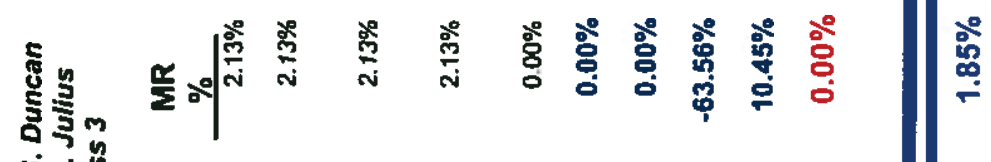

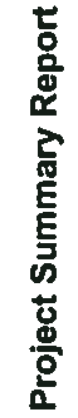

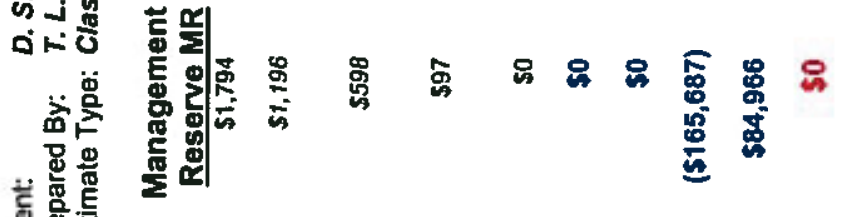

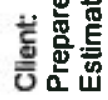

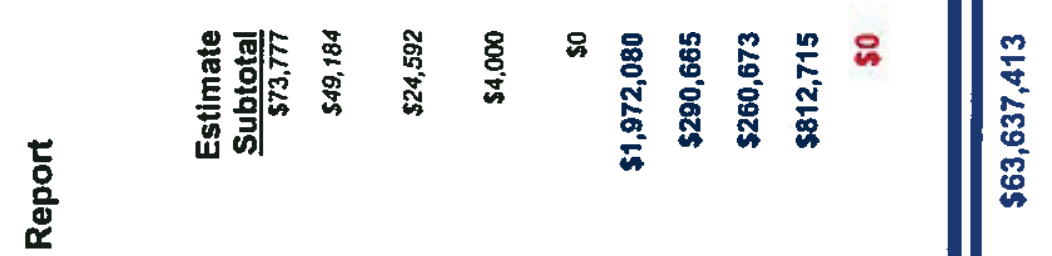

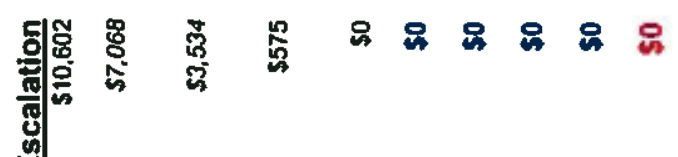
แ⿺辶⿻ 


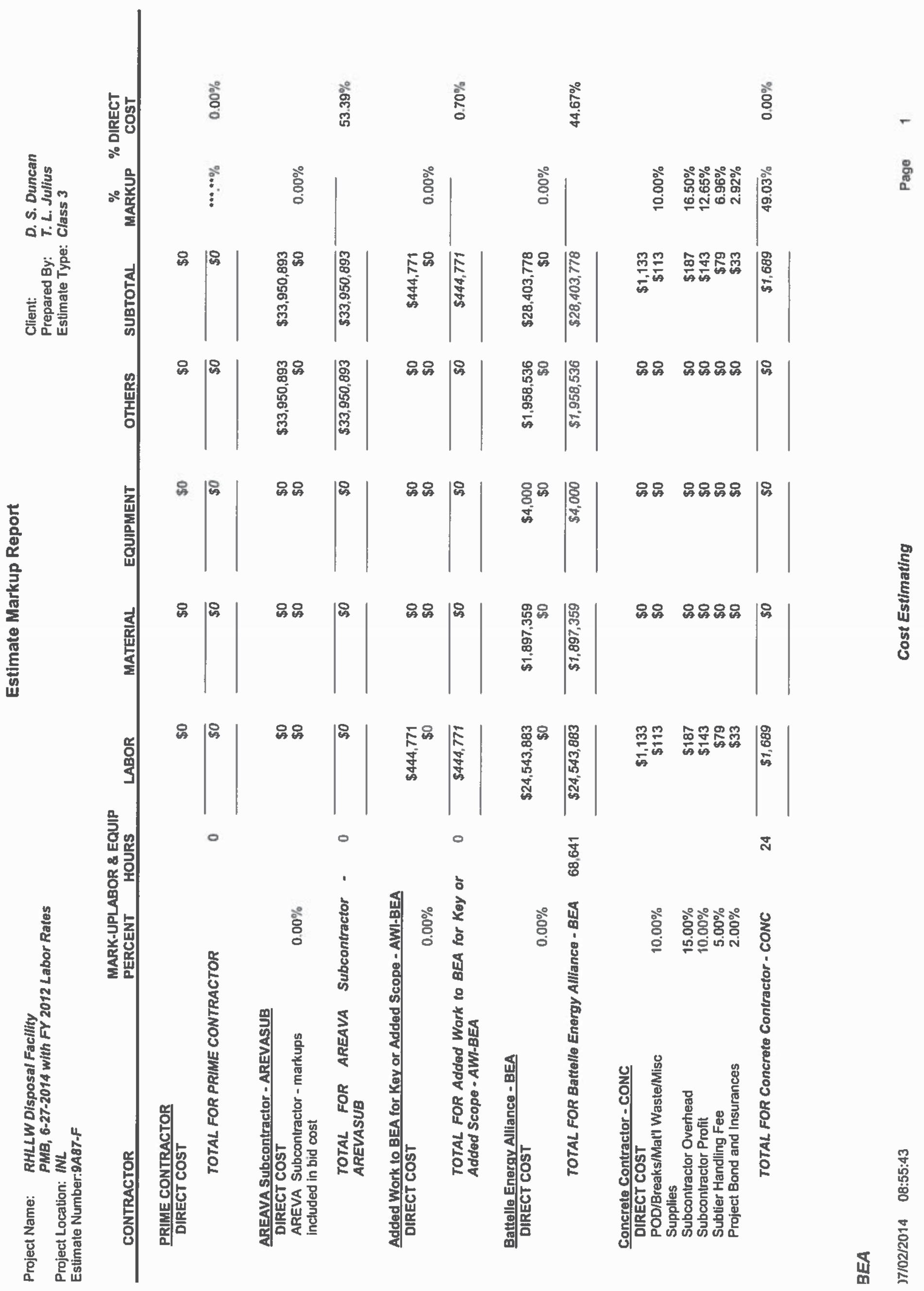




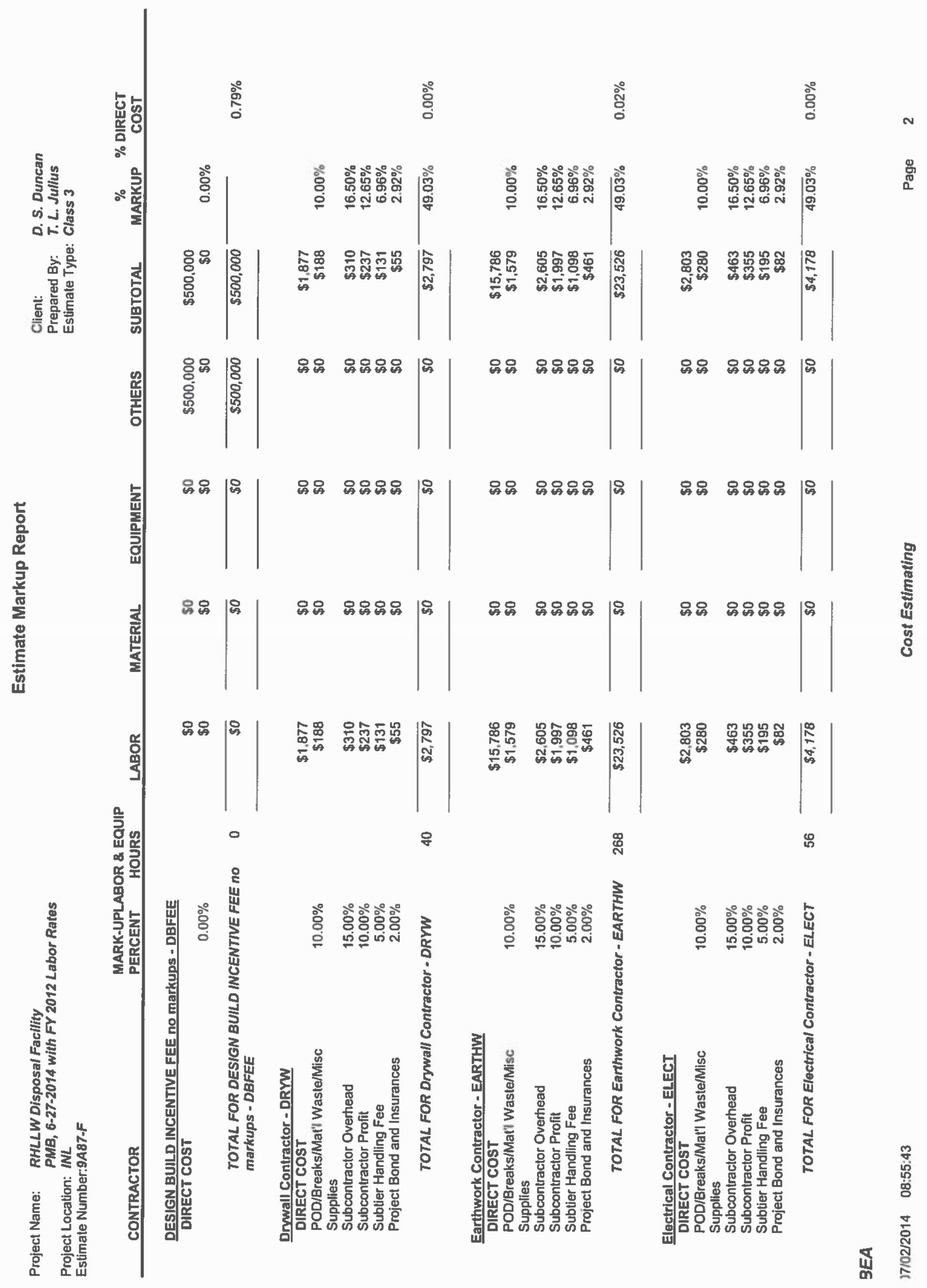




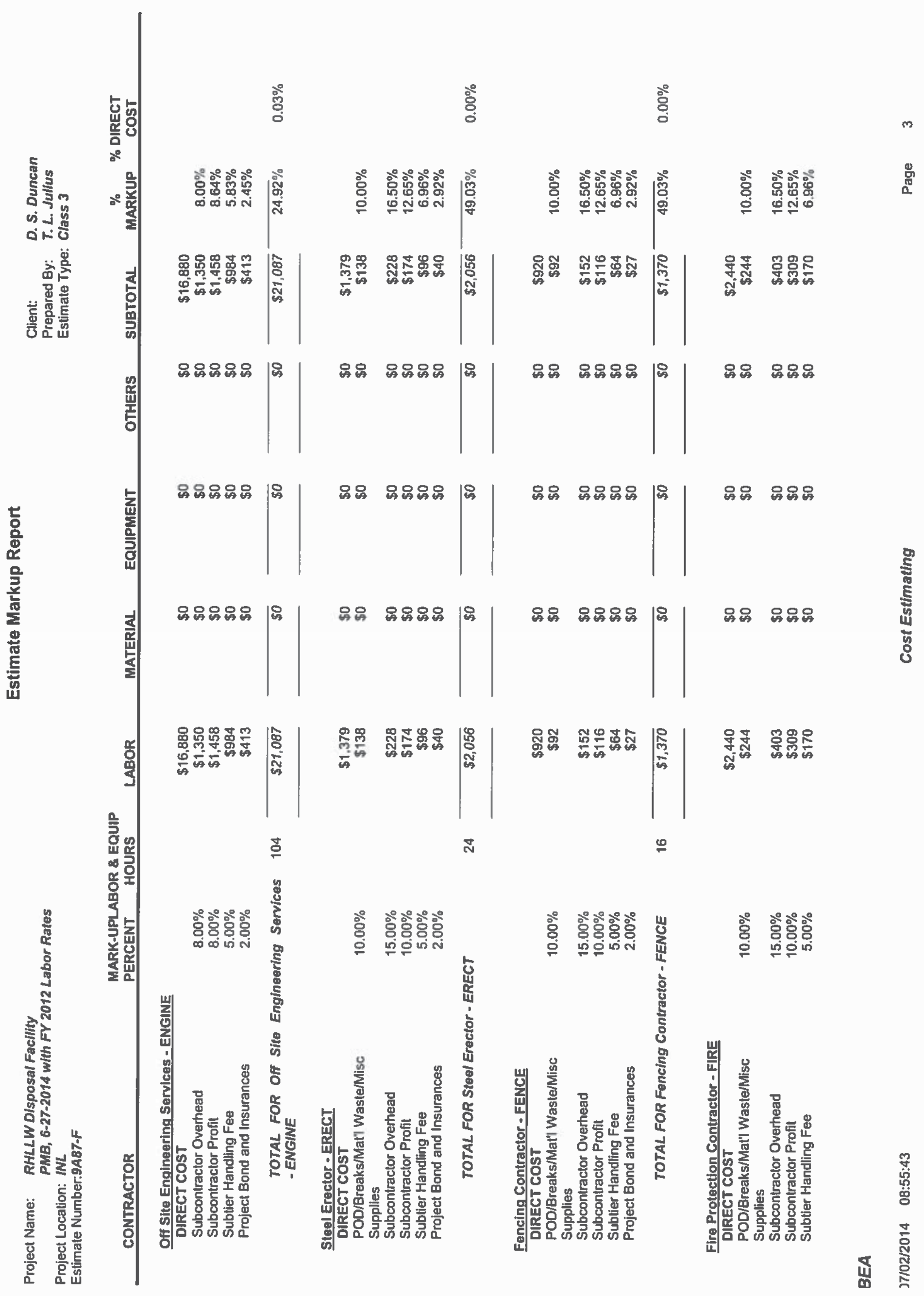




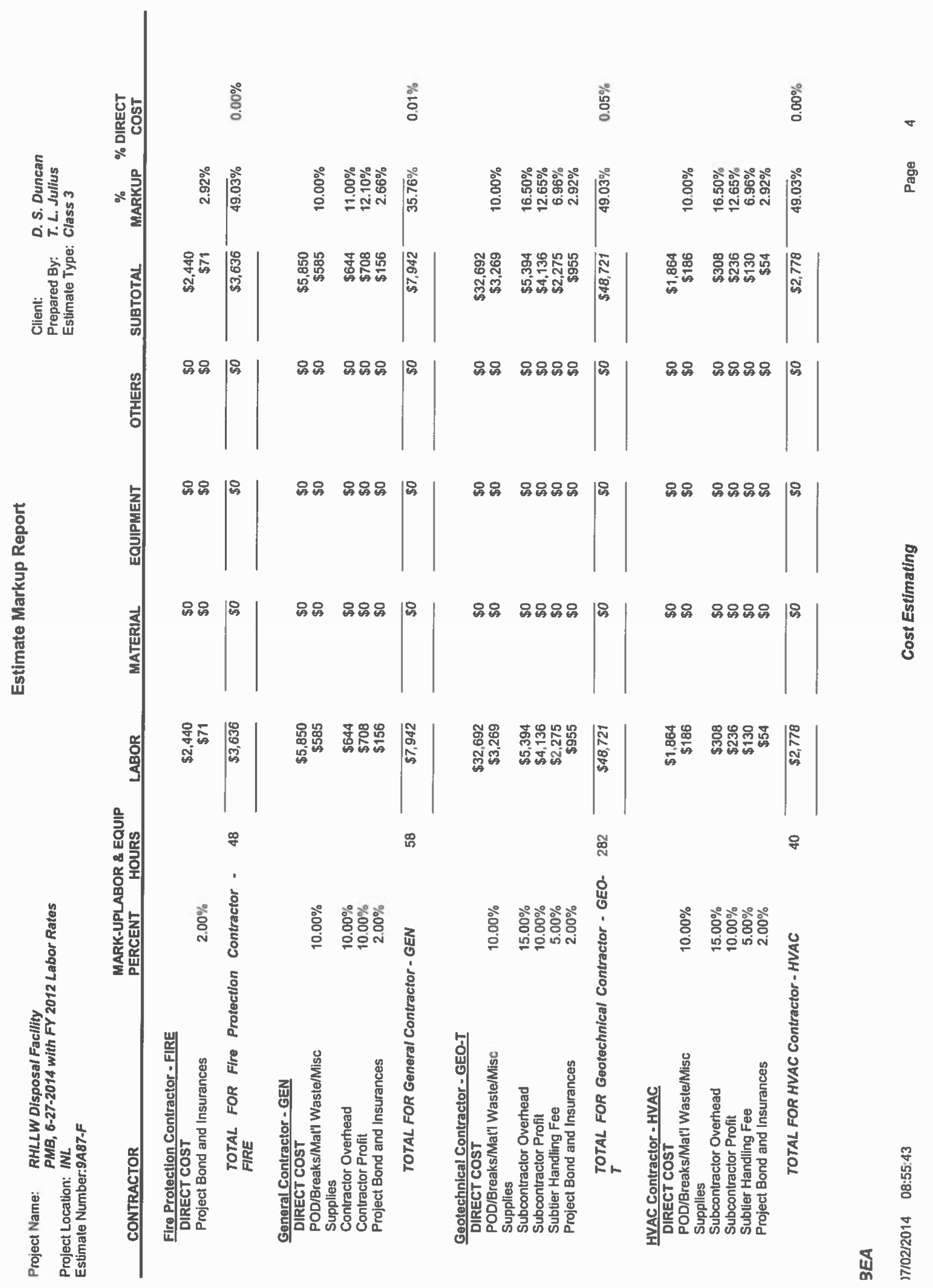




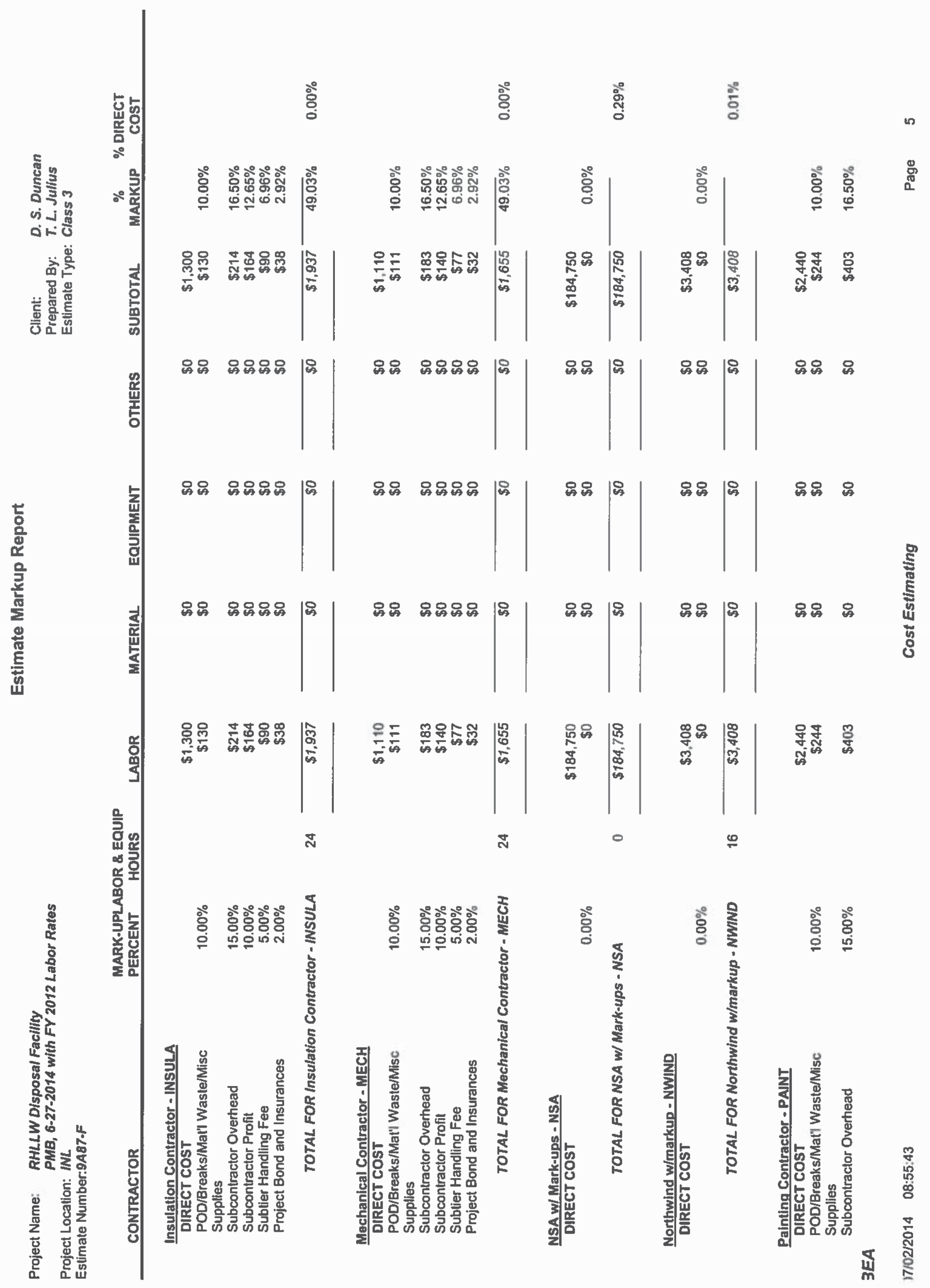




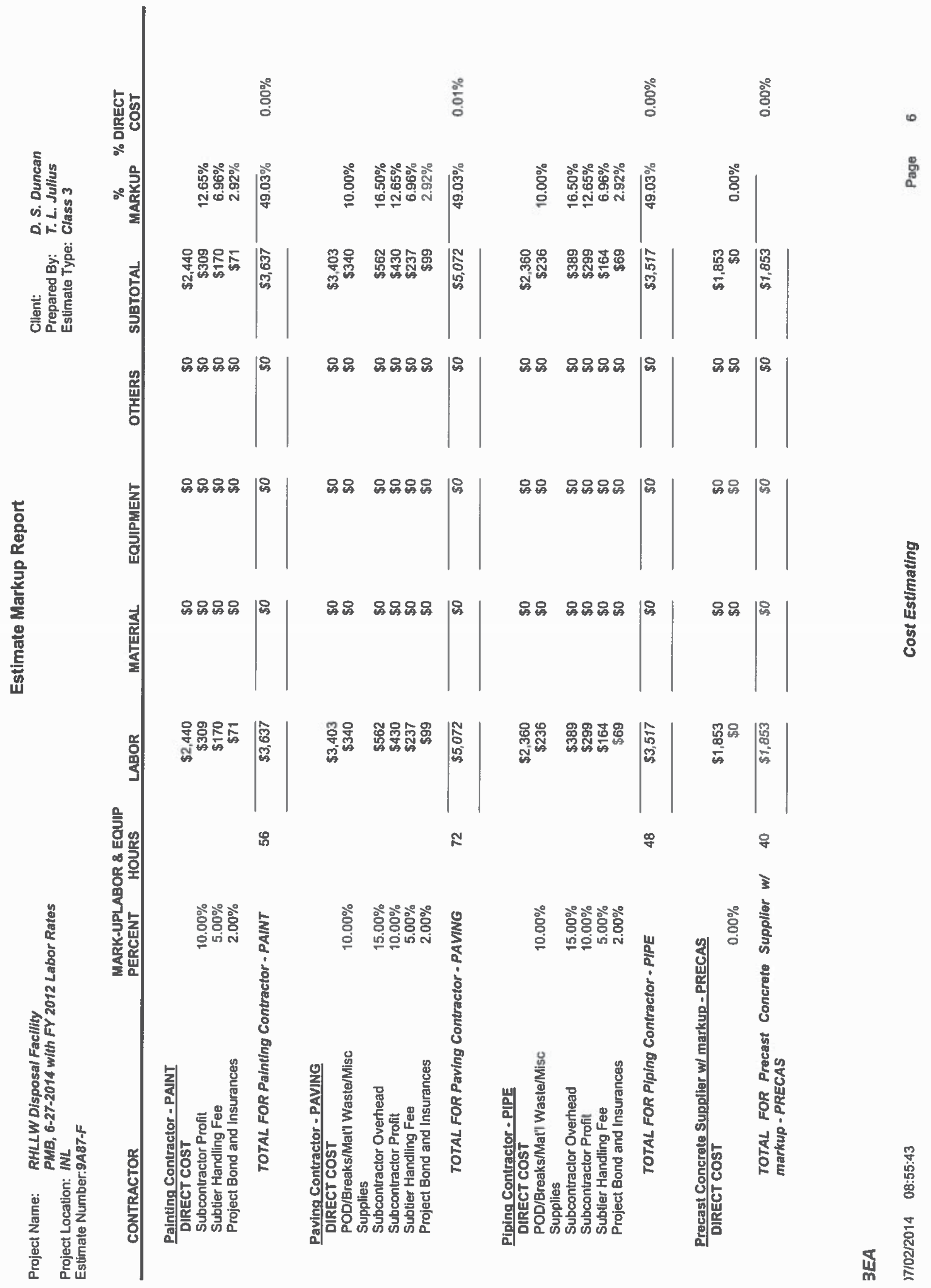




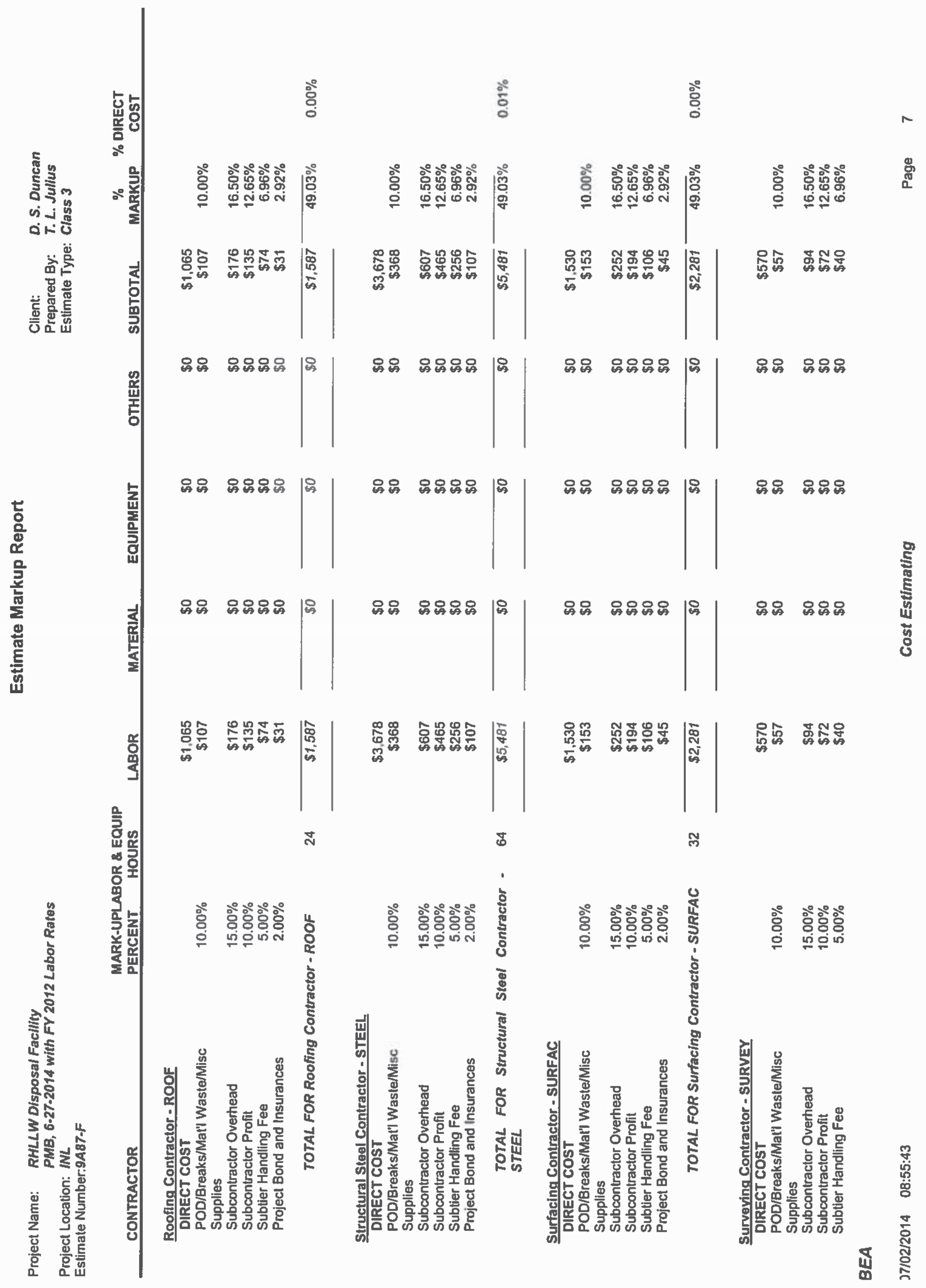




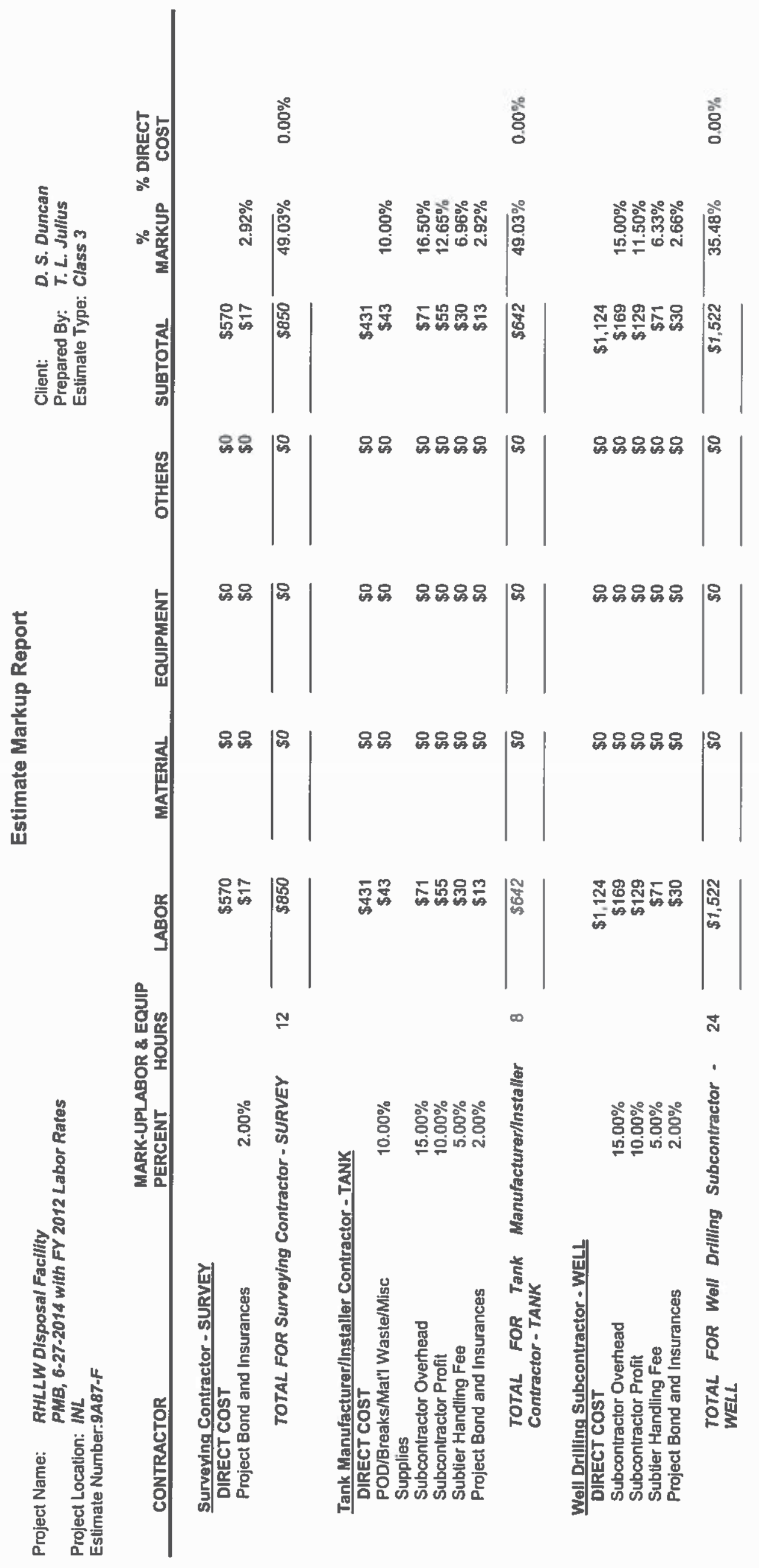




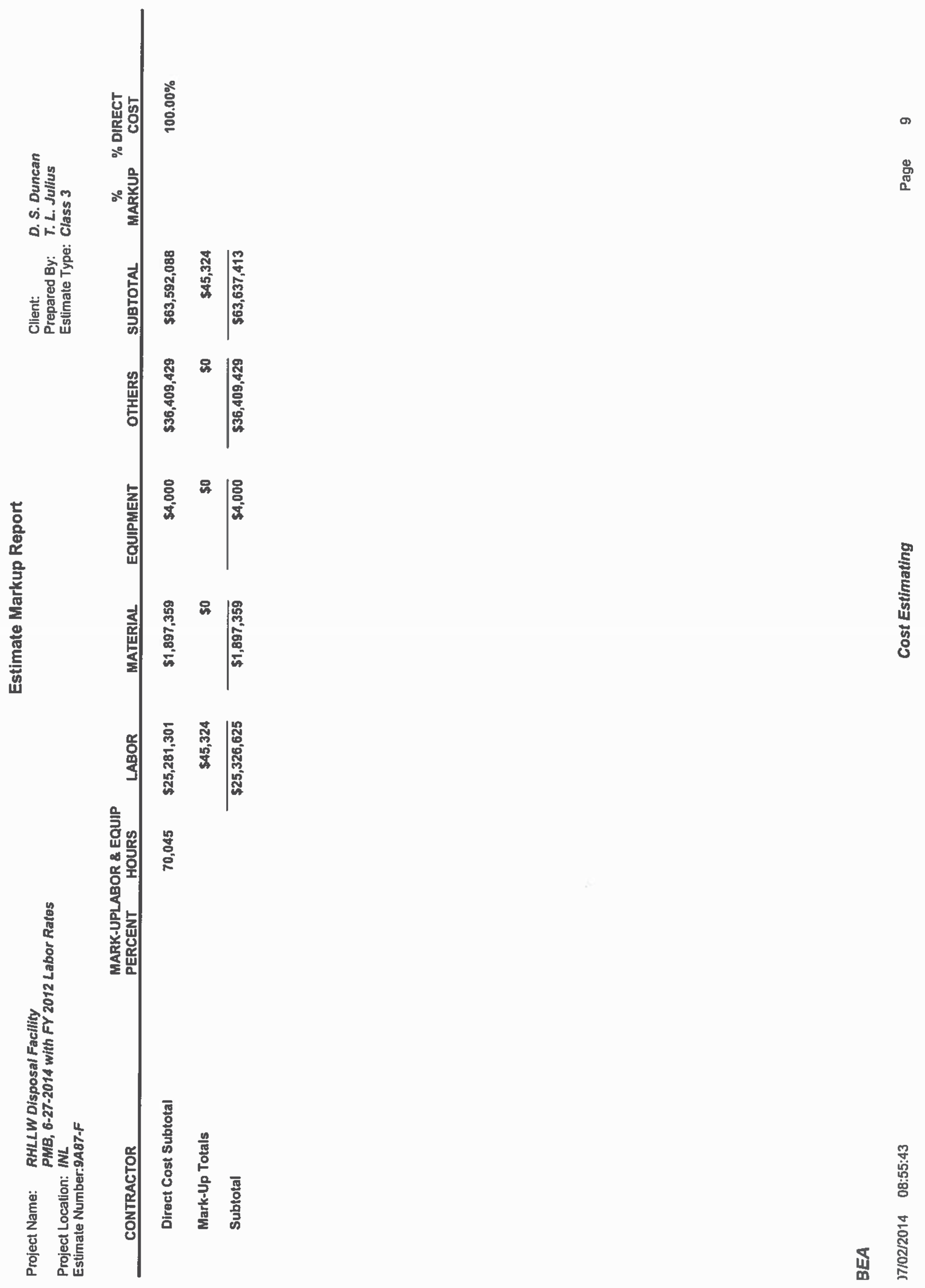




\section{Labor Resource Report}

Activity: $\quad$ Remote Handled Low Level Waste (RHLLW) Disposal Project

Group:

Level:

$\begin{array}{ll}\text { Project Name: } & \text { RHLLW Disposal Facility } \\ & \text { PMB, 6-27-2014 with FY 2012 Labor Rates } \\ \text { Project Location: } & \text { INL } \\ \text { Estimate Number: } & \text { 9A87-F }\end{array}$

\begin{tabular}{|c|c|c|c|c|c|}
\hline Code & Description & WDC Yoar & Rate $5 / \mathrm{Hr}$ & Hours & $\begin{array}{c}\text { Direct } \\
\text { Labor Cost }\end{array}$ \\
\hline A13Y5 & RECORD MGMT/DOCUMENT CONTROL & FY-12 & $\$ 59.73$ & 724 & $\$ 43,245$ \\
\hline A14J1 & ADMINISTRATIVE ASSIST/OFFICE COORDINATOR & $F Y-12$ & $\$ 70.43$ & 16 & $\$ 1,127$ \\
\hline C34Y2 & NETWORK ENGINEERING & FY -12 & $\$ 126.19$ & 6 & $\$ 757$ \\
\hline CNASBGF & ASBESTOS WORKERS - GF & $F Y-12$ & $\$ 54.15$ & 24 & $\$ 1,300$ \\
\hline CNCARP & CARPENTERS & $\mathrm{FY}=12$ & $\$ 46.92$ & 40 & $\$ 1,877$ \\
\hline CNCARPC & CARPENTERS - CONCRETE & FY -12 & $\$ 47.21$ & 24 & $\$ 1,133$ \\
\hline CNELEC & ELECTRICIANS & FY-12 & $\$ 50.06$ & 56 & $\$ 2,803$ \\
\hline CNIRON & IRONWORKERS & FY-12 & $\$ 57.47$ & 104 & $\$ 5,977$ \\
\hline CNLABCF & LABORERS - CONCRETE - FOREMAN & $F Y=12$ & $\$ 46.32$ & 40 & $\$ 1,853$ \\
\hline CNOPRE & OPERATORS - EXCAV & $F Y=12$ & $\$ 46.82$ & 240 & $\$ 11,237$ \\
\hline CNOPRL2 & OPERATORS - LOADER > 4 CUYD & $F Y-12$ & $\$ 47.82$ & 132 & $\$ 6,312$ \\
\hline CNPAIN & PAINTERS & $F Y-12$ & $\$ 43.58$ & 56 & $\$ 2,440$ \\
\hline CNPIPE & PIPEFITTERS & $F Y=12$ & $\$ 53.87$ & 24 & $\$ 1,293$ \\
\hline CNROOF & ROOFERS & $F Y-12$ & $\$ 42.90$ & 40 & $\$ 1,716$ \\
\hline CNROOFF & ROOFERS - FOREMAN & FY-12 & $\$ 44.38$ & 24 & $\$ 1,065$ \\
\hline CNSHTM & SHEETMETAL & FY-12 & $\$ 46.26$ & 40 & $\$ 1,850$ \\
\hline CNSPRN & SPRINKLER & $F Y-12$ & $\$ 50.83$ & 48 & $\$ 2,440$ \\
\hline CNSURVIM & SURVEYORS - INSTRUMENT MAN & FY-12 & $\$ 47.52$ & 12 & $\$ 570$ \\
\hline CS CFR & SubContractors Fleld Representative & $T J-12$ & $\$ 100.00$ & 40 & $\$ 4,000$ \\
\hline CS Foreman & Production Foreman & RRH-12 & $\$ 65.00$ & 10 & $\$ 650$ \\
\hline CS LabTech & Laboratory Technician & RRH-12 & $\$ 132.00$ & 16 & $\$ 2.112$ \\
\hline CS MechEng & Sub Mechanical Engineer & RRH-12 & $\$ 130.00$ & 56 & $\$ 7,280$ \\
\hline CS ProjMgr & Sub Project Manager & $T J-12$ & $\$ 175.00$ & 80 & $\$ 14,000$ \\
\hline
\end{tabular}

BEA 


\section{Labor Resource Report}

Activity: $\quad$ Remote Handled Low Level Waste (RHLLW) Disposal Project

Group:

Level:

Project Name: RHLLW Disposal Facility

Project Location: INL

PMB, 6-27-2014 with FY 2012 Labor Rates

Estimate Number: 9A87-F

\begin{tabular}{|c|c|c|c|c|c|}
\hline Code & Deseription & WDC Year & Rate S/Hr & Hours & $\begin{array}{l}\text { Direct } \\
\text { Labor Cost }\end{array}$ \\
\hline cs Qual & Sub Quality Assurance & RRH-12 & $\$ 114.00$ & 250 & $\$ 28,500$ \\
\hline CS Test & Sub Soils Testing Contractor & RRH-12 & $\$ 150.00$ & 8 & $\$ 1,200$ \\
\hline CSCivilEng & Sub Civil Engineer & $T J-12$ & $\$ 120.00$ & 24 & $\$ 2.880$ \\
\hline E04D5 & CIVIUSTRUCTURAL ENGR & FY-12 & $\$ 209.73$ & 18 & $\$ 3,775$ \\
\hline E04W1 & CIVIUSTRUCTURAL ENGR & FY-12 & $\$ 191.82$ & 1,265 & $\$ 242,652$ \\
\hline E04W2 & CIVIL/STRUCTURAL ENGR & $F Y-12$ & $\$ 191.82$ & 70 & $\$ 13,427$ \\
\hline E06W1 & ELECTRICAL ENGINEERING & $F Y=12$ & $\$ 153.28$ & 1,005 & $\$ 154,046$ \\
\hline E11W4 & MECHANICAL ENGINEERING & FY-12 & $\$ 154.01$ & 1,075 & $\$ 165,561$ \\
\hline E17Q5 & QUALITY ENGINEERING & FY-12 & $\$ 132.81$ & 60 & $\$ 7,969$ \\
\hline E17w5 & QUALITY ENGINEERING & FY-12 & $\$ 143.53$ & 2,481 & $\$ 356,098$ \\
\hline E18H6 & RADIOLOGICAL ENGINEERING & $F Y-12$ & $\$ 139.00$ & 168 & $\$ 23,352$ \\
\hline E19H1 & SAFETY ENGINEERING & $F Y-12$ & $\$ 148.45$ & 2,657 & $\$ 394,432$ \\
\hline E24P1 & SYSTEMSNALUE ENGR & $F Y-12$ & $\$ 161.79$ & $5, \mathbf{B g 9}$ & $\$ 954,399$ \\
\hline E27J1 & OTHER ENGINEERING & FY=12 & $\$ 162.15$ & 750 & $\$ 121,613$ \\
\hline E31W/3 & CRITICALITY SAFETY & $\mathrm{FY}-12$ & $\$ 160.66$ & 70 & $\$ 11,246$ \\
\hline E32W1 & SYSTEM/SSC ENGINEER & FY-12 & $\$ 157.43$ & 693 & $\$ 109,099$ \\
\hline E34W/2 & PROJECT ENGINEER & $F Y-12$ & $\$ 172.04$ & 3,640 & $\$ 626,226$ \\
\hline E41H1 & FIRE PROTECTION & FY-12 & $\$ 170.52$ & 158 & $\$ 26,942$ \\
\hline E41W1 & FIRE PROTECTION & FY-12 & $\$ 163.31$ & 145 & $\$ 23,680$ \\
\hline E48W4 & OPERATIONS ENGINEER, GENERAL & FY-12 & $\$ 131.13$ & 2,400 & $\$ 314,712$ \\
\hline E63W/3 & NUCLEAR SAFETY ANALYSIS & FY-12 & $\$ 138.69$ & 1,229 & $\$ 170,450$ \\
\hline F05GB & FAC OPERATIONS & $F Y-12$ & $\$ 141.61$ & 455 & $\$ 64,433$ \\
\hline F10GB & WORK PLANNING AND/OR SCHEDULING & FY $=12$ & $\$ 102.46$ & 181 & $\$ 18,545$ \\
\hline
\end{tabular}

BEA 


\section{Labor Resource Report}

Activity: $\quad$ Remote Handled Low Level Waste (RHLLW) Disposal Project

Group:

Level:

Project Name: RHLLW Disposal Facility

Project Location: INL

PMB, 6-27-2014 with FY 2012 Labor Rates

Estimate Number: 9A87-F

\begin{tabular}{|c|c|c|c|c|c|}
\hline Code & Description & WDC Year & Rate $\mathbf{S / H r}$ & Hours & $\begin{array}{c}\text { Direct } \\
\text { Labor Cost }\end{array}$ \\
\hline F22P2 & COST ESTIMATING & FY -12 & $\$ 113.77$ & 610 & $\$ 69,400$ \\
\hline F23F3 & PACKAGING AND TRANSPORTATION & FY-12 & $\$ 107.65$ & 393 & $\$ 42,306$ \\
\hline F26J1 & CONSTRUCTION FIELD ENGINEER & $F Y=12$ & $\$ 172.44$ & 2,022 & $\$ 348,674$ \\
\hline F31J1 & CONSTRUCTION - OTHER TECHNICAL & FY-12 & $\$ 117.89$ & 3,447 & $\$ 406,367$ \\
\hline F33P2 & PM SCHEDULING & $F Y-12$ & $\$ 119.73$ & 1,377 & $\$ 164,868$ \\
\hline F34P1 & PROJECT COORDINATOR & FY-12 & $\$ 120.91$ & 4 & $\$ 484$ \\
\hline F35P1 & PROJECT MANAGER & FY-12 & $\$ 184.48$ & 10,782 & $\$ 1,989,026$ \\
\hline GDTEL & General Dynamics Communication Tech & RRH-12 & $\$ 72.00$ & 6 & $\$ 432$ \\
\hline NWindCE & Northwind - Civil Engineer & RRH-12 & $\$ 213.00$ & 16 & $\$ 3,408$ \\
\hline P18F3 & PURCHASING/INV CONTROL & FY-12 & $\$ 80.97$ & 485 & $\$ 39,270$ \\
\hline P23J0 & TRAINING & FY-12 & $\$ 124.57$ & 80 & $\$ 9,966$ \\
\hline P37Y5 & TRAINING TECHNOLOGIST (CBT) & FY-12 & $\$ 106.66$ & 240 & $\$ 25,598$ \\
\hline P44F2 & PLANNING AND CONTROLS & FY $=12$ & $\$ 94.57$ & $\mathbf{3 , 3 2 9}$ & $\$ 314,776$ \\
\hline QWTEC & QWEST Communicalion Technician & TJ-12 & $\$ 89.00$ & 6 & $\$ 534$ \\
\hline S03B2 & EARTH \& LIFE SCIENCES & FY-12 & $\$ 190.21$ & 4,868 & $\$ 925,942$ \\
\hline S03B3 & EARTH \& LIFE SCIENCES & FY-12 & $\$ 190.21$ & 88 & $\$ 16,738$ \\
\hline S04B2 & ENVIRONMENTAL SCIENCES & FY-12 & $\$ 181.97$ & 40 & $\$ 7,279$ \\
\hline S06B3 & HEALTH PHYSICS & FY-12 & $\$ 205.22$ & 210 & $\$ 43,096$ \\
\hline so7B2 & HYDROLOGY & FY-12 & $\$ 204.71$ & 4,809 & $\$ 984,450$ \\
\hline S07B3 & HYDROLOGY & $\mathrm{FY}-12$ & $\$ 204.71$ & 65 & $\$ 13,265$ \\
\hline S08H1 & INDUSTRIAL HYGIENE & FY-12 & $\$ 146.62$ & 534 & $\$ 78,295$ \\
\hline S21H5 & REGULATORY COMPLIANCE - ENVIRONMENTAL & FY-12 & $\$ 157.83$ & 865 & $\$ 136.523$ \\
\hline \$22B3 & GEOPHYSICIST & $F Y=12$ & $\$ 171.00$ & 2,184 & $\$ 373,464$ \\
\hline
\end{tabular}

BEA 


\section{Labor Resource Report}

Activity: $\quad$ Remote Handled Low Level Waste (RHLLW) Disposal Project

Group:

Level:

Project Name: RHLLW Disposal Facility

Project Location: INL

PMB, 6-27-2014 with FY 2012 Labor Rates

Estimate Number: 9A87-F

\begin{tabular}{|c|c|c|c|c|c|}
\hline Code & Description & WDC Year & Rate $\mathbf{S / H r}$ & Hours & $\begin{array}{c}\text { Direct } \\
\text { Labor Cost }\end{array}$ \\
\hline T02J1 & CONST INSPECT TECH & FY-12 & $\$ 102.17$ & 244 & $\$ 24,929$ \\
\hline T03J1 & DRAFTER & FY-12 & $\$ 91.76$ & 280 & $\$ 25,693$ \\
\hline T09GC & INSTRUMENTATION/CALIBRATION TECH & FY-12 & $\$ 101.16$ & 218 & $\$ 22,053$ \\
\hline T13H6 & HEALTH PHYSICS TECH & $F Y-12$ & $\$ 104.92$ & 80 & $\mathbf{\$ 8 , 3 9 4}$ \\
\hline T17C5 & OTHER TECHSIOPS & $F Y-12$ & $\$ 101.93$ & 1,440 & $\$ 146,779$ \\
\hline U06GB & CARPENTER & FY -12 & $\$ 84.24$ & 36 & $\$ 3,033$ \\
\hline U11GC & ELECTRICIAN & $F Y=12$ & $\$ 98.20$ & 80 & $\$ 7,856$ \\
\hline U11J1 & ELECTRICIAN & FY-12 & $\$ 98.11$ & 66 & $\$ 6,475$ \\
\hline U12J1 & EQUIPMENT OPERATOR & FY-12 & $\$ 89.22$ & 48 & $\$ 4,283$ \\
\hline U16GB & FITTER & FY-12 & $\$ 86.70$ & 20 & $\$ 1,734$ \\
\hline U26J1 & MACHINIST & $F Y-12$ & $\$ 98.38$ & 4 & $\$ 394$ \\
\hline U29J1 & SYS MECHANIC & FY-12 & $\$ 98.84$ & 40 & $\$ 3,954$ \\
\hline U52.J1 & OPERATOR,UTILITY & FY-12 & $\$ 97.68$ & 60 & $\$ 5,861$ \\
\hline U60H6 & RADIOLOGICAL CONTROL TECH & $F Y-12$ & $\$ 101.91$ & 690 & $\$ 70,318$ \\
\hline U90GB & OPERATOR,TRA WASTE TECH & FY -12 & $\$ 83.92$ & 5 & $\$ 420$ \\
\hline U96M4 & SECURITY POLICE OFFICER II (SPO I) & FY-12 & $\$ 69.05$ & 380 & $\$ 26,239$ \\
\hline U97M4 & SECURITY POLICE OFFICER III (SPO III) & $F Y-12$ & $\$ 59.24$ & 80 & $\$ 4,739$ \\
\hline $\mathbf{X} 16 \mathrm{B3}$ & WASTE MANAGEMENT & $F Y-12$ & $\$ 184.81$ & 460 & $\$ 85,013$ \\
\hline $\mathrm{X} 18 \mathrm{H} 2$ & OCCUPATIONAL PHYSICIAN & $F Y-12$ & $\$ 272.05$ & 163 & $\$ 44.344$ \\
\hline Z02GB & MANAGER, FAC SUPPORT SERVICES & FY-12 & $\$ 160.03$ & 623 & $\$ 99.699$ \\
\hline Z03GB & MANAGER, OPERATIONS & FY-12 & $\$ 181.96$ & 80 & $\$ 14,557$ \\
\hline Z03GC & MANAGER, OPERATIONS & $F Y=12$ & $\$ 203.79$ & 1,925 & $\$ 392,377$ \\
\hline Z08GB & SUPERVISOR, OPERATIONS & FY-12 & $\$ 128.20$ & 10 & $\$ 1,282$ \\
\hline
\end{tabular}

BEA 


\section{Labor Resource Report}

Activity: Remote Handled Low Level Waste (RHLLW) Disposal Project

Group:

Level:

Project Name: $\quad$ RHLLW Disposal Facility

Project Location: INL

PMB, 6-27-2014 with FY 2012 Labor Rates

Estimate Number: 9A87-F 


\section{Appendix F \\ Cost Estimate Summary \\ for Operations and Closure (9A28-H4)}

Full cost estimate details are included on CD. 
Date: $\quad$ May 3, 2012

To: $\quad$ D. S. Duncan, Project Manager

From: $\quad$ R. D. Allen, Cost Estimator RA

Subject: $\quad$ RH LLW Disposal Project Operations, Disposal and Closeout FY 2018 - FY 2037

Reference: Previous Estimate File \#9A28-H3

Per your request, Cost Estimating revised the cost estimate (Class 4) for the above-mentioned subject. The total estimated cost, including escalation and management reserve, is $\$ 110,000,000$.

Please note the following:

A. Changes to this cost estimate from the previous estimate File \#9A28-H3 estimated cost of $\$ 112,460,000$ include the following:

1. Operations and maintenance (O\&M) costs were deleted for the leachate collection system and the evaporation pond. The leachate collection and evaporation pond are no longer required by the conceptual design report.

2. Labor rates were updated to current Battelle Energy Alliance (BEA) FY 2012 work discipline codes and rates.

3. Disposal authorization and monitoring well costs were combined and re-estimated based on material and labor resources provided by A. L. Schafer, BEA hydrologist.

4. Escalation rates were updated to reflect a new basis. Escalation guidance from the Department of Energy Office of Cost Analysis (CF-70) is no longer published; therefore, estimated escalation rates are now based on historical indexes from 1962 to today, as published by RS Means. Five-year, ten-year, and lifecycle trends were developed to estimate the most likely rates that have been used in this estimate.

5. BEA labor costs were adjusted to account for a $4.5 \%$ increase in labor rates due to standard labor rates (SLR) planned for FY 2014. Estimated impact to this project for SLR is based upon a study completed by B. J. Orchard, April 2012.

6. The remainder of the estimate is included exactly as presented in previous estimate File \#9A28-H3.

B. Per the requester, this work will be direct funded. General and Administrative (G\&A) costs are included in this estimate.

C. This cost estimate has been evaluated in the AACEI classification matrix as a Class 4 estimate (ref. DOE G. 430.1-1X, Appendix $J$ ). The primary characteristic used in this guideline to define the classification category is the degree of project definition at this time. The intent of this classification is to assist in the interpretation of the quality and value of the information available to prepare this cost estimate and the expected accuracy levels that can be produced. Per AACEI, a Class 5 indicates the lowest amount of project information 
D. S. Duncan

May 3, 2012

Page 2

quality and value with a graded approach to a Class 1 , which indicates the highest amount of project information quality and value.

D. A draft copy of the estimate was sent to D. L. Anderson, J. D. Jacobsen, D. S. Duncan, and A. L. Schafer on May 1, 2012 for review. This review allowed for the project team to review and comment on the perceived scope, basis of estimates, and assumptions that make up this cost estimate. Comments from this review have been incorporated into this estimate to reflect a project team consensus of this document.

E. This project has not been identified by the Idaho National Laboratory (INL) Construction Commercial Practices Evaluation for the purpose of construction scope, management, and field oversight. This project will be evaluated when the construction activities are better defined for the facility closure phase of the project in FY 2036.

Refer to the cost estimating summary, detail, markup, and labor sheets with the cost breakdowns. Also included for your use are the cost estimate recapitulation sheets describing the basis and assumptions used in development of this estimate. Minor changes to the original estimate File \#9A28-H1 recapitulation sheets have been made to reflect the changes noted. All other bases and assumptions have remained the same.

This estimate, the work, and the work breakdown structure are based on the information perceived by this estimator as to the scope of work to be completed. Any changes to the methodology used to prepare this estimate could have a significant effect on the cost estimate and/or schedule and should be reviewed by me. If you have any questions or comments, do not hesitate to contact me at 526-0769 or e-mail Ross.Allen@inl.gov.

Attachments

cc: $\quad$ Estimate File 9A28-H4

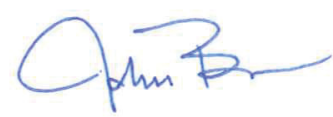

Uniform File Code: $\underline{8309}$

Disposition Authority: A16-1.5-b

Retention Schedule: Cut off at the end of each fiscal year. Destroy 10 years after cutoff

NOTE: Original disposition authority, retention schedule, and Uniform Filing Code applied by the sender may not be appropriate for all recipients. Make adjustments as needed. 

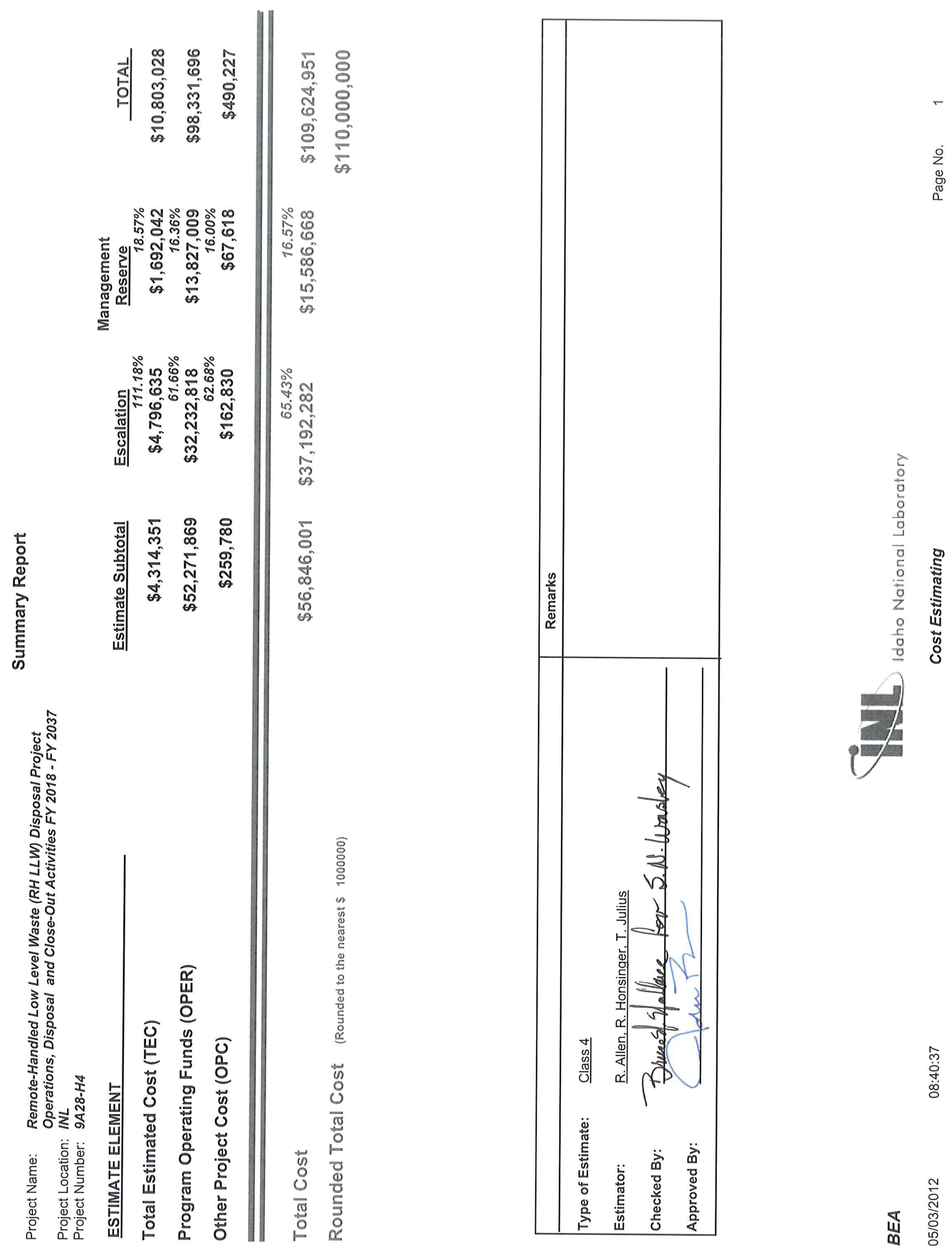


\section{FORMAL COST ESTIMATE SUPPORT DATA RECAPITULATION}

Project Title: $\quad$ Remote Handled Low Level Waste (RHLLW) Operations, Disposal and

\begin{tabular}{|ll} 
& Closeout Activities FY 2018 - FY 2037 \\
Estimator: & R. D. Allen / R. R. Honsinger / T. L. Julius \\
Date: & May 3, 2012
\end{tabular}

Estimate Type: Class 4

File:

Approved By:

9A28-H4

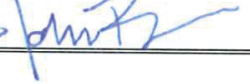

Page 1 of 7

I. PURPOSE: Brief description from the requester of the intent of how the estimate is to be used, i.e., for engineering study, comparative analysis, request for funding, proposal, etc.

This estimate determines a cost for the scope of work as stated below. This estimate will be used to support Critical Decision (CD)-2/3 approval for this project, per Department of Energy (DOE) CD Process for Capital Asset Projects. This estimate will be used to support the life cycle costs for this project.

II. SCOPE OF WORK: Brief statement of the project's objective. Thorough overview and description of the proposed project. Identify work to be accomplished, as well as any specific work to be excluded.

\section{A. Objective:}

The objective of this project is to receive and dispose of Idaho National Laboratory (INL) and tenant-generated remote-handled low-level waste (RH LLW) at a new remote-handled LLW disposal facility.

\section{B. Included:}

The scope of work required to achieve this objective includes the following:

1. Receive and dispose of RH LLW in disposal vaults starting October 1, 2017, and continuing through FY 2037.

2. Maintain DOE Order 435.1 Disposal Authorization.

3. Manage and maintain the RH LLW Facility including road ways, access areas within the facility, one maintenance building, and one administration building.

4. Maintain and operate large transfer casks, trailers, shielding equipment, platforms, and operating cranes and forklifts.

5. Operate and maintain the fire/potable water system and monitoring wells.

6. Maintain electrical power and communications system distributed throughout the facility.

7. Maintain the physical security of the area and vaults.

8. Decommissioning and demolition (D\&D) of the facility infrastructure and closeout and place into a safe, long-term closure mode.

9. Design and construct a closure cap over the vault areas. 
FORMAL COST ESTIMATE SUPPORT DATA RECAPITULATION

-Continued-

Project Title: Remote Handled Low Level Waste Operations, Disposal and Closeout Activities FY 2018 - FY2037

File: $\quad$ 9A28-H4

Page 2 of 7

\section{Excluded:}

This scope of work specifically excludes the following:

1. Design and construction of the new facility is addressed in estimate 9A87.

2. Costs for operations and maintenance of the leachate collection and evaporation pond. The leachate pond is no longer part of the design.

3. Costs for long-term and post-closure activities, including post-closure monitoring of the wells, are not included in this estimate.

4. Generator costs for the cask liners and the transportation to the facility. These costs will be the responsibility of the generator.

5. RH LLW disposal facility start-up costs.

III. ESTIMATE METHODOLOGY: Overall methodology and rationale of how the estimate was developed, i.e., parametric, forced detail, bottom up, etc. Total dollars/hours and rough order of magnitude (ROM) allocations of the methodologies used to develop the cost estimate.

Disposal operations are based substantially on the RH LLW disposal activities currently in use at the Subsurface Disposal Area (SDA) of the Radioactive Waste Management Complex (RWMC).

Procedures were reviewed and operators interviewed to provide the basis for all operations. Existing historical data for labor hours and shipping costs were accumulated to provide cost data.

Lists of wastes, including types and volumes, were assembled to provide basis for the number of operations and transfers to be conducted at different facilities.

The activities and resources were developed by the project team members and assembled by the cost estimator to provide the level of detail documented in the estimate.

\begin{tabular}{lc}
\hline \multicolumn{1}{c}{ Estimate Methodology } & ROM Percentage (\%) \\
\hline Project Team & 60 \\
Recorded Actuals & 0 \\
Parametric & 0 \\
Vendor Quotes & 0 \\
Other (e.g., RS Means) & 40 \\
\hline TOTAL & 100
\end{tabular}


FORMAL COST ESTIMATE SUPPORT DATA RECAPITULATION

-Continued-

Project Title: Remote Handled Low Level Waste Operations, Disposal and Closeout Activities FY 2018 - FY2037

File:

9A28-H4

Page 3 of 7

IV. BASIS OF THE ESTIMATE: Overall explanation of sources for resource quantities, pricing, and schedules.

A. Quantification Basis: The source for the measureable quantities in the estimate that can be used in support of earned value management. Source documents may include drawings, design reports, engineers' notes, and other documentation upon which the estimate is originated.

Labor hours for manpower resources are from a discussion held with an experienced RWMC operator (T. E. Sluder) on February 4, 2008, for how long each step would take and how the systems and personnel interface with each other. Operations personnel will dispose of waste in monthly campaigns and not be stationed at the facility full time but will work at other INL areas when not actively in disposal, preparation, and take down operations at the RH LLW Facility.

Maintenance activity costs were derived from The Whitestone Building Maintenance and Repair Cost Reference 2007-2008 version and discussions with D. E. Start, facility maintenance manager for tracking maintenance costs. Adders were included to reflect labor losses due to security, INL procedures, and working policies. Excavation, fill materials, and production labor hours were from RSMeans Facilities Construction Cost Data 2007 modified with current budget quotes from vendors conducting similar work at INL.

B. Planning Basis: The source for the execution and strategies of the work that can be used to support the project execution plan, identification of long-lead items, acquisition strategy, schedules, market conditions, and other documentation upon which the estimate is originated.

1. Battelle Energy Alliance, LLC (BEA) will provide all engineering, procurement, operating personnel, project and construction management resources.

2. Subcontractor markup rates are based on this estimator's judgment. These rates have been adjusted to reflect the anticipated market conditions.

C. Cost Basis: The source for the costing on the estimate that can be used in support of earned value management, funding profiles, and schedule of values. Sources may include published costing references, judgment, actual costs, preliminary quotes and/or other documentation upon which the estimate is originated.

1. The project scope for the general operations and waste disposal activities is based on the "Conceptual Design Report (CDR) for the Remote-Handled Low Level Waste Disposal Facility" Section 3.0 "Process Summary," document number INL/EXT-07-12901 Revision 5 dated May 5, 2011. 
FORMAL COST ESTIMATE SUPPORT DATA RECAPITULATION

-Continued-

Project Title: Remote Handled Low Level Waste Operations, Disposal and Closeout Activities FY 2018 - FY2037

File: $\quad$ 9A28-H4

Page 4 of 7

2. Specific operation activities for discharge of a 55-ton cask into the concrete vaults are documented from current procedures for a similar activity used at the RWMC SDA. The procedures referenced are the "55-ton Cask Discharge to RH LLW Concrete-Lined Vaults TPR-1757 Revision 37 and Revision 25." These procedures identify specific operations and labor resources required to complete them. These procedures form the basis for operations of all three planned vault configurations.

3. The labor hours for project management, security, and assessments are based on planned disposal operations.

4. Labor hours for periodic review and update of DOE Order 435.1 disposal authorization documentation are based on actual work completed for similar operations at RWMC and averaged over a 4 year period and input from project manager (B. J. Orchard).

5. The costs to sample and maintain the monitoring wells are included in the estimate as furnished by hydrologist, A. L. Schafer.

6. The closure cap design is based on a report from E. D. Mattson CCN 206124 dated July 11, 2006.

7. The medical surveillance costs for 10 CFR 851 are included in the estimate for the construction personnel only; most operations will be conducted by INL personnel.

8. INL labor rates, fees, and burdens are based on the current published rates as provided by BEA Planning and Financial Controls.

9. Craft labor rates are based on information provided by the "INL Site Stabilization Agreement." Adders (such as FICA, SUTA, and federal insurances) are based on an interpretation by Cost Estimating.

10. BEA labor costs were adjusted to account for a $4.5 \%$ increase in labor rates due to standard labor rates (SLR) to be implemented in FY 2014. Estimated impact to this project for SLR is based upon a study completed by B. J. Orchard, April 2012.

11. Estimated escalation rates are based on historical indexes from 1962 to today, as published by RS Means. Five-year, ten-year, and lifecycle trends were developed to estimate the most likely rates that have been used in this estimate. Inflationary and deflationary impacts will be addressed in management reserve.

12. Sales tax on materials is based on the current $6 \%$ rate charged by the State of Idaho.

13. Standard industry reference "R. S. Means" was used to help develop the estimated resources and their productivities and some material costs.

14. Preliminary vendor quotes were used to supply the major material costs.

15. Activity specific assumptions that are considered to also reflect the basis of the estimate have been included within the estimate body (reference cost estimating detail sheets). 
FORMAL COST ESTIMATE SUPPORT DATA RECAPITULATION

-Continued-

Project Title: $\quad$ Remote Handled Low Level Waste Operations, Disposal and Closeout Activities FY 2018 - FY2037

File: $\quad$ 9A28-H4

Page 5 of 7

V. ESTIMATE QUALITY ASSURANCE: A listing of all estimate reviews that have taken place and the actions taken from those reviews.

A. A draft copy of the estimate was sent to D. L. Anderson, J. D. Jacobsen, D. S. Duncan, and A. L. Schafer on May 1, 2012 for review. This review allowed for the project team to review and comment on the perceived scope, basis of estimates, and assumptions that make up this cost estimate. Comments from this review have been incorporated into this estimate to reflect a project team consensus of this document.

B. An internal organizational check has been performed on this estimate with the purpose of checking the methodology approach used, discussing the document with the estimator, and ensuring the document has been reviewed and discussed with the requester, reflects a team consensus, has adequately documented the basis, assumptions, and risks to the project, and has mitigated those risks.

VI. ASSUMPTIONS: Condition statements accepted or supposed true without proof of demonstration; statements adding clarification to scope. An assumption has a direct impact on total estimated cost.

A. The RH LLW Facility will be built to become operational by October 1, 2017, and operate for 20 years. This work will be performed during normal working hours. Costs for premium time will not be required for off shift or weekend work for the assessment and loading crews.

B. Transportation of the waste materials may be completed in other than normal business hours to minimize traffic delays but the loading of the vaults will be conducted during normal day shift.

C. Close out costs for relocating the tracked crane, relocation of the unloading station, and vault fixtures for the NRF 55 ton cask system are included in this estimate as this equipment may be used elsewhere.

D. D\&D of the facility infrastructure is included. The maintenance, office building, and firewater pump house will be torn down and disposed of including the concrete slabs. Water and sewer utilities will be removed to $3 \mathrm{ft}$. below grade including the firewater hydrants and capped off. All electrical power poles and underground power systems will be removed to $2 \mathrm{ft}$. below grade and cut off. The vault burial area will be capped with a $4 \mathrm{ft}$. layer of compacted soil and a $12 \mathrm{in}$. layer of top soil planted with natural vegetation to prevent soil losses. The soil cap will be sloped for water runoff. The access road, fence, and monitoring wells will remain in place for long term protection of the area. The graveled surfaces inside the fenced area will remain for minor maintenance and access.

E. Escalation has been included in this estimate to reflect the performance in that time frame. All costs are in FY 2012 dollars and have been escalated.

F. The radiological performance assessment and composite analysis prepared for the 
FORMAL COST ESTIMATE SUPPORT DATA RECAPITULATION

-Continued-

Project Title: Remote Handled Low Level Waste Operations, Disposal and Closeout Activities FY 2018 - FY2037

File: $\quad$ 9A28-H4

Page 6 of 7

new disposal facility in accordance with DOE Order 435.1, "Radioactive Waste Management," will not result in a facility Waste Acceptance Criteria (WAC) more restrictive than the RWMC WAC or result in substantial changes to the facility operations.

G. Operations and sampling of the monitoring wells are managed by BEA.

\section{MANAGEMENT RESERVE (MR) GUIDELINE IMPLEMENTATION:}

Management Reserve Methodologies: Explanation of methodology used in determining overall management reserve. Identify any specific drivers or items of concern and any inherent risks typical with this type of environment. Inflationary and deflationary impacts are addressed in this section.

As discussed with the requester, a contingency for each section was added by the estimator based on the risk and quality of the information for that section of the estimate. This resulted in the estimated cost, including management reserve. A formal risk evaluation was not performed.

A. Threats: Uncertain events that are potentially negative or reduce the probability that the desired outcome will happen.

1. No detailed design exists for this project. The estimated costs were based on the team's perceived idea as to the requirements and project scope that will be required. Completion of the project may increase the costs due to requirements or needs not identified in the scope of this estimate.

2. The cost estimate does not consider or address funding or labor resource restrictions. It is assumed that sufficient funding and labor resources will be available in a manner allowing optimum usage of that funding and resources as estimated and scheduled.

3. Preciseness in the details leaves little room if crews are unable to meet the estimated production rates. Factors could include, but are not limited to, changes to Integrated Safety Management (ISM) requirements, equipment breakdowns, resource impacts, and/or availability.

4. More than normal adverse weather (cold, snow, rain, and wind) would cause losses in productivity or even stop the work. This loss in productivity or stoppage would still require for the operating contractor's forces to be compensated.

5. Cost for labor inefficiencies is not addressed in this estimate. Inefficiencies may occur from using the waste transfer crew at this site for part of the month during a transfer campaign and expected to work other areas the rest of the time. 
FORMAL COST ESTIMATE SUPPORT DATA RECAPITULATION

-Continued-

Project Title: Remote Handled Low Level Waste Operations, Disposal and Closeout Activities FY 2018 - FY2037

File: $\quad$ 9A28-H4

Page 7 of 7

6. Potential for changes to the design and philosophy of operations. The estimate costs are based on a known and utilized design, current operation procedures with similar equipment and waste materials, and current requirements.

B. Opportunities: Uncertain events that could improve the results or improve the probability that the desired outcome will happen.

Well-planned-out work activities and scheduling by the subcontractors could result in increased production, thus producing lower bids and operating contractor oversight costs than what have been estimated.

C. Accepted Risks: Activities with a greater than 50\% and less than 100\% probability of occurrence have been accepted as part of this scope of work.

None.

D. Excluded Risks: Risks that have been identified and have a probability of occurrence but are specifically excluded from this estimate.

None.

Note: Management reserve does not increase the overall accuracy of the estimate; it does, however, reduce the level of risk associated with the estimate. Management reserve is intended to cover the inadequacies in the complete project scope definition, estimating methods, and estimating data. Management reserve specifically excludes changes in project scope, unexpected work stoppages, (e.g., strikes, disasters, and earthquakes) and excessive and/or unexpected inflation or currency fluctuations. This estimate does not contain any contingencies and has not been evaluated to include any contingencies and has not been evaluated to include any of the risks that pertain to Department of Energy.

VIII. OTHER COMMENTS/CONCERNS SPECIFIC TO THE ESTIMATE:

None. 


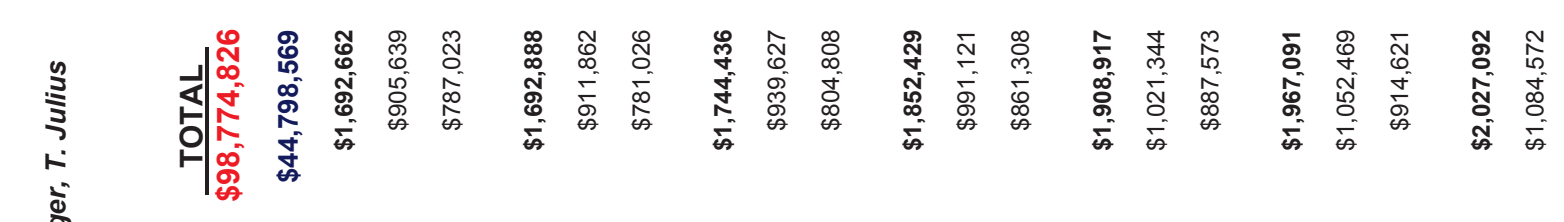

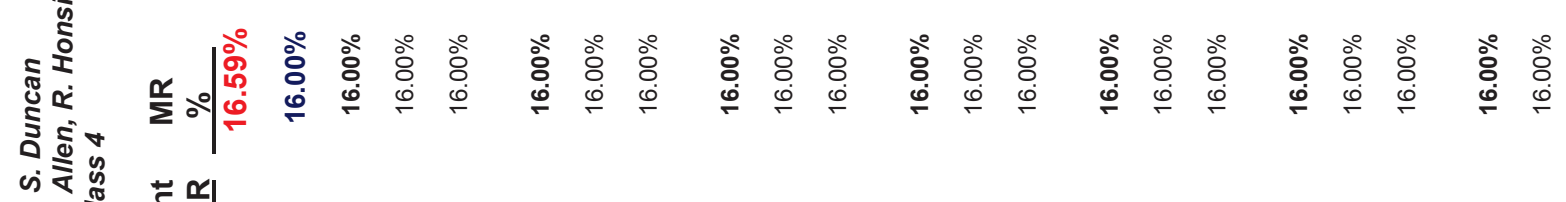

s.t.

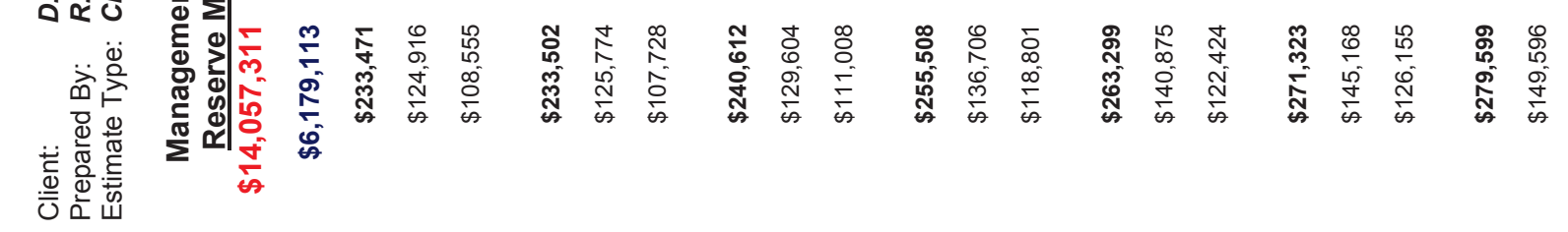

竞

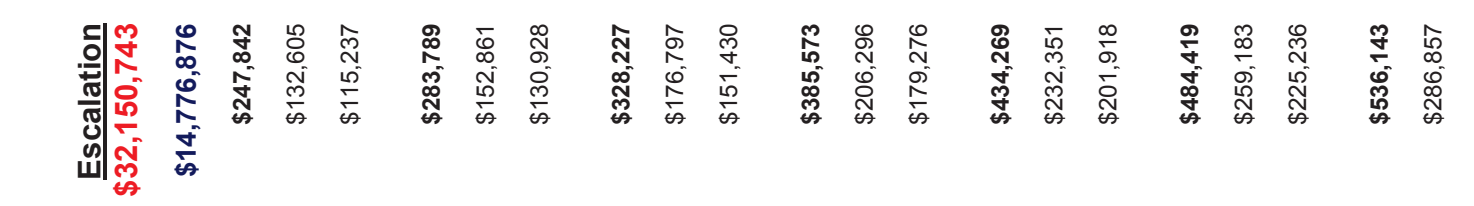

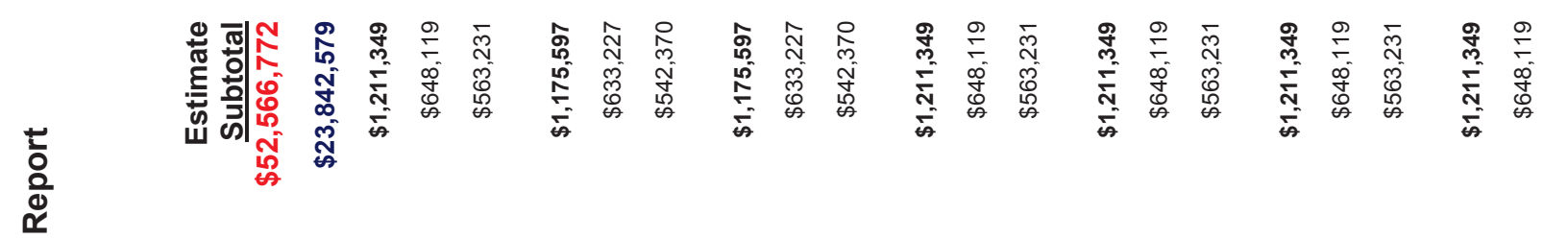

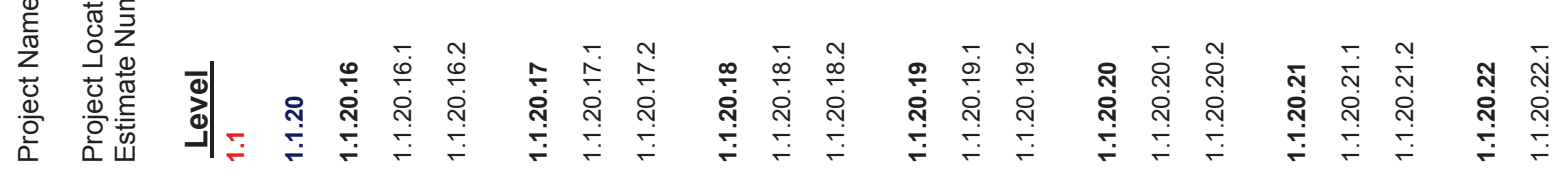




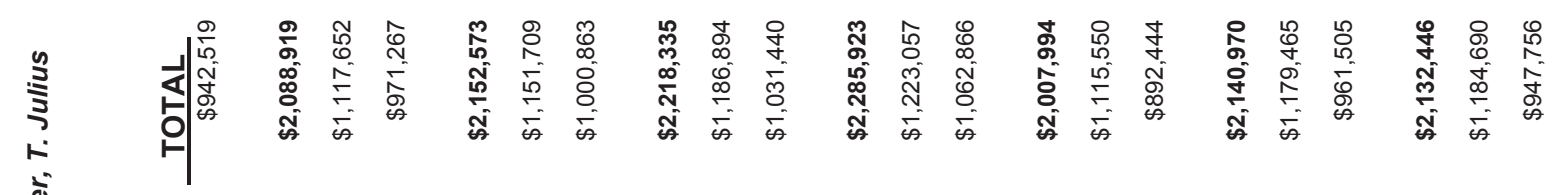

gon

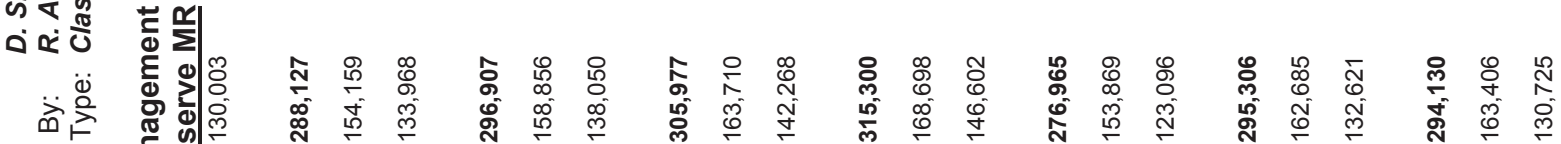

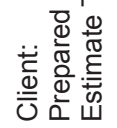

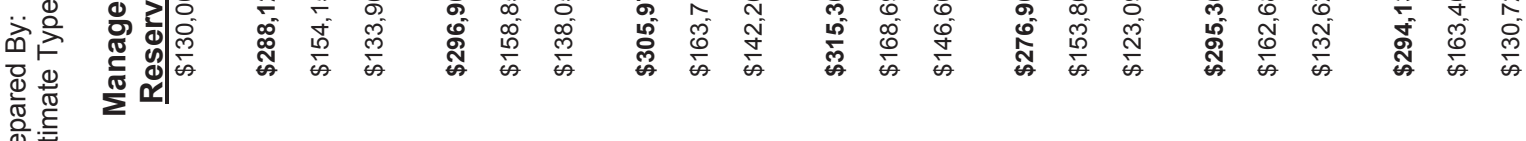

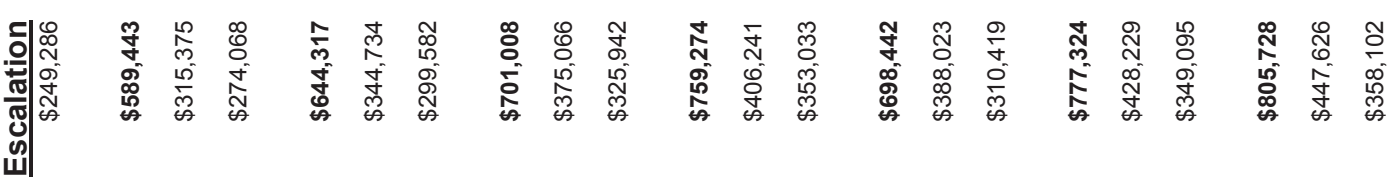

高竞

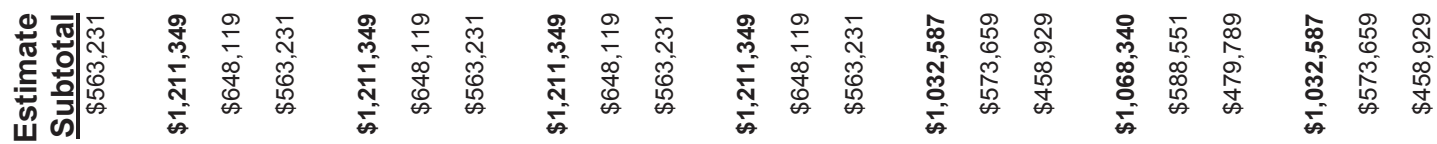

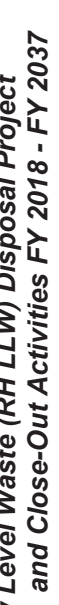

产要
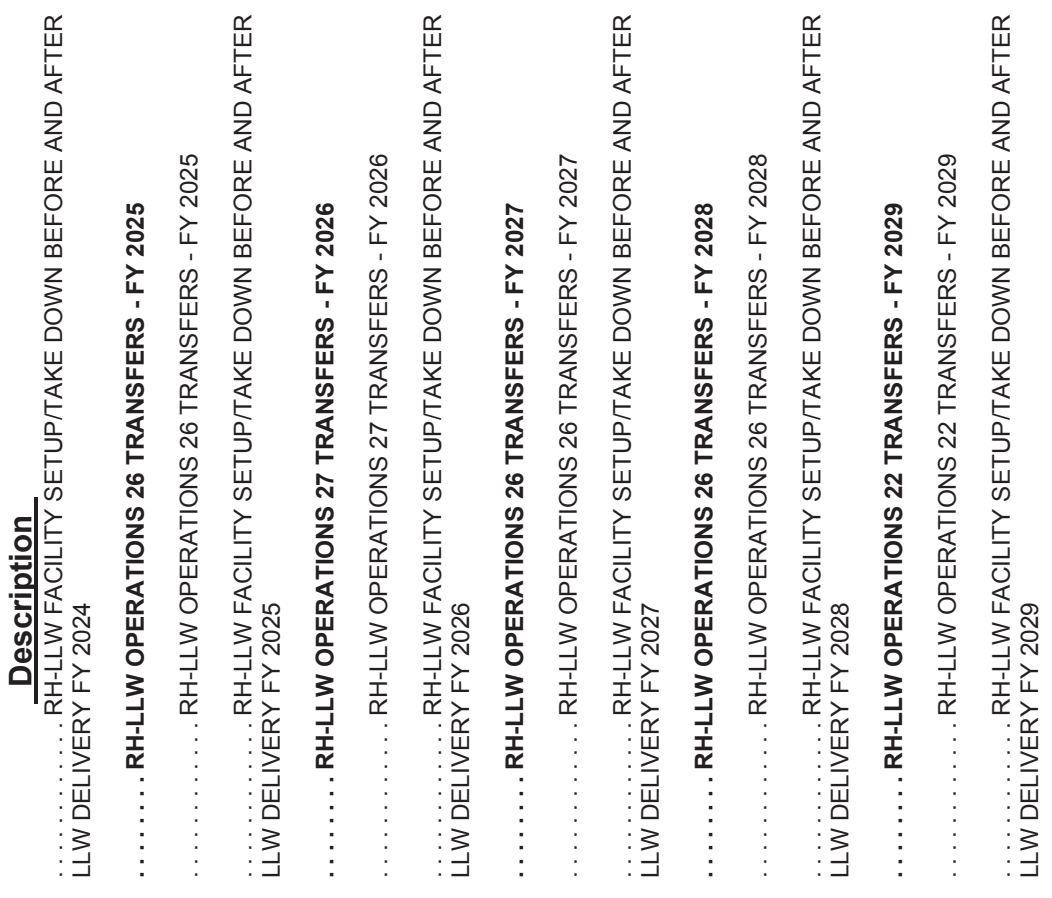

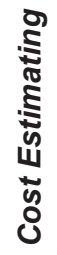

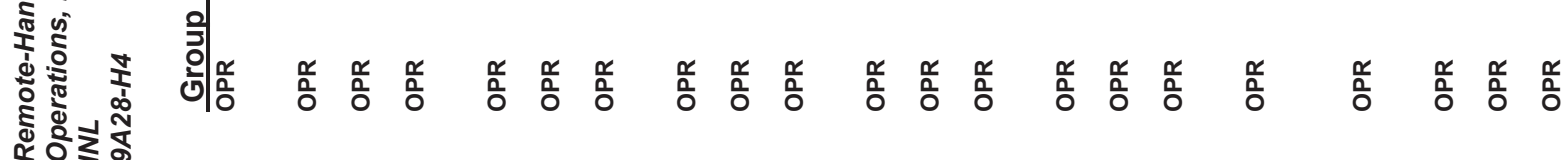

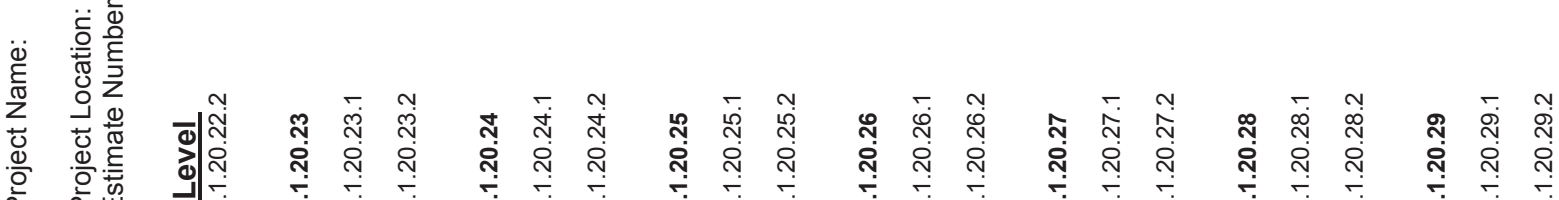




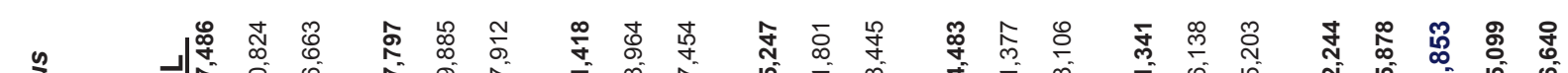

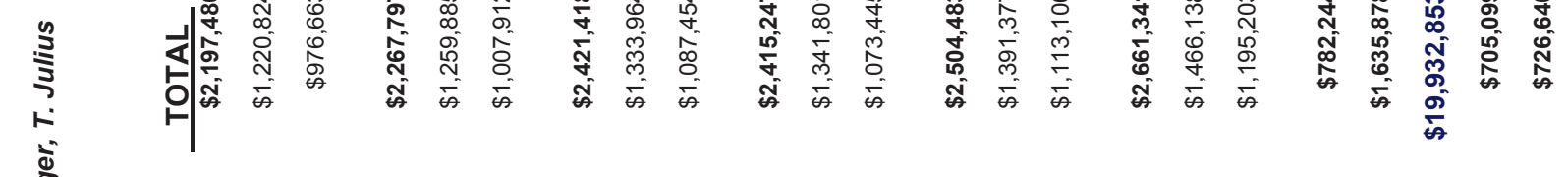

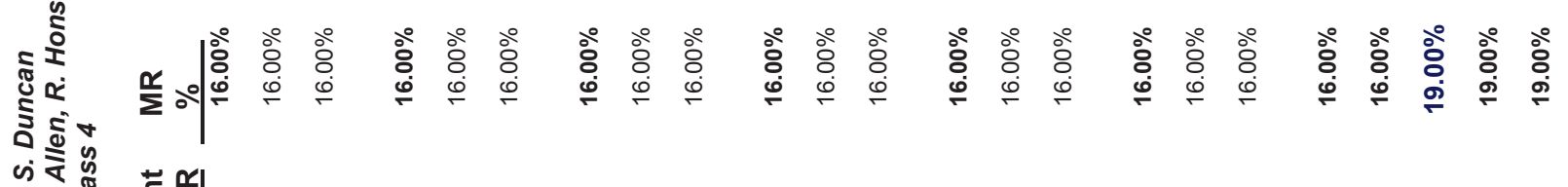

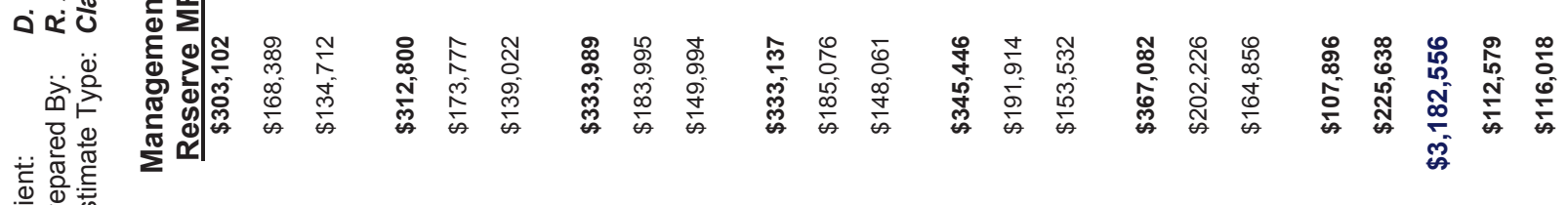

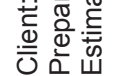

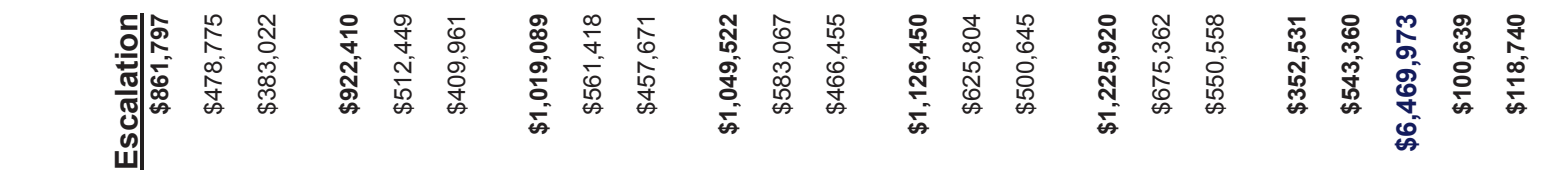

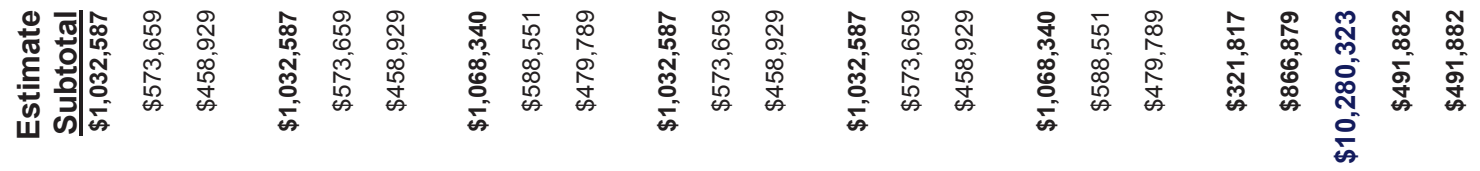

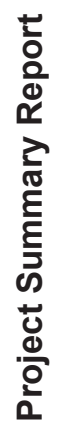

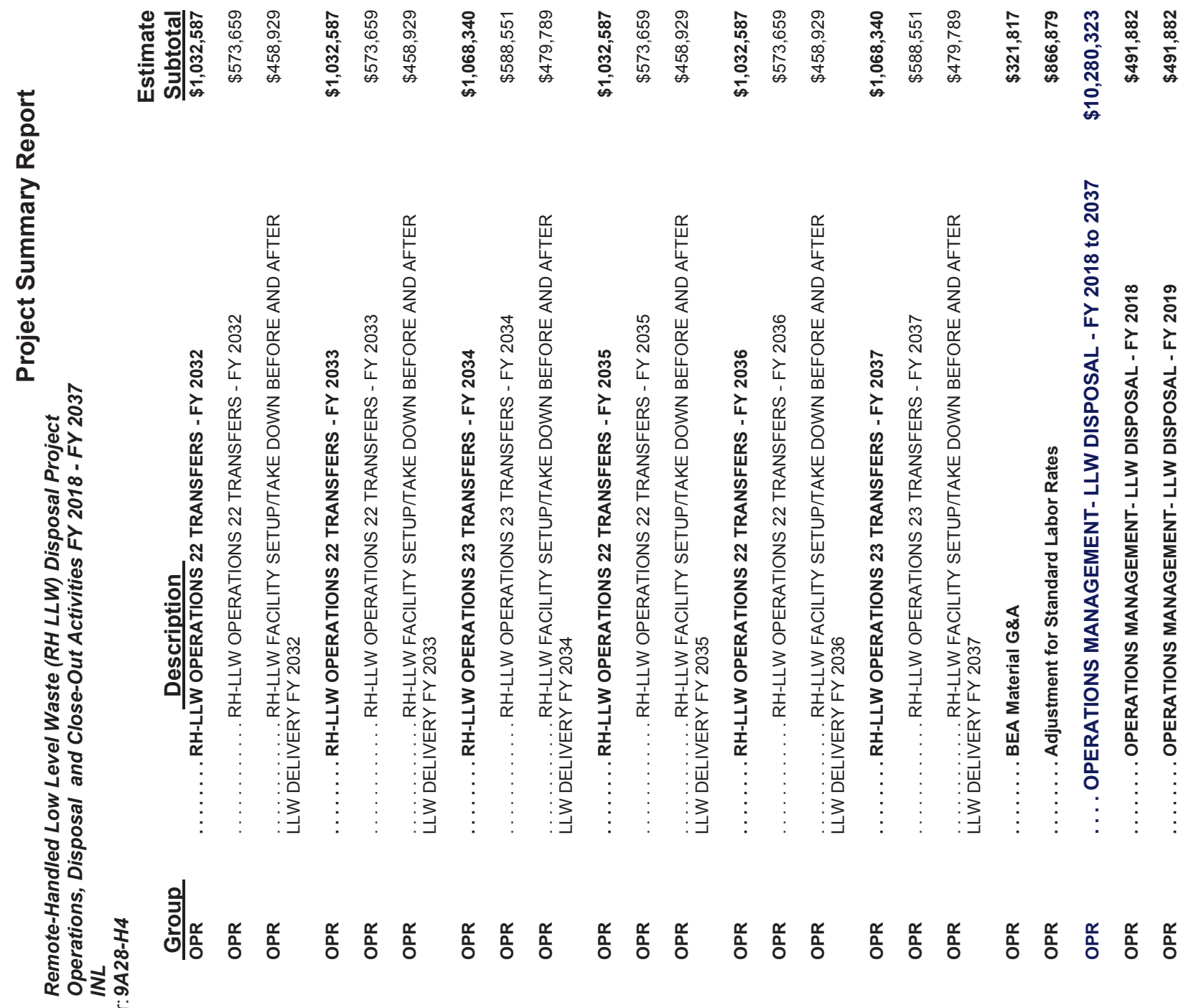

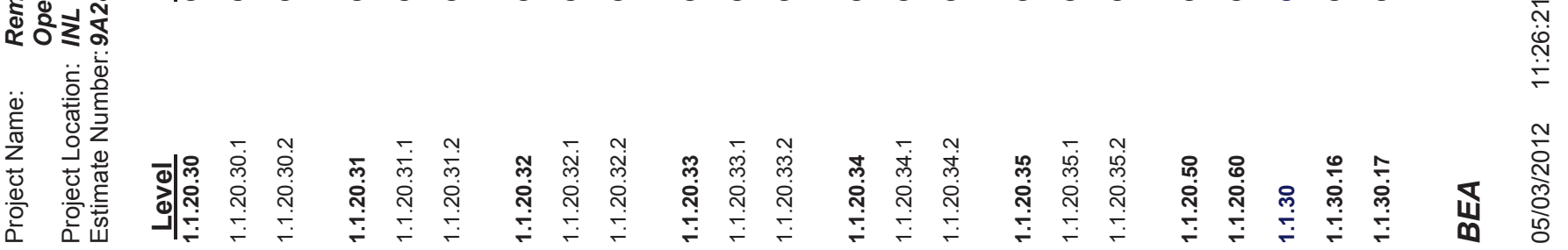




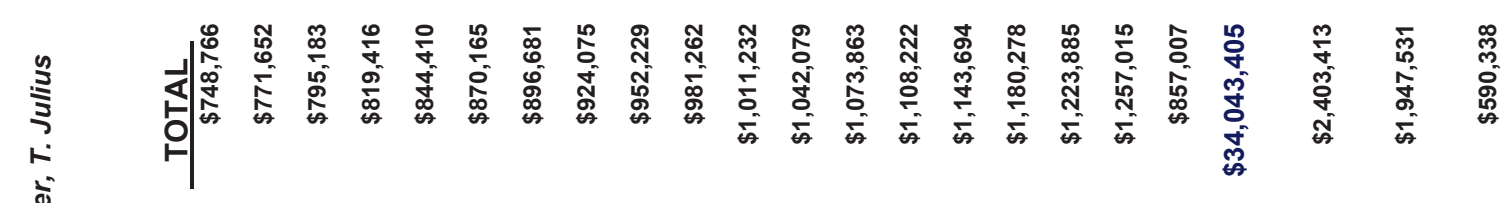

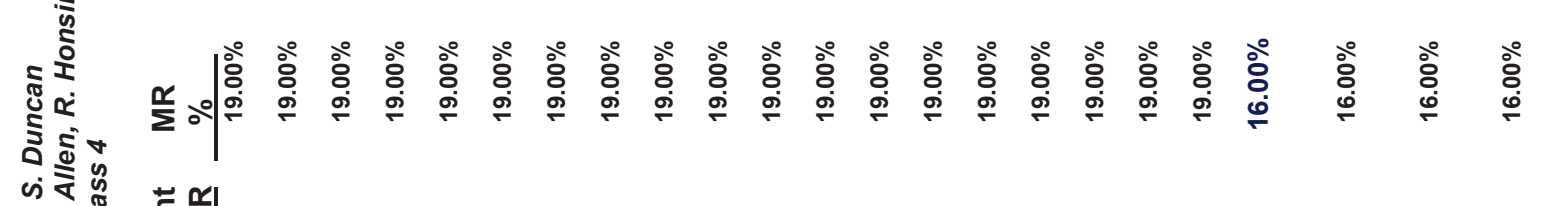

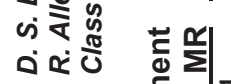

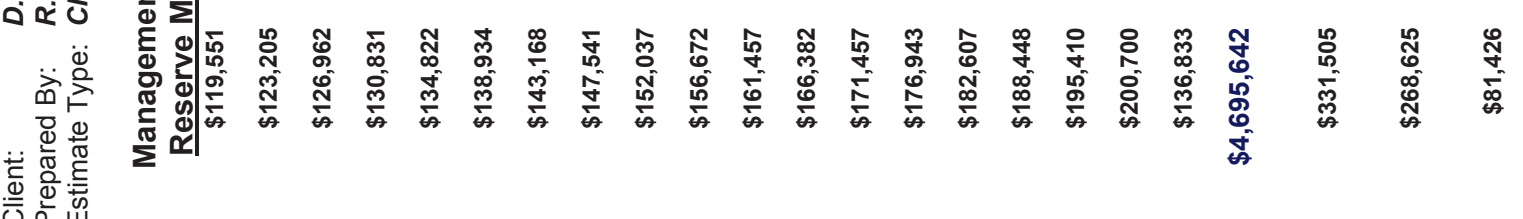

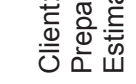

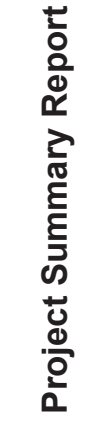

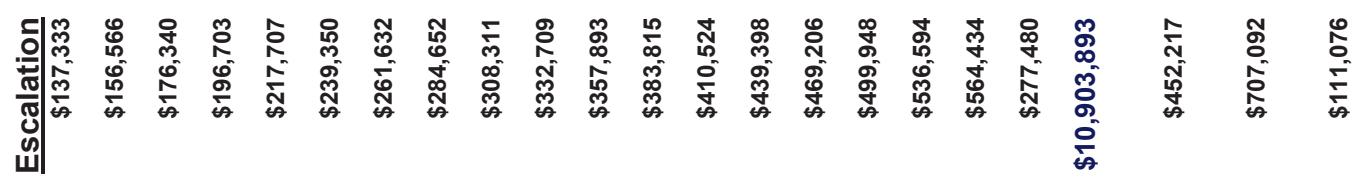

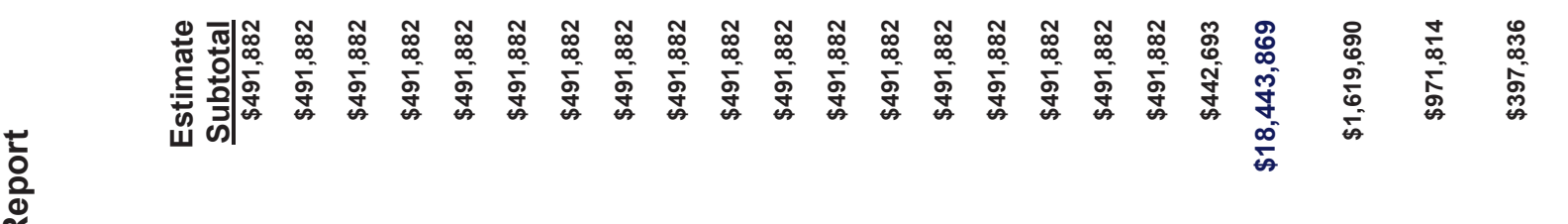

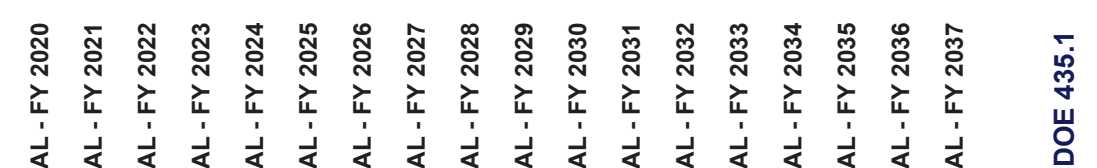

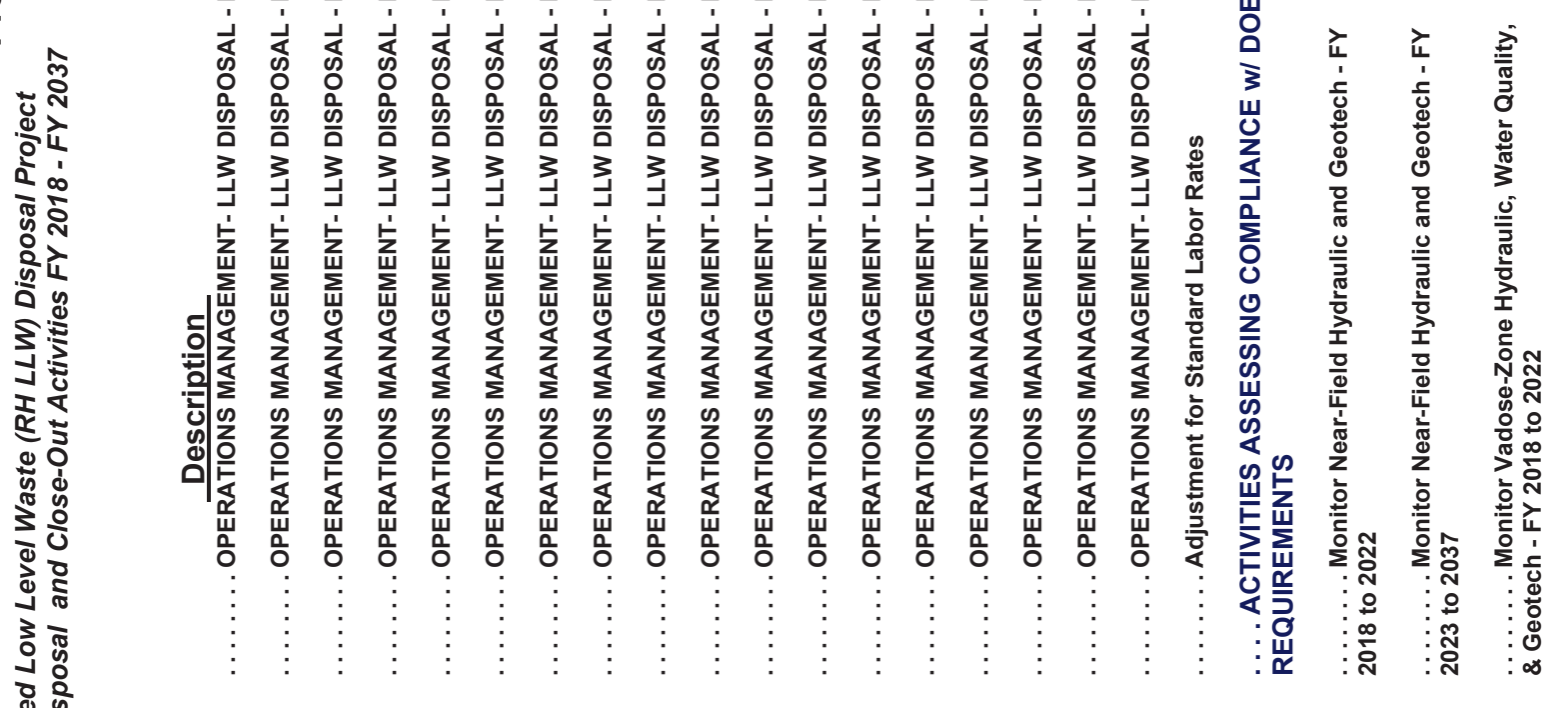

क⿺辶

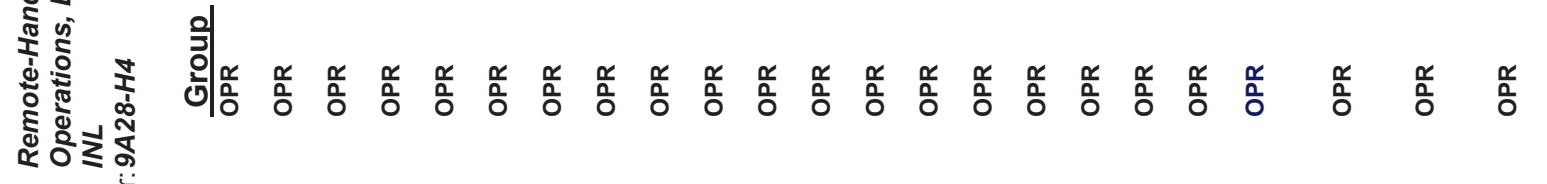

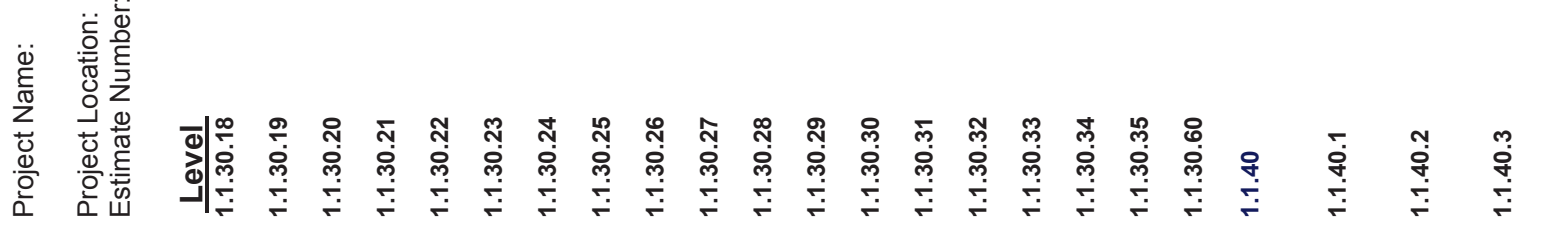




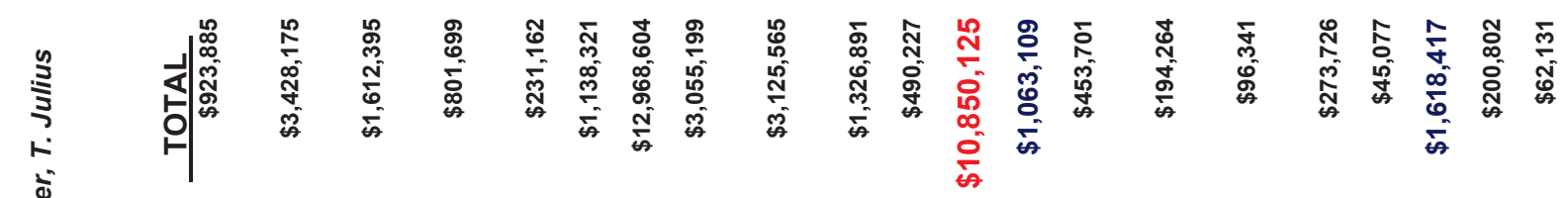

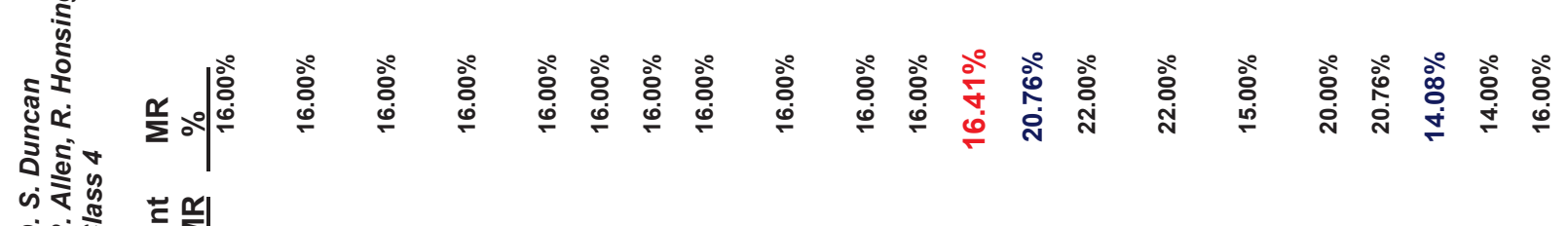

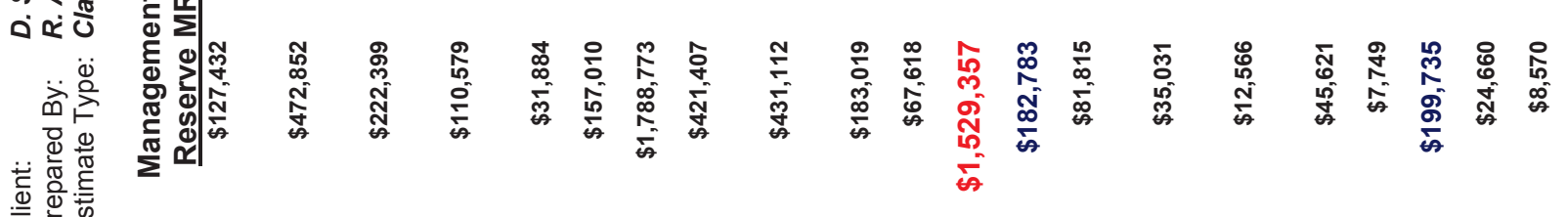

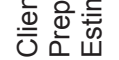

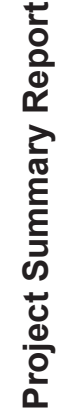

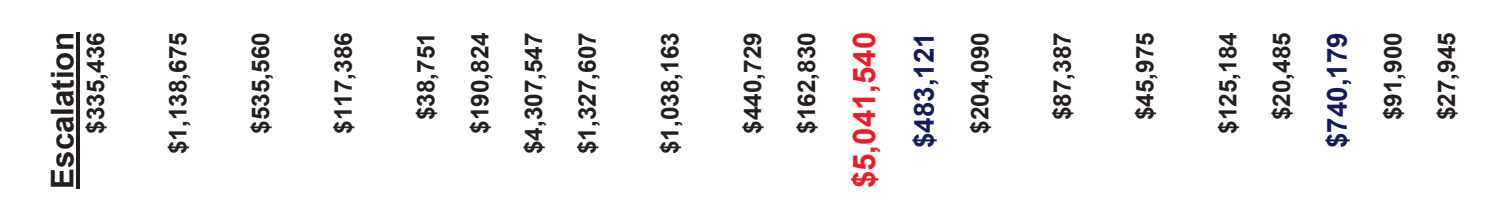

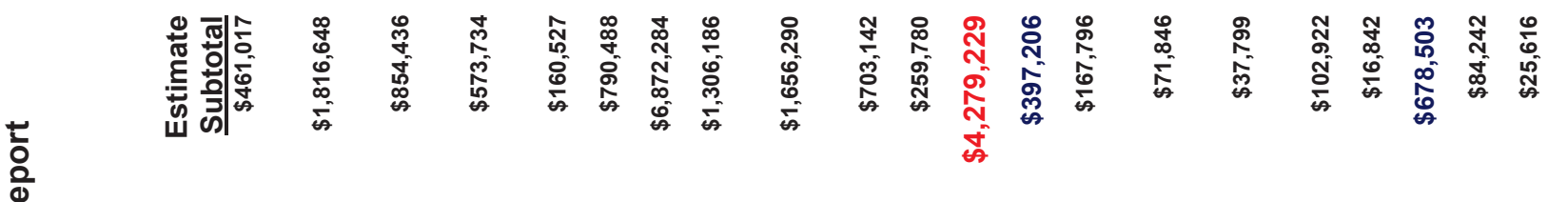

(2)

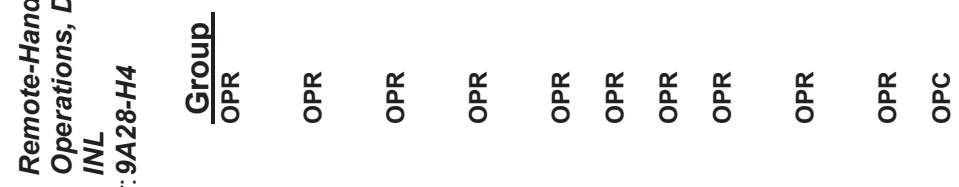




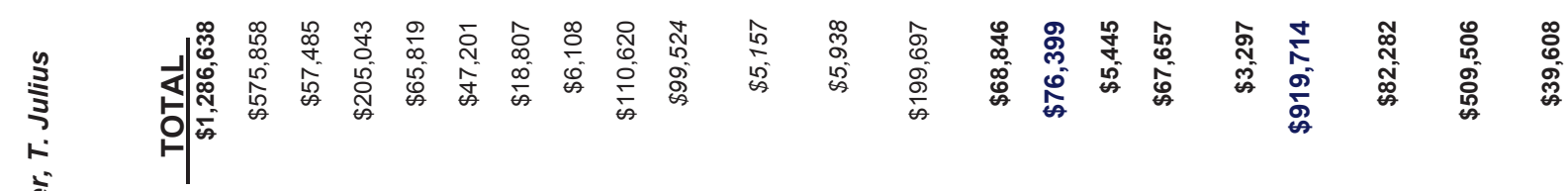

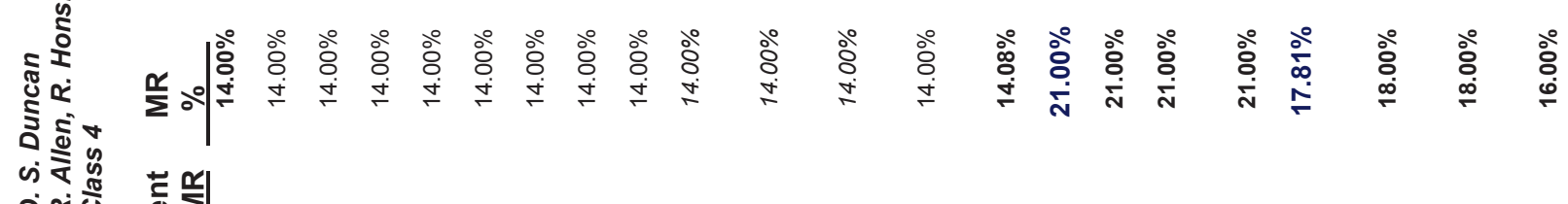

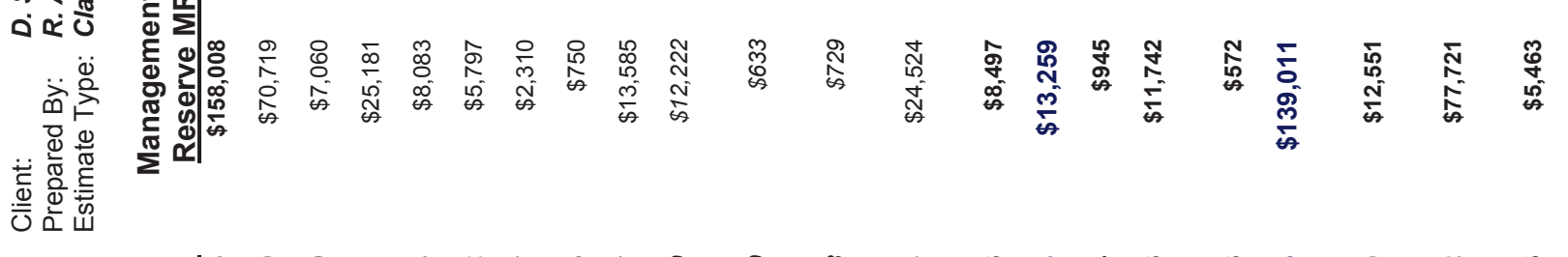
龆

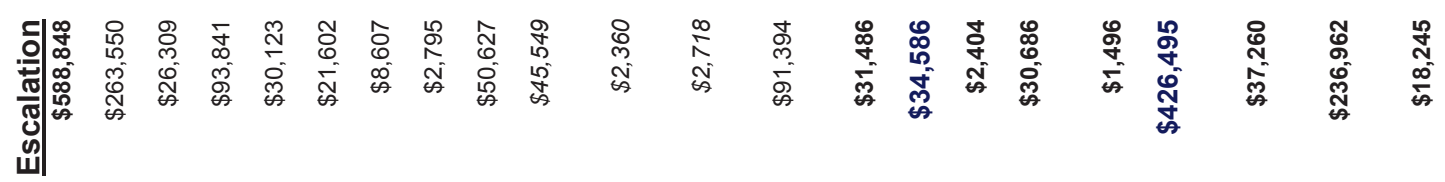

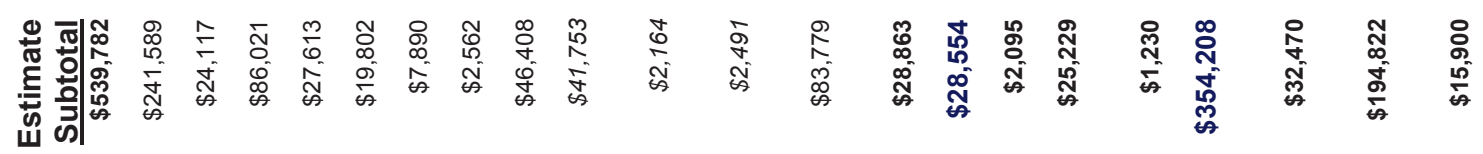

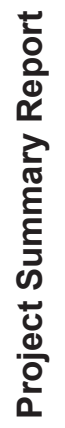

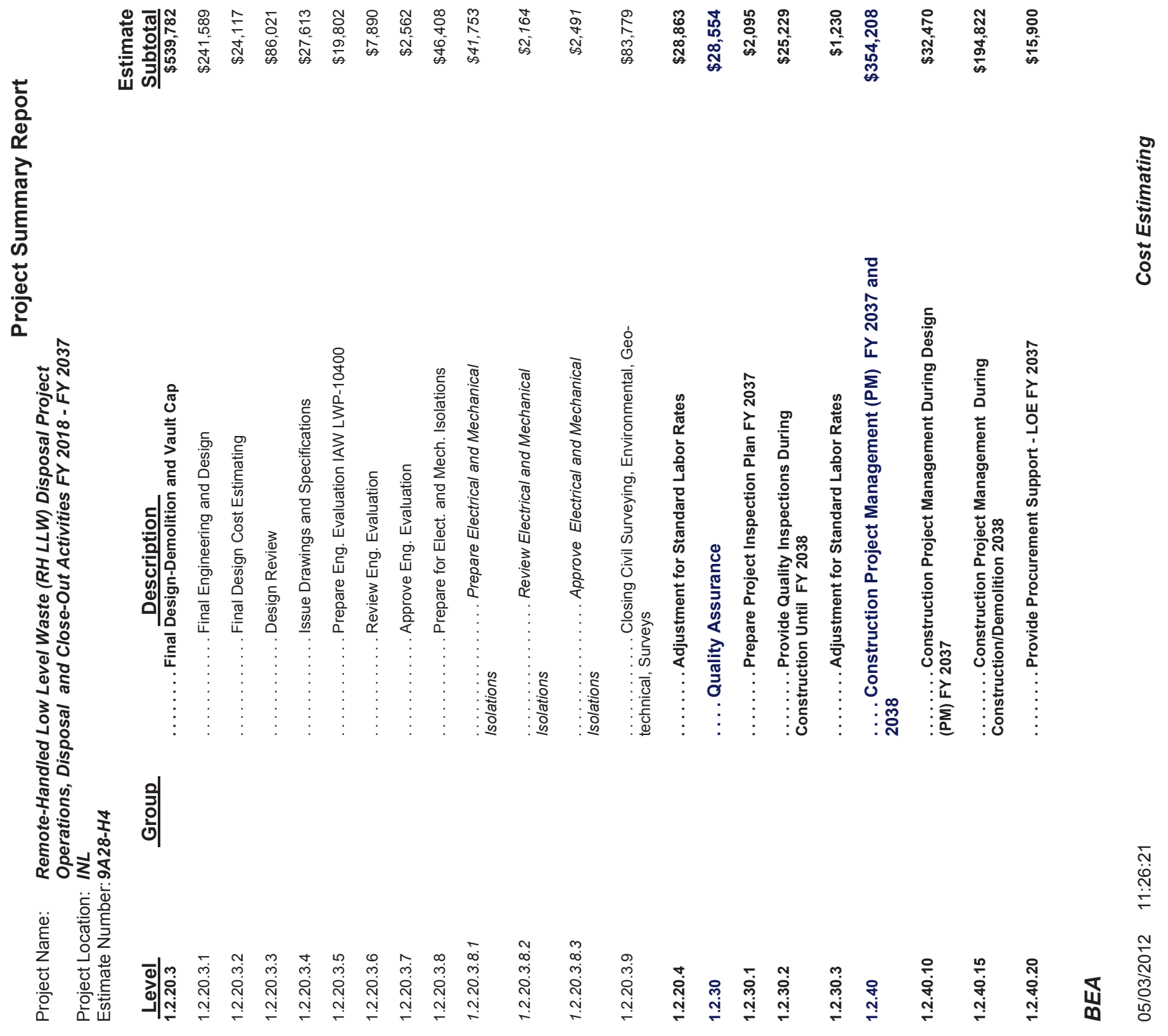




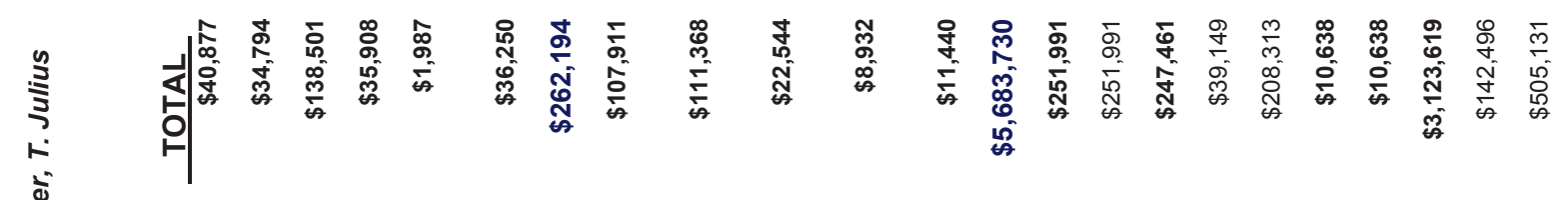

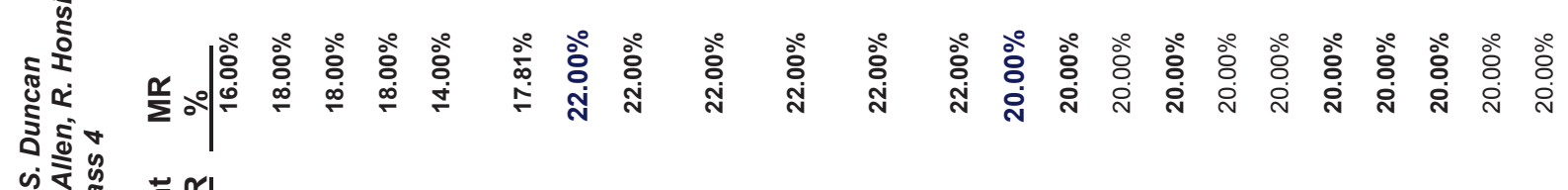

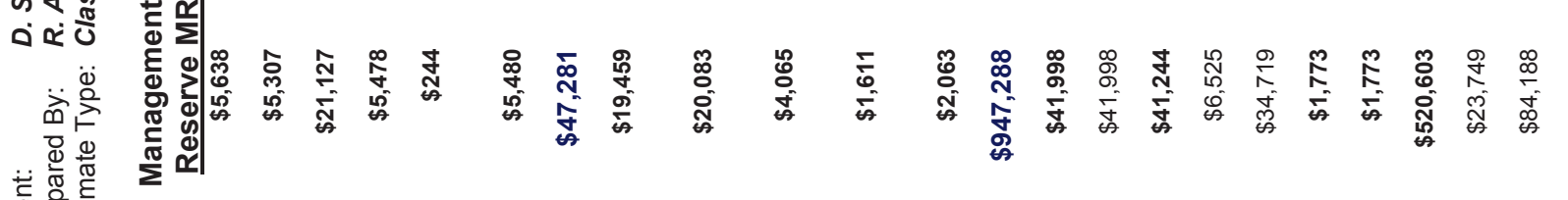

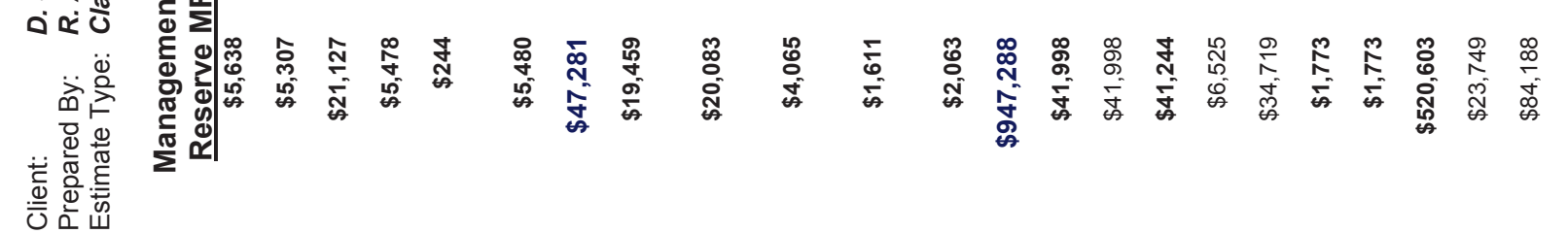

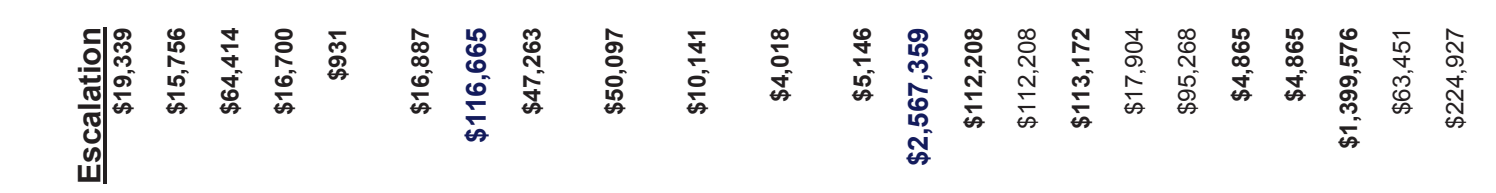

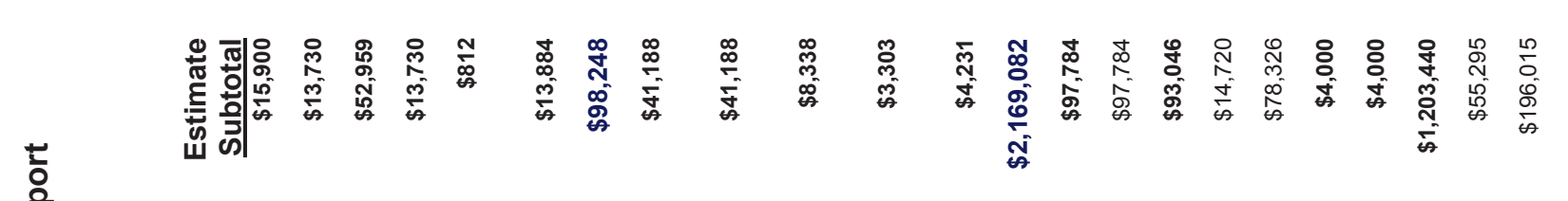

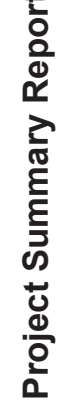

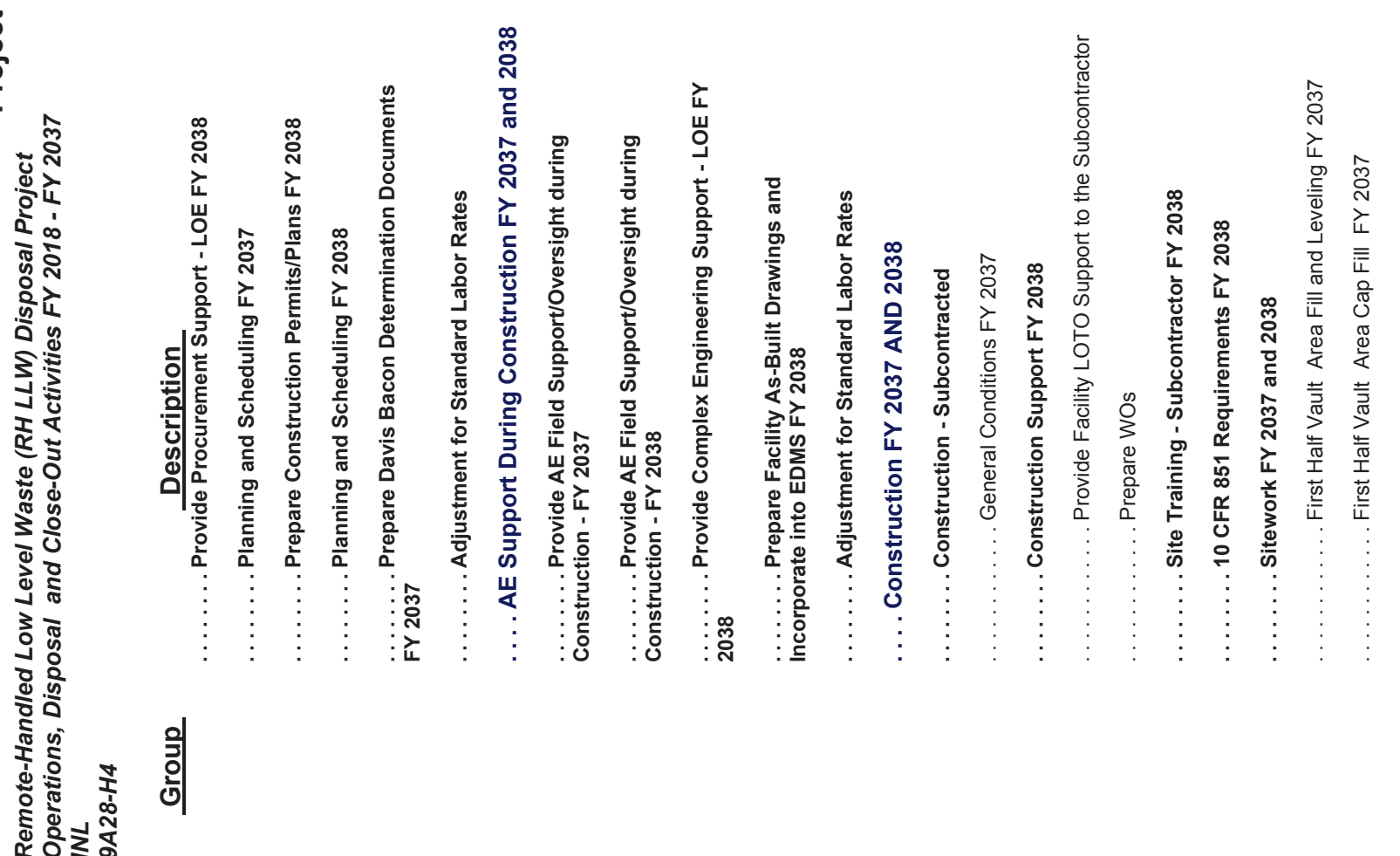

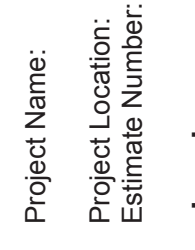




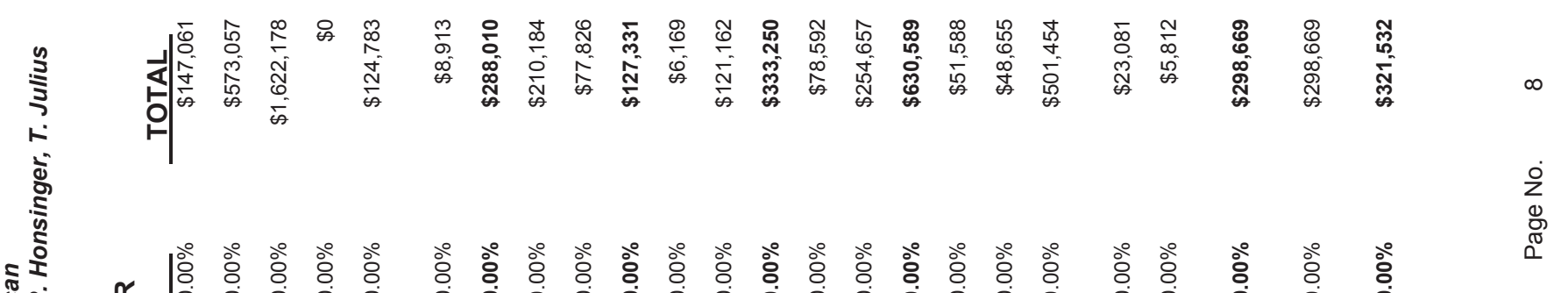

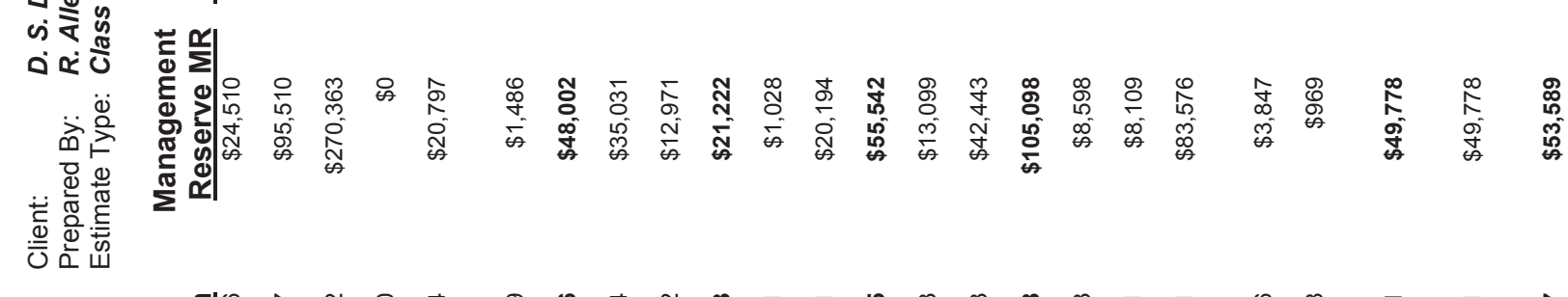

grif

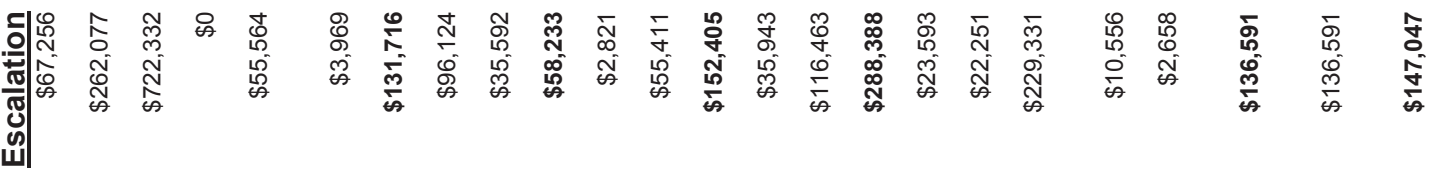

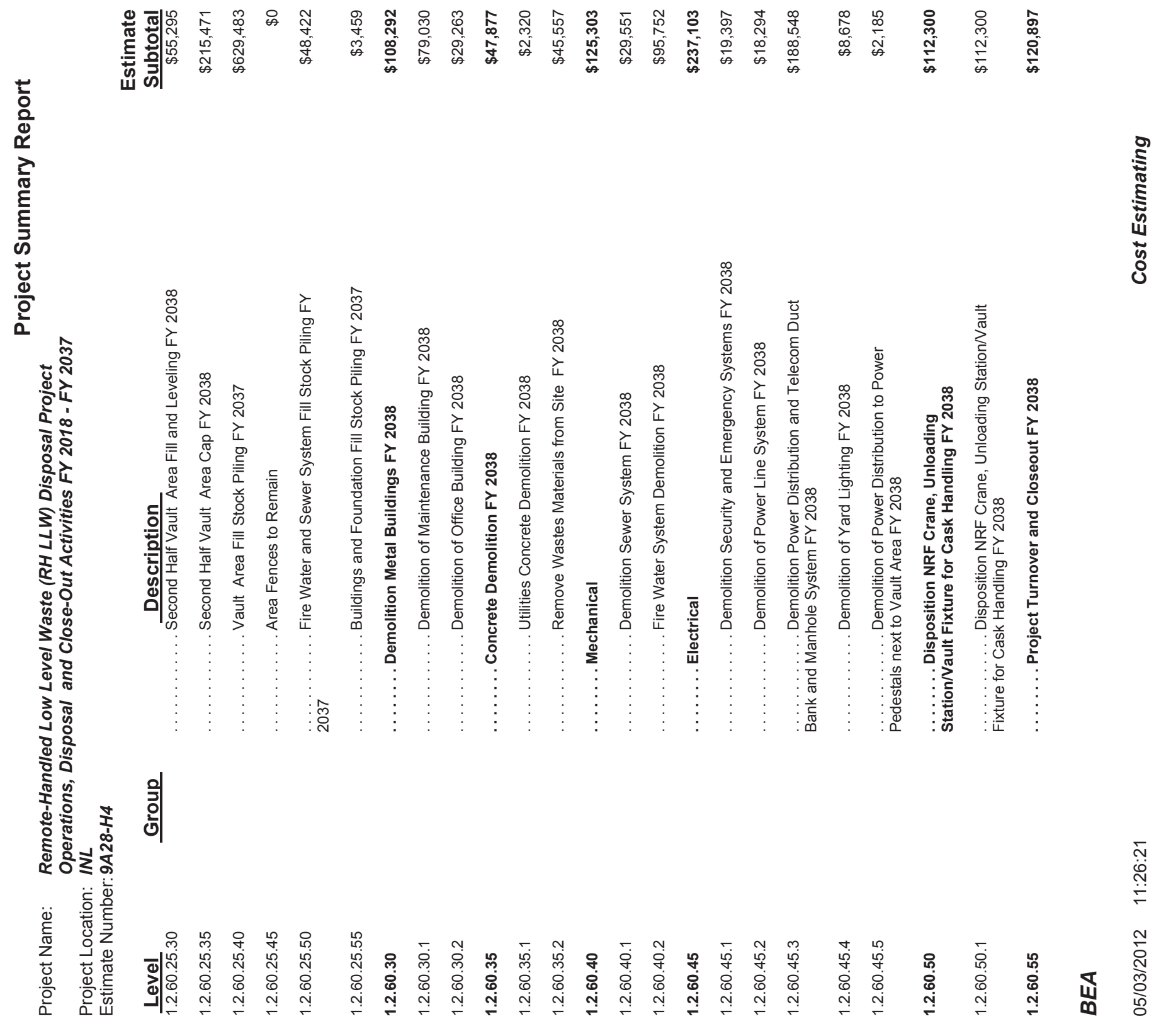




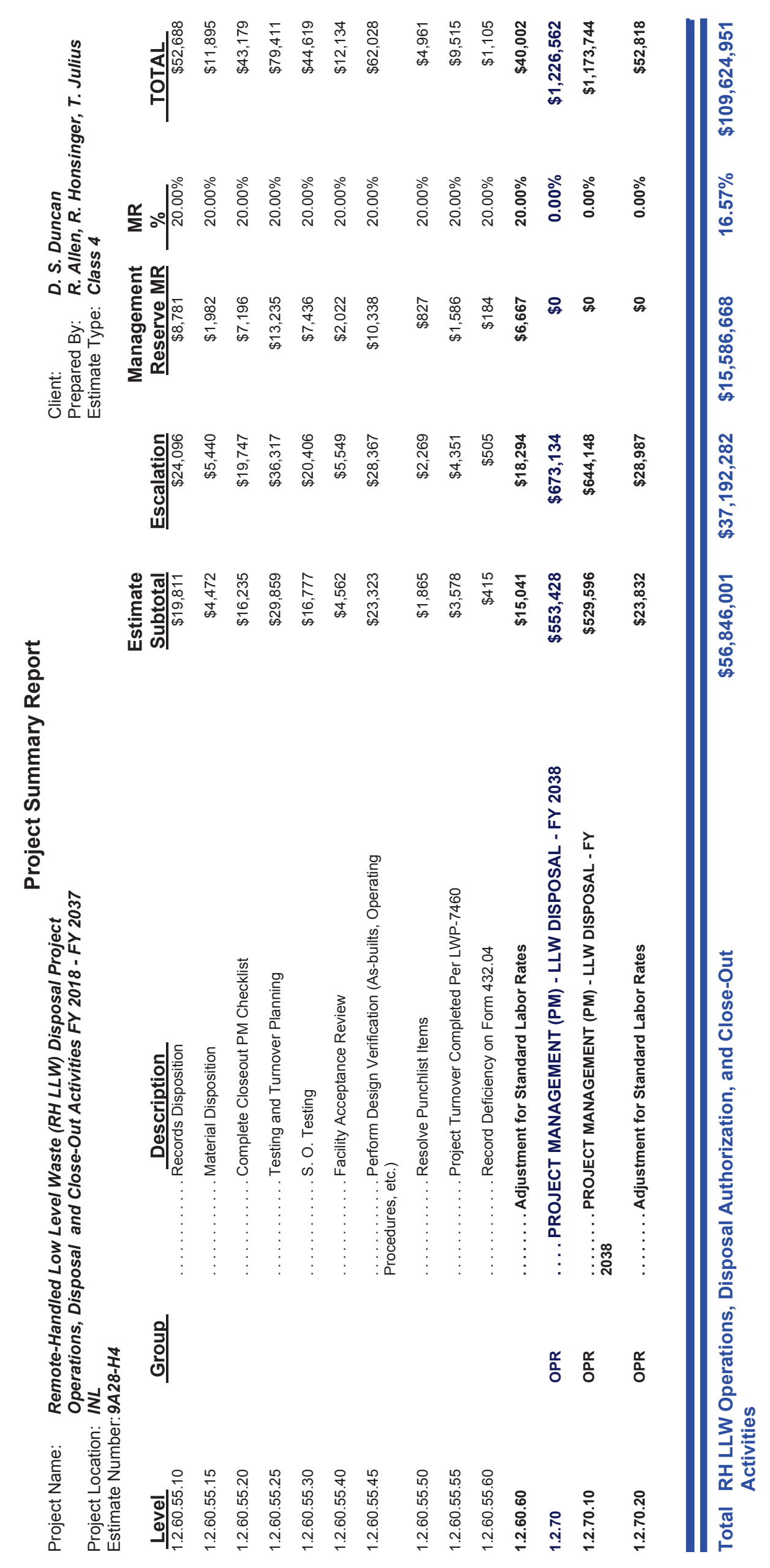

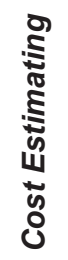

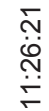

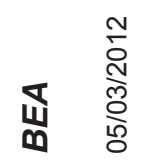




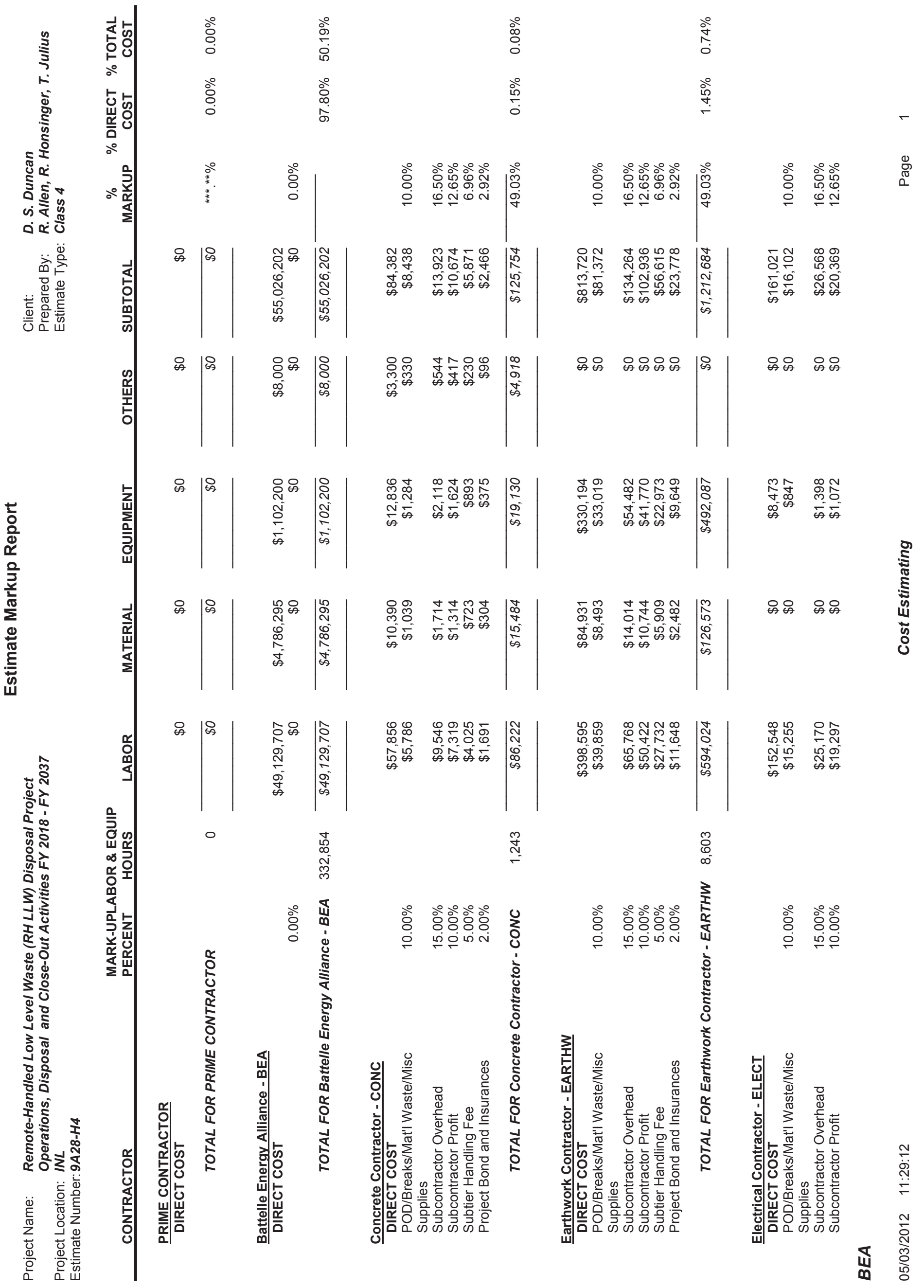




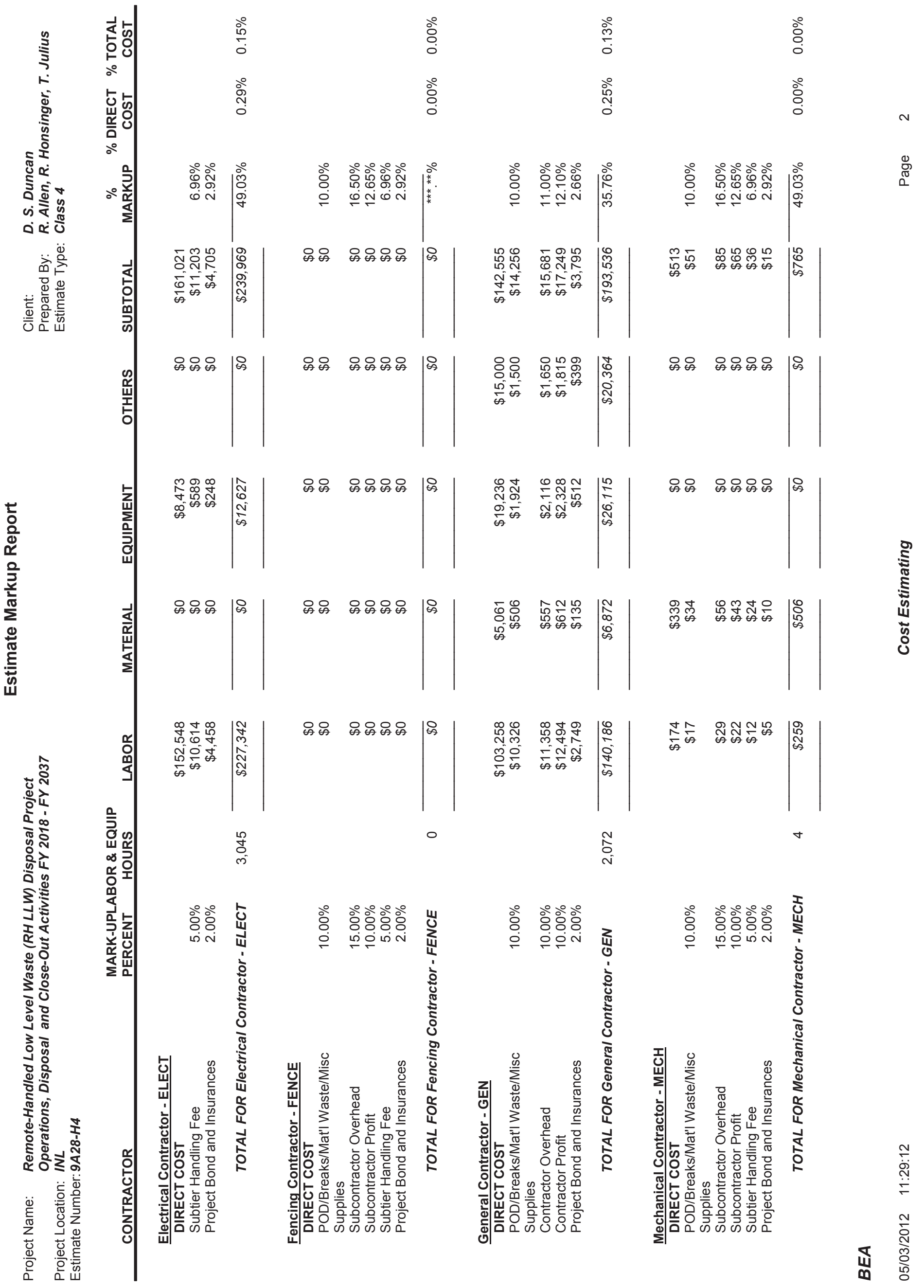




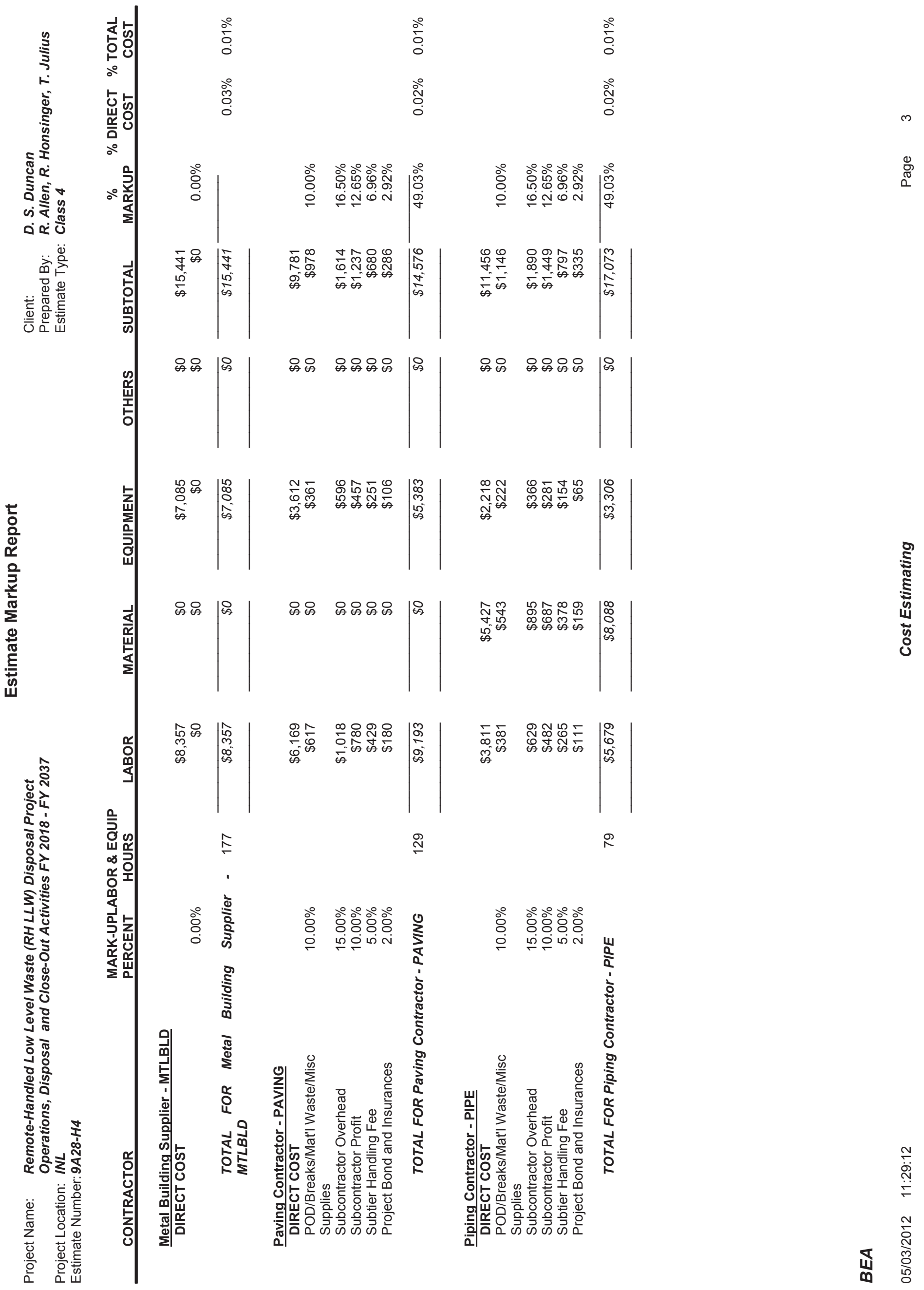




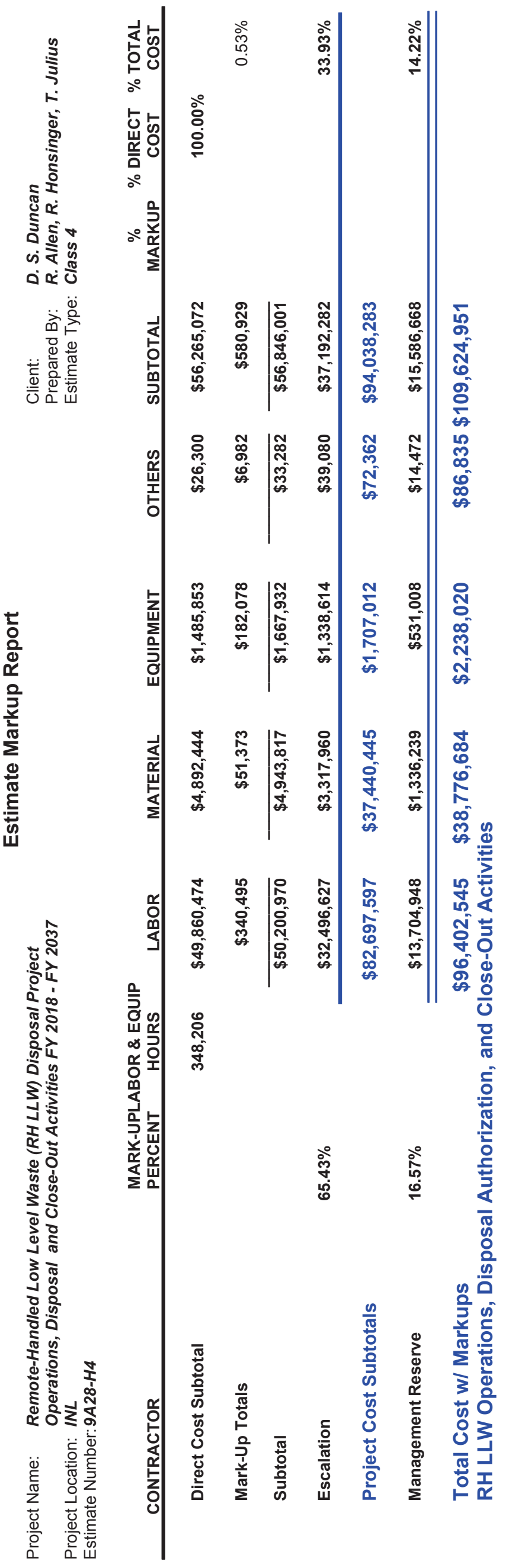




\section{Labor Resource Report}

Activity: $\quad$ RH LLW Operations, Disposal Authorization, and Close-Out Activities

Group:

Level:

Project Name: Remote-Handled Low Level Waste (RH LLW) Disposal Project

Project Location: INL

Operations, Disposal and Close-Out Activities FY 2018 - FY 2037

Estimate Number: 9 A28-H4

\begin{tabular}{|c|c|c|c|c|c|}
\hline Code & Description & WDC Year & Rate $\$ / \mathrm{Hr}$ & Hours & $\begin{array}{c}\text { Direct } \\
\text { Labor Cost }\end{array}$ \\
\hline A08F2 & PLANNING \& BUDGETS & $\mathrm{FY}-12$ & $\$ 57.21$ & 480 & $\$ 27,461$ \\
\hline A13J4 & RECORD MGMT/DOCUMENT CONTROL & FY-12 & $\$ 54.85$ & 488 & $\$ 26,767$ \\
\hline A14D4 & ADMINISTRATIVE ASSIST/OFFICE COORDINATOR & FY-12 & $\$ 73.70$ & 9,000 & $\$ 663,300$ \\
\hline A14D5 & SECRETARIAL & FY-12 & $\$ 73.70$ & 4 & $\$ 295$ \\
\hline A14J2 & SECRETARIAL & $\mathrm{FY}-12$ & $\$ 70.43$ & 3 & $\$ 211$ \\
\hline CNCARPC & CARPENTERS - CONCRETE & FY-12 & $\$ 47.21$ & 2 & $\$ 94$ \\
\hline CNELEC & ELECTRICIANS & FY-12 & $\$ 50.06$ & 2,592 & $\$ 129,751$ \\
\hline CNLABC & LABORERS - CONCRETE & $\mathrm{FY}-12$ & $\$ 44.80$ & 254 & $\$ 11,379$ \\
\hline CNLABPI & LABORERS - PIPING & FY-12 & $\$ 43.51$ & 4 & $\$ 174$ \\
\hline CNLINE & LINE CONSTRUCTION - LINEMAN & $\mathrm{FY}-12$ & $\$ 57.25$ & 16 & $\$ 893$ \\
\hline CNLINECS & LINE CONSTRUCTION - CABLE SPLICER & $\mathrm{FY}-12$ & $\$ 70.45$ & 2 & $\$ 141$ \\
\hline CNLINEEO & LINE CONSTRUCTION - EO & FY-12 & $\$ 56.23$ & 90 & $\$ 5,038$ \\
\hline CNLINEF & LINE CONSTRUCTION - FOREMAN & $\mathrm{FY}-12$ & $\$ 70.54$ & 40 & $\$ 2,822$ \\
\hline CNOPRCR & OPERATORS - CRANES & FY-12 & $\$ 48.36$ & 1,546 & $\$ 74,760$ \\
\hline CNOPRE & OPERATORS - EXCAV & FY-12 & $\$ 46.82$ & 22 & $\$ 1,030$ \\
\hline CNOPREF & OPERATORS - EXCAV - FOREMAN & FY-12 & $\$ 49.15$ & 1,040 & $\$ 51,116$ \\
\hline CNOPRL2 & OPERATORS - LOADER > 4 CUYD & $\mathrm{FY}-12$ & $\$ 47.82$ & 9,009 & $\$ 430,804$ \\
\hline CNOPRSC & OPERATORS - SCRAPERS & $\mathrm{FY}-12$ & $\$ 49.68$ & 109 & $\$ 5,417$ \\
\hline CNPIPE & PIPEFITTERS & $\mathrm{FY}-12$ & $\$ 53.87$ & 193 & $\$ 10,397$ \\
\hline CNTEAM & TEAMSTERS & FY-12 & $\$ 45.53$ & 83 & $\$ 3,779$ \\
\hline CNWELL & WELL DRILLER W EQUIPMENT & $\mathrm{FY}-12$ & $\$ 122.00$ & 26 & $\$ 3,172$ \\
\hline E04J1 & CIVIL/STRUCTURAL ENGR & FY-12 & $\$ 198.02$ & 1,062 & $\$ 210,198$ \\
\hline E06D1 & ELECTRICAL ENGINEERING & FY-12 & $\$ 172.71$ & 110 & $\$ 18,998$ \\
\hline
\end{tabular}

\section{BEA}




\section{Labor Resource Report}

Activity: $\quad$ RH LLW Operations, Disposal Authorization, and Close-Out Activities

Group:

Level:

Project Name: $\quad$ Remote-Handled Low Level Waste (RH LLW) Disposal Project

Operations, Disposal and Close-Out Activities FY 2018 - FY 2037

Project Location: INL

Estimate Number: $9 \mathrm{~A} 28-\mathrm{H} 4$

\begin{tabular}{|c|c|c|c|c|c|}
\hline Code & Description & WDC Year & Rate $\$ / \mathrm{Hr}$ & Hours & $\begin{array}{c}\text { Direct } \\
\text { Labor Cost }\end{array}$ \\
\hline E06J1 & ELECTRICAL ENGINEERING & $\mathrm{FY}-12$ & $\$ 160.29$ & 435 & $\$ 69,726$ \\
\hline E08D1 & ENVIRONMENTAL ENGINEERING & $\mathrm{FY}-12$ & $\$ 200.66$ & 200 & $\$ 40,132$ \\
\hline E11C4 & MECHANICAL ENGINEERING & $\mathrm{FY}-12$ & $\$ 180.16$ & 45 & $\$ 8,107$ \\
\hline E11J1 & MECHANICAL ENGINEERING & $\mathrm{FY}-12$ & $\$ 160.94$ & 442 & $\$ 71,135$ \\
\hline E17H3 & QUALITY ENGINEERING & $\mathrm{FY}-12$ & $\$ 104.77$ & 76 & $\$ 7,910$ \\
\hline E18H6 & RADIOLOGICAL ENGINEERING & FY-12 & $\$ 139.00$ & 72 & $\$ 9,939$ \\
\hline E19H1 & SAFETY ENGINEERING & $\mathrm{FY}-12$ & $\$ 148.45$ & 412 & $\$ 61,087$ \\
\hline E28C3 & PROJ MGMT & $\mathrm{FY}-12$ & $\$ 198.33$ & 14 & $\$ 2,777$ \\
\hline E28P5 & PROJ MGMT & $\mathrm{FY}-12$ & $\$ 131.30$ & 33 & $\$ 4,267$ \\
\hline E31W3 & CRITICALITY SAFETY & FY-12 & $\$ 160.66$ & 9,922 & $\$ 1,593,988$ \\
\hline E32J1 & SYSTEM/SSC ENGINEER & FY-12 & $\$ 173.70$ & 48 & $\$ 8,338$ \\
\hline E34J1 & PROJECT ENGINEER & $\mathrm{FY}-12$ & $\$ 176.62$ & 365 & $\$ 64,466$ \\
\hline E37D5 & SECURITY AND ALARMS & FY-12 & $\$ 155.60$ & 2,002 & $\$ 311,433$ \\
\hline E41H1 & FIRE PROTECTION & FY-12 & $\$ 170.52$ & 140 & $\$ 23,873$ \\
\hline E41J1 & FIRE PROTECTION & FY-12 & $\$ 168.80$ & 2 & $\$ 253$ \\
\hline F01C0 & BUILDING/FACILITY MANAGEMENT & $\mathrm{FY}-12$ & $\$ 164.78$ & 8,000 & $\$ 1,318,240$ \\
\hline F01G1 & BUILDING/FACILITY MANAGEMENT & $\mathrm{FY}-12$ & $\$ 115.23$ & 14 & $\$ 1,613$ \\
\hline F01J2 & BUILDING/FACILITY MANAGEMENT & FY-12 & $\$ 147.20$ & 102 & $\$ 14,941$ \\
\hline F05J2 & FAC OPERATIONS & $\mathrm{FY}-12$ & $\$ 120.83$ & 2 & $\$ 181$ \\
\hline F05J3 & FAC OPERATIONS & $\mathrm{FY}-12$ & $\$ 120.83$ & 14 & $\$ 1,692$ \\
\hline F06G0 & FAC OPERATIONS/NUCLEAR & $\mathrm{FY}-12$ & $\$ 108.65$ & 14 & $\$ 1,521$ \\
\hline F06G8 & FAC OPERATIONS/NUCLEAR & FY-12 & $\$ 108.65$ & 54 & $\$ 5,867$ \\
\hline F10J1 & WORK PLANNING AND/OR SCHEDULING & FY-12 & $\$ 114.75$ & 2,158 & $\$ 247,573$ \\
\hline
\end{tabular}

\section{BEA}




\section{Labor Resource Report}

Activity: $\quad$ RH LLW Operations, Disposal Authorization, and Close-Out Activities

Group:

Level:

Project Name: Remote-Handled Low Level Waste (RH LLW) Disposal Project

Project Location: INL

Operations, Disposal and Close-Out Activities FY 2018 - FY 2037

Estimate Number: 9 A28-H4

\begin{tabular}{|c|c|c|c|c|c|}
\hline Code & Description & WDC Year & Rate $\$ / \mathrm{Hr}$ & Hours & $\begin{array}{c}\text { Direct } \\
\text { Labor Cost }\end{array}$ \\
\hline $\mathrm{F} 12 \mathrm{~J} 3$ & SECURITY & $\mathrm{FY}-12$ & $\$ 96.55$ & 2 & $\$ 145$ \\
\hline F22J1 & COST ESTIMATING & FY-12 & $\$ 102.17$ & 160 & $\$ 16,347$ \\
\hline F22P4 & COST ESTIMATING & $\mathrm{FY}-12$ & $\$ 106.33$ & 240 & $\$ 25,519$ \\
\hline F26J1 & CONSTRUCTION FIELD ENGINEER & $\mathrm{FY}-12$ & $\$ 172.44$ & 22 & $\$ 3,794$ \\
\hline F31J1 & CONSTRUCTION - OTHER TECHNICAL & $\mathrm{FY}-12$ & $\$ 117.89$ & 1,358 & $\$ 160,095$ \\
\hline F35J1 & PROJECT MANAGER & FY-12 & $\$ 202.94$ & 2,668 & $\$ 541,444$ \\
\hline P19J4 & RECORDS MGMT/DOC CONTROL & FY-12 & $\$ 104.74$ & 50 & $\$ 5,237$ \\
\hline P21F5 & SUBCONTRACT ADMIN & $\mathrm{FY}-12$ & $\$ 89.75$ & 14 & $\$ 1,257$ \\
\hline P23J3 & TRAINING & $\mathrm{FY}-12$ & $\$ 100.40$ & 1 & $\$ 100$ \\
\hline P44F2 & PLANNING AND CONTROLS & $\mathrm{FY}-12$ & $\$ 94.57$ & 1,026 & $\$ 97,029$ \\
\hline S03B3 & EARTH \& LIFE SCIENCES & $\mathrm{FY}-12$ & $\$ 190.21$ & 35,600 & $\$ 6,771,476$ \\
\hline S06B2 & HEALTH PHYSICS & $\mathrm{FY}-12$ & $\$ 150.91$ & 250 & $\$ 37,728$ \\
\hline S07B3 & HYDROLOGY & $\mathrm{FY}-12$ & $\$ 204.71$ & 29,960 & $\$ 6,133,112$ \\
\hline S08H1 & INDUSTRIAL HYGIENE & $\mathrm{FY}-12$ & $\$ 146.62$ & 47 & $\$ 6,818$ \\
\hline S21C6 & REGULATORY COMPLIANCE - ENVIRONMENTAL & FY-12 & $\$ 150.41$ & 11 & $\$ 1,655$ \\
\hline S21H5 & REGULATORY COMPLIANCE - ENVIRONMENTAL & FY-12 & $\$ 157.83$ & 28,350 & $\$ 4,474,481$ \\
\hline S22B2 & GEOPHYSICIST & FY-12 & $\$ 178.63$ & 200 & $\$ 35,726$ \\
\hline S22B3 & GEOPHYSICIST & FY-12 & $\$ 171.00$ & 3,840 & $\$ 656,640$ \\
\hline T02J1 & CONST INSPECT TECH & $\mathrm{FY}-12$ & $\$ 102.17$ & 180 & $\$ 18,391$ \\
\hline T02J2 & CONST INSPECT TECH & FY-12 & $\$ 87.60$ & 288 & $\$ 25,229$ \\
\hline T03J1 & DRAFTER & FY-12 & $\$ 91.76$ & 1,361 & $\$ 124,885$ \\
\hline T06E1 & FAC OPS/HAZARD WASTE TECH & $\mathrm{FY}-12$ & $\$ 89.74$ & 14,880 & $\$ 1,335,331$ \\
\hline T12W5 & QUALITY INSPECT TECH & FY-12 & $\$ 87.84$ & 9,922 & $\$ 871,505$ \\
\hline
\end{tabular}

\section{BEA}




\section{Labor Resource Report}

Activity: $\quad$ RH LLW Operations, Disposal Authorization, and Close-Out Activities

Group:

Level:

Project Name: Remote-Handled Low Level Waste (RH LLW) Disposal Project

Project Location: INL

Operations, Disposal and Close-Out Activities FY 2018 - FY 2037

Estimate Number: 9 A28-H4

\begin{tabular}{|c|c|c|c|c|c|}
\hline Code & Description & WDC Year & Rate $\$ / \mathrm{Hr}$ & Hours & $\begin{array}{c}\text { Direct } \\
\text { Labor Cost }\end{array}$ \\
\hline T13H6 & HEALTH PHYSICS TECH & FY-12 & $\$ 104.92$ & 200 & $\$ 20,984$ \\
\hline T15B2 & ENVIRON/FIELD TECH & FY-12 & $\$ 82.67$ & 42 & $\$ 3,431$ \\
\hline T16H1 & INDUST SAFETY/HEALTH TECH & FY-12 & $\$ 83.40$ & 110 & $\$ 9,174$ \\
\hline T17J1 & OTHER TECHS/OPS & $\mathrm{FY}-12$ & $\$ 92.69$ & 180 & $\$ 16,684$ \\
\hline T27D5 & NETWORK TECHNICIAN & $\mathrm{FY}-12$ & $\$ 88.98$ & 1,000 & $\$ 88,980$ \\
\hline T29E5 & SMC MATERIAL HANDLING TECH & FY-12 & $\$ 72.91$ & 7,000 & $\$ 510,370$ \\
\hline T39J2 & FIRE PROTECTION TECHNICIAN & $\mathrm{FY}-12$ & $\$ 82.18$ & 14 & $\$ 1,151$ \\
\hline T41G8 & FACILITY AREA COORDINATORS & $\mathrm{FY}-12$ & $\$ 110.56$ & 10 & $\$ 1,106$ \\
\hline U11J1 & ELECTRICIAN & $\mathrm{FY}-12$ & $\$ 98.11$ & 1,800 & $\$ 176,598$ \\
\hline U12J1 & EQUIPMENT OPERATOR & $\mathrm{FY}-12$ & $\$ 89.22$ & 19,905 & $\$ 1,775,924$ \\
\hline U16J1 & FITTER & $\mathrm{FY}-12$ & $\$ 97.01$ & 3,200 & $\$ 310,432$ \\
\hline U21J2 & LABORER & $\mathrm{FY}-12$ & $\$ 64.31$ & 58 & $\$ 3,730$ \\
\hline U28J2 & MATERIAL SPECIALIST & $\mathrm{FY}-12$ & $\$ 74.54$ & 60 & $\$ 4,472$ \\
\hline U29J2 & SYS MECHANIC & $\mathrm{FY}-12$ & $\$ 98.84$ & 8,580 & $\$ 848,047$ \\
\hline U60H6 & RADIOLOGICAL CONTROL TECH & $\mathrm{FY}-12$ & $\$ 101.91$ & 30,720 & $\$ 3,130,675$ \\
\hline U71J1 & EQUIPMENT OPER,HEAVY & $\mathrm{FY}-12$ & $\$ 98.21$ & 19,840 & $\$ 1,948,486$ \\
\hline U96M2 & SECURITY POLICE OFFICER II (SPO II) & $\mathrm{FY}-12$ & $\$ 69.05$ & 14,880 & $\$ 1,027,464$ \\
\hline X13B2 & ENVIRONMENTAL RISK ASSESSMENT & $\mathrm{FY}-12$ & $\$ 158.19$ & 5 & $\$ 791$ \\
\hline X13B3 & ENVIRONMENTAL RISK ASSESSMENT & FY-12 & $\$ 187.65$ & 11,000 & $\$ 2,064,150$ \\
\hline X16B3 & WASTE MANAGEMENT & $\mathrm{FY}-12$ & $\$ 184.81$ & 14,880 & $\$ 2,749,973$ \\
\hline Z03GB & MANAGER, OPERATIONS & FY-12 & $\$ 181.96$ & 27,000 & $\$ 4,912,920$ \\
\hline Z03J0 & MANAGER, OPERATIONS & $\mathrm{FY}-12$ & $\$ 203.80$ & 5,620 & $\$ 1,145,356$ \\
\hline Z04D1 & MANAGER, SCI/ENG FUNCTION & $\mathrm{FY}-12$ & $\$ 246.17$ & 5 & $\$ 1,231$ \\
\hline
\end{tabular}

\section{BEA}




\section{Labor Resource Report}

Activity: $\quad$ RH LLW Operations, Disposal Authorization, and Close-Out Activities

Group:

Level:

Project Name: $\quad$ Remote-Handled Low Level Waste (RH LLW) Disposal Project

Project Location: INL

Operations, Disposal and Close-Out Activities FY 2018 - FY 2037

Estimate Number: $9 \mathrm{~A} 28-\mathrm{H} 4$

\begin{tabular}{|c|c|c|c|c|c|}
\hline Code & Description & WDC Year & Rate $\$ / \mathrm{Hr}$ & Hours & $\begin{array}{c}\text { Direct } \\
\text { Labor Cos }\end{array}$ \\
\hline Z04J1 & MANAGER, SCI/ENG FUNCTION & FY-12 & $\$ 228.32$ & 12 & $\$ 2,626$ \\
\hline Z08G1 & SUPERVISOR, OPERATIONS & FY-12 & $\$ 108.49$ & 10 & $\$ 1,085$ \\
\hline
\end{tabular}

\section{BEA}

